\title{
AnÁlise Multi-Escala de FORMAS BIDIMENSIONAIS
}

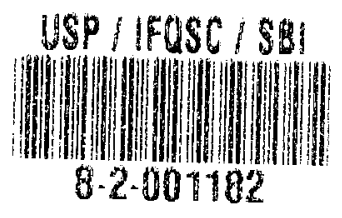

Roberto Marcondes CeSAR Junior

Tese apresentada ao Instituto de Física de São Carlos, da Universidade de São Paulo, para obtenção do título de Doutor em Ciências: Física Aplicada Opção: Física Computacional

Orientador: Prof. Dr. Luciano da Fontoura Costa

São Carlos

IFSC.USP Servigo de proloreca. 
Cesar Jr., Roberto Marcondes

Análise Multi-Escala de Formas Bidimensionais / Roberto Marcondes Cesar Junior.-São Carlos, 1997.

$255 \mathrm{p}$.

Tese (Doutorado)—Instituto de Física de São Carlos, 1997

Orientador: Prof. Dr. Luciano da Fontoura Costa

1. Visão Cibernética. 2. Análise de Formas. 3. Neurônios. 4 Wavelets I. Título 


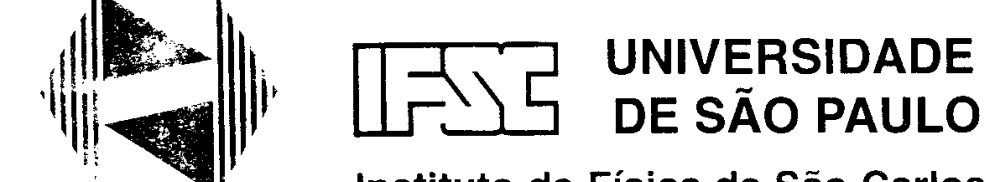

Instituto de Física de São Carlos
Av. Dr. Carlos Botelho, 1465 CEP 13560-250 - São Carlos - SP Brasil

Fone (016) 274-3444

Fax (016) 272-2218

MEMBROS DA COMISSÃO JULGADORA DA TESE DE DOUTORADO DE ROBERTO MARCONDES CESAR JÚNIOR APRESENTADA AO INSTITUTO DE FÍSICA DE SÃO CARLOS, DA UNIVERSIDADE DE SÃO PAULO, EM 26 DE NOVEMBRO DE 1997.

COMISSÃO JULGADORA:

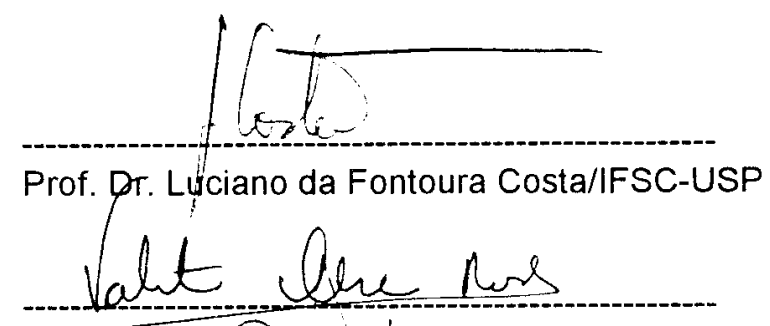

Prof. Dr. Valentin Obad Roda/IFSC-USP

$$
\text { ARn }
$$

Prof. Dr. Raborto de Alencar Lotufo/UNICAMP

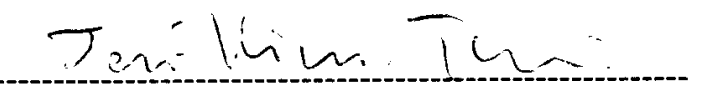

Prof. Dr. José Ricardo de Almeida Torreão/UFF

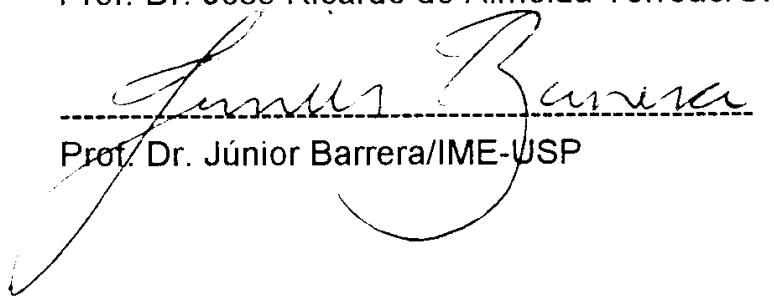


Dedico humildemente este trabalho aos meus 4 avós, aos meus 4 pais, aos meus 7 irmãos e à minha amada Dri.

Gostaria também de dedicá-lo à memória de algumas pessoas que faleceram recentemente: Renato Russo, Antonio Callado, Darcy Ribeiro, Chico Science, Betinho, Paulo Freire e Carl Sagan.

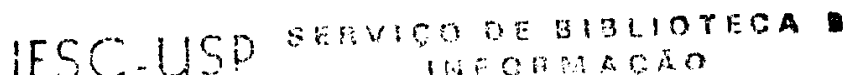




\section{AGRADECIMENTOS}

"...with a little help from my friends..."

Gostaria de deixar registrado meu profundo agradecimento às pessoas que, direta ou indiretamente, me ajudaram na elaboração desta tese. Como é usual nesse tipo de situação, eu divido as qualidades desse trabalho com todos os que me ajudaram, assumindo sob minha responsabilidade todas as suas imperfeições. É isso e muito mais que eu gostaria de dizer...

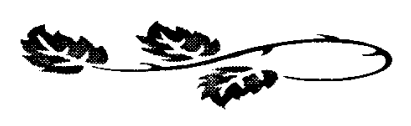

...à minha Dri,,$\ldots$

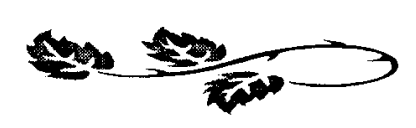

...aos meus pais e a toda a minha família,...

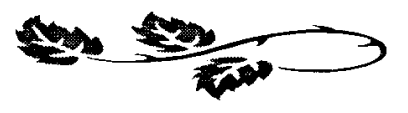

...à família da Dri,...

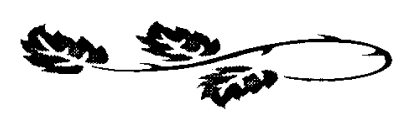

...ao meu orientador Luciano, pela mão amiga e paciente nesses anos,...

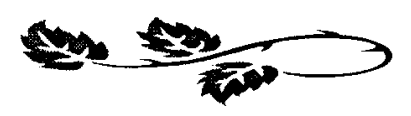

...ao Marcus e à Patty, pela amizade que vem resistindo nesses anos...

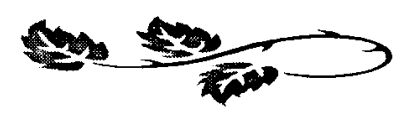
amigos...

...aos amigos que, apesar da distância das trajetórias no espaço-tempo, continuam

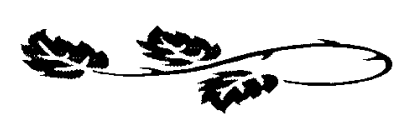

...à Mara e a todo o pessoal da biblioteca do IFSC,...

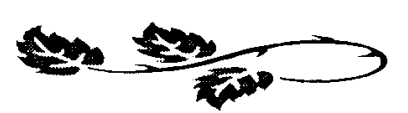

...ao Marquinhos, à Cláudia e a todos os outros funcionários que me auxiliaram nesses anos,...

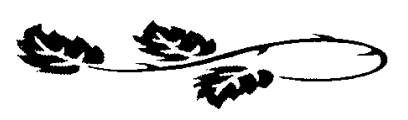

...a todo o pessoal do Grupo de Pesquisas em Visão Cibernética, que proporcionou (e proporciona!) um excelente ambiente de trabalho,... 


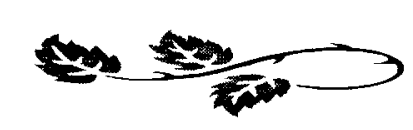
período,...

...a todos os professores e pesquisadores com quem pude aprender e discutir nesse

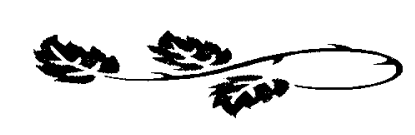

...à Jean-Pierre Antoine, qui a été patient et soigneux pendant la periòde que j'ai passé à Louvain-la-Neuve,...

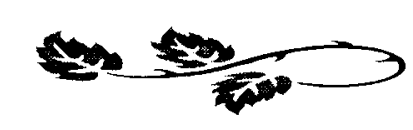

...à Cathy et aux autres amis de l'Intitut de Physique Théorique à Louvain-laNeuve,...

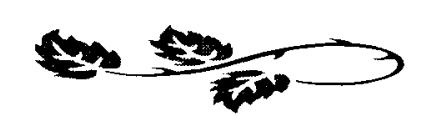

...à Damien Barache et sa famille, et à Pierre Vandergheynst et Nathalie, de bons copains qu'on a trouvé chez les belges,...

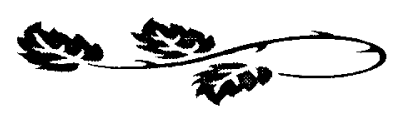

...aos professores Roberto de Alencar Lotufo, Raghuvir Arni e João Ruggiero Neto pelo suporte computacional parcial.,...

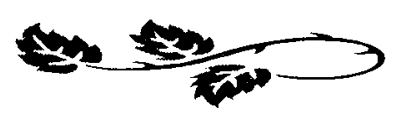

...aos professores Rafael Linden, Norberto Cairasco, Tânia Salvini, Jim Hutchins e todos os outros pesquisadores que forneceram lâminas e imagens de neurônios,...

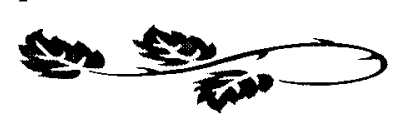

...à Regina Célia Coelho e Raimundo Rocha, pelo auxílio computacional,...

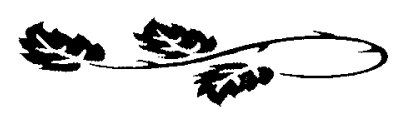

Agradeço também o suporte recebido do IFSC-USP (estrutura), do FYMA-UCLBélgica, da FAPESP (micros) e da CAPES (bolsa de doutoramento normal e sanduíche). 
Provavelmente todos os seres orgânicos que já existiram nesta terra descendem de alguma forma primordial, na qual a vida foi anteriormente revelada... Há grandiosidade nesta visão da vida... que, enquanto este planeta gira, de acordo com a lei imutável da gravidade, de um começo tão simples, formas infindáveis, as mais belas e perfeitas, evoluíram e estão evoluindo.

Charles Darwin, A Origem das Espécies, 1859

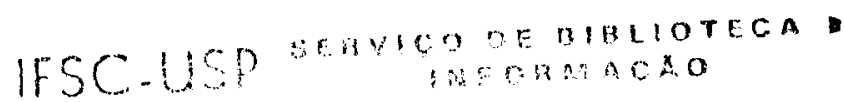




\section{Sumário}

LiSTA DE FiguraS

Lista de TABELaS

Lista de Abreviaturas e Símbolos

Resumo

Abstract

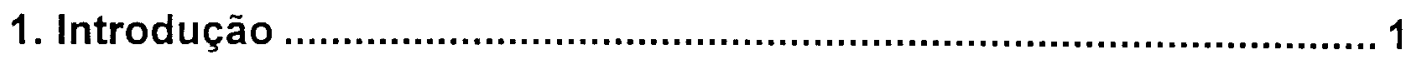

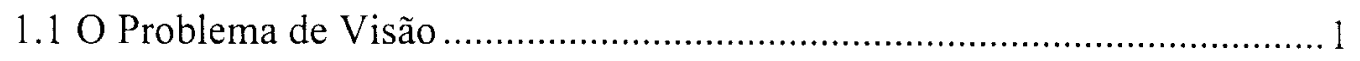

1.2 Processamento de Contornos e Visão ........................................................... 3

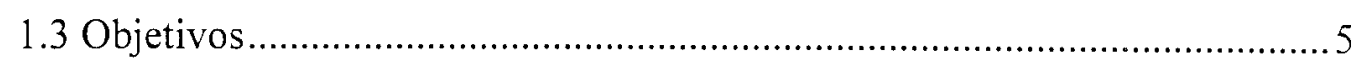

1.4 Revisão Introdutória: Alguns Problemas Centrais em Análise de Formas...7

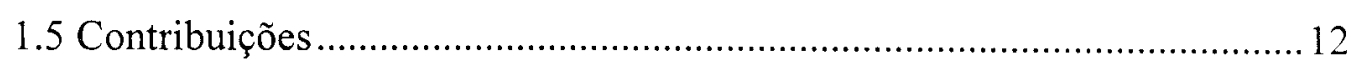

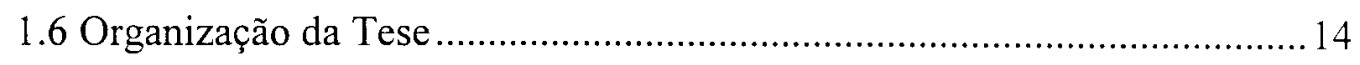

2. Revisão sobre Análise de Formas.................................................. 18

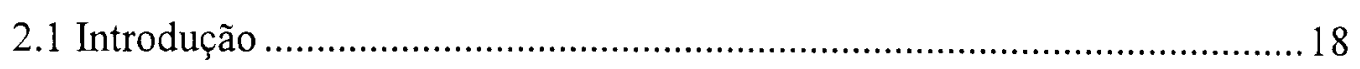

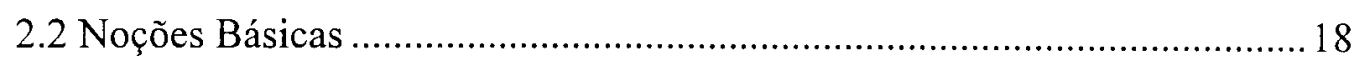

2.3 Rudimentos de Geometria Diferencial ....................................................22

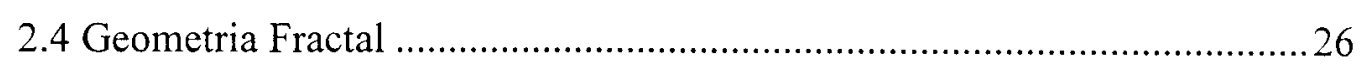

2.5 Conceitos Básicos de Processamento de Sinais...........................................29

2.6 Analisando Formas em Visão Computacional ...........................................33

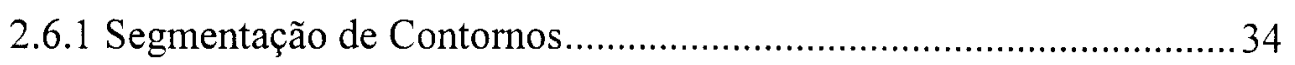

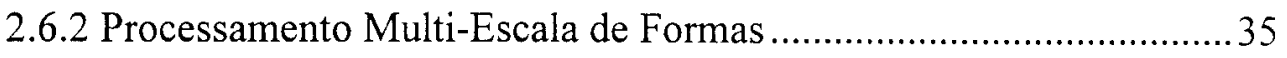

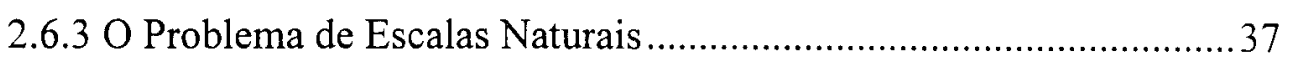

2.6.4 Análise de Complexidade de Formas .............................................. 38

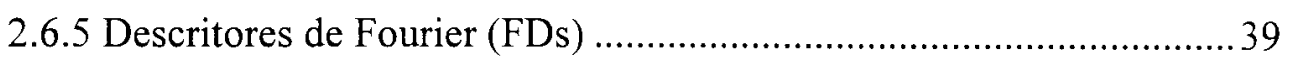

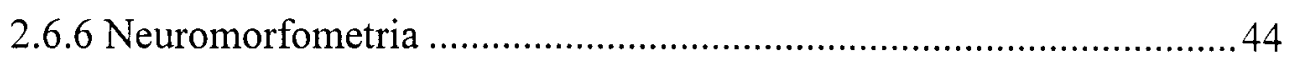


3. Transformadas Multi-Escala: Espaço-Escala, Gabor e Wavelets .. 47

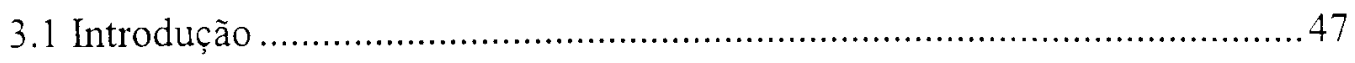

3.2 Uma Pequena Introdução Histórica ................................................... 48

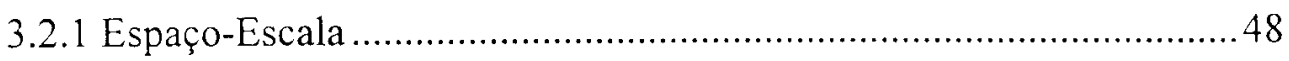

3.2.2 Transformadas Tempo-Freqüência ......................................... 50

3.2.3 Transformadas Tempo-Escala ou Wavelets ...............................5 52

3.3 Uma Visão Unificada das Transformadas Multi-Escala.......................... 57

3.4 Estudo de Caso: Interpretando as Transformadas..................................5 59

3.5 Análise das Transformadas Multi-Escala ..........................................63

4. Caracterização de Contornos através do Curvograma .................67

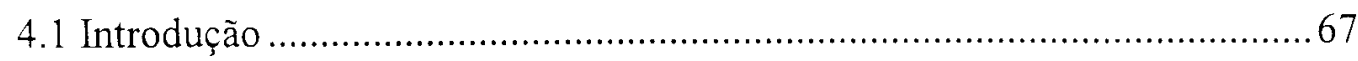

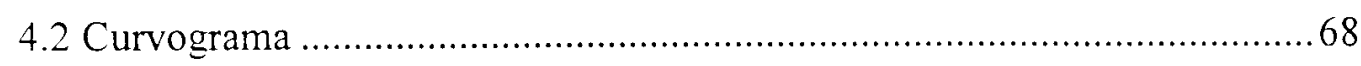

4.2.1 Cálculo da Curvatura através da Transformada de Fourier ..............68

4.2.2 Cálculo da Curvatura a partir de $u(t)$..........................................6 69

4.2.3 Implementação Numérica das Expressões de Curvatura ................... 71

4.2.4 Filtragem Gaussiana e o Esquema Multi-Escala ............................ 75

4.2.5 Soluções para o problema de contração do contorno ....................... 78

4.2.5.1 Prevenção à contração por conservação de energia .................. 78

4.2.5.2 Prevenção à contração por conservação de perímetro ............. 79

4.2.6 O Curvograma ......................................................................... 81

4.2.6.1 Discretização do Parâmetro de Escala ...................................82

4.3 Resultados Experimentais................................................................... 83

4.3.1 Avaliação da Precisão do Método ................................................. 90

4.3.2 Detecção de Vértices .........................................................96

5. Análise de Formas usando Wavelets ........................................ 98

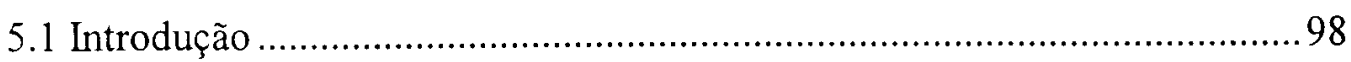

5.2 Considerações Preliminares ............................................................... 98

5.3 A Representação-W ............................................................... 100

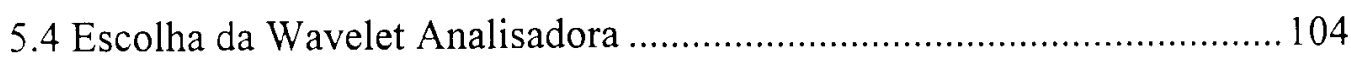

5.4.1 As Derivadas da Gaussiana..................................................... 104 
5.4.2 A Wavelet de Morlet ............................................................. 106

5.5 Análise de Formas a partir da Representação-W ….............................. 107

5.6 Detecção de Vértices ....................................................................... 108

5.7 Escalas Naturais e Freqüências Locais ................................................ 119

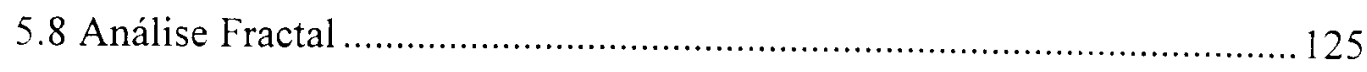

5.8.1 Análise Fractal usando a Transformada Contínua em Wavelets .... 125

5.8.2 Curvas Exatamente Auto-Similares........................................... 128

5.8.2.1 Exemplo: a curva triádica de Koch..................................... 130

5.9 Análise de Formas por Representações Tempo-Freqüuencia .................... 131

5.9.1 A Transformada de Gabor de um Contorno .................................. 133

5.10 Comparação entre as Representações Multi-Escala ............................. 137

6. Caracterização de Contornos Através de Energias Multi-Escala. 144

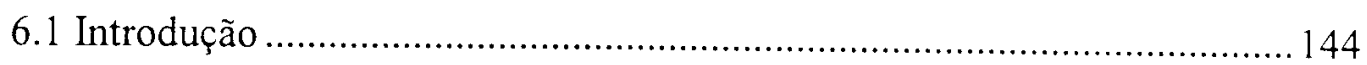

6.2 Energia de dobramento multi-escala................................................ 144

6.2.1 Interpretação da Energia de Dobramento...................................... 146

6.2.2 Efeito de alta curvatura mascarada e algumas possiveis soluções... 147

6.3 Neuromorfometria usando a Energia de Dobramento .......................... 152

6.3.1 Interpretando a Evolução em Escala da Energia de Dobramento .... 154

6.3.2 Exemplo do Efeito de Alta Curvatura Mascarada ......................... 157

6.3.3 Tolerância a Transformações Geométricas.....................................160

6.4 A Energia Multi-Escala Normalizada de Wavelets ................................ 163

6.5 Classificação Automática de Células Ganglionares ................................ 165

7. Geração Semi-Automática de Dendrogramas ............................. 180

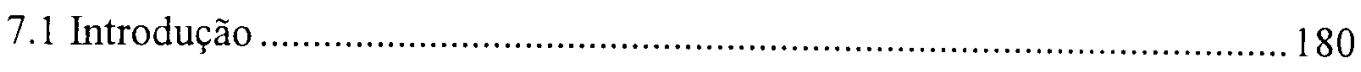

7.2 Convenções de Terminologia .............................................................. 183

7.3 O Problema de Geração do Dendrograma .............................................. 185

7.4 Segmentação do Contorno ............................................................. 186

7.5 GUI's e a Abordagem Semi-Automática ............................................. 188

7.6 Análise Sintática ........................................................................ 192

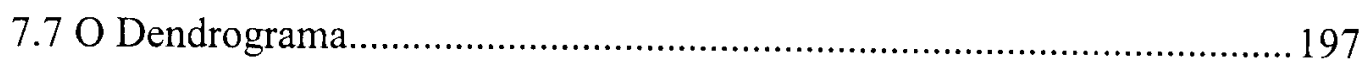


7.8 Obtendo o Esqueleto. 199

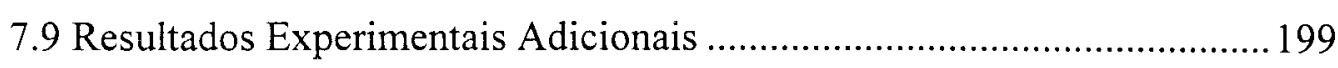

8. Conclusão e Comentários Finais .............................................. 204

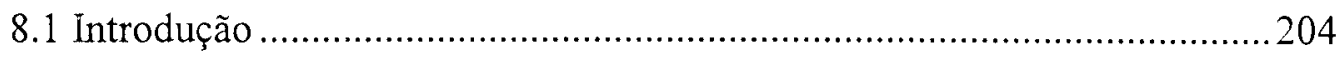

8.2 Considerações Finais: Análise Multi-Escala de Formas...........................204

8.3 Considerações Finais: O Curvograma ...............................................205

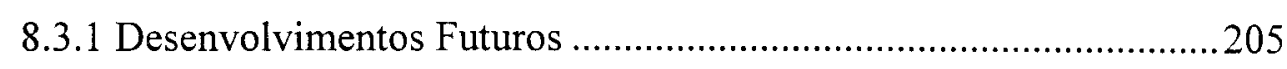

8.4 Considerações Finais: A Representação-W .............................................206

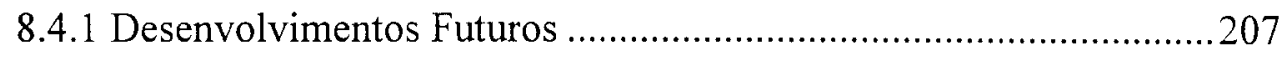

8.5 Comentários Finais Sobre as Energias Multi-Escala..............................208

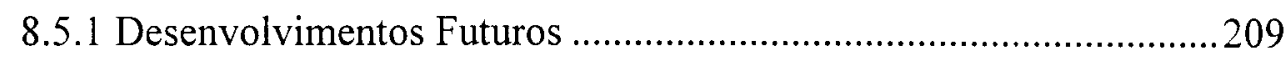

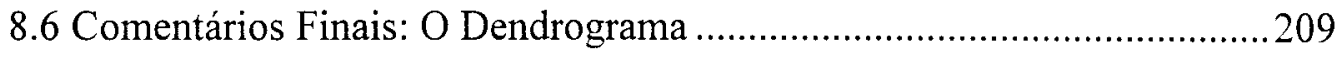

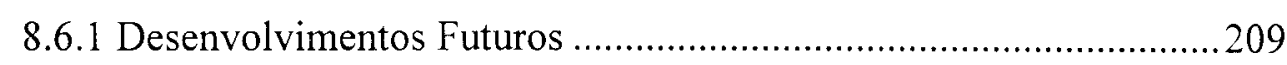

8.7 Comentários Finais: Neuromorfometria ...........................................209

8.7.1 Desenvolvimentos Futuros .......................................................2210

8.8 Desenvolvimentos Futuros Adicionais .............................................2 210

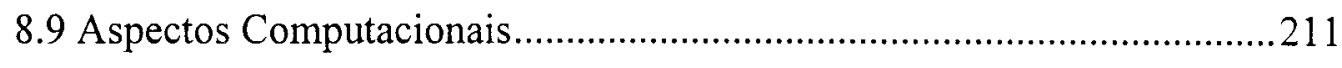

9. Referências Bibliográficas................................................... 213

Apêndice I: FFTshift e FFTunshift............................................228 


\section{Lista de Figuras}

Figura 1.1: Diferentes representações da informação pictórica: imagem em niveis de cinza, imagem segmentada, mapa de bordas e aproximação poligonal........4

Figura 1.2: As diferentes partes que compõem a cena vivem em escalas distintas...........5

Figura 1.3: Exemplos de experimentos apresentados por Attneave................................8

Figura 1.4: (b) e (c) apresentam dois possíveis particionamentos do contorno apresentado em (a) .11

Figura 2.1: Exemplos de diferentes objetos que podem ser reconhecidos apenas a partir de informações de formas $2 \mathrm{D}$.

Figura 2.2: Esquema básico do pré-processamento para a abordagem de análise de formas adotada nesta tese. .21

Figura 2.3: Construção da curva triádica de Koch. . .27

Figura 2.4: (a) Astróide, uma figura geométrica que possui quatro vértices; (b) Sinais $x$ e $y$ da astróide; (c) Curvatura-c; (d) Curvatura-c usando a variante discutida no texto. .36

Figura 2.5: Exemplo de célula neural criada por gramáticas formais. .40

Figura 2.6: Sinais e descritores de Fourier (módulo e fase) obtidos a partir do contorno parametrizado da célula da Figura 2.5. 41

Figura 2.7: Função de energia acumulada dos FDs do neurônio da Figura 2.5...........42

Figura 2.8: Reconstrução do neurônio da Figura 2.5 usando 2j FDs. . .43

Figura 3.1: A interpretação das transformadas de Gabor e em wavelets por bancos de filtros ilustra como a transformada de Gabor mantém a largura dos filtros para analisar as diferentes frequêencias enquanto que a transformada em wavelets usa filtros mais largos para analisar as freqüências mais altas......55

Figura 3.2: Transformada espaço-escala do sinal exibido em (a) .60

Figura 3.3: Sinal do exemplo e série de versões suavizadas, as quais compõem o espaço-escala...... 
Figura 3.4: Transformada de Gabor do sinal (a) .62

Figura 3.5: Transformada em wavelets do sinal (a) (usando Morlet)

Figura 4.1: Exemplo de diferenciação numérica pela transformada de Fourier .73

Figura 4.2: Esquema do banco de filtros gaussianos. .77

Figura 4.3: Contorno contendo dois cantos e um padrão periódico local..............81

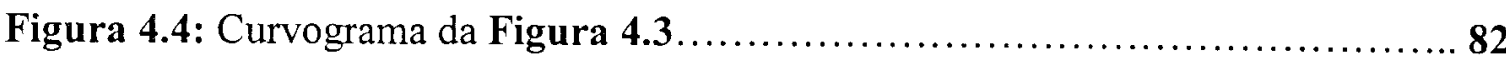

Figura 4.5: Resultados da estimação digital da curvatura de uma forma sintética...... .85

Figura 4.6: Primeira e segunda derivadas dos sinais $x(n)$ e $y(n)$ vistos na

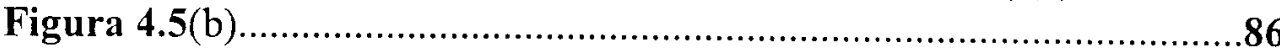

Figura 4.7: Efeitos da abordagem multi-escala no cálculo da curvatura.......................88

Figura 4.8: Algumas gaussianas de diferentes escalas........................................88

Figura 4.9: Exemplo da análise multi-escala de curvatura, incluindo o curvograma de um contorno real.

Figura 4.10: Estimação digital da curvatura de uma circunferência .90

Figura 4.11: Curva B-spline usada para experimento do curvograma. .93

Figura 4.12: Curvatura analítica, estimada e barra de erros entre as duas. .94

Figura 4.13: Série de medidas de erros entre a curvatura analítica e a estimada. .95

Figura 4.14: (a) Detecção de vértices usando o método desta tese; (b) Detecção de cantos usando o método proposto em [Medioni \& Yasumoto,

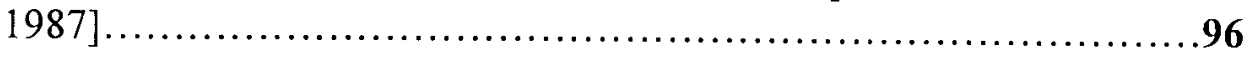

Figura 5.1: Arquitetura de um sistema de análise de formas usando características globais (FDs) e locais.

Figura 5.2: (a) Gaussianas em diferentes escalas, e suas respectivas primeira (b) e segunda (c) derivadas.

Figura 5.3: Wavelet de Morlet em diversas escalas: parte real (a) e imaginária (b)....106

Figura 5.4: Esquema geral da representação- $W$. Nas representações gráficas deste capítulo, as cores claras codificam os maiores valores do módulo das transformadas 
Figura 5.5: Detecção de singularidades e estimação do expoente de Hölder usando a transformada em wavelets.

Figura 5.6: Esquema de detecção de vértices através do módulo e da fase da transformada em wavelets.

Figura 5.7: Linhas de máximos da transformada em wavelets do contorno em forma de $\mathrm{L}$ e as linhas sobrepostas ao módulo da transformada.

Figura 5.8: Forma definida pela curva triádica de Koch.

Figura 5.9: Sinais $x$ e $y$ e esqueletos verticais da curva de Koch .115

Figura 5.10: Medidas de relevância para as linhas de máximos verticais... 116

Figura 5.11: Silhueta de um alicate, usada em um experimento. 117

Figura 5.12: Esqueleto antes e depois da limiarização pela medida de relevância. .117

Figura 5.13: Resultados de detecção de pontos dominantes através da representação- $W$ 118

Figura 5.14: Três tipos diferentes de partições naturais de formas... .120

Figura 5.15: Círculo com 3 tipos diferentes de textura senoidal.

Figura 5.16: Esqueleto horizontal da representação- $W$ do círculo mostrado na Figura 5.15 .

Figura 5.17: Esquema de detecção de escalas naturais e de pontos de transição entre padrões periódicos por meio do módulo e da fase da representação- $W \ldots .122$

Figura 5.18: Exemplo da ocorrência de um padrão periódico local em um objeto real e sua respectiva detecção pela representação- $W$.

Figura 5.19: Aproximação poligonal multi-escala da curva de Koch que captura a lei de geração dessa curva.....

Figura 5.20: Gráfico do módulo da representação- $W$ ao longo de uma linha de máximos verticais (log-log plot).

Figura 5.21: Conjunto de gaborettes e wavelets ilustrando as diferenças entre as duas abordagens.

Figura 5.22: Transformada de Gabor (módulo e fase) da circunferência apresentada na Figura 5.15 . 
Figura 5.23 Projeção da transformada de Gabor da Figura 5.22 e os respectivos pontos de transição detectados corretamente.

Figura 5.24 Série de transformadas de Gabor (módulo) da circunferência da Figura 5.15 para diferentes larguras da janela gaussiana da transformada. As larguras da janela do tempo diminuem de cima para baixo, da esquerda para direita.136

Figura 5.25: Contorno contendo dois cantos e um padrão periódico local.

Figura 5.26: Representações multi-escala da forma da Figura 5.25. (a) Curvograma; (b) Representação- $W$ com a wavelet de Marr; (c) Representação- $W$ com a wavelet de Morlet; (d) Transformada de Gabor do contorno. Níveis de cinza mais claros codificam valores mais altos. 139

Figura 5.27: (a) Transformada de Gabor do contorno da Figura 5.25. O módulo da transformada de Gabor apresentada na Figura 5.26(b) foi limiarizado de modo que os coeficientes menores que um dado limiar foram anulados. resultando na transformada acima; (b) Sobreposição dos esqueletos horizontal da transformada de Gabor apresentada em (a) desta figura e do esqueleto vertical da representação- $W$ com a wavelet de Marr apresentada na Figura 5.26 (b); (c) Análogo ao (b), exceto que o esqueleto vertical foi limiarizado em função do tempo de vida das linhas de máximos, conforme explicado na seção de detecção de cantos.

.141

Figura 5.28: Os pontos de cruzamento dos esqueletos vertical e horizontal da Figura 5.27 (c) correspondem aos pontos de segmentação indicado nesta figura 142

Figura 6.1: Evolução da elipse com textura através da filtragem multi-escala gaussiana com os pontos envolvidos no efeito de alta curvatura mascarada indicados.

Figura 6.2: $O$ curvograma da elipse com textura vista na Figura 6.1(a). Os pontos nos quais a curvatura aumenta com a escala, o que caracteriza o efeito de alta curvatura mascarada, são indicados na imagem. 148

Figura 6.3: Energia de dobramento da elipse com textura vista na Figura 6.1(a). 149

Figura 6.4: (a) Gaussiana usada como função de ponderação para a energia de dobramento modificada; (b) Nova energia de dobramento obtida pela soma ponderada das curvaturas ao quadrado; (c) curvaturas ordenadas da elipse com textura da Figura 6.1(a); (d) Curvaturas ordenadas da forma da Figura 6.1(a) ponderadas pela gaussiana; (e) Curvaturas ordenadas da forma da Figura 6.1(d); (f) Curvaturas ordenadas da forma da Figura 6.1(d) ponderadas pela gaussiana. 
Figura 6.5: Diferentes formas biológicas usadas em experimentos de avaliação da energia de dobramento

Figura 6.6: Energias de dobramento multi-escala para as células da Figura 6.1

Figura 6.7: Morfogramas dos contornos das Figuras 6.5(a), (e) e (1).

Figura 6.8: Energia de dobramento das Figuras 6.5(a), (e) e (1).

Figura 6.9: Detalhe da evolução dos contornos das Figuras 6.5(a), (e) e (1)

Figura 6.10: Formas do experimento que ilustra o efeito de alta curvatura mascarada..........................................................................156

Figura 6.11: Energia de dobramento das formas da Figura 6.10.

Figura 6.12: (a) Célula neural artificial; (b)-(d) Versões editadas da célula original, nas quais o padrão de ramificação de cada dendrito foi progressivamente apagado

Figura 6.13: Energias de dobramento das células da Figura 6.12

Figura 6.14: Diferentes versões de uma mesma célula neural obtidas por transformações geométricas: (a)-(d) Escalonamento, com os fatores de escala indicados sob cada célula; (e)-(h) Reflexão, sendo que as células foram refletidas para baixo (indicado pela letra $D$ ), para a direita (indicado pela letra $R$ ) e para baixo e para a direita (indicado pelas letras DR); (i)-(1) Rotação, no sentido horário, sendo que os ângulos de rotação em graus estão indicados sob cada célula

Figura 6.15: Energias de dobramento das formas vistas na Figura 6.14, ilustrando a tolerância a transformações geométricas. Todas as energias de dobramento foram sobrepostas no último gráfico de modo a mostrar como essa medida tem o mesmo comportamento para todas as versões da célula original....161

Figura 6.16: Versões rotacionadas e transladadas de um neurônio

Figura 6.17: Energias de dobramento das células vistas na Figura 6.16(a)-(c), utilizando os seguintes respectivos estilos de gráfico: $(-),(-\cdot)$ e $(\cdots)$ 162

Figura 6.18: Resultados da aplicação da energia de dobramento na caracterização de células ganglionares (gato). As células $\alpha$ são representadas pelo símbolo "*" enquanto que as células $\beta$ pelo símbolo "o". O protótipo para cada conjunto de medidas é definido como a média das energias de dobramento de cada classe. A linha de decisão é indicado como um limiar quase ótimo para discriminação entre as duas classes 
Figura 6.19: Protótipos de células ganglionares dos tipos $\alpha$ e $\beta$, ilustrando as principais características e diferenças estruturais entre essas duas classes morfológicas de células neurais 165

Figura 6.20: Células $\alpha$ usadas nos experimentos de classificação .166

Figura 6.21: Células $\beta$ usadas nos experimentos de classificação. 167

Figura 6.22: (a) Ilustração esquemática de uma auto-interseção e o problema resultante na etapa de extração do contorno; (b) $\mathrm{O}$ contorno editado permite que o algoritmo de extração de contorno gere um contorno mais significativo em relação à forma do neurônio original.

Figura 6.23: (a) e (c) apresentam duas células neurais artificiais, sendo a célula vista em (c) mais complexa que a em (a); (b) e (d) apresentam os respectivos sinais $x(t)$ e $y(t)$

Figura 6.24: Módulo das representações- $W$ das células apresentadas na Figura 6.23.170

Figura 6.25: Distância de separação de classes para as diferentes características testadas na caracterização de células ganglionares.

Figura 6.26: Distribuições indicando a alta correlação entre características extraídas de energias multi-escala adjacentes. .175

Figura 6.27: Distribuições dos diferentes vetores de características avaliados para classificação das células ganglionares $\alpha$ e $\beta$. . .

Figura 6.28: Distribuições do número de pontas em função dos neurônios.

Figura 7.1: A ocorrência de uma ramificação tripla (b) devido à quantização do neurônio mostrado em (a) pode ser tratada como duas duplas (c).......... 181

Figura 7.2: Célula neural artificial e seu respectivo dendrograma.............................182

Figura 7.3: Esquemas ilustrando a terminologia adotada neste capítulo 183

Figura 7.4: Célula neural artificial e seu respectivo contorno. .184

Figura 7.5: Esquema do contorno segmentado de um grande ramo dendrítico. 185

Figura 7.6: Três diferentes árvores de derivação para a mesma cadeia de caracteres...187

Figura 7.7: Ilustração do procedimento semi-interativo de ajuste de escala. 189 
Figura 7.8: (a) Ajuste dos limiares de segmentação; (b) Ajustes finais de segmentação. .190

Figura 7.9: Ordem correta das substituições para o grande ramo principal da Figura 7.5. .193

Figura 7.10: Partes de um grande ramo dendrítico. 196

Figura 7.11: (a) Árvore de derivação sintática; (b) Dendrograma; (c) Esqueleto. Todos obtidos a partir do grande ramo dendrítico da Figura 7.5. .198

Figura 7.12: Resultados da utilização de diversas características no dendrograma de um grande ramo dendrítico hipotético. Particularmente, o dendrograma apresentado em (d) codifica o comprimento de cada segmento, sua espessura média e sua energia de dobramento respectivamente pelo comprimento de cada segmento de reta horizontal, sua espessura e seu nível de cinza (maiores valores codificados por níveis mais escuros).

201

Figura 7.13: Geração do dendrograma de uma grande ramo dendrítico típico de uma célula ganglionar do tipo $\alpha$ (gato).

Figura 7.14: Dendrograma do grande ramo apresentado na Figura 7.13(a) .202 


\section{Lista de Tabelas}

Tabela 1.1: Algumas relações concluídas a partir do trabalho de Attneave. 10

Tabela 2.1: Tabela indicando o número de bolas $M(\varepsilon)$ necessárias para cobrir uma curva de Koch como função do raio $\varepsilon$ das bolas.

Tabela 4.1: Tabela com resultados do erros médios quadráticos (EMQ) com e sem a normalização por compensação de energia.............................................87

Tabela 6.1: "Aspect ratios" dos contornos das Figuras 6.5(a), (e) e (l). 155

Tabela 6.2: Classificação correta das células ganglionares baseada na separação linear dos "clusters" de cada vetor de características. 178

Tabela 6.3: Resultados de classificação das células ganglionares. 178 


\section{Lista de Abreviaturas e Símbolos}

- $x$ e $y$ : coordenadas cartesianas;

- $C(t)=(x(t), y(t))$ : curva paramétrica contínua;

- $C(n)=(x(n), y(n)):$ curva paramétrica discreta;

- $t$ : parâmetro contínuo do tempo;

- $n$ : parâmetro discreto do tempo;

- $i=\sqrt{-1}$;

- $\dot{x}$ e $\ddot{x}$ : primeira e segunda derivadas de $x$;

- $x^{(j)}: j$-ésima derivada de $x$;

- $\underline{v}$ : notação para indicar que $v$ é um vetor;

- $\underline{v} . \underline{w}$ : produto interno entre os vetores;

- $L$ : perímetro de contornos;

- $k(t)$ : curvatura de uma curva paramétrica;

- $s$ : parâmetro discreto da freqüência;

- $f$ : parâmetro contínuo da frequiência;

- $\omega$ : parâmetro contínuo da frequiência angular, em que $\omega=2 \pi f$;

- $U(f)$ e $U(\omega)$ : transformadas de Fourier de $u(t)$;

- $U(s)$ : transformada discreta de Fourier de $u(n)$;

- $F\{u(t)\}$ e $F\{u(n)\}$ : indicam as transformadas de Fourier;

- $F^{-1}\{U(f)\}, F^{-1}\{U(\omega)\}$ e $F^{-1}\{U(s)\}$ : indicam as transformadas inversas de Fourier;

- $u(t) * g(t)$ : convolução de dois sinais;

- FDs: Descritores de Fourier;

- $|z|$ e $\arg (z)$ : módulo e fase de um número complexo $z$;

- $M$ : no Capítulo 5 denota o módulo da transformada em wavelets, enquanto que no Capítulo 6 denota o conjunto de características testadas pelos algoritmos de classificação estatística;

- $E$ : energia (pode possuir diferentes definições que devem ser contextualizadas);

- $E$ : apenas no Capítulo 7 é um símbolo não-terminal de uma gramática formal;

- $U(b, a)$ : transformada multi-escala de $u(t)$, com $b$ representando o parâmetro temporal e $a$ o parâmetro de escala; 
- $U(b, f)$ : transformada multi-escala de $u(t)$, com $b$ representando o parâmetro temporal e $f$ o parâmetro de frequiência;

- $z^{*}$ : conjugado complexo de $z$;

- $g_{a}(t)$ : gaussiana $g_{a}(t)=\frac{1}{a \sqrt{2 \pi}} e^{\frac{-t^{2}}{2 a^{2}}}$

- $g(t)$ : pode especificar uma gaussiana de desvio padrão igual a 1 ou, alternativamente, algum outro sinal. A distinção deve ser clara no contexto;

- $G(f)$ : transformada de Fourier da gaussiana;

- $\Psi(t)$ : wavelet;

- $\Psi^{*}{ }_{b, a}(t):$ núcleo do produto interno;

- $\operatorname{Im}\{z\}$ : parte imaginária do número complexo $z$;

- FFT: "Fast Fourier Transform” ou Transformada Rápida de Fourier;

- floor $(x)$ : função de truncamento de $x$;

- $L_{v}$ : linhas de máximos verticais;

- $L_{h}$ : linhas de máximos horizontais;

- $f$ : medida de relevância de linhas de máximos;

- B: energia de dobramento;

- NMBE: "Normalized Multiscale Bending Energy" ou Energia de Dobramento Multi-Escala Normalizada;

- NMWE: "Normalized Multiscale Wavelet Energy" ou Energia de Wavelets Multi-Escala Normalizada;

- $e$ : símbolo associado às extremidades dos ramos dendríticos no Capítulo 7;

- $b$ : símbolo associado às bifurcações dos ramos dendríticos no Capítulo 7; 


\section{Resumo}

Esta tese introduz um conjunto de novos métodos para análise de formas bidimensionais (2D) dentro do contexto da resolução de problemas de visão computacional e análise de formas neurais ou neuromorfometria. Mais especificamente, este trabalho apresenta o desenvolvimento de conceitos e algoritmos para a representação e análise multi-escala de contornos de objetos em imagens digitais. Assim, o contorno dos objetos é representado por um sinal que assume valores complexos e que pode ser subseqüentemente analisado por uma transformada multi-escala. Nesse sentido, os desenvolvimentos apresentados nesta tese valeram-se matematicamente de ferramentas desenvolvidas na área de processamento de sinais e de imagens, bem como em outras áreas da matemática como a geometria diferencial. Técnicas de análise de contornos através da curvatura multi-escala e das transformadas de Gabor e em wavelets são introduzidas, incluindo algoritmos específicos para a detecção de vértices, caracterização de escalas naturais, análise fractal de curvas deterministicamente autosimilares e extração de vetores de características associadas a diferentes aspectos de formas como complexidade e retangularidade.

Particularmente em relação aos métodos de análise multi-escala de curvatura, esta tese apresenta um novo esquema de estimação digital de curvatura baseado em propriedades da transformada de Fourier e novas abordagens para a prevenção à contração dos contornos devido à filtragem gaussiana. Esse novo esquema de estimação de curvatura foi testado exaustivamente, incluindo uma avaliação da precisão do método através de uma análise de erro entre valores da curvatura analítica e a estimada baseada em curvas B-splines. O novo esquema apresentou resultados encorajadores em todas as avaliações, corroborando sua eficiência.

Em relação à parte específica de análise de formas neurais, as contribuições desta tese residem em duas áreas. Inicialmente, novas medidas de formas, correspondentes às energias multi-escala, foram introduzidas para a caracterização e classificação automática de neurônios baseada na complexidade das formas; experimentos de classificação estatística de células ganglionares (gato) são relatados. Finalmente, descreve-se uma nova técnica para a criação semi-automática de dendrogramas, os quais são estruturas de dados abstratas que descrevem células neurais. Todas as técnicas foram extensivamente testadas em imagens reais e sintéticas e os respectivos resultados, que corroboram a eficiência dos algoritmos, são incluídos ao longo da tese. 


\begin{abstract}
This thesis introduces a set of new methods for two-dimensional shape analysis for computer vision and neural shape analysis applications. More specifically, this work develops concepts and algorithms for multiscale contour representation and analysis of objects present in digital images. Therefore the object contour is represented by a complex-valued signal that can be subsequently analyzed by a multiscale transform. Different mathematical tools from signal and image processing fields, as well as differential geometry, underlie the developments in this work. Techniques for contour analysis through multiscale curvature and the Gabor and wavelet transforms are introduced. The new techniques include specific algorithms for corner detection, natural scales characterization, fractal analysis of self-similar curves and feature vector extraction associated with different shape aspects such as complexity and rectangularity.

As far as the multsicale curvature analysis methods are concerned, this thesis presents a new framework for digital curvature estimation based on Fourier transform properties and new approaches for contour shrinking prevention due to gaussian filtering. The new framework of curvature estimation has been extensively evaluated, including precision assessment of the error of the estimation based on B-spline curves. The new framework has performed successfully in all assessment experiments, which corroborates its efficiency.

As far as the neural shape analysis is concerned, the contributions of this thesis are twofold. On one hand, some new shape measures, corresponding to the multiscale energies, have been devised for characterization and classification of neural cells based on shape complexity; statistical pattern recognition experiments using retinal ganglion cells (cat) are reported. On the other hand, a new technique for semi-automated dendrogram generation, i.e. abstract data structures that represent different neural cell features, is described. All the techniques have been extensively assessed using both real and computer-generated images and some of the respective results, which corroborate the robustness of the algorithms, are included throughout the thesis.
\end{abstract}




\section{Capítulo 1 - Introdução}

Os olhos continuaram a dizer cousas infinitas, as palavras da boca é que nem tentavam sair, tornavam ao coração caladas, como vinham...

Machado de Assis, Dom Casmurro

No princípio, Deus criou os céus e a terra. A terra estava informe e vazia: as trevas cobriam o abismo e o Espírito de Deus pairava sobre as águas.

Deus disse: "Faça-se a luz". E a luz foi feita.

Gênesis, 1, 1-4, Biblia 


\section{INTRODUÇÃO}

5 ste capítulo apresenta os aspectos principais que motivaram o problema central tratado nesta tese: a análise de formas a partir de contornos. Em particular, o problema de visão computacional é introduzido com uma breve discussão sobre seu principal objetivo, suas dificuldades e sua importante relação com os estudos sobre visão biológica. Dentre os diferentes aspectos concernentes à pesquisa e desenvolvimento de sistemas artificiais de visão, salienta-se a importância da obtenção, a partir da imagem original, de representações intermediárias que permitam, ao mesmo tempo, reduzir a redundância dos dados e enfatizar as características importantes da imagem. É exatamente nesse ponto que nasce a importância dos métodos de análise de contornos. Este capítulo discute ainda os objetivos, as contribuições e a forma de organização deste trabalho.

\subsection{O PROBLEMA DE VISÃO}

1 área de visão computacional, ou visão por máquina, trata de problemas relacionados à obtenção de descrições simbólicas de dados pictóricos, sendo um dos campos de pesquisa dos mais instigantes e profícuos. Embora a definição de qualquer área muito ampla do conhecimento seja uma tarefa difícil e com grandes chances de conter imperfeições, pode-se dizer que a pesquisa em visão computacional busca o desenvolvimento de métodos para extração e interpretação de descrições abstratas a partir de informação pictórica contida em imagens. Nesse sentido, o termo imagem deve ser entendido em seu sentido mais amplo, incluindo as tradicionais imagens bidimensionais (2D) obtidas a partir da reflexão da luz nos objetos do mundo real, bem como sequiências de imagens de vídeo, imagens de profundidade ("range images"), imagens multi-dimensionais ou multi-espectrais e outros conjuntos de dados. De certa maneira, o problema de visão pode ser encarado como sendo aquele referente à obtenção de descrições a partir de uma entidade visual.

Sendo uma área cuja história começa desde o advento do computador, a visão computacional possui um vasto leque de aplicações que inclui visão robótica, análise de imagens médicas e biológicas, inspeção visual em aplicações industriais. segurança pública e privada, pesquisa sobre percepção humana (e em outros animais) e em outras áreas de ciências cognitivas. De fato, esse grande número de aplicações não deve causar surpresa, tendo-se em vista a importância do sentido da visão para os seres humanos. Porém, embora o ato de ver apresente-se para nós, seres humanos, 
como algo simples e natural, existem enormes dificuldades concernentes à criação de sistemas computacionais de visão que sejam versáteis e confiáveis: se por um lado os cientistas da computação já foram capazes de desenvolver um programa capaz de vencer o maior enxadrista (humano) do mundo, através da exploração ad hoc de milhões de possibilidades em cada jogada, os sistemas atuais mais avançados de visão por máquina mal podem ser comparados com a potencialidade da visão de uma criança de poucos anos de idade. O caráter interdisciplinar da pesquisa em visão ilustra o nível de complexidade normalmente requerido às abordagens desenvolvidas, as quais normalmente se utilizam de ferramentas de processamento de imagens, inteligência artificial, reconhecimento de padrões, processamento de sinais, redes neurais artificiais, computação gráfica e áreas de visão biológica e ciências cognitivas, como a neurofisiologia e a psicofísica.

Deve-se por outro lado lembrar que existem poucas dúvidas sobre o fato de que tais sistemas confiáveis e versáteis sejam possíveis, fato já provado pela existência de inúmeros sistemas visuais biológicos, e, em especial, o sistema visual dos primatas, o qual apresenta uma extraordinária, e até o momento não atingida, performance em tempo-real e sob as condições mais precárias e exigentes. Portanto, não devem existir surpresas se tais sistemas biológicos puderem fornecer novos "insights" para a introdução de novos conceitos e métodos em visão artificial, como já aconteceu no caso da abordagem de deteç̧ão de bordas desenvolvida por D. Marr [Marr, 1982]; na relação entre o conceito biológico de campos receptivos e filtros de Gabor 2D, introduzida por J. Daugman [Daugman, 1988]; nos modelos artificiais de redes neurais, iniciados por McCullogh \& Pitts [Anderson, 1995]; e na importância da percepção humana de vértices e pontos de alta curvatura em formas, para a qual $F$. Attneave chamava a atenção já na década de 50 [Attneave, 1954]. Tal interrelacionamento entre os campos de visão natural e artificial tem sido uma das principais filosofias adotadas pelo Grupo de Pesquisa em Visão Cibernética do IFSCUSP [Costa, 1993; Costa et al., 1994], no seio do qual esta tese foi desenvolvida. É importante observar que um dos projetos que vem sendo desenvolvidos por esse grupo consiste em um sistema de visão computacional versátil, com diversos aspectos de inspiração biológica, chamado Cyvis-I [Costa et al., 1994]. O projeto desse sistema inclui uma série de módulos de processamento dedicados à análise de alguns atributos específicos de imagens, como cor, textura e bordas, estruturados em uma arquitetura hierárquica, cada qual comunicando-se ativamente com os outros, na tentativa de melhorar a performance da análise visual [Costa et al., 1994]. Um aspecto particularmente importante do Cyvis-I, bem como em algumas outras abordagens de visão computacional, concerne à maneira pela qual a informação visual é codificada e representada em cada um dos níveis hierárquicos da arquitetura do sistema. Afinal, uma das mais importantes lições que a natureza tem a ensinar em relação ao desenvolvimento de sistemas de visão mais poderosos diz respeito à adoção de representações visuais efetivas das cenas a serem analisadas.

Antes de se discutir uma das representações mais importantes comumente adotadas por sistemas de visão, os contornos, os quais estão no centro do domínio desta tese, é válido que se conclua esta seção a propósito da importância da forma de representação de informações adotada relembrando um exemplo apresentado por David Marr sobre esse assunto [Marr, 1982]. Trata-se do problema de adição de números inteiros [Meyer, 1992]. De fato, a descrição de um algoritmo para a soma de 
dois números inteiros deve começar pela definição de um sistema de numeração, o qual nada mais é do que a escolha de um conjunto de símbolos que irão representar tais números. Assim, por exemplo, um número inteiro pode ser representado por algarismos romanos, no tradicional sistema decimal ou ainda no sistema binário. Embora qualquer um desses sistemas sirvam perfeitamente para a representação de um número inteiro, é evidente que cada sistema implicará em um conjunto particular de algoritmos para operar sobre essa representação. Assim, a importância de uma escolha correta da representação na eficiência (em todos os sentidos) dos algoritmos que nela operam pode ser facilmente percebida.

Ainda em relação à importância dos contornos, é importante ressaltar que este trabalho é não somente o resultado da pesquisa desenvolvida pelo autor durante o programa de doutorado, mas remonta aos trabalhos de iniciação científica desenvolvidos pelo autor a partir de 1989 [Cesar, 1989; Cesar 1990; Cesar 1991], tendo tido uma continuação durante o programa de mestrado [Cesar, 1993] e culminado no programa de doutoramento.

\subsection{Processamento de Contornos e Visão}

A redução da redundância tipicamente presente em imagens naturais por parte das representações adotadas nos diferentes níveis de um sistema de visão implica em uma codificação muito mais compacta do estímulo visual original, permitindo que o processo de reconhecimento aja de maneira mais rápida e eficiente [Barlow, 1994]. Deve-se, porém, observar que compacidade não é a única restrição que deve ser buscada por esquemas adequados de representação de informação visual. Um outro ponto muito importante diz respeito à capacidade da representação de salientar aspectos visuais mais relevantes, os quais influenciam fortemente no sucesso dos algoritmos de classificação, ou mesmo em seu desenvolvimento. A natureza ainda possui lições a dar com respeito à escolha de um esquema de representação (ou representações) adequado, o qual deve depender das características dos algoritmos de reconhecimento e das cenas a serem trabalhadas. É um fato relativamente bem aceito que a retina dos mamíferos implementa algum tipo de mecanismo para enfatizar bordas de objetos contrastantes na imagem, acarretando uma dramática redução da quantidade de dados visuais [Barlow, 1994; Marr, 1982]. Além disso, conjecturou-se que tais representações de objetos na imagem em termos de suas bordas codificam totalmente a informação original, ou ainda, em termos de processamentos de sinais, que o sinal original pode ser reconstruído a partir de seus cruzamentos por zero [Marr \& Hildreth, 1980; Marr, 1982], o que acabou acarretando o desenvolvimento de inúmeros algoritmos de reconstrução que podem gerar aproximações muito boas de imagens normalmente encontradas.

O próximo esquema de representação importante adotado no nível cortical do sistema visual dos primatas é caracterizado pela aproximação poligonal, ou linear por partes, dos contornos gerados pelos detectores de borda. A segmentação e representação de contornos particionados é uma das etapas fundamentais em sistemas de visão, tanto natural como artificial [Attneave, 1954; Marr, 1982]. Sabe-se que os sistemas biológicos de visão fazem uso de representações poligonais como um subsídio para a análise de imagens, acreditando-se que boa parte do córtex visual seja 
dedicada à codificação e ao processamento da informação em termos da representação por segmentos lineares [Attneave, 1954]. Tais fatos explicam o grande interesse no desenvolvimento de métodos de detecção de vértices ou pontos de alta curvatura em contornos por parte dos pesquisadores em visão computacional [Cesar \& Costa, 1995b; Cesar, 1993]. Como será amplamente discutido, esse é um dos pontos centrais desta tese.

A Figura 1.1 esquematiza as representações discutidas. Um mapa de bordas pode ser criado a partir da imagem original (em níveis de cinza). Um conjunto de pontos criticos pode ser identificado a partir das bordas ou contornos dos objetos. Tais pontos críticos, os quais estão indicados pelo símbolo "+" no contorno da Figura 1.1, são geralmente associados a pontos de alta curvatura e vértices. Finalmente, a representação dos objetos da cena por polígonos pode ser facilmente obtida ligando-se os pontos críticos por segmentos de reta, e o resultado também é mostrado na Figura 1.1. Assim, uma boa parte da informação mais importante da imagem original, a qual necessitava de $512 \times 512 \times 8=2097152$ bits, pode ser representada por uma ou duas dezenas de pares de números inteiros.

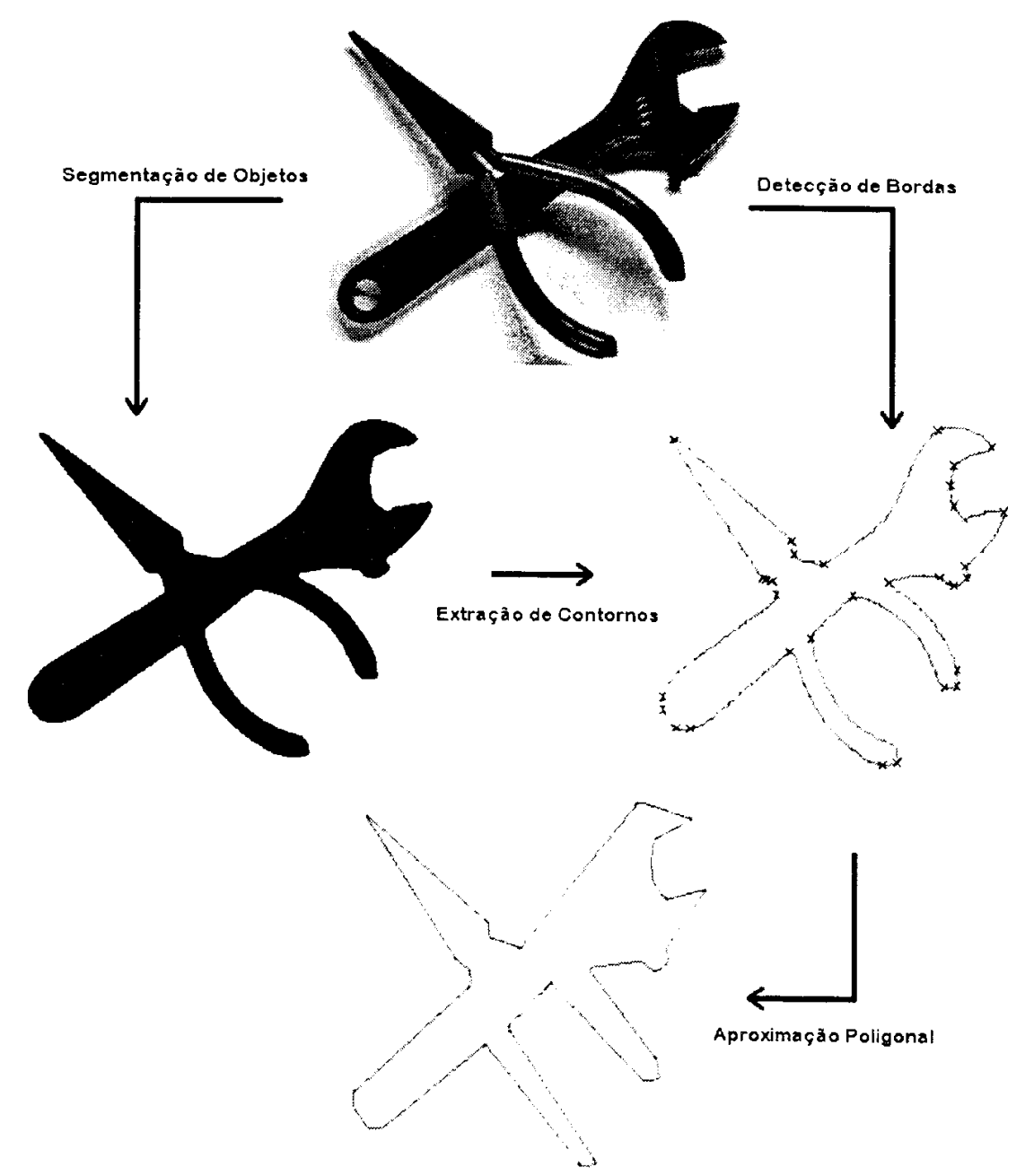

Figura (1.1): Diferentes representações da informação pictórica: imagem em níveis de cinza, imagem segmentada, mapa de bordas e aproximação poligonal. 
A Figura 1.1 também ilustra um caminho alternativo na obtenção do mapa de contornos de uma imagem. Trata-se do processo de segmentação da imagem por regiões, através do qual os objetos de interesse são inicialmente separados de outros objetos e do fundo da imagem, obtendo-se assim uma imagem binária. A imagem binária, contendo as silhuetas dos objetos, pode ser usada diretamente na extração dos contornos. O Capítulo 2 discute um pouco mais esses processos.

\subsection{OBJETIVOS}

1 entro do universo da pesquisa em visão computacional, esta tese trata do problema de caracterização de formas $2 D$ através da análise de contornos. Nesse sentido, um dos objetivos deste trabalho é o desenvolvimento de representações de contornos e da subseqüente extração de características ou de medidas de formas que forneçam informações significativas sobre a forma em questão. Tais medidas podem, por exemplo, ser usadas como vetores de características para classificadores estatísticos de padrões, em um processo de reconhecimento de formas.

Um fato bem conhecido pelos pesquisadores de análise de imagens é o de que a identificação de uma característica importante de uma imagem depende da escala de observação dessa característica. Nesse sentido, diferentes escalas de observação podem levar a diferentes conjuntos de características ou medidas. Por exemplo, a Figura 1.2 apresenta uma imagem e alguns detalhes de estruturas que a compõem e que vivem em diferentes escalas de observação. Tendo-se em vista essas considerações, esta tese também se preocupa com a definição de representações multi-escala de formas. Tais representações, em vez de escolherem uma escala $a$ priori, fornecem a descrição de um determinado aspecto do contorno em um conjunto de escalas, o que permite a observação da evolução de cada característica através das múltiplas escalas.

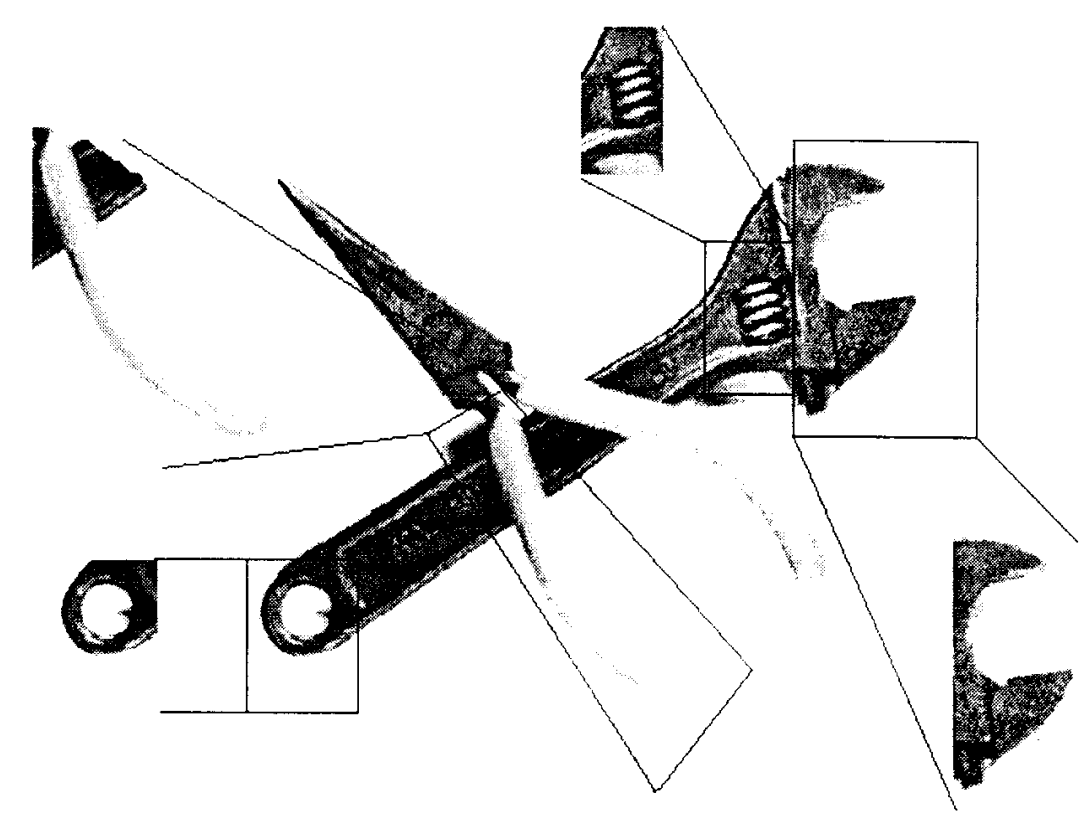

Figura (1.2): As diferentes partes que compõem a cena vivem em escalas distintas. 
Existem diferentes maneiras de se abordar um problema dentro do paradigma multi-escala. Dentre elas, a área de processamento de sinais acabou desenvolvendo um conjunto de ferramentas bem fundamentadas matematicamente para a representação e a análise multi-escala de sinais. Essas ferramentas, as quais serão reunidas em 3 classes genéricas denominadas espaço-escala, tempo-freqüência e tempo-escala, formam os instrumentos básicos para análise de formas neste trabalho (veja o Capítulo 3 para as definições desses termos).

Um outro aspecto que dominou o trabalho desenvolvido e reunido nesta tese é seu caráter prático de implementação. Como foi comentado na Seção 1.1, os trabalhos em visão computacional geralmente envolvem a pesquisa em diferentes áreas, cada qual possuindo um grau de complexidade não trivial ${ }^{1}$. Assim, se por um lado existem ferramentas poderosas em diferentes áreas e que podem ser aplicadas com grande potencial de sucesso aos problemas de visão computacional, por outro o processo de identificação dos instrumentos corretos, de familiarização com a teoria e suas principais propriedades, de implementação correta e calibração dos inúmeros parâmetros normalmente envolvidos pode mostrar-se extremamente árduo e consumir uma grande quantidade de tempo e esforço, o que pode vir a inviabilizá-lo, principalmente levando-se em conta que o pesquisador em visão computacional freqüentemente precisa pesquisar ferramentas de diferentes áreas do conhecimento. Dentro desse contexto, esta tese procura apresentar de maneira prática um conjunto de técnicas para análise multi-escala de formas, de modo que outros pesquisadores que, porventura, vierem a aproveitá-la em seu trabalho possam utilizar essas técnicas da maneira mais direta possível, reservando tempo para o estudo de outros tópicos eventualmente envolvidos em seu trabalho. Além disso, esta tese também procura introduzir a teoria básica necessária para a motivação e uma melhor compreensão das técnicas desenvolvidas.

Ainda dentro dessa preocupação em descrever as técnicas para que possam ser aplicadas o mais diretamente possivel, o trabalho desenvolvido também devotou uma atenção especial à validação dos métodos desenvolvidos, principalmente sob o ponto de vista da aplicação dos algoritmos a dados reais, corrompidos com ruídos e artefatos normalmente encontrados em situações experimentais reais. Sabe-se bem que a utilização de grande parte dos algoritmos em situações experimentais reais normalmente leva o pesquisador a desenvolver um certo "know-how", ou seja, um conjunto de conhecimentos experimentais ${ }^{2}$, que é indispensável para o sucesso de sua aplicação. De certa maneira, procurou-se transmitir ao máximo esse tipo de conhecimento.

Finalmente, embora todas as técnicas desenvolvidas nesta tese possam ser igualmente aplicadas a diferentes problemas de análise de imagens e visão, o pano de fundo dos experimentos realizados foi a análise de formas de células neurais, ou neuromorfometria, uma das linhas de pesquisa desenvolvidas junto ao Grupo de

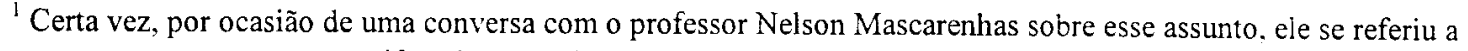
esse ponto com uma metáfora bastante instrutiva segundo a qual cada área "é um poço" no qual devemos mergulhar para encontrar as ferramentas que nos interessam.

2 "Bizu" é uma palavra do português falado em alguns estados do nordeste do Brasil e que melhor traduz esse tipo de conhecimento.
} 
Pesquisa em Visão Cibernética - IFSC - USP. Nesse sentido, procurou-se desenvolver um conjunto de técnicas e medidas úteis e confiáveis que pudessem ser aplicadas em problemas de caracterização, análise e classificação de neurônios.

Dessa maneira, os objetivos do trabalho desenvolvido podem ser sumariados na seguinte lista:

1. Desenvolvimento de representações multi-escala de formas que se fundamentam em técnicas de processamento de sinais;

2. Definição de medidas de formas que são obtidas a partir das representações multi-escala introduzidas;

3. Apresentação das novas técnicas de maneira prática, incluindo detalhes de implementação, para que o leitor deste trabalho seja capaz de aproveitá-lo da maneira mais direta, chegando a estar apto a reproduzir e aplicar os resultados;

4. Avaliação e validação do desempenho das técnicas introduzidas;

5. Aplicação a problemas de neuromorfometria.

\subsection{Revisão Introdutória: Alguns Problemas Centrais em ANÁLISE DE FORMAS}

omo já foi dito, a descrição e análise de formas ocupa um papel singular dentre os processos envolvidos na visão computacional. Para melhor sublinhar esse aspecto, pode-se citar uma expressão em inglês, "to link into shape", que significa colocar em condições de bom funcionamento. Com certeza, a maioria das pessoas que a empregam não imaginam o significado que tal expressão pode possuir aos olhos de um pesquisador de visão computacional. Afinal, em uma imagem, uma das informações mais importantes a ser determinada é a forma ("shape") dos objetos dessa imagem; e o "bom funcionamento" de um processo de visão, seja qual for a abordagem utilizada, depende diretamente de uma boa descrição/representação da forma de cada objeto.

A representação e análise de formas cumpre um papel central em diversas aplicações de visão computacional. De fato, procedimentos de neuromorfometria, reconhecimento ótico de caracteres, casamento de contornos para reconstrução tridimensional de imagens biomédicas, inspeção visual em ambientes industriais e muitas outras tarefas visuais podem ser realizadas por processos baseados em reconhecimento de formas. I De maneira geral, existem duas abordagens básicas para a representação e a análise de formas: a abordagem por contornos e a por regiões. Exemplos de representação de formas baseada em regiões são as "octrees", as "quadtrees", os esqueletos e eixos de simetria, e a decomposição morfológica [Pitas \& Venetsanopoulos, 1990; Pitas \& Venetsanopoulos, 1992]. Por outro lado, a aproximação poligonal, o código da cadeia, as primitivas geométricas, as curvas paramétricas, os descritores de Fourier e a transformada de Hough são exemplos de representações de formas baseadas em contornos. Esses métodos compartilham um conjunto de características comuns: 


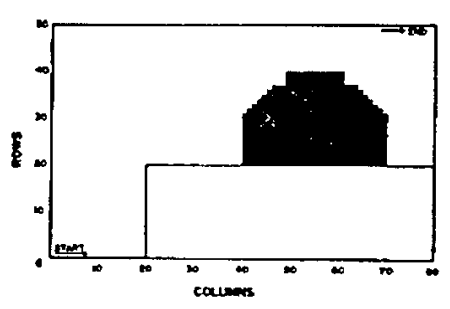

(a)

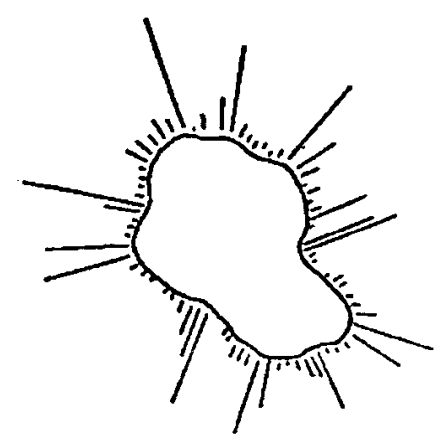

(b)

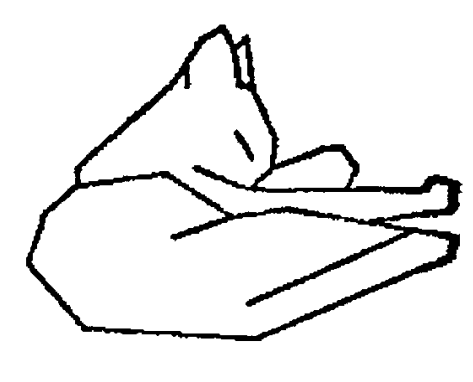

(c)

Figura (1.3): Exemplos de experimentos apresentados por Attneave.

1. Extração de informação significativa sobre a forma: a representação deve facilitar a compreensão de um determinado conjunto de características do objeto. Dentro desse contexto, é importante salientar a deteç̧ão de vértices e pontos de alta curvatura. Embora um número menor de métodos da literatura dependam de uma etapa de avaliação de curvatura, sua importância na análise de formas é um fato bem conhecido e aceito. Com efeito, existem inúmeros resultados psicofísicos que demonstram o papel fundamental cumprido pela curvatura na percepção humana de formas. A maior dificuldade envolvida nessa tarefa se refere à natureza discreta das curvas digitais, tornando a maioria dos métodos dependentes do ruído e da escala de análise;

2. Compressão de dados: uma das metas da representação pode ser a redução da quantidade de dados, sendo que as razões de compressão típicas podem variar de 2:1 a 20:1, dependendo do método e do contorno. Esse tópico está relacionado com uma outra maneira de classificação de métodos de representação de contornos, ou seja, existem métodos que preservam informação o bastante de maneira a possibilitar a reconstrução da forma original (ou aproximada), enquanto que outros métodos não preservam essa informação. Assim, se por um lado os descritores de Fourier permitem a reconstrução da forma original, medidas como área e o perímetro não o fazem, tendo-se em vista a existência de uma infinidade de formas diferentes que podem ter a mesma área ou o mesmo perímetro. Porém, é importante salientar que tais características não indicam que os métodos que preservam informação são superiores, principalmente tendo-se em vista que inúmeras medidas que não preservam informação revelam-se bastante úteis em muitas situações práticas. A compressão de dados está relacionada com o próximo tópico;

3. Eliminação de ruído e redundância: curvas digitais são freqüentemente corrompidas com ruído e detalhes indesejáveis que, aumentando a redundância da informação, podem prejudicar o desempenho dos classificadores de formas. A representação deve filtrar tais componentes perniciosos.

No que concerne aos experimentos em psicofisica sobre percepção de formas, o pesquisador Fred Attneave possui um papel bastante importante. Em um de seus trabalhos mais importantes para as pesquisas em análise de formas em visão computacional [Attneave, 1954], Attneave chamou a atenção para a importância que 
eventos transitórios e quebras de simetria cumprem no processo de percepção e extrapolação realizadas por seres humanos. Em seu trabalho, Attneave procura explorar as ferramentas de processamento de informação na pesquisa em psicologia, argumentando que a informação visual é altamente redundante. Tal redundância, a qual ocorre simultaneamente no espaço e no tempo, faz com que o mundo visual seja coerente no sentido de possuir uma estrutura a ser explorada pelos sistemas visuais. De fato, a existência de redundância na informação visual tornou possível o aparecimento dos sistemas de visão na natureza que exploram essa redundância para compensar os efeitos inerentes do ruído presente tanto na informação luminosa como nos sistemas neurais que a processam. Em um dos experimentos seminais efetuados, Attneave explora o fato de que os pontos da cena nos quais é mais provável que a pessoa avaliada durante o experimento cometa erros são aqueles que possuem uma maior carga de informação ${ }^{3}$. $O$ experimento baseia-se na cena mostrada na Figura 1.3 (a), a qual possui um vidro de tinta preto colocado sobre uma mesa marrom, ambos situados contra uma parede branca. Essa cena foi dividida em 4000 células, organizadas em uma matriz de 50 linhas por 80 colunas. Em seguida, a cena era mostrada célula por célula, de cima para baixo e da esquerda para direita, ou seja, em ordem "scanline". O experimento resumia-se a um "jogo de adivinhação", no qual o sujeito deveria adivinhar a cor da próxima célula dentre as 3 possíveis. No início do experimento, depois de alguns erros, o sujeito percebe a homogeneidade do fundo da parede e passa a acertar a cor branca das células até que o topo do vidro de tinta é atingido, o qual corresponde a uma célula com alto índice de erros. Depois que o sujeito comete alguns erros, volta a perceber a homogeneidade de cor do interior do vidro, recomeçando a série de acertos devidos à extrapolação. Essas considerações formam, na verdade, um outro exemplo da importância de bordas ou contornos em cenas visuais, como já foi considerado no início deste capítulo.

O próximo tipo de coerência explorado pelo sujeito consiste nas retas formadas pelas bordas. Assim, enquanto a primeira célula da linha do topo do vidro de tinta ou a da mesa concentra grande quantidade de informação (o que é equivalente a dizer que essas células possuem grande incidência de erros), nas próximas linhas o sujeito passa a inferir corretamente a borda do objeto devido à continuidade dessa em linha reta. Colocando isso em outros termos, pode-se concluir que os vértices e pontos de alta curvatura possuem probabilidade maior de erro por parte do sujeito, ou seja, concentram maior quantidade de informação.

E o que dizer do padrão serrilhado da borda inclinada do vidro de tinta? $\mathrm{O}$ experimento mostrou que, depois de alguns erros preliminares, o sujeito inferiu a repetição periódica do padrão do tipo "escada" existente naquela borda, diminuindo assim o número de pontos de erro.

Finalmente, os sujeitos foram capazes de extrapolar a simetria do vidro de tinta, usando essa inferência para diminuir a quantidade de erros referentes ao lado direito do vidro de tinta.

${ }^{3}$ É importante salientar que esse tipo de análise explica uma das grandes vantagens da análise em wavelets, a saber, sua boa capacidade de deteç̧ão e análise de fenômenos transitórios. 


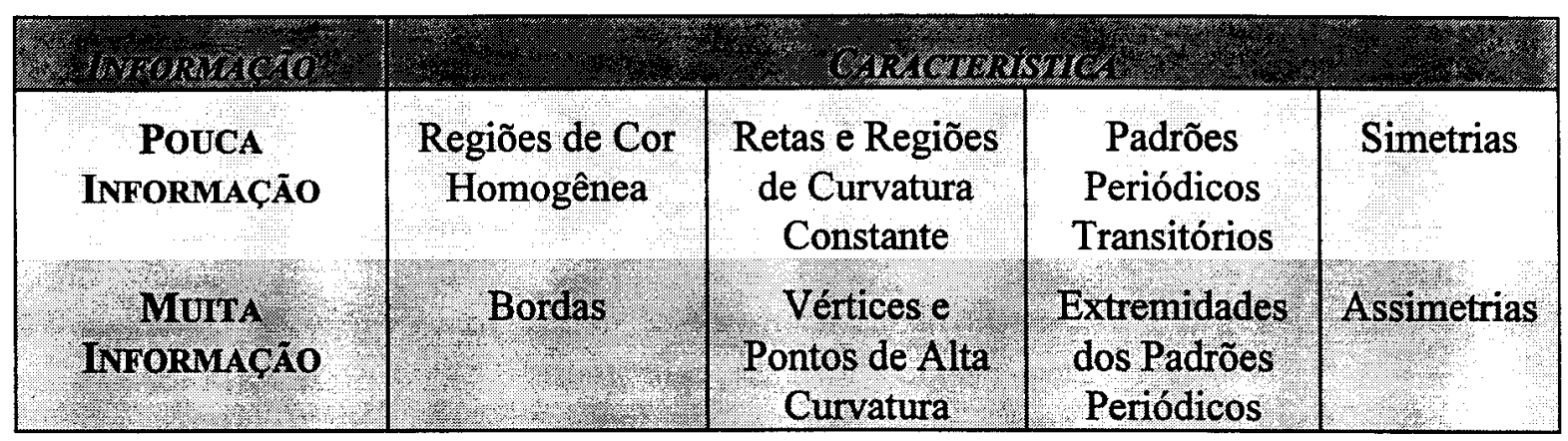

Tabela (1.1): Algumas relações concluídas a partir do trabalho de Attneave.

Assim, de certa forma pode-se contrapor as características de pouca e muita informação na percepção de formas em função da redundância de cada uma dessas características, e a Tabela 1.1 resume essa análise.

Attneave chama a atenção para o fato de que mesmo os princípios da Gestalt podem ser interpretados sob a ótica da exploração de redundância de informação. As imagens Gestalt típicas possuem um grau elevado de algum tipo de redundância, e sua percepção envolve a tentativa de nosso sistema perceptual de reduzir a incerteza através da exploração dessa redundância.

Existem ainda dois experimentos apresentados por Attneave nesse seu importante trabalho que são dignos de nota. No primeiro deles, uma série de formas bidimensionais foi apresentada aos sujeitos, os quais deveriam representar cada forma por um conjunto de 10 pontos. A Figura 1.3(b) mostra um resultado típico em que as barras radiais formam um histograma dos votos que cada ponto recebeu de um conjunto de sujeitos. Novamente, aos pontos de alta curvatura atribuiu-se uma importância maior. Finalmente, Attneave gerou uma imagem hoje clássica ao apresentar o esboço da Figura 1.3(c), o qual foi obtido identificando-se os pontos de alta curvatura de uma fotografia normal de um gato dormindo, sendo esses pontos ligados por linhas retas.

É importante situar esta tese dentro do contexto dessa discussão. A caracterização de cenas através da análise de contornos nasce justamente da importância das bordas em cenas visuais. Além disso, um conjunto de ferramentas para a detecção e a caracterização de vértices e pontos de alta curvatura é introduzido, além de outras medidas de caracterização de complexidade de formas em função da curvatura. É também importante salientar que, além da introdução dos métodos para identificação dos pontos de alta curvatura, são desenvolvidos outros algoritmos que utilizam esses pontos, como é o caso das técnicas de geração de dendrogramas de células neurais (Capítulo 7). Finalmente, o problema de detecção e caracterização de padrões periódicos transitórios que ocorrem em formas recebeu atenção muito menor por parte dos pesquisadores de visão. Mais recentemente, alguns trabalhos começaram a relatar a importância de escalas naturais de objetos, e o trabalho desenvolvido nesta tese mostra como o tratamento dado a esses dois conceitos pode ser unificado. $\mathrm{Na}$ verdade, não existe na literatura uma definição genérica e completa de o que vem a ser uma escala natural, de maneira análoga à inexistência de uma definição para textura [Castleman, 1996], e esta tese apresenta um novo aspecto desse problema em função de padrões periódicas ou regularidades 
transitórias. Seguindo essa linha de raciocínio, esta tese apresenta a abordagem de análise local de sinais, através dos métodos tempo-freqüência e tempo-escala, como uma ferramenta natural no tratamento de padrões periódicos.

Essas considerações sugerem a segmentação do contorno e a representação de cada segmento por uma determinada primitiva geométrica (seja uma linha reta ou um padrão periódico, por exemplo). De fato, do ponto de vista da visão por máquina, há aproximadamente 30 anos os pesquisadores já haviam percebido que era inviável representar formas completas por polinômios ou séries, e grande parte da pesquisa nessa área concentrou-se na elaboração de algoritmos de representação de contornos por partes [Pavlidis, 1986]. Segundo esse paradigma, o contorno deve ser particionado, o que implica na localização de pontos dominantes ou pontos característicos da curva, seguida da representação de cada segmento por alguma primitiva. Nesse sentido, a identificação dos pontos dominantes no contorno é o passo crucial dessa abordagem.

Observe a Figura 1.4, que apresenta duas possíveis representações por partes (b) e (c)) de um contorno inicial (a). Assim, tem-se que ABCDEFGH foi representado (ou aproximado) por ABCDE no contorno da Figura 1.4(b) e por $A B C D E F G$ no contorno da Figura 1.4(c) (esse exemplo baseia-se na explicação apresentada por Theo Pavlidis em [Pavlidis, 1986]). Existe uma diferença importante entre essas duas aproximações. A aproximação da Figura 1.4(b) possui um número menor de pontos dominantes, apresentando uma quantidade menor de detalhes de pequena escala e salientando as principais características da forma em uma escala maior. Por outro lado, a Figura 1.4(c) é uma representação em pequena escala do contorno original, apresentando uma maior quantidade de detalhes finos. Esse exemplo ilustra a importância do conceito de escala de observação na caracterização de formas. Existe um "trade-off" entre as duas opções: enquanto a observação em pequena escala possui uma quantidade maior de informação (mais detalhes), tais detalhes podem estar misturados com ruído, o qual pode prejudicar (e mesmo inviabilizar) a busca por informações importantes (por exemplo, pontos dominantes). Na medida que é aumentada a escala de análise, o ruído vai sendo filtrado, bem como alguns detalhes de pequena escala que podem ser importantes para o processo de análise do contorno. Além disso, é importante perceber que cada possível escala de análise enfatiza um determinado conjunto de estruturas da forma, de modo que estruturas importantes podem ocorrer ( $e$, de fato, ocorrem freqüentemente) em diferentes escalas. Todas essas considerações fazem parte do conjunto de motivações da criação da abordagem multi-escala de análise de formas, a qual procura não só

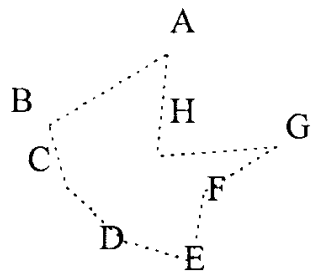

(a)

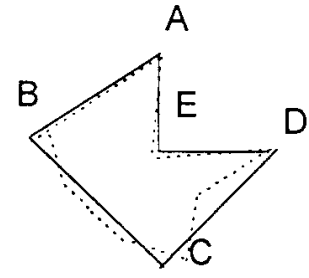

(b)

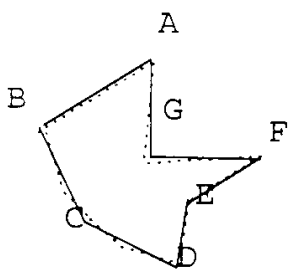

(c)

Figura (1.4): (b) e (c) apresentam dois possiveis particionamentos do contorno apresentado em (a). 
analisar os contornos em uma escala específica, mas também a evolução de suas estruturas componentes através da variação das escalas. Tal filosofia está por trás de diferentes abordagens de análise multi-escala de formas, como a curvatura-c de Larry Davis [Davis, 1977], as aproximações poligonais hierárquicas propostas por Ann Bengtsson e Jan-Olof Eklund [Bengtsson \& Eklund, 1991] e o espaço-escala de curvatura proposto por Farzin Mokhtarian e Alan Mackworth, e constitui o paradigma básico adotado no desenvolvimento dos métodos deste trabalho.

Paralelamente, existem diferentes sinais que podem ser obtidos de um contorno, os quais podem ser usados para descrição de formas através de técnicas de processamento de sinais, o que será explorado com maior profundidade no Capítulo 2. Dentro desse contexto, as chamadas transformadas tempo-escala e tempofreqüência [Daubechies, 1992; Flandrin, 1993; Lindeberg, 1994; Torrésani, 1995] são de especial interesse, visto que elas incorporam o paradigma multi-escala. Tais transformadas, como as wavelets e a transformada de Gabor, vêm sendo intensamente estudadas nas últimas décadas, tendo sido aplicadas, por exemplo, em problemas como reconstrução $3 \mathrm{D}$ e visualização de volumes, modelagem geométrica, segmentação de texturas, reconhecimento de caracteres e outros. Esse assunto receberá maior atenção ao longo deste trabalho.

Finalmente, é importante comentar brevemente a principal área na qual as técnicas desenvolvidas nesta tese foram aplicadas, ou seja, a neuromorfometria ou análise da forma de células neurais. A forma de um neurônio é especialmente importante pois ela determina, em grande parte, as propriedades funcionais de tais células. Em particular, a análise automática ou semi-automática de células neurais pode ser usada de diferentes maneiras interessantes como na classificação automática de neurônios (baseada em sua forma), na criação de modelos artificiais de células neurais, na pesquisa sobre a relação entre forma e função das células, entre outras. É importante salientar que existem poucas medidas padronizadas para a caracterização da forma neural, bem como pouco consenso entre os pesquisadores de neurociências sobre quais aspectos são mais importantes. Células neurais são frequientemente bastante complexas e de formato irregular, características que acabam impondo interessantes desafios para essa linha de pesquisa.

\subsection{CONTRIBUIÇÕES}

D e modo geral, esta tese introduz um conjunto de novos algoritmos para análise de formas $2 \mathrm{D}$, bem como a avaliação, o melhoramento e a generalização de outros métodos já propostos na literatura pesquisada. Essas contribuições podem ser divididas em 4 partes mais genéricas:

1. Diagramas multi-escala de curvatura (curvogramas): Os diagramas de descrição multi-escala da curvatura de contornos foram aqui introduzidos e diferentes ferramentas de análise de contornos a partir dos curvogramas foram desenvolvidos. Em relação aos métodos de análise multi-escala de curvatura já existentes, esta tese introduz uma nova abordagem que explora os descritores de Fourier de contornos (ver Seção 2.6.5), em conjunto com a aplicação da propriedade das derivadas de Fourier. Além disso, um dos problemas tradicionais de filtragem gaussiana de contornos, ou seja, a contração de contornos, foi resolvido de diferentes maneiras, 
cada qual sendo mais adequada a determinadas situações, o que é discutido neste trabalho. Finalmente, foram introduzidos diferentes algoritmos de análise de contornos a partir do curvograma;

2. Análise de formas baseada em contornos pela transformada contínua em wavelets (a representação- $W$ ): Esta tese introduz a transformada contínua em wavelets de contornos, o que define a representação- $W$ como uma nova técnica de representação e caracterização multi-escala de contornos. Propriedades matemáticas da teoria das wavelets são aplicadas no desenvolvimento de novos algoritmos para análise de contornos e para a detecção de características importantes, como vértices e singularidades em contornos. Além desses algoritmos, esta tese apresenta um novo conceito de escalas naturais, relacionando-o com padrões periódicos que podem ocorrer em formas (ver Seção 5.7), e mostra como elas podem ser detectadas e caracterizadas pela representação- $W$, bem como pela transformada de Gabor do contorno, a qual é introduzida de maneira análoga;

3. Análise de formas por energia multi-escala: As principais representações multi-escala introduzidas nesta tese, isto é, o curvograma e a representação- $W$, são exploradas na derivação de medidas de energia que fornecem medidas de forma e são usadas para a caracterização de complexidade. O curvograma é utilizado particularmente na definição da energia elástica multi-escala normalizada ou energia multi-escala normalizada de dobramento, sendo que tais energias são vetores de medidas de caracterização de formas. Estratégias para escolha das escalas mais significativas são também apresentadas. Experimentos de classificação automática de células ganglionares de gato são apresentados;

4. Geração semi-automática de dendrogramas: Esta tese introduz uma nova abordagem para a geração de dendrogramas e discute os algoritmos envolvidos. Tais algoritmos aproveitam o curvograma e suas técnicas associadas interagindo com o usuário através de interfaces gráficas. Tal abordagem permite que o usuário assista a execução do programa, intervindo quando necessário. O novo método fornece uma descrição estrutural de neurônios em termos de uma árvore sintática que permite a caracterização de sua forma, incluindo uma maneira simples e direta de extração de esqueletos das células neurais.

Além dessas contribuições, é importante salientar que foi realizado um levantamento e acompanhamento bibliográfico sistemáticos, com auxílio de diferentes mecanismos de busca automática em acervos encontrados em CD-ROM e na INTERNET e a partir das próprias listas de referências dos artigos obtidos. Não foi fixado um período para o levantamento, e os trabalhos identificados incluem desde os mais antigos até aqueles encontrados durante a redação deste trabalho. Em um certo sentido, dois aspectos principais caracterizam a importância desse trabalho realizado. Em primeiro lugar, a análise multi-escala de formas, em suas diferentes abordagens, tornou-se recentemente um campo relativamente maduro, e diversas aplicações bem sucedidas vêm sendo relatadas. Embora apresentar e comparar as diferentes técnicas dessa abordagem não seja a meta deste trabalho, são discutidas as principais técnicas que estão, de uma maneira ou de outra, relacionadas ao assunto desta tese. E em segundo lugar, procurou-se reunir, de maneira mais extensa e completa possível, a bibliografia sobre representação e análise de formas por wavelets e transformada de Gabor, uma tendência surgida bem mais recentemente. 
Finalmente, é importante lembrar que a principal classe de formas utilizadas nos experimentos consiste nas células neurais, o que acabou por fundar diversos aspectos do desenvolvimento deste trabalho. Assim, as novas técnicas introduzidas nesta tese, além de contribuírem com a área de análise de formas $2 \mathrm{D}$, possuem um potencial especial referente às pesquisas em neurociências.

\subsection{ORganização da TESE}

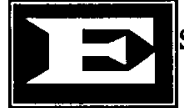
sta tese prossegue apresentando, no Capítulo 2, os principais conceitos teóricos que formam os pré-requisitos básicos para os desenvolvimentos subseqüentes. Esse capítulo inclui seções introdutórias à geometria diferencial, da qual são utilizadas as ferramentas de representação e caracterização de curvas paramétricas $2 \mathrm{D}$, à geometria fractal, que fornece as informações para as seções que tratam de caracterização de curvas exatamente auto-similares por wavelets (Seção 5.8 em diante), e ao processamento de sinais, discutindo as diferentes modalidades de transformada de Fourier e suas principais propriedades, bem como as principais operações dessa área que são utilizadas neste trabalho. Finalmente, o esse capítulo apresenta uma revisão dos principais métodos de representação e análise de formas, discutindo os aspectos históricos que são importantes para o trabalho desenvolvido nesta tese, bem como as principais tendências em análise de formas que estão, de uma maneira ou de outra, relacionadas a este trabalho.

O Capitulo 3 introduz as três abordagens de processamento e análise de sinais que são exploradas nesta tese, ou seja, o espaço-escala, a transformada de Gabor e as wavelets. Nesse capítulo são apresentadas brevemente as perspectivas históricas associadas a cada uma dessas abordagens, alguns exemplos didáticos - a fim de fornecer um maior "feeling" para a exploração dessas ferramentas em análise de formas - e uma discussão sobre as relações, semelhanças e diferenças entre elas. Esse capítulo serve como uma introdução aos métodos desenvolvidos nos Capítulos 4 e 5 .

O conceito de curvatura multi-escala é explorado no Capítulo 4, o qual introduz o curvograma. Esse capítulo inclui a definição e processamento de diferentes ferramentas de geometria diferencial (como curvatura e perímetro) a partir dos sinais complexos que representam os contornos (como será visto no Capítulo 2). $\mathrm{O}$ curvograma é ainda aplicado nos Capítulos 6 e 7.

Os algoritmos de análise de formas que se utilizam da transformada contínua em wavelets e a transformada de Gabor são apresentados no Capítulo 5. Nesse capítulo introduz-se a representação- $W$, a qual é definida como a transformada em wavelets do contorno do objeto de interesse na imagem. Esse capítulo inclui algoritmos para detecção de vértices, escalas naturais e análise fractal de curvas deterministicamente auto-similares, bem como uma discussão sobre diferentes estratégias para exploração de representações tempo-escala e tempo-frequiência para a caracterização de formas.

O Capítulo 6 mostra como diferentes conceitos de energia multi-escala podem ser definidos para a caracterização de complexidade de formas, energias estas que são definidas a partir do curvograma (Capítulo 4) e da representação-W (Capítulo 5). 
Medidas multi-escala apresentam propriedades peculiares que devem ser estudadas antes de sua utilização por parte de algoritmos de classificação de formas, o que é também discutido nesse capítulo. Em particular, são apresentadas estratégias para a seleção das escalas mais importantes para a discriminação de formas. Experimentos de classificação automática de células ganglionares de gato também são incluídos nesse capítulo.

A nova abordagem para a geração semi-automática de dendrogramas é introduzida no Capítulo 7, que discute a maneira pela qual o método de análise de curvatura multi-escala do Capítulo 4 é aproveitado para a segmentação de neurônios. Esse capítulo inclui ainda a descrição da interface de interação com o usuário desenvolvida através dos recursos gráficos do Matlab (GUI's) e as técnicas de reconhecimento sintático de padrões que são aplicadas na descrição estrutural de neurônios.

Finalmente, esta tese é concluida no Capítulo 8, em que apresenta-se uma discussão sobre alguns possíveis desdobramentos do trabalho desenvolvido que podem se materializar por ocasião de pesquisa futura. $\dot{E}$ importante que o leitor consulte a lista de símbolos e notações adotadas na tese e que está incluída no início deste trabalho.

A seguir é apresentado um esquema da divisão desta tese levando-se em consideração as relações entre seus capitulos e apêndices. 


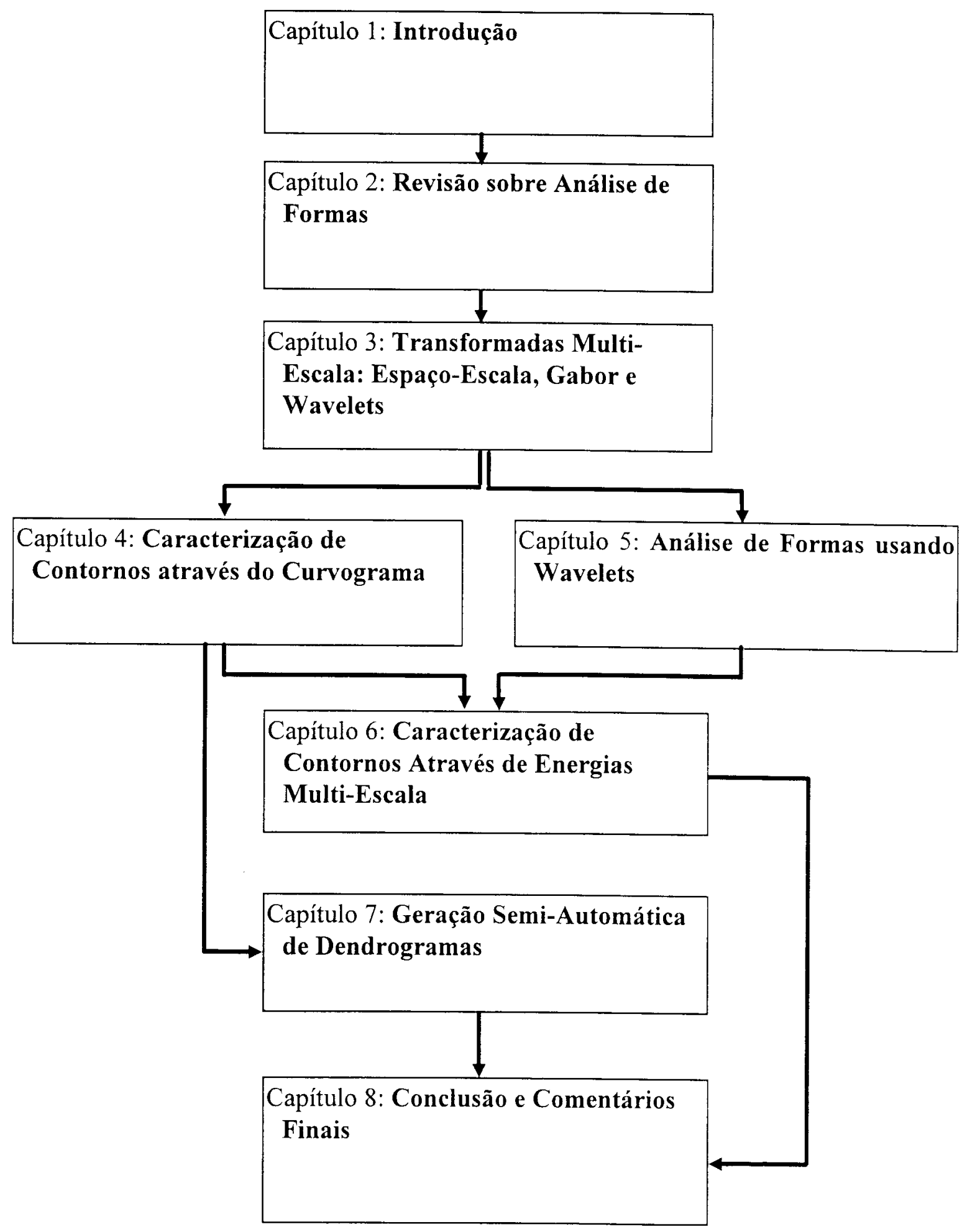




\section{Capítulo 2 - Revisão sobre Análise de Formas}

Comme je l'ai expliqué tout à l'heure, l'entité saillante est fondée, elle dispose de sa forme définie par la discontinuité, celle de son bord. C'est une idée très profonde, clé de la physique aristotélicienne. II y a des citations de la physique d'Aristote que je pourrais vous donner là, mais c'est sans intérêt... Pour lui, la forme d'un objet physique est quelque chose comme son bord; au sens abstrait de la définition, l'eidos c'est quelque chose également comme une forme dans un espace abstrait, avec son bord. II y a une matière intelligible, qui est en quelque sorte comprimée par sa définition. Orismos signifie définition; c'est presque le même mot que oros qui veut dire bord. C'est assez remarquable.

René Thom - Prédire n'est pas Expliquer, 1991 


\section{REVISÃo SOBRE ANÁLISE DE FORMAS}

\subsection{INTRODUÇÃO}

$\mathbf{N}$ este capítulo são discutidos os principais conceitos que servem de base para os desenvolvimentos desta tese. Assim, a abordagem de análise de formas 2D por contornos, sobre a qual já se traçaram alguns comentários no capítulo introdutório, é apresentada de forma mais detalhada e prática. Basicamente, todos as técnicas desenvolvidas neste trabalho partem, direta ou indiretamente, da representação complexa de contornos parametrizados. Além disso, as ferramentas da teoria de processamento de sinais que são fundamentais para o entendimento deste trabalho são também introduzidas, bem como noções de geometria diferencial e fractal. Finalmente, os principais tópicos de análise de formas que estão relacionados com esta tese são apresentados sob as perspectivas histórica e de tendências atuais. Embora este capítulo tenha por finalidade realizar uma revisão introdutória dos principais conceitos e ferramentas matemáticas e metodológicas que são utilizadas nos capítulos seguintes, observa-se que ele já apresenta algumas contribuições, principalmente por tentar reunir, em sua discussão, trabalhos e tendências atuais em análise de formas, ao mesmo tempo que busca resgatar o histórico das pesquisas que vieram dar lugar às abordagens atuais (por exemplo, ao retomar e chamar a atenção para o trabalho multi-escala de Larry Davis, um dos pioneiros na pesquisa de curvatura multi-escala e análise de máximos locais).

\subsection{NOÇÕES BÁSICAS}

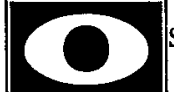

$\mathrm{S}$ métodos desenvolvidos nesta tese se baseiam na análise de contornos presentes na imagem como sendo o meio para extração de informação importante sobre a região que tal contorno delimita. É comum imaginar que essa região é a borda de um objeto na imagem, ou a borda de sua silhueta. Um fato de extrema importância para o desenvolvimento e sucesso de métodos de análise de formas $2 \mathrm{D}$ é que tais formas conseguem capturar grande parte da informação de forma de objetos reais, valendo ainda notar que seres humanos são especialmente bem adaptados para o reconhecimento de formas a partir de silhuetas, não importando a ausência de outros 


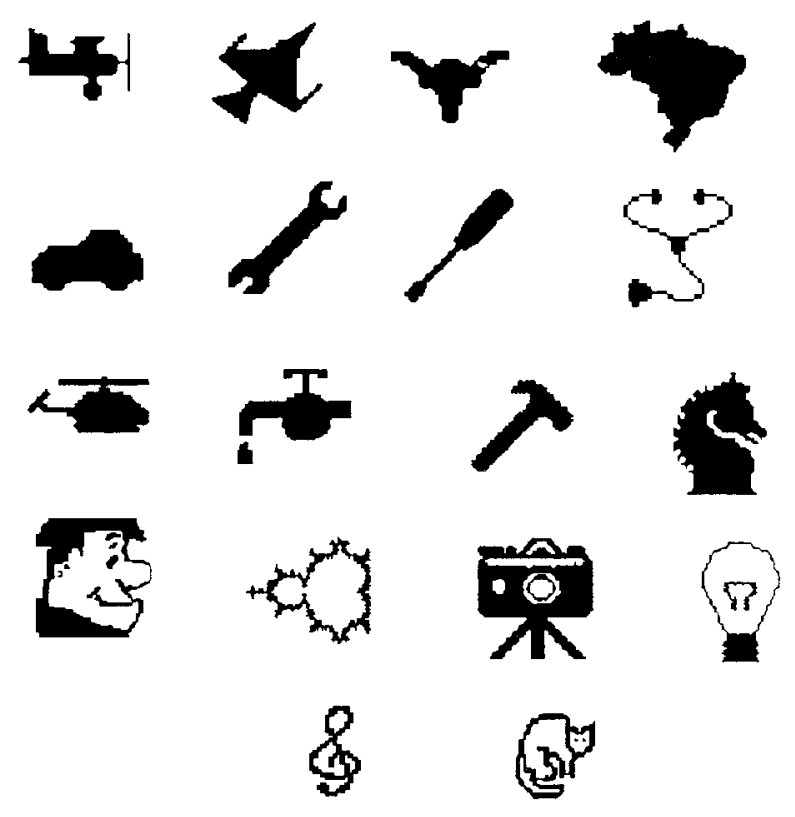

Figura (2.1): Exemplos de diferentes objetos que podem ser reconhecidos apenas a partir de informações de formas 2D. tipos importantes de informação visual como cor, textura e estruturas 3D. A Figura 2.1 ilustra esse fato.

É importante ainda observar que, no caso do exemplo da Figura 2.1, dois tipos de informação 2D estão envolvidos: enquanto que alguns objetos podem ser reconhecidos apenas por regiões preenchidas (como é o caso das três primeiras linhas da Figura 2.1), outros são compostos de partes desconexas e buracos, caracterizando um tipo de informação topológica diferente (caso das duas últimas linhas). Porém, ambos os casos envolvem apenas informação 2D. Embora seja mais intuitivo pensar que métodos de análise de contornos sejam melhor adaptados para a análise de objetos compostos por uma só região preenchida, é importante notar que tal idéia intuitiva não pode se aplicar como uma restrição: cada parte dos objetos pode ser representada e analisada a partir de seu respectivo contorno (sendo que buracos no objeto definem contornos internos), e o objeto como um todo pode ser analisado estruturalmente a partir da organização espacial dos contornos que o formam. Assim, o Fred Flinstone da Figura 2.1 pode ser analisado tomando-se cada contorno interno e externo que contribui na composição total de seu rosto (por exemplo, o contorno externo, o contorno interno que delimita a face, o contorno do olho, da sobrancelha, e assim por diante). Tendo reconhecido os contornos, constrói-se uma estrutura hierárquica que reflita a organização desses contornos (um contorno de forma oval sobre a cavidade da boca é reconhecido como um olho, e assim por diante).

Assim, a abordagem de análise de formas adotada nesta tese pressupõe a obtenção dos contornos dos objetos e de suas partes na imagem. A extração de contornos é um interessante tópico de pesquisa em visão artificial, não possuindo uma solução ótima e geral. É importante enfatizar a existência de dois processos distintos envolvidos na obtenção de um contorno em uma imagem: a segmentação da imagem e a extração do contorno. Neste trabalho, o termo segmentação de imagens diz respeito ao processo de obtenção de uma partição da imagem em regiões segundo um determinado critério qualquer. Assim, poder-se-ia segmentar uma imagem em regiões cujos pixels possuam a mesma cor ou o mesmo nível de cinza, por exemplo. Uma vez que a imagem tenha sido segmentada, o contorno de cada uma das regiões pode ser extraído percorrendo-se sua fronteira. Por outro lado, a segmentação da imagem e extração dos contornos também podem ser realizadas na ordem inversa: em vez de buscar identificar as regiões cujos 
pixels possuam uma mesma dada propriedade, alguns métodos buscam diretamente por contornos na imagem. A identificação dos contornos irá definir o particionamento da imagem. Dentre os muitos métodos de extração de contornos relatados na literatura, pode-se distinguir algumas abordagens gerais, apresentadas a seguir. As três primeiras abordagens baseiam-se na busca por contornos diretamente sobre a imagem enquanto a quarta fundamenta-se na segmentação da imagem seguida da extração do contorno de cada fronteira das regiões segmentadas.

- Filtros de deteç̧ão de bordas em imagens: filtros como Sobel ou Marr-Hildreth podem ser usados para a deteç̧ão de descontinuidades definidas como bordas na imagem. Um problema com essa abordagem é que as bordas obtidas podem ser descontínuas, tornando necessária a aplicação de algoritmos de pós-processamento para preenchimento de buracos ou complementação dos contornos;

- Transformada de Hough: Essa transformada também pode ser usada para a detecção de retas, arcos e outras primitivas, as quais podem ser conectadas posteriormente para a formação dos contornos;

- "Snakes" ou contornos ativos: Os contornos ativos formam uma classe de métodos de ajuste de curvas em imagens que vem ganhando grande impulso desde suas formulações iniciais [Kass et al., 1988]. Os contornos ativos são curvas paramétricas que se ajustam à imagem de modo a minimizar uma integral de energia que envolve restrições internas (energia de dobramento da curva), restrições da imagem (que atraem a curva fazendo com que ela "se cole" a entidades importantes da imagem, como bordas e terminações), e restrições externas (que podem ser definidas pelo usuário de maneira semi-automática). Essas restrições externas podem ser definidas como pontos de controle indicados pelo usuário, os quais exercem uma força atrativa ou repulsiva sobre a curva, que se aproxima ou se afasta dependendo do tipo do ponto;

- Segmentação e extração de contornos: Esse esquema separa as etapas de segmentação e de extração do contorno, sendo que esta última reduz-se a um algoritmo de detecção de objetos em imagens binárias seguida da extração de seus contornos [Bennett \&. Mac Donald, 1975]. É claro que a etapa de segmentação da imagem é crucial nessa abordagem e a grande maioria dos livros de processamento de imagens e visão apresenta revisões sobre esses métodos (por exemplo, [Ballard \& Brown, 1982; Castleman, 1996; Fu, 1982; Morel \& Solimini, 1995; Pavlidis, 1977]). Por outro lado, a área de segmentação de imagens possui uma grande diversidade de métodos e paradigmas que fornece a possibilidade de desenvolvimento de algoritmos dedicados e que pode fornecer bons resultados se desenvolvidos visando uma aplicação particular. Assim, as informações de textura e cor podem ser incorporadas, melhorando os resultados (vale lembrar que a incorporação de outras fontes de informação visual, como cor e textura, também pode ser feita nos métodos de contornos ativos).

Todos os experimentos desta tese foram realizados com contornos obtidos pelo último desses métodos, ou seja, segmentação seguida de extração de contornos. A 
Figura 2.2 apresenta, de forma esquemática, as etapas envolvidas nesse esquema. $O$ primeiro passo consiste na geração de uma imagem binária contendo o(s) objeto(s) de interesse. No caso da Figura 2.2, o processo de segmentação utilizado consiste basicamente no seguinte procedimento padrão utilizado em praticamente todos os exemplos deste trabalho. A imagem em níveis de cinza (Figura 2.2(a)) é segmentada por definição de limiar ("thresholding"), sendo que a imagem binária obtida é processada para eliminação de ruídos e preenchimento de buracos, visto que, em todos os exemplos deste trabalho, o interesse era o processamento do contorno exterior do objeto (Figura 2.2(b)). Esse pós-processamento da imagem binária geralmente envolve filtragem mediana e aplicação de filtros morfológicos, tendo-se em vista a eliminação de pequenas partículas e o preenchimento de buracos, podendo incluir edição da imagem em um processo interativo.

Uma vez que o objeto de interesse na imagem tenha sido isolado, o contorno de tal objeto é extraído percorrendo-se sua borda a partir de um ponto inicial qualquer e armazenando-se as coordenadas $x$ e $y$ de cada ponto como uma função do parâmetro associado ao caminho percorrido ao longo da borda (Figura 2.2(c) e (d)). É importante lembrar que, devido à natureza digital da imagem, esse "passeio" ao longo da borda do objeto pode ser visto como a realização de um caminho sobre uma grade retangular, hexagonal, ou de algum outro tipo, dependendo do esquema de discretização da imagem. O artigo de Bennett \& Mac Donald, 1975, apresenta e compara uma série de métodos para a extração de contornos. Assim, seja $n$ o parâmetro associado à caminhada ao longo da borda do objeto, sendo que a caminhada é iniciada em $n=0$. Dessa maneira, as

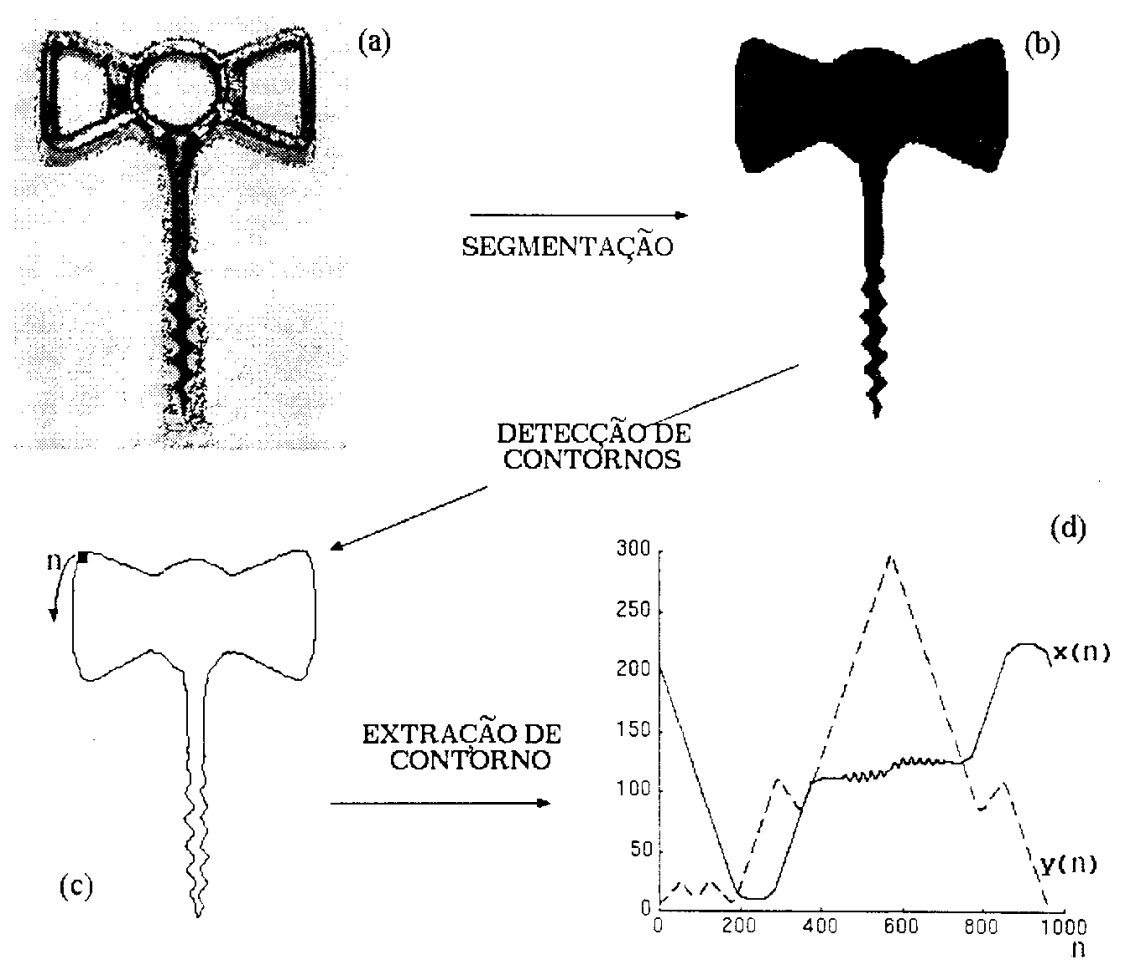

Figura (2.2): Esquema básico do pré-processamento para a abordagem de análise de formas adotada nesta tese. 
coordenadas do contorno do objeto podem ser descritas por uma curva paramétrica discreta $C(n)=(x(n), y(n))$. Essa curva é discreta devido à natureza discreta da imagem digital. Como em alguns desenvolvimentos desta tese será interessante imaginar que existe uma curva contínua associada a $C(n)$, então será definida a curva $C(t)=(x(t), y(t))$, em que o parâmetro $t$ é varia continuamente ao longo da borda do objeto. De agora em diante, far-se-á a diferença entre um sinal discreto $x(n)$ e um sinal contínuo $x(t)$ pelo parâmetro, sendo que $n$ fica associado a sinais discretos (ou discretizados a partir de um sinal contínuo) e $t$ a sinais contínuos. A Figura 2.2(d) apresenta os sinais $x(n)$ e $y(n)$ obtidos da silhueta do saca-rolhas.

Os processos de análise de contornos podem ser realizados diretamente a partir dos sinais $x(n)$ e $y(n)$. Existem, de fato, métodos para cálculo de inúmeras medidas de forma que podem ser usadas como características para classificadores estatísticos de padrões, como área, perímetro, centro de massa ou outros momentos estatísticos [Marshall, 1989; Pavlidis, 1977; Pavlidis, 1980; van der Heijden, 1994]. Por outro lado, tomando-se o plano da imagem como o plano complexo, em que o eixo $x$ fica associado à parte real e o eixo $y$ à parte imaginária dos números, pode-se formar o seguinte sinal complexo parametrizado que representa a borda do objeto [Granlund, 1972; Persoon \& Fu, 1977]:

$$
u(n)=x(n)+i y(n)
$$

sendo que $i=\sqrt{-1}$. De maneira análoga, pode-se definir o sinal complexo contínuo

$$
u(t)=x(t)+i y(t)
$$

O sinal $u(n)$ (ou $u(t)$ ) forma a base de todos os métodos desenvolvidos nesta tese, como será mostrado.

\subsection{Rudimentos de Geometria DifERENCIAL}

eguindo a notação da Seção 2.2 , seja $C$ a representação paramétrica de uma curva, sendo que $C=C(t)$, ou seja, $C$ é dada em função de um parâmetro $t \in[\alpha, \beta]$. A curva $C$ é representada como:

$$
C(t)=(x(t), y(t)), t \in[\alpha, \beta]
$$


Pode-se dizer que a curva $C$ é definida como o conjunto dos pontos no plano que satisfazem a relação 2.3 [Zucker, 1985]. A curva $C(t)$ é contínua no intervalo $t \in[\alpha, \beta]$ se $x(t)$ e $y(t)$ são definidos continuamente nesse intervalo [Stoker, 1969]. Além disso, $C(t)$ é diferenciável se $x(t)$ e $y(t)$ forem diferenciáveis em relação ao parâmetro $t$. A seguinte notação é adotada nesta tese:

$$
\begin{array}{ll}
\dot{x}=\dot{x}(t)=\frac{d x}{d t}(t) & \ddot{x}=\ddot{x}(t)=\frac{d^{2} x}{d t^{2}}(t) \\
\dot{y}=\dot{y}(t)=\frac{d y}{d t}(t) & \ddot{y}=\ddot{y}(t)=\frac{d^{2} y}{d t^{2}}(t) \\
\dot{C}=\dot{C}(t)=\frac{d C}{d t}(t)=(\dot{x}, \dot{y}) & \ddot{C}=\ddot{C}(t)=\frac{d^{2} C}{d t^{2}}(t)=(\ddot{x}, \ddot{y})
\end{array}
$$

Esta tese também adota a notação $x^{(j)}(t)$ para indicar a j-ésima derivada de $x(t)$, principalmente quando derivadas de ordens superiores a 2 estiverem envolvidas.

Se $\ddot{C}(t)$ for contínua no intervalo $[\alpha, \beta]$ e $\dot{C}(t)$ for não-nula diz-se que $C(t)$ é uma curva regular. Seja $t_{0} \in[\alpha, \beta]$. O vetor tangente $\Phi\left(t_{0}\right)$ de $C\left(t_{0}\right)$ é definido como o vetor de coordenadas definidas por $\dot{C}(t)$ e transladado paralelamente de maneira que sua origem coincida com $C\left(t_{0}\right)$. Neste trabalho, $\Phi$ é a notação adotada para indicar vetores (veja a lista de símbolos no início da tese). $\mathrm{O}$ conceito de vetor tangente é particularmente importante para aplicações em visão computacional, visto que pode ser usado em processos de seleção de orientação preferencial [Zucker, 1985]. Uma outra propriedade importante de curvas paramétricas para a pesquisa em sistemas de visão é a direção tomada para percorrer a curva, ou seja, a orientação da curva. Essa direção, que depende da parametrização escolhida, define a direção do vetor tangente, podendo ser aproveitada na explicação de problemas de percepção "object-ground" [Hoffman \& Richards, 1988]. Além disso, a orientação da curva também define o sinal da curvatura, o qual pode ser usado na discriminação entre regiões côncavas e convexas. O comprimento $l(t)$ de um segmento de curva entre um ponto inicial $C\left(\alpha_{0}\right)$ e $C(t)$ é definido como:

$$
l(t)=\int_{\alpha_{0}}^{t} \sqrt{\underline{\dot{C}}(\tau) \cdot \underline{\dot{C}}(\tau)} d \tau
$$

A notação "." indica o produto interno entre dois vetores. Se $l$ for usado como parâmetro de $C$ (a partir da re-parametrização exibida na Equação 2.4, se necessária), através do que obtém-se $C=C(l)$, então: 


$$
\begin{gathered}
l=\int_{\alpha_{0}}^{l} \sqrt{\dot{C}(\tau)^{2}} d \tau \\
|\dot{C}(t)|=1
\end{gathered}
$$

Tal parametrização é denominada parametrização por tamanho de arco de $C$. Nesta tese assume-se que o parâmetro $t$ já é definido a partir da parametrização por tamanho de arco da curva correspondente, ou seja, $t=l$.

- Definição 2.1 (Orientação Tangente de uma Curva): Seja $C(t)=(x(t), y(t))$ uma curva paramétrica do parâmetro $t \in[0, L)$ e seja $\phi(t)$ a função vetor tangente da curva $C(t)$. Então a orientação tangente $\Theta(t)$ da curva $C(t)$ no ponto to é definida como o ângulo entre o vetor $\Phi\left(t_{0}\right)$ e o eixo $x$.

A curvatura da curva $C(t)$ pode ser definida a partir de $\Theta(t)$, como é mostrado na próxima definição:

- Definição 2.2 (Curvatura a partir da Orientação Tangente de uma Curva): Seja $C(t)=$ $(x(t), y(t))$ uma curva paramétrica do parâmetro $t \in[0, L)$ e seja $\Theta(t)$ a orientação tangente de $C(t)$. Então, a curvatura $k(t)$ de $C(t)$ pode ser definida como a primeira derivada de $\Theta(t)$, isto é:

$$
k(t)=\dot{\Theta}(t)
$$

Além disso, pode-se também mostrar, no caso da parametrização por tamanho de arco, que o módulo da curvatura pode ser calculado a partir da norma da segunda derivada de $C(t)$ :

$$
|k(t)|=|\ddot{C}(t)|
$$

Assim, se $k(t)=0$, então $\ddot{C}(t)=0$ e $\underline{C}(t)$ é um vetor constante, o que significa que $\underline{C}(t)$ pode ser descrito na forma $\underline{C}(t)=\underline{c}_{1}+\underline{c}_{2} t$, sendo $\underline{c_{1}}$ e $\underline{c_{2}}$ vetores constantes. Em outras palavras, $C(t)$ é um segmento de reta. 
Tendo-se em vista que a definição da curvatura a partir de $\ddot{C}(t)$ possui a desvantagem de não permitir a análise de seu sinal, o qual pode ser de grande utilidade prática, deve-se realizar uma definição alternativa da curvatura que inclua o seu sinal. Sejam $\underline{v}(t)$ e $\underline{w}(t)$ dois vetores definidos sobre cada ponto $C(t)$, sendo $\underline{v}(t)=\underline{\phi}(t)$ e $\underline{w}(t)$ normal a $\underline{v}(t)$. Além disso, exige-se que $\underline{v}(t)$ e $\underline{w}(t)$ tenham a mesma orientação da base dos eixos coordenados. Dessa maneira, os vetores $\underline{v}(t)$ e $\underline{w}(t)$ definem um campo vetorial único ao longo de $C(t)$ [Stoker, 1969]. O sinal de $k(t)$ pode ser determinado definindo-se:

$$
k(t) \underline{w}(t)=\underline{C}(t)
$$

Nesse caso, a curvatura será positiva se $\underline{C}(t)$ tiver o mesmo sentido de $\underline{w}(t)$, sendo negativa em caso contrário. A curvatura assim definida possui algumas limitações práticas como, entre outras, o modo de cálculo do sinal da curvatura e a necessidade da parametrização por tamanho de arco. A seguinte fórmula, a qual resolve esses problemas e é mais genérica, é mais comumente adotada:

$$
k(t)=\frac{\dot{x}(t) \ddot{y}(t)-\ddot{x}(t) \dot{y}(t)}{\left(\dot{x}(t)^{2}+\dot{y}(t)^{2}\right)^{3 / 2}}
$$

É importante notar que o sinal da curvatura depende da direção tomada para percorrer a curva. Assim, assumindo-se que a parametrização é definida no sentido antihorário, regiões convexas de curvatura não-nula possuem curvatura positiva, enquanto que as côncavas de curvatura não nula possuem curvatura negativa. A parametrização no sentido horário apenas inverte os sinais da análise acima. Esse tipo de informação é utilizado pelo método de segmentação de contornos utilizado na geração semiautomática de dendrogramas (Capítulo 7).

Finalmente, a curvatura de uma curva parametrizada por tamanho de arco é uma representação completa dessa curva, o que é assegurado pela existência de duas fórmulas que permitem a reconstrução da curva original. Assim, partindo-se de $k(t)$, em que $t$ é uma parametrização por tamanho de arco, tem-se que:

$$
\Theta(t)=\Theta(0)+\int_{0}^{t} k(\tau) d \tau
$$

Além disso, co...lui-se: 


$$
C(t)=C(0)+\underline{v}_{1} \int_{0}^{t} \cos \Theta(\tau) d \tau+\underline{v_{2}} \int_{0}^{t} \sin \Theta(\tau) d \tau
$$

em que $\underline{\underline{v}}_{\underline{1}}$ e $\underline{\underline{\nu}}_{2}$ são vetores unitários na direção dos eixos coordenados.

\subsection{GeOMETRIA Fractal}

$\boldsymbol{\sigma}$ ma das grandes motivações para o desenvolvimento da teoria dos fractais provem dos trabalhos de grandes matemáticos atuantes no final do século passado e começo deste século, como o matemático de expressão alemã (mas nascido em São Petersburgo em 1845) Georg Cantor e o italiano Giuseppe Peano, que trataram do problema referente ao entendimento apropriado de certos conjuntos altamente irregulares e fragmentados [Mandelbrot, 1982].

Assim, deve-se entender duas definições distintas de dimensão de um conjunto pertencente ao espaço euclideano $\mathbb{R}^{N}$ : a dimensão topológica, a qual coincide com o número de graus de liberdade que caracterizam a posição que um determinado ponto pode assumir no conjunto, tendo sido definida por Brouwer, Lebesgue, Menger e Urysohn, e denotada por $d_{T}$; e a dimensão de Hausdorff-Besicovitch, formulada em 1919 pelo matemático alemão Felix Hausdorff e desenvolvida posteriormente por Besicovitch, a qual será denotada por $d$. No caso de conjuntos do $\mathbb{R}^{N}$, as dimensões $d_{T}$ e $d$ devem ser de no mínimo 0 e no máximo $N$, sendo que a dimensão topológica deve assumir sempre valores inteiros, regra esta que não precisa ser obedecida pela dimensão de HausdorffBesicovitch. As dimensões $d_{T}$ e $d$ de um determinado conjunto não precisam necessariamente coincidir, devendo apenas obedecer à desigualdade de Szpilrajn [Mandelbrot, 1982]:

$$
d_{T} \leq d
$$

No caso especial de curvas, a dimensão $d$ é um importante conceito que pode ser aplicado a problemas de análise de formas pois, quanto mais próximo $d$ estiver de 2 , mais a curva associada cobre o plano onde está inserida. Dessa maneira, essa dimensão pode ser adotada como uma medida de complexidade de formas.

Cabe aqui lembrar o nome do matemático francês Benoit Mandelbrot (de origem polonesa, nascido em Varsóvia em 1924), o qual soube reconhecer que aquilo que se acreditava serem casos patológicos de conjuntos eram, freqüentemente, a regra e possuíam importância central na explicação de muitas estruturas encontráveis na natureza [Mandelbrot, 1982]. Assim, Mandelbrot definiu a noção de um conjunto fractal para o qual a dimensão de Hausdorff-Besicovitch é maior do que sua dimensão topológica e, tendo-se em vista que $d_{T}$ pode assumir freqüentemente um valor não inteiro, ele passou a denominar $d_{T}$ como sendo a dimensão fractal.

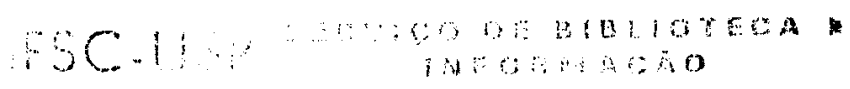




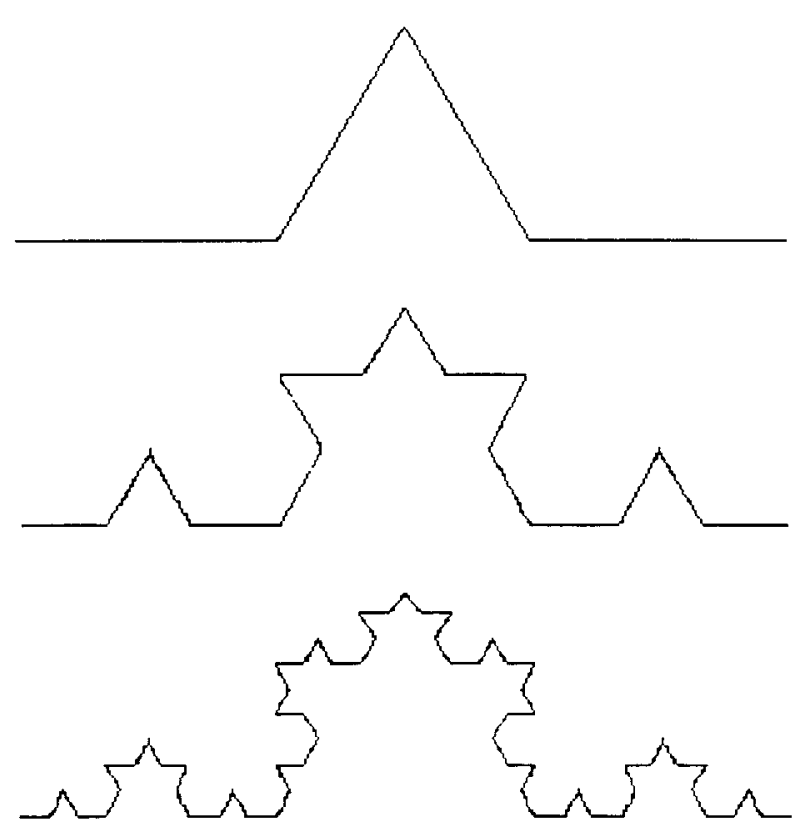

Figura (2.3): Construção da curva triádica de Koch.

Dadas as dificuldades práticas da estimação da dimensão de Hausdorff em sua formulação original, uma nova definição de dimensão fractal deve ser introduzida, o que é feito da seguinte maneira [Arnèodo et al., 1995]: seja $S$ um conjunto qualquer do $\mathbb{R}^{N}$ e $M(\varepsilon)$ o número de bolas de raio $\varepsilon^{4}$ que são necessárias para cobrir $S$. A dimensão fractal $d$ pode ser definida como:

$$
M(\varepsilon) \sim \varepsilon^{-d}
$$

Assim, a dimensão fractal explica como o número de bolas varia em função do tamanho do raio destas (isto é, da escala). Esse tipo de definição de dimensão fractal é também conhecido como dimensão de capacidade, não correspondendo exatamente à dimensão de Hausdorff. No entanto, ela possui um maior atrativo do ponto de vista prático, sendo comumente adotada na literatura [Arnèodo et al., 1995].

Um melhor entendimento do significado da Equação 2.6 pode ser obtido através de um exemplo com a curva triádica de Koch, a qual será também aproveitada no Capítulo

\footnotetext{
4 Uma bola aberta centrada em $\left(x_{0}, y_{0}\right)$ de raio $\varepsilon$ no $\mathbb{R}^{2}$ pode ser definida como o conjunto $\left\{(x, y) \in \mathbb{R}^{2} \mid\left(\left(x-x_{0}\right)^{2}+\left(y-y_{0}\right)^{2}\right)^{1 / 2}<\varepsilon\right\}$
} 


\begin{tabular}{|l|l|}
\hline$\varepsilon$ & $M(\varepsilon)$ \\
\hline $1 / 2=(1 / 2)(1)=(1 / 2)(1 / 3)^{0}$ & $1=4^{0}$ \\
$1 / 6=(1 / 2)(1 / 3)=(1 / 2)(1 / 3)^{1}$ & $4=4^{1}$ \\
$1 / 18=(1 / 2)(1 / 9)=(1 / 2)(1 / 3)^{2}$ & $16=4^{2}$ \\
$\ldots$ & $\ldots$ \\
\hline
\end{tabular}

Tabela (2.1): Tabela indicando o número de bolas $M(\varepsilon)$ necessárias para cobrir uma curva de Koch como função do raio $\varepsilon$ das bolas.

5. Como é ilustrado na Figura 2.3, um segmento da curva triádica de Koch pode ser construído a partir de um segmento de reta, dividindo-se esse segmento em três porções e substituindo-se a porção intermediária por dois segmentos de tamanho igual a cada uma das 3 porções iniciais. Essa mesma regra de construção deve ser aplicada novamente a cada um dos segmentos resultantes, sendo a verdadeira curva fractal obtida se repetido esse processo ad infinitum. A Figura 2.3 mostra 3 gerações da construção da curva triádica de Koch. Uma breve análise sobre $M(\varepsilon)$ e $\varepsilon$, assumindo-se que o segmento de reta inicial possui 1 unidade de extensão, fornece os seguintes valores da Tabela 2.1.

A Tabela 2.1 indica que, quando $\varepsilon$ diminui de um fator de $1 / 3, M(\varepsilon)$ aumenta de um fator de 4, isto é, partindo da Equação 2.6 tem-se que:

$$
4 \sim(1 / 3)^{-d}
$$

Conclui-se, portanto, que:

$$
d=\log (4) / \log (3) \cong 1.26,
$$

que é a dimensão fractal da curva de Koch.

Ainda em relação à essa curva de Koch, é importante introduzir o conceito de curva exatamente auto-similar, a qual é construída recursivamente a partir de uma mesma regra geratriz. No caso da curva de Koch, essa regra substitui a porção média de cada segmento por dois segmentos de tamanhos idênticos, como foi explicado. Dentro desse contexto, pode-se traduzir a dimensão fractal em termos da dimensão de similaridade [Mandelbrot, 1982], a qual pode ser entendida da seguinte maneira: uma curva auto-similar pode ser dividida em $M$ partes, as quais são obtidas, por rotação e/ou simetria, a partir de uma cópia da própria curva escalonada por um fator $r$. A dimensão de similaridade dessas curvas é definida como:

$$
d=\log (M) / \log (1 / r)
$$

No caso da curva de Koch, tem-se que a curva pode ser dividida em $M=4^{\prime}$ partes, as quais são cópias escalonadas (com exceção de rotação) da curva original por um fator $r=(1 / 3)^{\prime}$. Assim, tem-se que: 


$$
d=\log \left(4^{j}\right) / \log \left(3^{j}\right)=\log (4) / \log (3)
$$

como era esperado.

\subsection{Conceitos BÁsicos de PRocessamento de SinAIS}

$\boldsymbol{0}$ propósito desta seção não é realizar uma introdução geral à teoria de processamento de sinais [Brigham, 1974; Papoulis, 1962], mas apenas apresentar as principais definições e notações usadas no restante desta tese. Além disso, é importante chamar a atenção para um aspecto ligado à aplicação de algumas propriedades de Fourier, as quais vão delinear o desenvolvimento de diversas ferramentas introduzidas nesta tese. Trata-se da aplicação de propriedades da transformada contínua de Fourier, como a propriedade da derivada dada pela Equação 2.11, a dados discretos decorrentes da natureza das imagens digitais (contornos amostrados espacialmente). De fato, esse procedimento é legítimo, o que pode ser mostrado pelo seguinte raciocínio: o processo de extração de um contorno digital fornece um sinal complexo discreto e periódico, sendo que sua transformada discreta de Fourier define os coeficientes da série de Fourier de um sinal complexo contínuo e muito bem comportado, no sentido de ser de banda limitada e derivável, o que define a classe de formas que podem ser tratadas pelos métodos aqui apresentados. Essa idéia permeia a aplicação das propriedades de Fourier ao longo desta tese (bem como da transformada contínua em wavelets). É ainda importante notar que a representação fiel do contorno original pelo sinal contínuo definido pela série de Fourier depende da própria amostragem da imagem, etapa na qual os devidos cuidados referentes à taxa de amostragem devem ser tomados para que problemas como "aliasing" sejam evitados. O trabalho de Young e colaboradores apresenta detalhes mais formais sobre esses aspectos [Young et al., 1974]. A importância da utilização de ferramentas de matemática contínua em problemas com dados discretos (caso, por exemplo das transformadas contínuas de Fourier e em wavelets) advém da existência das propriedades extremamente úteis que esse lado da matemática tem a fornecer. Assim, por exemplo, enquanto conceitos como o da derivada não se aplicam a dados discretos, a utilização da estimação das transformadas contínuas a partir de dados discretos (por exemplo, contornos digitais) permite a estimação da derivada desses sinais discretos, a estimação da curvatura de contornos em imagens discretas, etc.

A transformada de Fourier [Brigham, 1974; Castleman, 1996; Papoulis, 1962] de um sinal contínuo $u(t)$ é definida por:

$$
U(f)=F\{u(t)\}=\int_{-\infty}^{\infty} u(t) \mathrm{e}^{-i 2 \pi f t} d t
$$


A variável $f$ denota a freqüência, ou seja, a variável básica do domínio de Fourier. A transformada inversa de Fourier é definida por:

$$
u(t)=F^{-1}\{U(f)\}=\int_{-\infty}^{\infty} U(f) \mathrm{e}^{\mathrm{i} 2 \pi f t} d f
$$

Uma condição suficie e para a existência da transformada de Fourier de um sinal é que ele seja integrável, ou soja:

$$
\int_{-\infty}^{\infty}|u(t)| d t<\infty
$$

Essa condição é suficiente mas não necessária, no sentido que existem condições mais fracas que incluem outros sinais que não satisfazem essa condição [Brigham, 1974].

Não existe uma única definição do par de transformadas de Fourier, e as seguintes definições também podem ser utilizadas:

$$
\begin{gathered}
U(\omega)=F\{u(t)\}=\int_{-\infty}^{\infty} u(t) \mathrm{e}^{-i t \omega} d t \\
u(t)=F^{-1}\{U(\omega)\}=\frac{1}{2 \pi} \int_{-\infty}^{\infty} U(\omega) \mathrm{e}^{\mathrm{i} t \omega} d t
\end{gathered}
$$

em que $\omega=2 \pi f$ é a freqüência angular. A transformada de Fourier possui diversas propriedades úteis, tais como linearidade e conservação de energia, além de uma propriedade que relaciona a transformada de Fourier de um sinal com as transformadas de suas derivadas, as quais serão apresentadas e aplicadas ao longo deste trabalho. Em particular, a propriedade que relaciona as derivadas de um sinal e sua transformada é dada por:

$$
\frac{d^{(n)} u}{d t^{(n)}}(t) \Leftrightarrow(i 2 \pi f)^{n} U(f)
$$


É interessante notar que essa propriedade permite a definição de derivadas fracionárias de um sinal, para $n \in \mathbb{R}$.

A convolução de um sinal $u(t) \operatorname{com} g(t)$ é definida como:

$$
v(t)=u(t) * g(t)=\int_{-\infty}^{\infty} u(\tau) g(t-\tau) d \tau
$$

Um teorema fundamental relaciona a operação de convolução entre dois sinais e suas respectivas transformadas de Fourier, teorema esse que pode ser expresso pela seguinte equação:

$$
u(t) * g(t)=F^{-1}\{U(f) G(f)\}
$$

A equação acima ilustra o fato de que a operação de convolução no domínio do tempo implica em uma operação de multiplicação das transformadas de Fourier dos sinais envolvidos na convolução. Assim, em outras palavras, a convolução entre dois sinais pode ser calculada através da transformada inversa de Fourier do produto das transformadas de Fourier dos sinais envolvidos na convolução.

A série de Fourier pode ser introduzida como um caso especial da transformada de Fourier [Brigham, 1974]. Assim, seja $u(t)$ uma função periódica de período $T_{0}$, a qual pode ser expressa pela seguinte série de Fourier:

$$
u(t)=\sum_{s=-\infty}^{\infty} \alpha_{s} e^{i 2 \pi s f_{0} t}
$$

em que $\alpha_{s}$ são os coeficientes (complexos) da série e $f_{0}=1 / T_{0}$ é a freqüência fundamental da série. Pode-se mostrar que:

$$
\alpha_{s}=\frac{1}{T_{0}} \int_{-T_{0} / 2}^{T_{0} / 2} u(t) e^{-i 2 \pi s f_{0} t} d t, s=0, \pm 1, \pm 2, \ldots
$$

Assim, pode-se pensar que a série de Fourier está associada à transformada de Fourier por meio de uma operação de discretização ou amostragem do domínio da freqüência, em função da característica periódica do sinal de entrada. Tal fato explica a aplicação da série de Fourier nas diferentes definições dos descritores de Fourier (ver 
Seção 2.6.5), visto que contornos fechados são intrinsecamente periódicos e que, como será explicado naquela seção, contornos abertos podem ser tratados de maneira análoga com a aplicação de determinados cuidados.

De maneira similar, a transformada discreta de Fourier também pode ser derivada da transformada contínua de Fourier, sendo obtida, nesse caso, através das operações de discretização do parâmetro $t$ da função $u(t)$, de sua transformada de Fourier $U(f)$ e do truncamento desses domínios por meio da multiplicação por uma janela quadrada, de modo que apenas um número finito de amostras da função, por exemplo $N$, seja tratado pelas transformadas direta e inversa. Assim, a transformada discreta de Fourier e a transformada inversa discreta de Fourier são definidas como:

$$
\begin{aligned}
& U\left(\frac{s}{N T}\right)=\sum_{n=0}^{N-1} u(n T) e^{-i 2 \pi n s / N}, s=0,1, \ldots, N-1 \\
& u(n T)=\sum_{s=0}^{N-1} U\left(\frac{s}{N T}\right) e^{i 2 \pi n s / N}, n=0,1, \ldots, N-1
\end{aligned}
$$

em que $T$ é o intervalo de amostragem de $u(t)$. É comum expressar o par de transformadas acima substituindo-se $n T$ por $n$ e $s / N T$ por $s$, para uma simplificação da notação, obtendo-se:

$$
\begin{gathered}
U(s)=\sum_{n=0}^{N-1} u(n) e^{-i 2 \pi n s / N}, s=0,1, \ldots, N-1 \\
u(n)=\frac{1}{N} \sum_{s=0}^{N-1} U(s) e^{i 2 \pi n s / N}, n=0,1, \ldots, N-1
\end{gathered}
$$

A transformada discreta de Fourier e sua inversa possuem inúmeras aplicações em processamento de imagens e visão computacional, dentre as quais os descritores de Fourier (Seção 2.6.5) formam um dos exemplos mais bem sucedidos e explorados. Nesta tese, porém, o principal papel cumprido pelas transformadas discretas de Fourier (direta e inversa) reside na estimação digital de transformadas contínuas, bem como na aplicação de propriedades da transformada contínua de Fourier. 
Finalmente, a função gaussiana e sua transformada de Fourier, a qual também é uma gaussiana, serão extensamente usadas nesta tese e, assim, define-se:

$$
g_{\sigma}(t)=\frac{1}{\sigma \sqrt{2 \pi}} \exp \left(\frac{-t^{2}}{2 \sigma^{2}}\right) \Leftrightarrow G_{\sigma}(f)=\exp \left(-2 \sigma^{2} \pi^{2} f^{2}\right)
$$

como sendo a gaussiana de desvio padrão $\sigma$ e sua respectiva transformada de Fourier.

\subsection{Analisando Formas em Visão Computacional}

1 xistem diferentes problemas e metas envolvidos na caracterização de contornos planares e inúmeras abordagens diferentes para resolvê-los. Tal pletora de métodos pode ser bem compreendida levando-se em conta que o conjunto desses algoritmos inclui desde simples técnicas de detecção de vértices até abordagens baseadas em conceitos físicos, como a definição de temperatura ${ }^{5}$, entropia e carga elétrica de curvas [Wu \& Levine, 1995; DuPain et al., 1986]. Como o levantamento e apresentação completa dessas abordagens foge ao escopo desta tese, esta seção limitarse-á à introdução das abordagens mais importantes associadas aos problemas tratados nesta tese. Mais especificamente, esta seção apresenta uma introdução aos seguintes tópicos:

1. Segmentação de Contornos;

2. Processamento Multi-Escala de Formas;

3. O Problema de Escalas Naturais;

4. Análise de Complexidade de Formas;

5. Descritores de Fourier;

6. Neuromorfometria.

Cada um desses tópicos será introduzido a seguir. Alguns trabalhos como [Pavlidis, 1980; Marshall, 1989; Fairney \& Fairney, 1994; Teh \& Chin, 1989] apresentam panoramas introdutórios mais genéricos de análise de formas em visão.

\footnotetext{
${ }^{5}$ A temperatura de uma curva $C$ é definida como $T=\log (2 L /(2 L-C L))^{-1}$, em que $L$ é o tamanho da curva e $C L$ é o tamanho do feixo convexo ("convex hull") dessa curva. Essa temperatura, bem como a entropia de uma curva. $\dot{e}$ definida por meio do formalismo de termodinâmica, conjecturando-se que tais conceitos possuem ligações com análise fractal de curvas. O trabalho de DuPain, Kamae e Michel Mendès France (filho de Pierre Mendès France, um grande político radical- socialista francês deste século, e um dos responsáveis pelo final da guerra da Indochina e pela autonomia interna da Tunísia) apresenta maiores detalhes sobre essa interessante abordagem.
} 


\subsubsection{Segmentação de Contornos}

ma tarefa particularmente importante e difícil é a da segmentação ou particionamento do contorno em partes significativas [Fischler \& Wolf, 1994; Garcia et al., 1995]. Tal particionamento do contorno em segmentos pode ser aproveitado de diferentes maneiras, como pelos métodos de reconhecimento sintático de padrões [Pavlidis, 1977] ou de reconhecimento baseado em modelos [Tsang et al., 1994].

A abordagem clássica para segmentação de contornos baseia-se na detecção de vértices, isto é, de pontos correspondentes a máximos locais do módulo da curvatura ao longo do contorno. A importância desses pontos para a percepção humana, sob o ponto de vista da psicofísica, já foi amplamente discutida na Seção 1.4 , e sua aplicação técnica pode ser traçada até o começo da década de 60 [Tsang et al., 1994].

Pode-se dividir grande parte dos métodos de detecção de vértices em contornos em duas classes: métodos globais e métodos locais [Cesar, 1993]. Os métodos globais geralmente baseiam-se na aproximação poligonal do contorno em questão, de modo a minimizar algum critério de erro como, por exemplo, a maior distância entre o contorno e as arestas do polígono. Os trabalhos desenvolvidos por Urs Ramer [Ramer, 1972], Steven Horowitz e Theodosios Pavlidis [Pavlidis, 1973; Pavlidis \& Horowitz, 1974] no início da década de 70 são representantes especialmente importantes dessa classe de algoritmos, principalmente por estarem dentre os pioneiros da área e serem aproveitados até hoje. Em particular, Ramer criou um algoritmo elegante do tipo "split", estendido pelo trabalho de Horowitz e Pavlidis, que introduziram a técnica de "split-and-merge" para segmentação de contornos. Essa técnica é também amplamente usada em segmentação de imagens, possuindo conexões importantes com a abordagem de métodos variacionais de segmentação de imagens que vêm sendo desenvolvidos recentemente [Morel \& Solimini, 1995].

Por outro lado, os métodos locais baseiam-se na procura por pontos de alta curvatura ao longo do contorno, sendo que a decisão sobre se um dado ponto possui ou não alta curvatura é tomada com base em uma vizinhança em torno desse ponto. Essa abordagem ilustra um problema que será retomado em maior profundidade no Capítulo 4. De maneira sumária, essa abordagem depende da análise da curvatura de contornos amostrados espacialmente, o que requer a estimação de derivadas de primeira e segunda ordem (veja a Equação 2.5). O procedimento para solucionar esse problema pode ser realizado através da convolução do contorno com a primeira e segunda derivada de uma função de suavização, como a gaussiana. Nesse sentido, o tamanho da vizinhança sobre a qual as derivadas são estimadas é determinada pela escala da função de suavização (no caso da gaussiana, seu desvio padrão). Essa discussão será retomada na próxima seção, a qual apresenta e discute o modelo digital de pontos de alta curvatura proposto por Johnston e Rosenfeld em 1973 e sua generalização multi-escala criada por Larry Davis em 1977.

$\mathrm{Na}$ maioria desses métodos, o contorno é comumente segmentado em partes que consistem em vértices, retas (curvatura nula), arcos de circunferência e de elipses 
[Castleman, 1996] e outras primitivas geométricas [Wuescher \& Boyer, 1991; Fischler \& Wolf, 1994]. Alternativamente, primitivas geométricas sintáticas descrevem o contorno em termos de símbolos terminais de uma gramática formal [Fu, 1982], sendo que tais técnicas são bastante usadas na abordagem sintática de reconhecimento de padrões. Uma outra importante classe de métodos de representação de contornos por partes baseia-se em curvas paramétricas da forma:

$$
P(t)=\sum_{j=1}^{n} V_{j} F B_{j}(t)
$$

em que $t$ é o parâmetro, $F B_{j}$ é a j-ésima função base e $V_{j}$ é o j-ésimo ponto de controle. Embora as curvas paramétricas sejam mais populares na área de síntese de imagens (computação gráfica), o fato é que existem aplicações interessantes em problemas de visão, como representação de impressões digitais [Chong et al., 1992], reconhecimento de formas parcialmente escondidas [Salari \& Balaji, 1991] e recuperação de curvas e segmentação de imagens usando curvas gaussianas racionais [Goshtasby, 1993].

Embora as diferentes técnicas para detecção de vértices em contornos incluam as mais variadas abordagens, como redes neurais [Sanchiz et al., 1996], distribuição de cargas elétricas [Wu \& Levine, 1995] e algoritmos não-lineares que não dependem da estimação da curvatura em dados discretos [Zhu \& Chirlian, 1995], a verdade é que esse problema de aparência tão simples para a percepção humana não possui uma solução algorítmica ótima, o que explica a pluralidade de métodos que são publicados até hoje (por exemplo, [Cornic, 1997]). Como será explicado na próxima seção, uma das dificuldades do particionamento de contornos é que essa tarefa pode depender da escala de observação, o que consiste em uma das motivações para o desenvolvimento de métodos multi-escala.

\subsubsection{Processamento Multi-Escala de Formas}

fato de que as características em uma imagem ocorram em diferentes escalas é reconhecido pelos pesquisadores em visão [Marr, 1982; Witkin, 1983; Koenderink, 1984], o que motivou o desenvolvimento de técnicas de representação multi-escala de formas [Asada \& Brady, 1986; Lowe, 1989; Mokhtarian \& Mackworth, 1986; Mokhtarian \& Mackworth, 1992; Rattarangsi \& Chin, 1992]. A importância da análise multi-escala de formas foi logo reconhecida em visão computacional, sendo a definição da curvatura-c ("c-curvature") por Larry S. Davis, em 1977, um dos primeiros trabalhos clássicos a incorporarem esse paradigma [Davis, 1977]. Davis partiu do modelo digital de pontos de alta curvatura criado por Johnston e Rosenfeld em 1973 [Johnston \& Rosenfeld, 1973]. Seja uma curva discreta $C(n)=(x(n), y(n))$. Define-se:

$$
\begin{aligned}
& \underline{v}_{j}(n)=(x(n)-x(n+j), y(n)-y(n+j)) \\
& \underline{w}_{j}(n)=(x(n)-x(n-j), y(n)-y(n-j))
\end{aligned}
$$




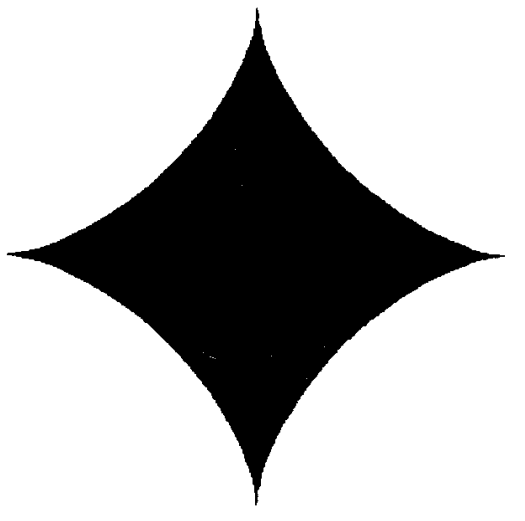

(a)

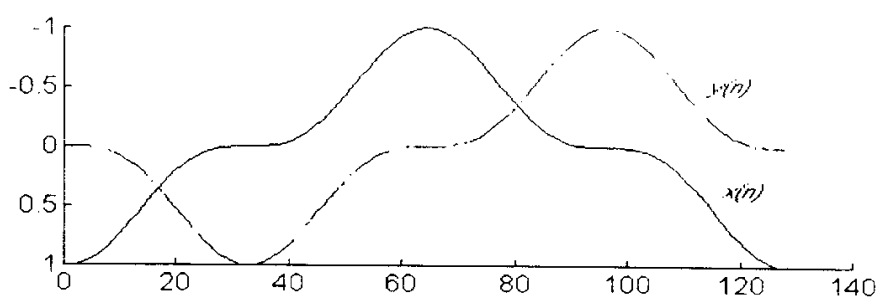

(b)

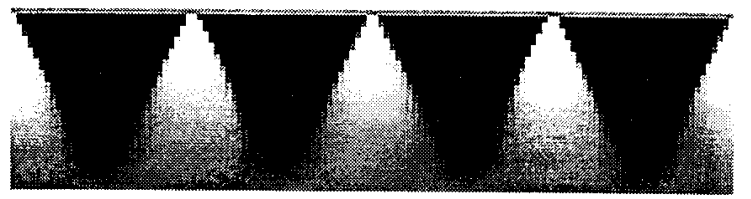

(c)

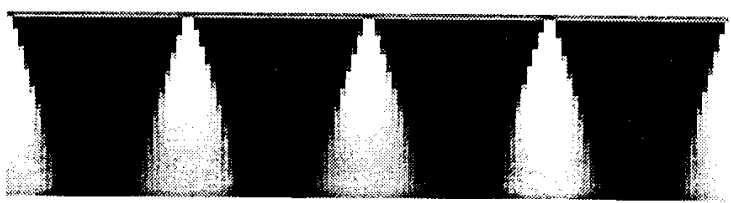

(d)

Figura (2.4): (a) Astróide, uma figura geométrica que possui quatro vértices; (b) Sinais $x$ e $y$ da astróide; (c) Curvatura-c; (d) Curvatura-c usando a variante discutida no texto. Nos diagramas (c) e (d), os níveis de cinza mais claros codificam os valores mais altos da curvatura-c.

$$
k_{j}(n)=\left(\underline{v}_{j}(n) \cdot \underline{w}_{j}(n)\right) /\left|\underline{v}_{j}(n)\right|\left|\underline{w}_{j}(n)\right|
$$

$k_{j}(n)$ é o cosseno do ângulo entre os vetores $\underline{v}_{j}(n)$ e $\underline{w}_{j}(n)$, de maneira que $-1 \leq k_{j}(n) \leq 1$, $k_{j}(n)=-1$ para linhas retas (o ângulo mais aberto) e $k_{j}(n)=1$ para o ângulo $0^{\circ}$ (o ângulo mais fechado). Os vetores $\underline{v}_{j}(n)$ e $\underline{w}_{j}(n)$ são criados entre o ponto em questão $C(n)$ e seu $j$ ésimo vizinho de um lado, $C(n-j)$, e o do outro lado, $C(n+j)$. Na medida que o valor de $j$ aumenta, uma vizinhança maior é levada em consideração no cálculo de $k_{j}(n)$, ou seja, a curvatura é estimada em uma escala maior. A utilização de maiores vizinhanças faz com que a curvatura torne-se mais tolerante à ruídos locais, normalmente presentes em curvas experimentais digitais, embora também cause perda de precisão. Davis desenvolveu um método de descrição hierárquica de formas baseado na evolução de $k_{j}(n)$ na medida que $j$ varia. A Figura 2.4(a) mostra uma astróide, cujo contorno apresenta os sinais $x$ e $y$ vistos na Figura 2.4(b). A curvatura-c de Davis é apresentada na Figura 2.4(c), em que o eixo horizontal representa o parâmetro $n$ ao longo do contorno e o eixo vertical, o qual cresce para baixo, representa o parâmetro de escala $j$. Como pode-se perceber, na medida que a escala $j$ decresce, o diagrama da curvatura-c afunila em torno dos quatro vértices da astróide. Uma variante interessante da curvatura-c pode ser obtida tomandose não somente as extremidades $C(n-j)$ e $C(n+j)$ das vizinhanças em torno de $C(n)$, mas todos os pontos dentro dessa vizinhança. Isso pode ser feito calculando-se os dois 
vetores resultantes da soma de todos os vetores definidos por $C\left(n \pm j^{\prime}\right)-C(n), j^{\prime}=1, \ldots, j$, seguido do cálculo do ângulo entre eles. Essa segunda abordagem é ainda mais tolerante a ruídos de discretização, sendo a curvatura-c para essa variante no caso da astróide apresentada na Figura 2.4(d).

Exemplos mais recentes de representação hierárquica por partes de contornos incluem as "strip-trees" [Ballard \& Brown, 1982] e os super-segmentos [Stein \& Medioni, 1992].

Um dos métodos mais populares de representação multi-escala de formas é o espaço-escala de curvatura ("curvature scale-space") [Mokhtarian \& Mackworth, 1986], que foi posteriormente desenvolvido e aplicado em diferentes trabalhos [Cesar \& Costa, 1996e; Lowe, 1989; Mokhtarian \& Mackworth, 1992; Rattarangsi \& Chin, 1992]. (veja o Capítulo 3 para maiores detalhes sobre o espaço-escala). Basicamente, esses métodos derivam uma descrição da forma através de uma análise da evolução da curva baseada na equação do calor [Mokhtarian \& Mackworth, 1992]. Seja $\Gamma_{0}$ uma curva planar. A família de curvas $\Gamma$ gerada por $\Gamma_{0}$ é obtida pela solução da equação do calor tendo $\Gamma_{0}$ como condição de contorno, isto é [Widder, 1975]:

$$
\frac{\partial \Gamma}{\partial \sigma}=\frac{\partial^{2} \Gamma}{\partial t^{2}}
$$

em que o parâmetro $t$ define a parametrização ao longo da curva e o parâmetro $\sigma$ a escala.

Diferentes representações podem ser obtidas a partir da familia de curvas $\Gamma_{0}$, em geral em função dos zeros, máximos e mínimos locais da curvatura de cada curva parametrizada. Na prática, a família $\Gamma$ é obtida através da convolução da curva inicial $\Gamma_{0}$ com um banco de filtros gaussianos indexados pelo parâmetro de escala $a$ [Mokhtarian \& Mackworth, 1992], isto é, um conjunto de funções gaussianas que variam de acordo com seu desvio padrão. Esse desvio padrão é determinado por $a$, o qual controla a largura de banda de cada filtro passa-baixas. Recentemente, outros modelos de difusão vêm sendo propostos [Kimia et al., 1995; Sapiro \& Tannenbaum, 1993].

\subsubsection{O Problema de Escalas Naturais}

1 스 pesar de diferentes estruturas específicas de formas ocorrerem em diferentes escalas, tais estruturas não aparecem em todas as escalas, evidenciando o fato de que determinadas escalas podem ser mais importantes que outras. Mais recentemente, alguns métodos que tentam definir e identificar tais escalas mais importantes, isto é, as 
escalas naturais de uma forma, vêm sendo estudados [Garcia \& Fdez-Valdivia, 1994; Garcia et al., 1995; Rosin, 1992; Rosin \& Venkatesh, 1993; Rosin, 1994]. A idéia básica que permeia tais métodos consiste em identificar, dentre as possíveis escalas de análise, aquelas que carregam mais informação útil (o que pode depender dos objetivos e propósitos envolvidos).

A importância do desenvolvimento de tais critérios deve-se ao fato de que representações multi-escala são geralmente redundantes e difíceis de serem tratadas por algoritmos de análise. Por outro lado, é importante notar que uma escala natural ou mais importante é um conceito subjetivo difícil de ser formalizado. Paul Rosin, em seus trabalhos, testou a definição de diferentes "medidas de relevância" para escalas, como a densidade de cruzamentos em zero do espaço-escala de curvatura [Rosin, 1992] e máximos locais do módulo dos descritores de Fourier da curva [Rosin \& Venkatesh, 1993].

O problema de escolha de escalas mais relevantes não é particular dos métodos de análise de formas, sendo de grande interesse em outros campos como, por exemplo, o de suavização gaussiana de imagens (ou outro tipo análogo de filtragem passa-baixas) e o de aplicação de filtros de detecção de bordas, como o filtro de Marr-Hildreth [Marr \& Hildreth, 1980]. Esses tipos de filtragem possuem um parâmetro de escala que deve ser especificado, sendo que a determinação da(s) escala(s) mais apropriada(s) pode ser vista dentro do contexto da caracterização de escalas naturais (para maiores detalhes, veja [Lindeberg, 1994; García-Silvente et al., 1996]).

\subsubsection{Análise de Complexidade de Formas}

1 ma outra característica importante para a classificação de formas, particularmente no caso de formas biológicas como células e órgãos, por exemplo, diz respeito ao conceito subjetivo de complexidade. $\mathrm{Na}$ verdade, esse conceito é difícil de ser formalizado e as pessoas podem possuir opiniões diversas sobre o que significa a complexidade de uma forma. Assim, esse conceito pode estar relacionado, para citar apenas algumas possíveis interpretações, com a ausência de previsibilidade [Smith et al., 1996] (relativa, por exemplo, a experimentos como o de Attneave [Attneave, 1954], veja a Seção 1.4), à diferença entre o objeto de interesse e uma circunferência (a forma perfeita) [Young et al., 1974] ou à dificuldade de memorização da forma [Fischler \& Wolf, 1994].

Uma das medidas de forma normalmente adotadas para a descrição de complexidade de formas é a dimensão fractal [Mandelbrot, 1982]. A análise fractal aparece em diferentes situações nas áreas de visão computacional e processamento de imagens, sendo que o conceito de objeto fractal provou ser útil em diferentes situações práticas como a de caracterização de células neurais [Caserta et al., 1990; Coelho \& Costa, 1996; Smith et al., 1996; Alves et al., 1996]. Geralmente, a análise fractal é aplicada a problemas de caracterização de formas como uma medida de complexidade e/ou cobertura espacial por arborizações. A dimensão de contagem de caixas ("box- 
counting") ou capacidade [Falconer, 1990, Feder, 1988] é geralmente calculada (em vez da dimensão de Hausdorff, que é uma medida teórica dificil de ser calculada na prática, veja a Seção 2.4) sendo que um objeto é dito ser mais complexo que outro se sua capacidade for maior. Embora o método de contagem de caixas seja geralmente aplicado para se estimar a capacidade de qualquer objeto em imagens, incluindo texturas, conjuntos e curvas, a análise fractal de curvas é um problema que possui idiossincrasias geralmente ignoradas na literatura [Tricot, 1993]. A análise fractal, dentro do âmbito da neuromorfometria, pode ainda ser estendida para que sejam incluídas medidas complementares como a análise multifractal [Smith et al., 1996].

Uma outra medida de complexidade de formas que será intensamente explorada nesta tese é a energia de dobramento ou energia elástica (Capítulo 6). Pode-se compreender facilmente o significado da energia de dobramento através de uma analogia física. Basta imaginar um arame, inicialmente dobrado em uma forma $F_{1}$, que será dobrado até atingir uma forma final $F_{2}$. A energia de dobramento entre $F_{l}$ e $F_{2}$ é a aquela que deve ser despendida no processo de modelagem do arame para que este assuma a forma $F_{2}$. Pode-se imaginar, por exemplo, o processo de dobrar um arame, inicialmente na forma de uma circunferência, até que ele atinja a forma de um quadrado. A energia de dobramento foi introduzida no contexto de análise de formas em visão computacional por Ian Young, Joseph Walker e Jack Bowie em 1974 [Young et al., 1974; Bowie \& Young, 1977], tendo se tornado uma medida de forma classicamente utilizada em muitos problemas de reconhecimento de padrões. É particularmente importante notar que o trabalho desenvolvido por Bowie e Young em 1977 [Bowie \& Young, 1977] inclui ainda testes psicofísicos e opiniões de diferentes grupos de profissionais (médicos e leigos) sobre a percepção humana de complexidade de formas.

Existem ainda outras medidas de complexidade de formas adotadas na literatura de visão, como o perímetro ao quadrado sobre a área do objeto, algumas das quais são comentadas no Capítulo 6.

\subsubsection{Descritores de Fourier (FDs)}

1 s descritores de Fourier (FDs) são uma das mais populares classes de representação de formas para aplicações em reconhecimento de padrões. $O$ fato de os descritores de Fourier serem referidos como uma classe, e não como um método, deve-se às diferentes maneiras de se definir o conjunto de descritores de Fourier. A idéia básica dessa abordagem consiste em representar o objeto de interesse por um sinal (uni- ou bidimensional), tomar a transformada de Fourier desse sinal e calcular o conjunto de descritores de Fourier a partir dessa transformada. Os descritores de Fourier foram originalmente introduzidos por R. L. Cosgriff em 1960 [Cosgriff, 1960] (portanto, há 37 anos!), tendo sido popularizados na comunidade de reconhecimento de padrões pelos trabalhos de Gösta H. Granlund [Granlund, 1972], Charles T. Zahn e Ralph Z. Roskies [Zahn \& Roskies, 1972] e, um pouco posteriormente, por Eric Persoon e King-Sun Fu [Persoon \& Fu, 1977]. Em particular, os trabalhos de Granlund e Zahn \& Roskies apresentam duas abordagens diferentes na 
obtenção do sinal inicial que descreve o objeto na imagem, sendo oportuno relembrá-las aqui.

Assim, segundo o trabalho de Zahn \& Roskies, 1972, seja $\Gamma$ a curva definida pelo contorno de um objeto, curva esta representada por suas coordenadas paramétricas $C(t)=(x(t), y(t))$, com $t$ representando uma parametrização por tamanho de arco (ver Seção 2.3) da curva, $0 \leq t \leq L$, e $L$ o perímetro dessa curva. Define-se ainda a direção angular $\theta(t)$ de $\Gamma$ e $\delta_{0}=\theta(0)$ a direção angular no ponto inicial $C(0)$. Seja ainda a função angular acumulativa $\Phi(t)$ obtida pela integral acumulada de $\theta(t)$ de 0 a $t$. A definição de um conjunto de descritores invariantes à translação, à rotação e à escala requer a definição de uma função normalizada $\Phi_{N}(t)$ :

$$
\Phi_{N}(t)=\Phi(L t / 2 \pi)+t
$$

Pode-se representar $\Phi_{N}(t)$ por uma série de Fourier (forma polar), isto é:

$$
\Phi_{N}(t)=\mu_{0}+\sum_{k=1}^{\infty} A_{k} \cos \left(k t-\alpha_{k}\right)
$$

Os coeficientes $A_{k}$ e $\alpha_{k}$, representando, respectivamente, módulo e fase harmônicos, formam o conjunto de descritores de Fourier da curva $\Gamma$.

Como foi comentado anteriormente, Granlund [Granlund, 1972] propõe uma versão alternativa de um conjunto de descritores de Fourier. Inicialmente deve-se construir um sinal complexo $u(t)$, definido na Seção 2.2. Nota-se que $u(t)$ é um sinal complexo periódico (no caso de curvas fechadas) de periodo igual ao perímetro de $\Gamma$, isto é, $u(t+j L)=u(t)$. Supondo sem perda de generalidade que $L=2 \pi$, pode-se

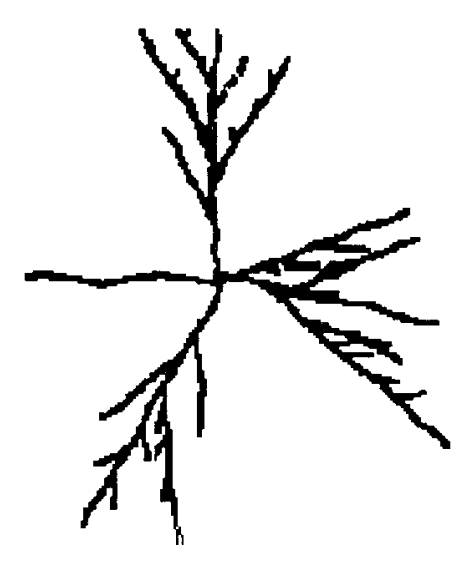

Figura (2.5): Exemplo de célula neural criada por gramáticas formais. expandir $u(t)$ em uma série complexa de Fourier definida por:

$$
F D(s)=\frac{1}{L} \int_{0}^{L} u(t) e^{-i 2 \pi s t / L} d t
$$

Assim,

$$
u(t)=\sum_{-\infty}^{\infty} F D(s) e^{i 2 \pi s t / L}
$$



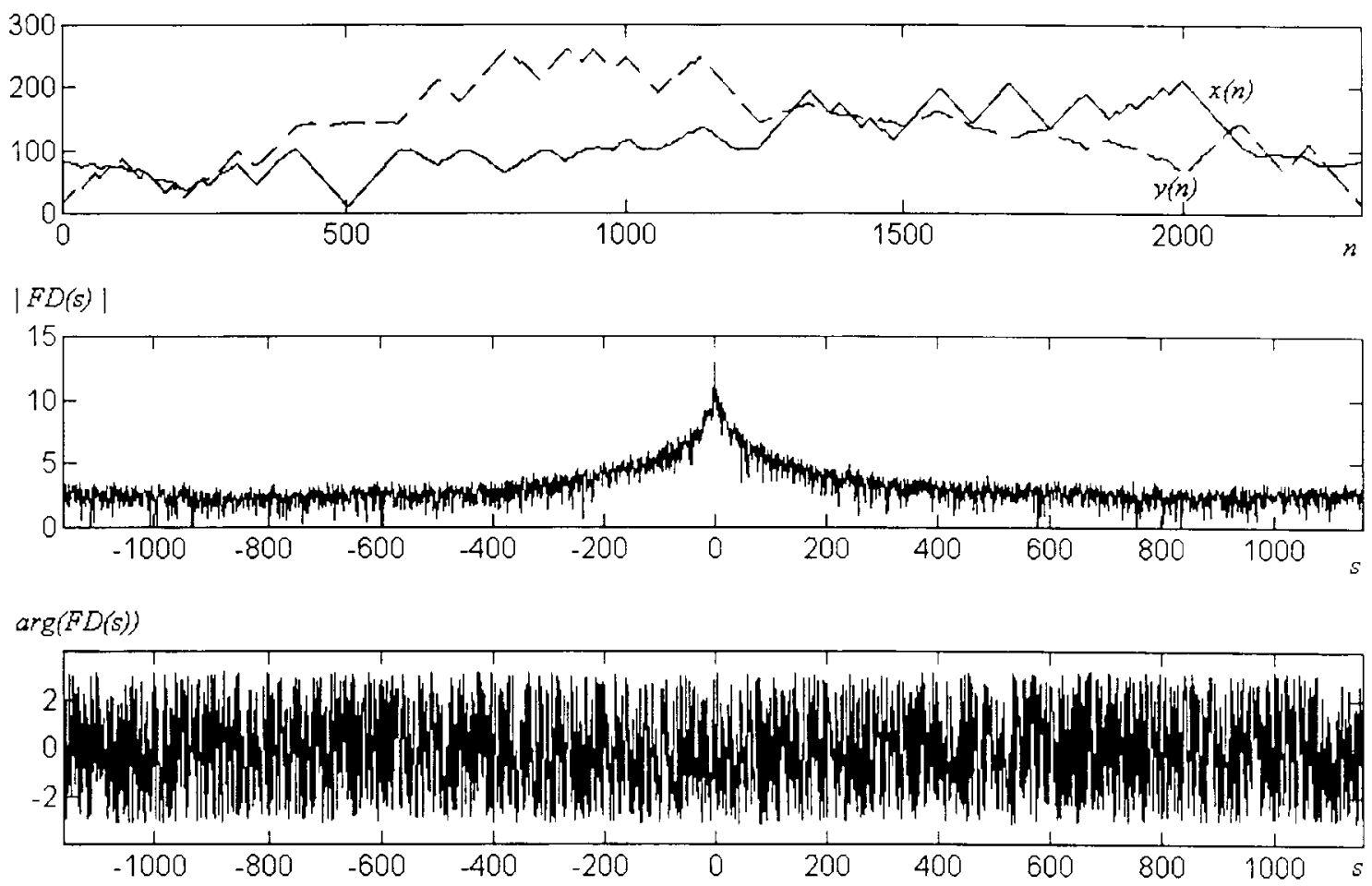

Figura (2.6): Sinais e descritores de Fourier (módulo e fase) obtidos a partir do contorno parametrizado da célula da Figura 2.5.

Existem técnicas específicas para o tratamento de curvas abertas, como gerar um contorno que "vai e volta" sobre o mesmo caminho definido pela curva, as quais permitem a aplicação dos mesmo descritores de Fourier [Mokhtarian \& Mackworth, 1986; Persoon \& Fu, 1977], embora algumas instabilidades numéricas possam ocorrer. Os coeficientes $F D(s)$ formam os descritores de Fourier definidos por Granlund. Algumas propriedades dos descritores de Fourier, as quais decorrem diretamente da teoria associada a séries e transformadas de Fourier, contribuíram para que eles tenham se tornado um dos conjuntos de características para análise de formas dos mais populares, encontrando incontáveis aplicações em suas quase 4 décadas de existência. Vale notar algumas dessas propriedades e aplicações:

1. Facilidade de implementação e eficiência de cálculo: É importante notar que a implementação da Equação 2.17 pode ser feita através de algoritmos de FFT e da transformada discreta de Fourier. Assim, pode-se definir:

$$
F D(s)=\sum_{t=0}^{N-1} u(n) \mathrm{e}^{-i 2 \pi n s / N}, s=0, \ldots, N-1
$$




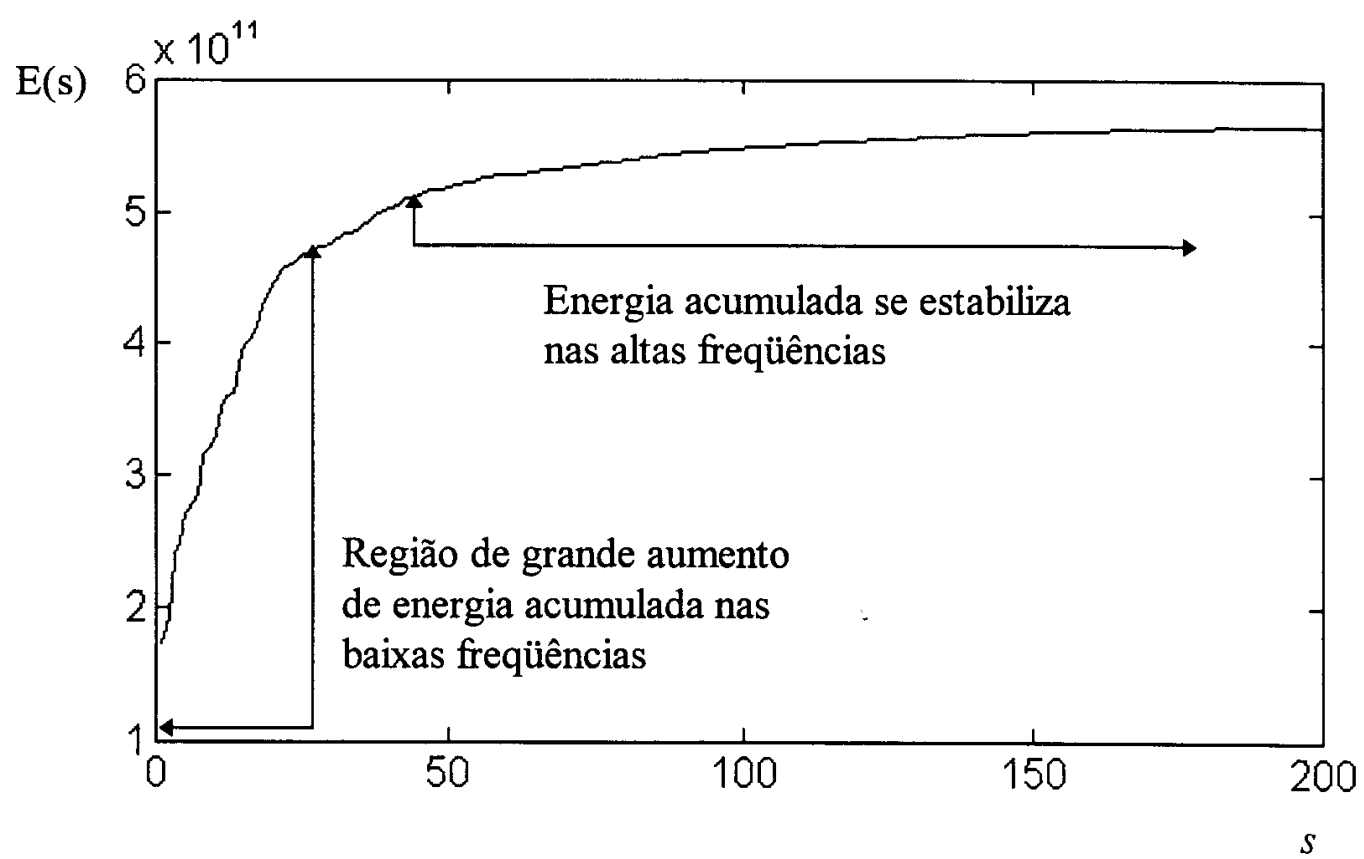

Figura (2.7): Função de energia acumulada dos FDs do neurônio da Figura 2.5.

2. Informação concentrada em alguns harmônicos de baixa freqüência: É um fato bem conhecido o de que a energia espectral dos sinais obtidos a partir de objetos típicos em análise de imagens tende a se concentrar nas baixas freqüências. Por exemplo, tome a célula neural (criada por uma técnica de geração de neurônios por gramáticas formais [Coelho \& Costa, 1994]) da Figura 2.5, a partir da qual extraiu-se a representação por sinal complexo $u(n)$, seguido do cálculo dos descritores de Fourier $F D(s)$ definidos pela Equação 2.18. Os sinais parametrizados $x(n), y(n)$, o módulo $|F D(s)|$ (log-plot) e a fase $\arg (F D(s))$ dos descritores de Fourier desse neurônio são apresentados na Figura 2.6. sendo:

Define-se então a função de energia acumulada dos descritores de Fourier como

$$
E(s)=\sum_{j=0}^{s}|F D(j)|^{2}
$$

Essa função, denotada por $E(s)$, descreve como a energia dos descritores de Fourier aumenta a medida que mais harmônicos são considerados (note que função de energia acumulada é definida apenas para freqüências positivas). A função de energia acumulada referente aos descritores de Fourier do neurônio da Figura 2.5 é mostrada na Figura 2.7. Como pode ser notado, a energia acumulada sofre um crescimento acentuado nos primeiros 30 harmônicos, tendendo a estabilizar-se gradativamente nas altas frequiências, o que indica que a maior parte da energia do sinal se concentra nas baixas freqüências. 

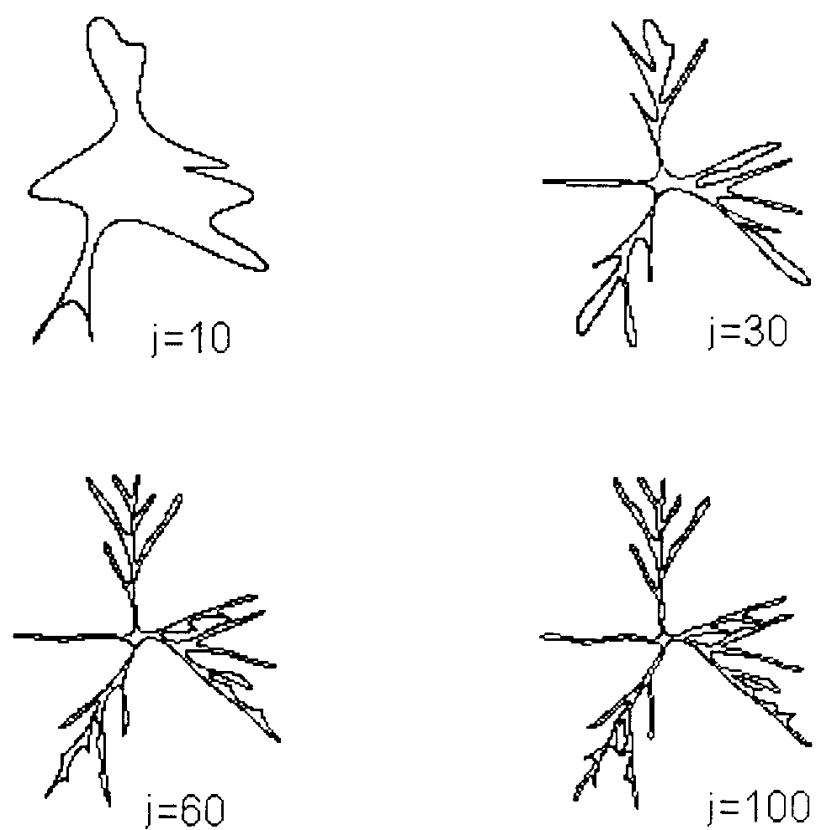

Figura (2.8): Reconstrução do neurônio da Figura 2.5 usando 2j FDs.

Para ganhar maior intuição sobre o que isso significa, um outro exemplo é apresentado na Figura 2.8. Nesse experimento, o contorno foi reconstruído a partir de 4 conjuntos de descritores de Fourier, sendo que cada conjunto era formado pelos $j$ primeiros e $j$ últimos harmônicos (isto devido à natureza da transformada discreta de Fourier da Equação 2.18 que concentra as baixas freqüências nas extremidades dos coeficientes da transformada, enquanto que as altas freqüências se localizam nos coeficientes intermediários), totalizando $2 j$ coeficientes. A Figura 2.8 apresenta a reconstrução desses quatro conjuntos que foram criados para $j=10,30,60$ e 100 . Como pode-se notar, enquanto que a reconstrução para $j=10$ apresenta apenas uma caricatura grosseira do contorno da forma original (compare com a Figura 2.5), o conjunto referente a $j=30$ já fornece uma reconstrução onde as principais características estruturais da arborização dendrítica começa a ser notada. No caso de $j=60$, detalhes de pequena escala já começam a ser notados, fornecendo ao contorno reconstruído grande parte da informação estrutural que o compõe a partir do conjunto de descritores de Fourier para $j=100$. É importante lembrar que o contorno original possui 2319 pontos, o que implica que a representação total pela transformada de Fourier pode requerer o mesmo número de coeficientes! Essa propriedade de concentrar a maior porção de informação em uns poucos coeficientes torna os descritores de Fourier especialmente úteis para serem utilizados em vetores de características de classificadores estatísticos de padrões. Inúmeras aplicações relatadas na literatura já utilizaram com sucesso os descritores de Fourier em problemas de reconhecimento de padrões, aplicações estas tão diversas como a de classificação de calcificações em mamografia [Shen et al., 1994] e a de reconhecimento de caracteres arábicos [Mahmoud, 1994]. 
3. Cálculo de outras características a partir dos descritores de Fourier: A base matemática que permeia a teoria de análise de Fourier equipa a representação de formas por descritores de Fourier com uma vasta gama de propriedades que podem ser usadas para a derivação de diferentes características da curva. Assim, Kiryati \& Maydan derivaram fórmulas que permitem o cálculo da área e de momentos de segunda ordem do contorno a partir de seus descritores de Fourier [Kiryati \& Maydan, 1989], enquanto que van der Heidjen mostra como se calcular uma aproximação do perímetro da curva, dentre outras características [van der Heijden, 1994]. Baroni \& Barletta, 1992, incluem a estimação da curvatura digital com auxílio da série de Fourier. Esta tese utiliza extensivamente o teorema da convolução a partir dos descritores de Fourier no cálculo de diferentes representações multi-escala do contorno. Uma outra propriedade de Fourier bastante utilizada neste trabalho é a propriedade da derivada, apresentada na Seção 2.5 .

Outros exemplos da aplicação de transformadas em análise de contornos incluem ainda a transformada de Hadamard [Ma et al., 1986], a qual, segundo os autores, permite a criação de medidas de forma invariantes às principais transformações geométricas em visão e a implementação em algoritmos mais eficientes que a FFT.

\subsubsection{Neuromorfometria}

^. pesar de sua importância, a relação entre forma e função de células neurais é Uum tópico freqüentemente esquecido por grande parte dos neurocientistas nas últimas décadas. $O$ fato de que os sistemas neurais biológicos incluem um grande número de diferentes tipos de células neurais (aproximadamente entre 50 e 500 tipos [Cesar \& Costa, 1997a]), bem como os recentes trabalhos experimentais investigando a relação entre forma e função de neurônios, fornece indicações da importância da morfologia dos neurônios relacionando-a com suas funções. De fato, a pesquisa em neuromorfometria, dentro do contexto da análise de ligações entre forma e função, possui a possibilidade de ser aproveitada no estabelecimento de regras relacionadas ao crescimento e à diferenciação celular.

A caracterização de formas neurais por neurocientistas tem evoluído historicamente de uma terminologia e conceituação subjetiva a medidas cada vez mais precisas e objetivas. Assim, no começo do século os neurônios eram ditos "cerrados" ou "estrelados" [Ramon y Cajal, 1911], termos intuitivos avaliados subjetivamente pelo cientista. Com o decorrer do tempo, tais termos subjetivos começaram a dar lugar a medições de tamanho e distribuição espacial dos ramos das arborizações dendríticas [Panico \& Sterling, 1995]. Um exemplo de um desses métodos é a análise de Sholl, proposta em 1983, que se baseia no estabelecimento de uma série de "anéis" centrados no corpo celular do neurônio. A chamada análise de Sholl consiste na obtenção de um histograma baseado na contagem do número de ramos e extremidades existentes em cada um dos anéis [Costa, 1997]. Essa abordagem assemelha-se à "ring projection", utilizada por pesquisadores de reconhecimento de padrões, a qual fornece um sinal 1D baseado na distribuição de massa de uma forma $2 \mathrm{D}$ ao longo de anéis concêntricos, centrados no 
centro de massa do objeto de forma a cobrí-lo completamente [Tang et al., 1996]. Posteriormente, métodos cada vez mais sofisticados, confiáveis e completos começaram a ser desenvolvidos e aplicados, como os dendrogramas e os conceitos de geometria fractal [Costa, 1997].

Assim, células ganglionares têm recebido uma atenção especial sob a perspectiva de ligação entre função e forma, não só devido à sua relativa simplicidade morfológica (tais células apresentam freqüentemente arborizações dendríticas bidimensionais), mas também devido ao fato de que seus campos receptivos e interconexões são bem conhecidos. Diferentes possibilidades de pesquisa têm sido limitadas pela falta de técnicas precisas e efetivas para a análise neuromorfológica, bem como pela demanda computacional intensa tipicamente requerida por sistemas de inspeção visual. Além disso, o problema de análise de formas biológicas é uma tarefa complexa devido ao ruído e distorções sempre presentes em imagens reais. Porém, apesar de tais desvantagens, algumas abordagens para a caracterização neuromorfométrica têm sido relatadas na literatura [Costa, 1995]. 


\section{Capítulo 3 - Transformadas Multi-Escala: Espaço-Escala, Gabor e Wavelets}

Há uma idéia -estranha, apelativa-, uma das mais estranhas conjecturas na ciência ou religião. É totaimente indemonstrável, talvez nunca seja provada. Mas é excitante. Somos informados de que existe uma hierarquia infinita de universos, de modo que uma particula elementar, como um elétron, em nosso universo, se penetrada, revelaria ser universo fechado e inteiro. Dentro dela, organizada no equivalente local de galáxias e estruturas menores, haveria um número imenso de outras, muitíssimo menores, particulas elementares, que são elas mesmas universos no nível seguinte, e assim por diante - uma regressão descendente infinita, universos dentro de universos, sem fim. $E$ ascendente também. Nosso universo familiar de galáxias e estrelas, planetas e povo, seria uma única partícula elementar no próximo universo acima, o primeiro passo de outra regressão infinita. 


\section{TRANSFORMADAS MULTI-ESCALA: EsPaÇO-EsCALA, GABOR E WAVELETS}

\subsection{INTRODUÇÃO}

1 ste capítulo apresenta uma breve introdução às transformadas multi-escala que formam a ferramenta básica para grande parte dos métodos introduzidos nesta tese. Este capítulo não pretende ser exaustivo e completamente rigoroso, sendo que grande parte dos detalhes matemáticos e algorítmicos relacionados às transformadas é apresentada juntamente com os algoritmos de análise de formas introduzidos nos capítulos subseqüentes. $O$ intuito deste capítulo é tentar transmitir um pouco do espírito do paradigma de análise multi-escala, seus diferentes propósitos associados aos diferentes problemas que ele pode tratar, como ele foi se formando dentro das áreas de visão, processamento de imagens e de sinais, e como esse espirito está implícito nas chamadas transformadas multi-escala. Dentro desse contexto, os conceitos de plano espaço-escala, tempo-freqüência e tempo-escala cumprem um papel central, como será discutido neste capítulo. De maneira genérica, pode-se pensar no processo de análise por uma transformada multi-escala da seguinte maneira: um sinal $u(t)$ contém um conjunto de informações ou eventos que "vivem" em diferentes escalas (como será explicado na próxima seção, esse conceito de diferentes escalas pode ter diferentes conotações). Esse sinal é então analisado por uma transformada $U(b, a)$, a qual possui duas variáveis, a variável $b$ - associada ao tempo, ou seja, ao parâmetro $t$ do sinal $u(t)$ - e a variável $a$ associada à informação de escala. É comum associar-se o inverso da variável de escala com a freqüência [Antoine, 1994; Rioul \& Vetterli, 1991], ou seja, $1 / a \cong f$, o que geralmente permite uma interpretação dual para essas transformadas: ora comenta-se a escala, ora comenta-se a freqüência, sendo, ambas, conceitos complementares. Assim, um sinal $1 \mathrm{D} u(t)$ é desdobrado em uma transformada 2D $U(b, a)$, com o propósito de tornar explícita a informação sobre estruturas existentes em diferentes escalas. Por outro lado, é importante perceber que há um aumento substancial de redundância de dados nesse processo: um sinal 1D é desdobrado em uma transformada $2 \mathrm{D}$ e, nesse sentido, o processo de análise complica-se. Porém, a aplicação de uma transformada multi-escala 
adequada, seguida da utilização de algoritmos de extração de informações que agem sobre $U(b, a)$, podem fornecer excelentes resultados para uma análise multi-escala de $u(t)$. Alguns princípios básicos dos algoritmos de extração de informações da transformada multi-escala também são discutidos neste capítulo.

\subsection{UMA PEQUENA INTRODUÇÃo HISTÓRICA}

S técnicas de análise de sinais e imagens através de transformadas multi-escala podem ser divididas de diferentes maneiras. Neste trabalho, optou-se por classificá-las em 3 grandes grupos: métodos de espaço-escala, transformadas tempofreqüencia e transformadas tempo-escala. Essa classificação não é rígida e segue alguns princípios pessoais do autor deste trabalho, principalmente em relação ao desenvolvimento dessas teorias dentro das áreas relacionadas à visão. Embora essas 3 classes se sobreponham em alguns momentos, essa abordagem reflete algumas das principais linhas de pesquisa em desenvolvimento atualmente.

\subsubsection{Espaço-Escala}

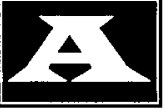

abordagem espaço-escala é uma das mais populares, tendo recebido crescente atenção desde a publicação do artigo de Andrew Witkin em 1983 [Witkin, 1983]. Uma das preocupações do autor em seu artigo original de Witkin reside no fato de que, em geral, momentos importantes em um sinal (sob o ponto de vista da informação que esse sinal carrega) estão associados a pontos extremos ou singularidades no sinal ou em uma de suas derivadas. Ora, um problema prático que se levanta é que a derivada de sinais numéricos não pode ser calculada analiticamente, mas deve ser estimada a partir de uma vizinhança do ponto o qual se deseja calcular a derivada. Tendo-se em vista que o processo de diferenciação numérica deve ser realizado com base em uma vizinhança de cada ponto do sinal, resta definir o comprimento dessa vizinhança, ou seja, a escala de análise. Basicamente, Witkin desenvolveu algumas idéias implícitas do operador de Marr-Hildreth, ou seja, o Laplaciano da gaussiana, sendo que o ponto central do artigo apresentado por Witkin consiste na definição do parâmetro de escala como uma variável contínua da convolução do sinal com o filtro gaussiano (ou uma das derivadas da gaussiana). Define-se, assim, o chamado espaçoescala pela evolução das singularidades e outras características de interesse ao longo de representações obtidas por borramentos progressivos do sinal original. Formalmente, seja $u(t)$ o sinal de entrada, e $g_{a}(t)$ uma gaussiana de desvio padrão igual a $a>0$, isto é:

$$
g_{a}(t)=\frac{1}{a \sqrt{2 \pi}} \exp \left(-t^{2} / 2 a^{2}\right)
$$

Seja, ainda, a convolução de $u(t) \operatorname{com} g_{a}(t)$, isto é: 


$$
U(t, a)=u(t) * g_{a}(t)
$$

$U\left(t, a_{0}\right)$, para $a_{0}$ fixo, é uma versão suavizada de $u(t)$, isto é, uma versão de $u(t)$ observada na escala $a$. Os extremos de $U(t, a)$ podem ser definidos pelos cruzamentos por zero de $U^{(1)}(t, a)$ definido por:

$$
U^{(1)}(t, a)=u(t) * g_{a}^{(1)}(t)
$$

em que $g_{a}^{(1)}(t)$ denota a primeira derivada de $g_{a}(t)$.

De maneira geral, os extremos de $U^{(n)}(t, a)$ podem ser definidos em função dos cruzamentos por zero do espaço-escala gerado por $g_{a}^{(n+1)}(t)$. O espaço-escala de um sinal permite o rastreamento de pontos extremos de um sinal (ou de uma de suas derivadas) através da dimensão da escala, permitindo a verificação de uma conjectura que remonta aos trabalhos de David Marr [Marr, 1982], segundo a qual pontos característicos perceptualmente importantes em sinais (ou imagens) correspondem a extremos que sobrevivem mais tempo na medida que a escala de análise é incrementada. Essa idéia é aproveitada e discutida com maior profundidade na seção que apresenta o algoritmo de detecção de pontos dominantes através da transformada contínua em wavelets (veja o Capítulo 5).

Uma questão tão importante quanto à criação de uma transformada multi-escala reside no fato de que a simples introdução do parâmetro extra escala não apresenta nenhuma vantagem a priori para a análise. Pelo contrário, a criação de um novo parâmetro introduz um grau extra de redundância da representação, implicando a necessidade do desenvolvimento de algoritmos mais sofisticados que explorem essa redundância de maneira adequada. Witkin apresenta um algoritmo para a derivação de uma árvore ou dendrograma do espaço-escala que organiza as características importantes do sinal de forma hierárquica em função do tempo de vida de cada linha de máximos do espaço-escala.

A segunda contribuição fundamental para a teoria do espaço-escala foi fornecido pelo trabalho de Jan Koenderink [Koenderink, 1984], professor de biofísica da universidade de Utrecht. A partir de uma informação dada por Andrew Witkin durante uma conferência em homenagem à Marr em 1983, Koenderink percebeu que a derivação do espaço-escala $U(t, a)$ de um sinal a partir de uma série de convoluções do sinal com gaussianas pode ser descrita pela equação de difusão (1D) [Widder, 1975]:

$$
\frac{\partial U}{\partial a}=\frac{\partial^{2} U}{\partial t^{2}}
$$


Assim, o espaço-escala, conforme definido anteriormente, pode ser redefinido como a solução da equação a derivadas parciais 3.1, tendo como condições iniciais $U(t, 0)=u(t)$. Além da introdução dessa definição dual do espaço-escala de um sinal, Koenderink também mostrou que o núcleo gaussiano é o único a obedecer à restrição de que novas estruturas não sejam criadas durante o processo de filtragem do sinal na medida que a escala aumenta. Diferentes formulações alternativas desse fato foram posteriormente provadas (veja [Lindeberg, 1994], página 14, para uma discussão mais completa dessas formulações).

Desde então, a teoria do espaço-escala não parou de se desenvolver, o que se pode facilmente perceber por meio do grande número de trabalhos e sessões especiais dedicados ao tema em conferências internacionais e revistas especializadas ${ }^{6}$. Assim, essa teoria vem sendo aplicada a áreas que compreendem desde a derivação de representações de baixo nivel da informação visual, o chamado "front-end" de um sistema de visão [Lindeberg, 1994], até o espaço-escala de curvatura, conforme comentado na Seção 2.1.

\subsubsection{Transformadas Tempo-Freqüência}

A s transformadas tempo-freqüência surgiram como uma alternativa à análise de Fourier que incorporasse a possibilidade de realização de uma análise local do sinal. De fato, as limitações da transformada de Fourier, a qual não pode tratar eventos transitórios de maneira satisfatória, , são conhecidas há bastante tempo e a definição de frequiência local remonta à tese de doutorado de Sommerfeld, apresentada em 1890 [Flandrin, 1993]. Retome a transformada de Fourier (Equação 2.7):

$$
U(f)=F\{u(t)\}=\int_{-\infty}^{\infty} u(t) \mathrm{e}^{-i 2 \pi f t} d t
$$

Pode-se observar que a transformada está baseada na integração de todo o sinal para o cálculo de cada freqüência, e que eventos que venham a ocorrer no sinal em momentos distintos e mesmo bastante remotos contribuem de maneira global para a transformada, afetando a representação como um todo. A transformada de Fourier janelada ("windowed Fourier transform") ou transformada de Fourier a curto-termo ("short-time Fourier transform") introduz uma janela de observação sobre o sinal, no intuito de desconsiderar eventos do sinal que estejam fora dessa janela. Observe a seguinte transformada obtida a partir da de Fourier:

\footnotetext{
${ }^{6}$ Realizar-se-á, no ano de 1997 , a primeira conferencia internacional inteiramente dedicada ao tema, a "First International Conference on Scale-Space Theory in Computer Vision, July 2-4 1997, Utrecht, the Netherlands."
} 


$$
U(b, f)=\int_{-\infty}^{\infty} \rho^{*}(t-b) u(t) \mathrm{e}^{-i 2 \pi f t} d t
$$

em que $\rho(t)$ é a função que cumpre o papel de janela, a qual desliza sobre a função $u(t)^{\top}$. No caso de análise tempo-frequiência, uma importante ferramenta é a transformada de Gabor, isto é, a transformada janelada de Fourier com uma janela gaussiana, desenvolvida a partir do trabalho de $\mathrm{D}$. Gabor sobre a decomposição de sinais por funções bem localizadas tanto no domínio do tempo como no da freqüência [Gabor, 1946]. É comum aplicar a restrição de que $\rho(t)$ deve ser bem localizada simultaneamente nos domínios do tempo e da freqüência. A transformada janelada de Fourier pode ser analisada a partir de pontos de vista duais. Em primeiro lugar, observa-se que, para cada valor de $b$, a janela é situada em torno de $b$ (supondo que $\rho(t)$ concentra-se em torno da origem, ou seja, em torno de $t=0$ ). Em seguida, $u(t)$ é multiplicado por essa versão transladada de $\rho(t)$, o que significa que apenas a porção de $u(t)$ que $\rho(t)$ "enxerga" sobrevive a essa multiplicação. Finalmente, toma-se a transformada de Fourier do sinal resultante dessa multiplicação, o qual contém principalmente a informação contida na porção "observada" por $\rho(t-b)$. Isso explica a propriedade de localização no tempo da transformada $U(b, f)$.

A transformada de Gabor também pode ser escrita em termos das transformadas de Fourier do sinal e da janela como:

$$
U(b, f)=e^{-i 2 \pi f b} \int_{-\infty}^{\infty} G^{*}(v-f) U(v) e^{i 2 \pi v b} d v
$$

A equação acima mostra que a transformada de Gabor pode ser vista como a transformada inversa de Fourier do produto entre as transformadas de Fourier do sinal e uma versão transladada da transformada de Fourier da janela, sendo isso tudo modulado por uma exponencial complexa. $\mathrm{O}$ fato de que a janela deve ser bem localizada também no domínio da freqüência implica que o produto $G^{*}(v-f) U(v)$ resulta em um janelamento em torno da freqüência $f$. Ou seja, a transformada de Gabor também realiza uma análise local no domínio da freqüência em termos de magnitude.

Por outro lado, em vez de imaginar a multiplicação de $\rho(t-b) u(t)$, pode-se, primeiramente, formar o núcleo $h_{f}(t)=\rho^{*}(t) e^{-i 2 \pi f t}$ para cada valor fixo de $f$. Os núcleos $h_{f}(t)$ são funções obtidas diretamente da janela $\rho(t)$ modulada por uma exponencial

\footnotetext{
${ }^{7}$ Em francés, essa transformada é também chamada Fourier à fenêtre glissante, isto é, Fourier com janela deslizante.
} 
complexa $e^{-i 2 \pi f t}$ sintonizada na freqüiencia $f$. A transformada de Gabor pode também ser definida como [Carmona et al., 1996]:

$$
U(b, f)=\int_{-\infty}^{\infty} h_{f}(t-b) u(t) d t
$$

Segundo essa linha de raciocínio, a equação acima mostra que a transformada $U(b, f)$ pode ser vista como sendo o resultado da convolução de $u(t)$ com um núcleo bem localizado em torno da freqüência $f$, ou seja, $h_{f}(-t)$, o que explica a boa localização em freqüencia da transformada $U(b, f)$. Diversos conceitos importantes, como a noção de freqüência instantânea, podem ser obtidos a partir de considerações desse tipo; porém, tendo-se em vista que a discussão de tais conceitos foge do escopo dessa tese, o leitor que desejar aprofundar seus conhecimentos nessa área pode-se remeter a textos mais específicos como os tutoriais de L. Cohen [Cohen, 1989] e de Hlawatsch \& BordreauxBartels [Hlwatsch \& Bordreaux-Bartels, 1992], ou o livro de Patrick Flandrin [Flandrin, $1993]$.

Existe ainda uma segunda classe igualmente importante para a análise tempofreqüência que envolve transformações não-lineares, como as distribuições de WignerVille, baseadas no trabalho de J. Ville de 1948 (contemporâneo ao trabalho de Gabor, portanto!). Essa abordagem parece encontrar base nos trabalhos de mecânica quântica desenvolvidos por E.P. Wigner em 1932 (ver [Hlwatsch \& Bordreaux-Bartels, 1992; Cohen, 1989; Flandrin, 1993] para maiores detalhes).

\subsubsection{Transformadas Tempo-Escala ou Wavelets}

teoria das wavelets possui uma história bastante rica, encontrando raízes em diferentes trabalhos desenvolvidos ao longo do século passado e deste, começando com o trabalho de Jean-Baptiste Fourier, de 1807. Este capítulo, no entanto, não procura ser exaustivo, apresentando apenas as idéias mais importantes para a compreensão desta tese; o leitor pode-se remeter ao livro de Yves Meyer para uma revisão mais completa dessa história [Meyer, 1992]. A apresentação desta seção segue a abordagem desenvolvida por Ingrid Daubechies [Daubechies, 1996], enfatizando apenas os aspectos relacionados à pesquisa visão.

A transformada em wavelets, da maneira como é conhecida sob esse nome, foi introduzida por J. Morlet no contexto de prospecção de petróleo e formalizada pelo próprio Morlet em conjunto com o físico teórico Alex Grossmann [Grossmann \& Morlet, 1984]. J. Morlet trabalhava com sinais que apresentavam eventos transientes, como freqüências locais, mas que possuíam uma característica muito peculiar: eventos associados a altas freqüências geralmente duravam pouco, enquanto as componentes de baixas freqüências geralmente eram mais importantes em eventos que duravam mais 
tempo durante a evolução do sinal. A aplicação da tradicional transformada janelada de Fourier possui uma característica não-desejável para a análise desse tipo de sinal, pois o tamanho da janela $\rho(t)$ permanece constante para todas as freqüências. Morlet introduziu uma transformada na qual o tamanho da janela de observação varia com a frequiência, permitindo que eventos de alta freqüência possam ser localizados com uma maior resolução temporal, ao passo que componentes de baixa freqüência possam ser analisadas com uma maior resolução no domínio da freqüência. Essa característica, formalizada pelo conceito de largura relativa de banda ou constante- $Q$, constitui uma das principais diferenças entre a transformada em wavelets e a transformada janelada de Fourier [Rioul \& Vetterli, 1991]. Apesar do potencial dessa nova idéia, e da formalização construída em conjunto com Grossmann, Morlet enfrentou uma certa resistência inicial por parte de seus colegas geofísicos - chegando a caracterizar a atitude de sua audiência com a seguinte frase: "If it were true, then it would be in math books. Since it isn't in there, it is probably worthless" [Daubechies, 1996].

Um melhor entendimento de uma das diferenças mais importantes entre as transformadas de Gabor e em wavelets e da acima mencionada constante-Q pode ser alcançado a partir da formulação do conceito de largura de banda. Assim, dada a janela $\rho(t)$ e sua transformada de Fourier $\mathrm{P}(f)$, define-se a largura de banda $\Delta f$ do filtro $\rho(t)$ como:

$$
\Delta f^{2}=\frac{\int f^{2}|\mathrm{P}(f)|^{2} d f}{\int|\mathrm{P}(f)|^{2} d f}
$$

Pode-se definir, de maneira análoga, a largura de $\rho(t)$ no domínio do tempo como:

$$
\Delta t^{2}=\frac{\int t^{2}|\rho(t)|^{2} d t}{\int|\rho(t)|^{2} d t}
$$

Enquanto que $\Delta f$ é uma medida de resolução freqüencial de $\rho(t), \Delta t$ é uma medida de resolução temporal de $\rho(t)$. Embora fosse desejável que a janela pudesse ter a melhor resolução possível nos domínios do tempo e da freqüência, isso não pode ocorrer. $\mathrm{Na}$ verdade, o produto das duas medidas de resolução possui um limite inferior, dado por:

$$
\Delta t \Delta f \geq 1 / 4 \pi
$$


Esse fato caracteriza o principio da incerteza ou principio de Heisenberg, implicando que quanto mais se ganha resolução em um domínio mais se perde no outro. E qual é então a principal diferença entre a transformada janelada de Fourier e a transformada em wavelets frente à essa discussão? A diferença é que, enquanto a transformada janelada de Fourier mantém $\Delta t$ e $\Delta f$ constantes na medida que varia a freqüência de análise, a transformada em wavelets varia esses parâmetros, fazendo com que $\Delta f$ seja proporcional a $f$, ou seja:

$$
\Delta f / f=Q
$$

em que $Q$ é uma constante. A Figura 3.1 exibe os dois tipos de bancos de filtros, ilustrando como eles diferem na medida que a escala de análise varia. O Capítulo 5 discute um pouco mais esses aspectos. 


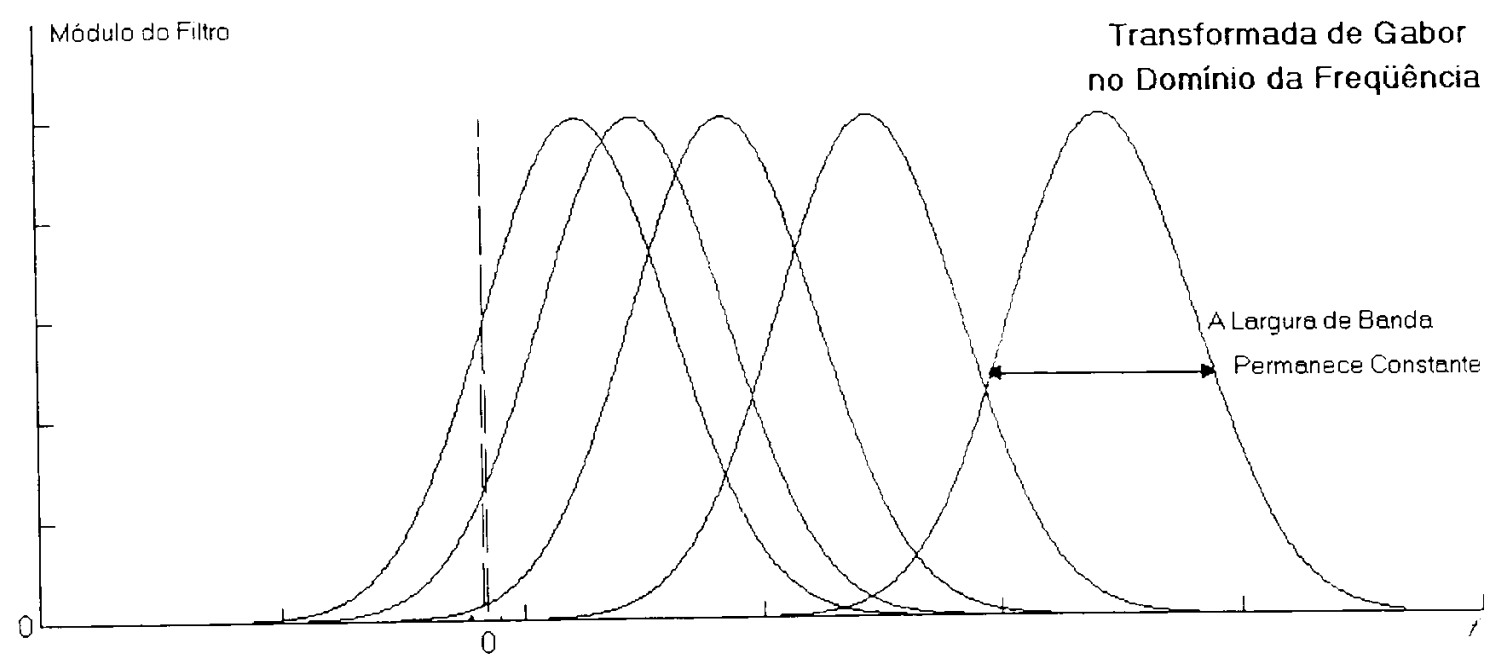

(a)

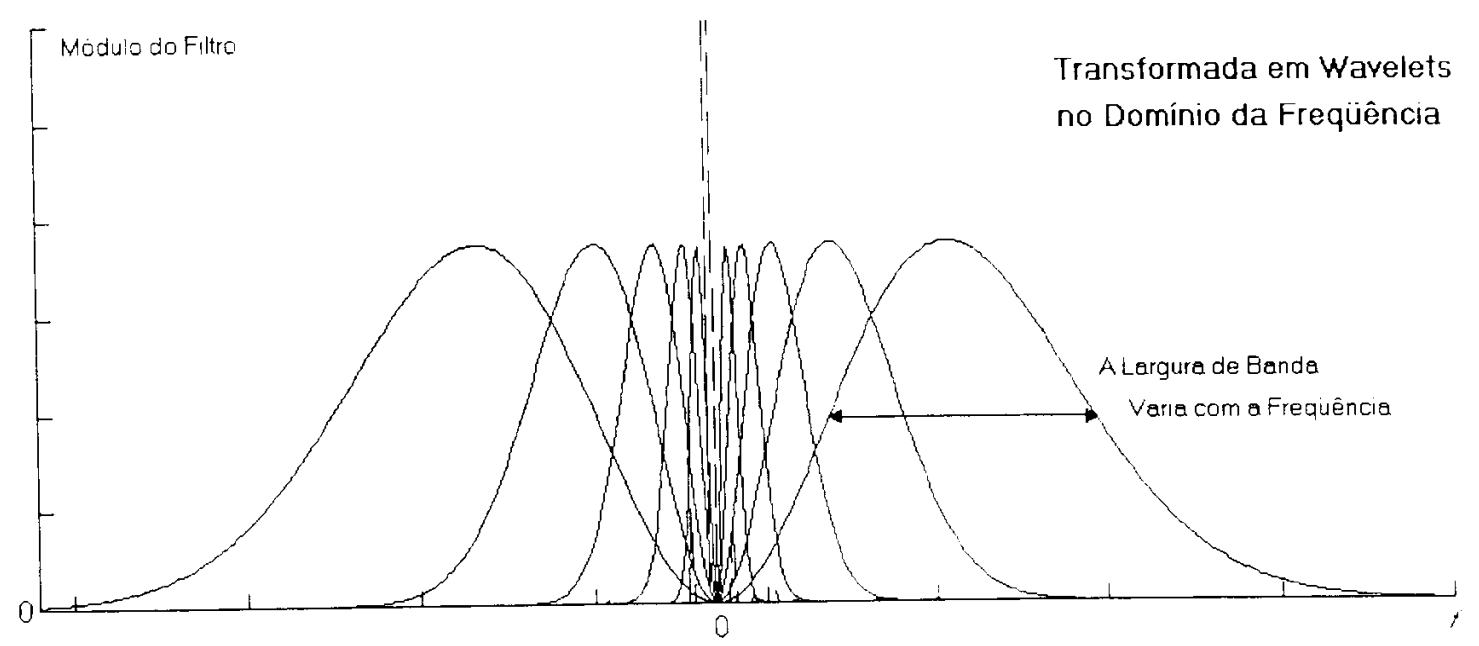

(b)

Figura (3.1): A interpretação das transformadas de Gabor e em wavelets por bancos de filtros ilustra como a transformada de Gabor mantém a largura dos filtros para analisar as diferentes frequiências enquanto que a transformada em wavelets usa filtros mais largos para analisar as frequiências mais altas.

Dentre os importantes desdobramentos que a teoria das wavelets teve desde então, é importante salientar sua conexão com a análise multiresolução, desenvolvida nos trabalhos de Yves Meyer e Stéphane Mallat [Meyer, 1992; Mallat, 1989], com a decomposição sub-banda por banco de filtros [Mallat, 1989] e as wavelets ortonormais desenvolvidas por Ingrid Daubechies (que foi aluna de doutorado de Grossmann) [Daubechies, 1992]. Esses tópicos, que estão relacionados à transformada discreta em wavelets e encerram importância fundamental para aplicações à codificação e transmissão de sinais e imagens, não serão abordados neste trabalho por fugirem a seu 
domínio. Porém, algumas de suas principais características e aplicações podem ser listadas em poucas linhas.

Em primeiro lugar, qual é a principal diferença entre a transformada contínua e a discreta em wavelets? Essa é uma pergunta dificil de se responder sinteticamente, principalmente tendo-se em vista o grande volume que essas duas teorias encerram. Mas, de maneira genérica, pode-se dizer que duas características marcantes da transformada contínua é que ela é bastante redundante e pode trabalhar com wavelets analisadoras bem comportadas e com boas características para análise de sinais. Por outro lado, a transformada discreta possui algoritmos extremamente rápidos e pode alcançar altíssimas taxas de compressão de dados, principalmente quando utilizada concomitantemente com técnicas de codificação vetorial ("vector coding"), o que explica seu sucesso para codificação e síntese de sinais ${ }^{8}$. Além disso, a transformada discreta também tem proporcionado ótimos em análise numérica, ao permitir a criação de algoritmos muito eficientes para multiplicação de matrizes, e em matemática pura, sendo usada na construção de bases de espaços funcionais, na resolução de equações a derivadas parciais, em problemas estatísticos e outros. O leitor que desejar se aprofundar sobre esses tópicos deve procurar os números especiais sobre wavelets de revistas técnicas [Special Issue, 1992; Special Issue, 1993; Special Issue, 1996; Special Issue, 1998; Special Issue, 1999] e os livros de Ingrid Daubechies [Daubechies, 1992] e Martin Vetterli e Jelena Kovacevic [Vetterli \& Kovacevic 1995].

Finalmente, é importante comentar dois conceitos desenvolvidos no seio das pesquisas em visão computacional e que tornaram-se precursores da teoria das wavelets ao influenciarem diretamente o trabalho desenvolvido por Mallat, ele mesmo um pesquisador na área de visão.

O primeiro conceito é o de pirâmide de imagens, uma estrutura de dados que representa a imagem em diferentes níveis de resolução. Esse tipo de estrutura começou a ser desenvolvido no início da década de 70, tendo contado com trabalhos pioneiros de pesquisadores como S. Tanimoto, T. Pavlidis e A. Rosenfeld. O desenvolvimento dessa estrutura culminou nos trabalhos de J. Crowley e P.J. Burt \& E.H. Adelson [Burt \& Adelson, 1983; Lindeberg, 1994]. A construção de uma pirâmide de imagens baseia-se na filtragem da imagem (por exemplo, filtragem gaussiana) seguida de uma operação de sub-amostragem, o que gera uma imagem de menor resolução (maior escala). A aplicação sucessiva dessa operação permite a criação da pirâmide.

O segundo conceito advém da transformada introduzida por D. Marr e E. Hildreth [Marr \& Hildreth, 1980] no contexto de detecção de bordas. Esses pesquisadores estavam interessados na detecção de mudanças bruscas (ou seja, singularidades) dos níveis de cinza de uma imagem. Como esses pontos singulares podem ocorrer em diferentes escalas, a transformada de Marr-Hildreth é capaz de detectar, separadamente,

\footnotetext{
${ }^{8}$ Uma tendência promissora que vem sendo buscada recentemente por pesquisadores em wavelets discretas é o da definição de transformadas que mapeiam números inteiros em números inteiros, as quais seriam de importância central para problemas de codificação e transmissão de dados, ver [Calderbank et al, 1997] para maiores detalhes.
} 
as diferentes singularidades em diferentes escalas. Eles então propuseram a detecção dos cruzamentos por zero da imagem resultante da convolução da imagem com o Laplaciano da gaussiana, em que pode-se controlar a escala de observação por meio da variância da gaussiana. É interessante notar que a segunda derivada da gaussiana, a qual satisfaz as condições para ser uma wavelet genuína, acabou por se tornar uma das wavelets mais populares [Arnèodo et al., 1995; Grossmann, 1988]

A transformada contínua em wavelets $2 \mathrm{D}$, a qual possui importantes aplicações em processamento e análise de imagens e em física, foi posteriormente desenvolvida por Romain Murenzi durante o desenvolvimento de sua tese de doutorado em Louvain-laNeuve, Bélgica, sob a orientação do físico teórico Jean-Pierre Antoine [Murenzi, 1990].

\subsection{UMA VISÃo UNIFICADA DAS TRANSFORMADAS MULTI-ESCALA}

7 sta seção aborda as três classes de transformadas multi-escala discutidas neste capítulo sob o ponto de vista de produtos internos, o que permite uma abordagem unificada das três classes. Assim, todas as transformadas multi-escala discutidas neste trabalho podem ser definidas como um produto interno entre o sinal sob análise e um determinado núcleo, sendo que cada classe de transformadas é definida por um respectivo tipo de núcleo. De maneira geral, um sinal $u(t)$ é analisado através de uma transformada $U(b, a)$ obtida a partir de $u(t)$ pelo produto interno desse sinal com um conjunto de núcleos $\psi_{b, a}^{*}(t)$ [Antoine, 1994; Kaiser, 1994], isto é:

$$
U(b, a)=<u(t), \psi_{b, a}^{*}(t)>
$$

em que adota-se o produto interno:

$$
<u(t), \psi(t)>=\int_{-\infty}^{\infty} u(t) \psi(t) d t
$$

Dessa forma, as diferentes abordagens para uma análise multi-escala do sinal $u(t)$ podem ser definidas dependendo do núcleo $\psi_{b, a}^{*}(t)$ escolhido. Assim, no caso do espaço-escala, tem-se que o núcleo $\psi_{b, a}^{*}(t)$ é dado pela gaussiana:

$$
\psi_{b, a}^{*}(t)=g_{a}(b-t)=\frac{1}{a \sqrt{2 \pi}} \exp \left(-(b-t)^{2} / 2 a^{2}\right)
$$


Assim, substituindo-se 3.3 em 3.2, tem-se que, para o espaço-escala:

$$
U(b, a)=\frac{1}{a \sqrt{2 \pi}} \int_{-\infty}^{\infty} u(t) \exp \left(-(b-t)^{2} / 2 a^{2}\right) d t=\int_{-\infty}^{\infty} u(t) g_{a}(b-t) d t
$$

Ou seja, $U(b, a)$ é definido por um conjunto de convoluções do sinal com gaussianas indexadas pelo desvio padrão $a$, a variável de escala. É importante salientar que o espaço-escala gaussiano, no sentido definido por Witkin, também compreende a utilização de derivadas da gaussiana, bastando incluir uma de suas derivadas no lugar da gaussiana na definição 3.3 .

O núcleo para a transformada de Gabor, isto é, a transformada janelada de Fourier com uma janela gaussiana, é definido como:

$$
\psi_{b, a}^{*}(t)=\frac{1}{\sigma \sqrt{2 \pi}} \exp \left(-(t-b)^{2} / 2 \sigma^{2}\right) \exp (-i 2 \pi t / a)=g_{\sigma}(t-b) \exp (-i 2 \pi t / a)
$$

O núcleo da transformada de Gabor é, portanto, formado por uma versão transladada de uma gaussiana de desvio padrão $\sigma$ modulada por uma exponencial complexa de freqüência $f=1 / a$. A transformada pode, então, ser escrita como:

$$
U(b, a)=\int_{-\infty}^{\infty} u(t) g_{\sigma}(b-t) \exp (-i 2 \pi t / a) d t
$$

que é a transformada janelada de Fourier com uma janela gaussiana, como foi discutido na seção anterior.

Finalmente, no caso das transformações tempo-escala, tem-se a transformada continua em wavelets, com:

$$
\psi_{b, a}^{*}=\frac{1}{\sqrt{a}} \psi\left(\frac{t-b}{a}\right)
$$

isto é, o conjunto de núcleos é obtido por translação e dilatação de uma mesma wavelet analisadora $\psi(t)$, que deve obedecer à condição de admissibilidade simplificada (isto é, ser de média nula) e ser bem localizada nos domínios do tempo e de Fourier [Antoine, 1994]. A transformada pode, então, ser escrita como: 


$$
U(b, a)=\frac{1}{\sqrt{a}} \int_{-\infty}^{\infty} u(t) \psi\left(\frac{\mathrm{t}-\mathrm{b}}{\mathrm{a}}\right) d t
$$

\subsection{ESTUDO DE CASO: INTERPRETANDO AS TRANSFORMADAS}

1 sta seção elucida como a transformada multi-escala $U(b, a)$ de um sinal (ou de um contorno, como será visto a partir do próximo capítulo) pode ser imaginada, visualizada e analisada. De fato, os próprios Morlet e Grossmann, juntamente com R. Kronland-Martinet, escreveram um artigo ([Grossmann et al., 1989]) tratando somente da interpretação de uma transformada desse tipo!

Primeiramente, deve-se observar que a transformada $U(b, a)$ pode ser vista como uma função do $\mathbb{R}^{2}$ a valores reais ou a valores complexos, dependendo da transformada e do sinal, isto é, pode-se ter:

$$
U(b, a): \mathbb{R}^{2} \rightarrow \mathbb{R}^{\prime}
$$

ou

$$
U(b, a): \mathbb{R}^{2} \rightarrow \mathbb{C}
$$

No caso em que $U(b, a)$ assume apenas valores reais, essa transformada pode ser vista como uma superfície ou, ainda, como uma imagem, o que é mais comum. No caso de $U(b, a)$ assumir valores complexos, então esses valores devem ser observados ou em módulo e fase (mais comum), ou em parte real e parte imaginária.

Será apresentado agora um exemplo comparativo entre as três abordagens e o tipo de análise que pode ser feita a partir de cada transformada. A Figura 3.2(a) apresenta a transformada espaço-escala de um sinal que contém 3 partes distintas: uma porção inicial e outra final consistindo em uma onda cossenoidal de uma dada freqüência constante e uma porção intermediária que consiste em um chirp linear, isto é, em uma onda do tipo $\cos ((m t+n) t)$, na qual a freqüência aumenta linearmente com o tempo [Torrésani, 1995]. Além disso, a esse sinal foi somado um delta $\delta(t-1024)$, o qual representa uma singularidade no meio do sinal.

A Figura 3.2(b) apresenta, na forma de uma imagem em níveis de cinza, a transformada espaço-escala $U(b, a)$ do sinal de exemplo. Nessa imagem, o eixo horizontal está associado à coordenada $b$ (tempo), ao passo que o eixo vertical está associado à coordenada $a$ (escala). $O$ eixo vertical cresce para baixo e os níveis de cinza codificam os valores de $U(b, a)$ em cada ponto $(b, a)$ sobre o plano, o qual será chamado plano espaço-escala. No caso desse exemplo, os maiores valores de $U(b, a)$ são codificados por meio de cores mais escuras. Outros exemplos desta tese adotarão uma codificação invertida, em que as cores mais claras codificam valores mais elevados, e 

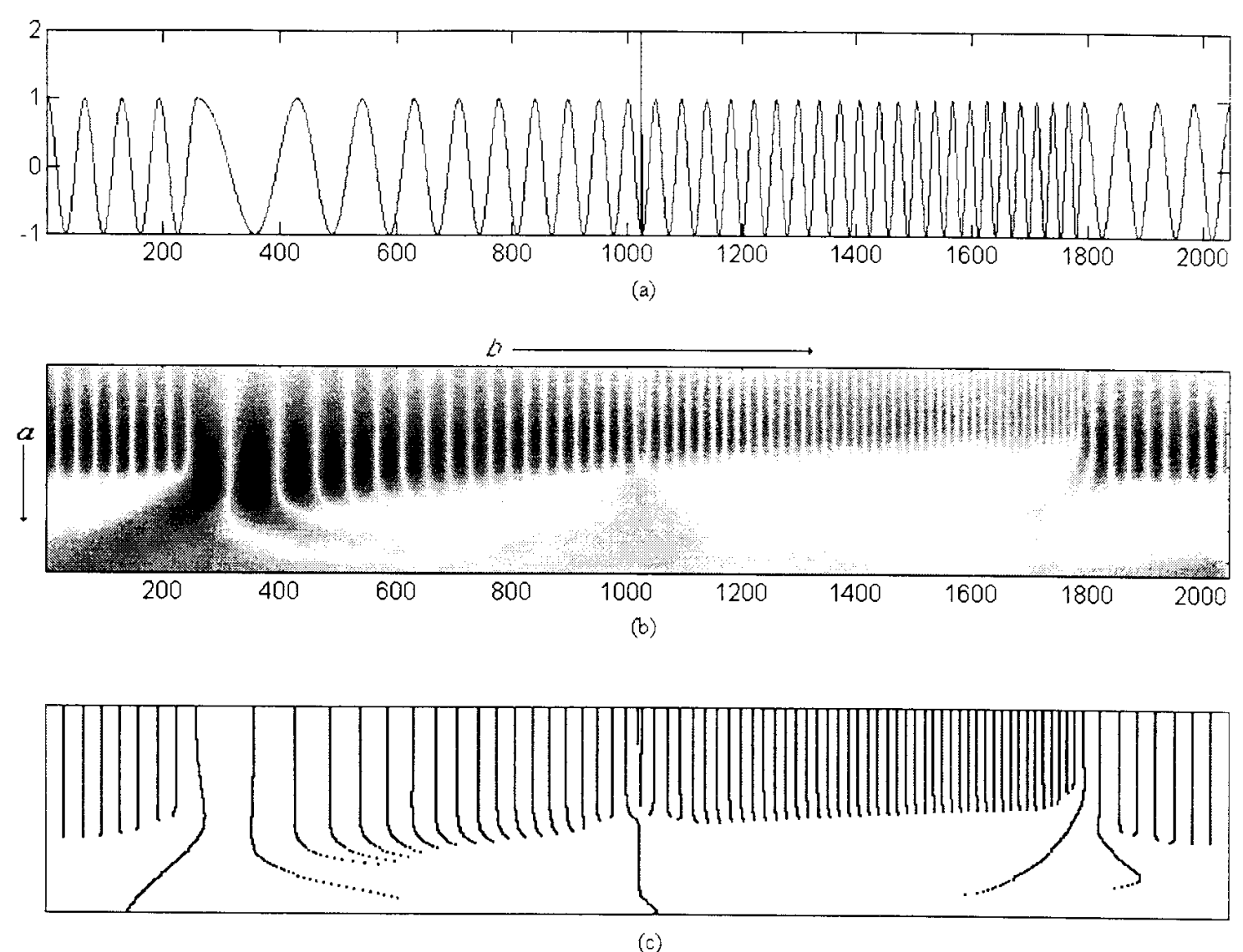

Figura (3.2): Transformada espaço-escala do sinal exibido em (a).

essa convenção será indicada quando de sua ocorrência. Como pode-se perceber, os detalhes de pequena escala, presentes na medida que a freqüência do sinal aumenta, são filtrados e desaparecem na medida que a escala aumenta, pois o sinal vai sendo suavizado por convoluções com gaussianas de desvio padrão cada vez maior. Além disso, a transformada é capaz de detectar 3 singularidades, as quais persistem até as maiores escalas. Trata-se do delta no meio do sinal e dos dois pontos de transição entre as três porções do sinal. Finalmente, a Figura 3.2(c) exibe as linhas de máximos locais de $U(b, a)$ (ou seja, os cruzamentos por zero de Marr). O Capítulo 5 apresenta definições formais dessas linhas de máximos.

Para entender melhor a construção do espaço-escala desse sinal, veja a Figura 3.3, a qual apresenta, na primeira linha, o sinal do exemplo, e nas linhas restantes, versões suavizadas em ordem crescente de escala. Cada uma dessas versões suavizadas consiste em uma linha horizontal de $U(b, a)$, ou seja, são sinais $U\left(b, a_{0}\right)$ para uma série de 5 valores diferentes de $a_{0}$, valores esses que aumentam para baixo na Figura 3.3. Como se pode perceber, na medida que a escala aumenta, os detalhes de alta freqüência vão perdendo sua força no sinal, e apenas as componentes de baixa freqüência permanecem. 

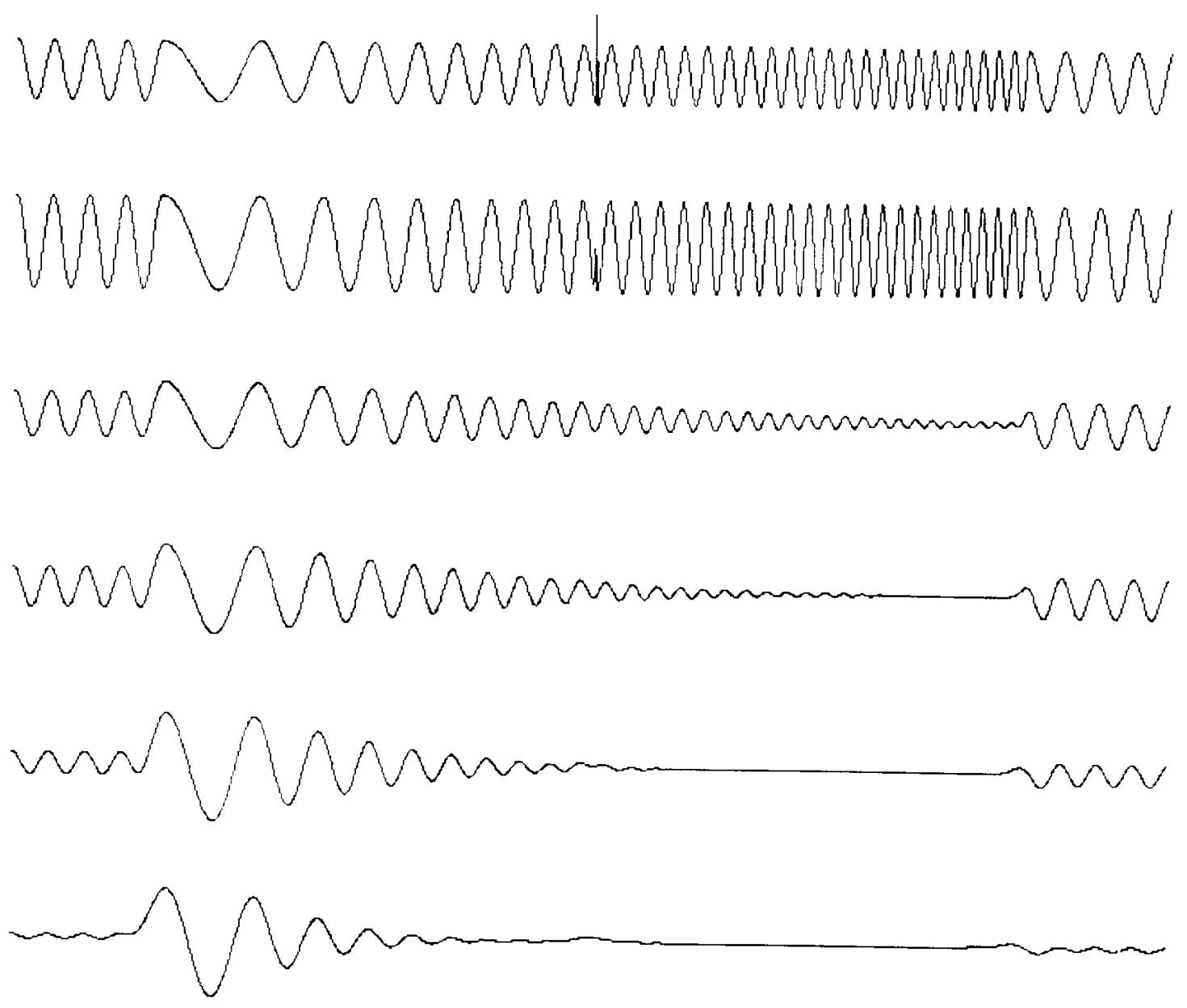

Figura (3.3): Sinal do exemplo e série de versões suavizadas, as quais compõem o espaço-escala.

A Figura 3.4 apresenta os resultados análogos para a transformada de Gabor. Pois que a transformada de Gabor assume valores complexos, a Figura 3.4(b) apresenta o módulo da transformada $|U(b, a)|$. Como pode ser percebido, a transformada de Gabor possui a característica de responder com maior força apenas quando está corretamente sintonizada à frequiência local do sinal, além de também poder perceber as singularidades. Assim, ela responde mais fortemente em duas regiões horizontais nos vértices esquerdo e direito do plano tempo-freqüencia, correspondentes à freqüência das porções cossenoidais no início e no fim do sinal, e também na tira inclinada, que corresponde à freqüência crescente do chirp. As convenções de representação do plano tempo-freqüência são as mesmas que para o plano do espaço-escala, ou seja, o eixo horizontal é associado ao tempo e o eixo vertical é associado à escala, a qual aumenta para baixo. É importante perceber que, devido à relação $a=1 / f$, isto é, a escala sendo vista como o inverso da freqüência, no plano tempo-freqüência a freqüência aumenta para cima. 

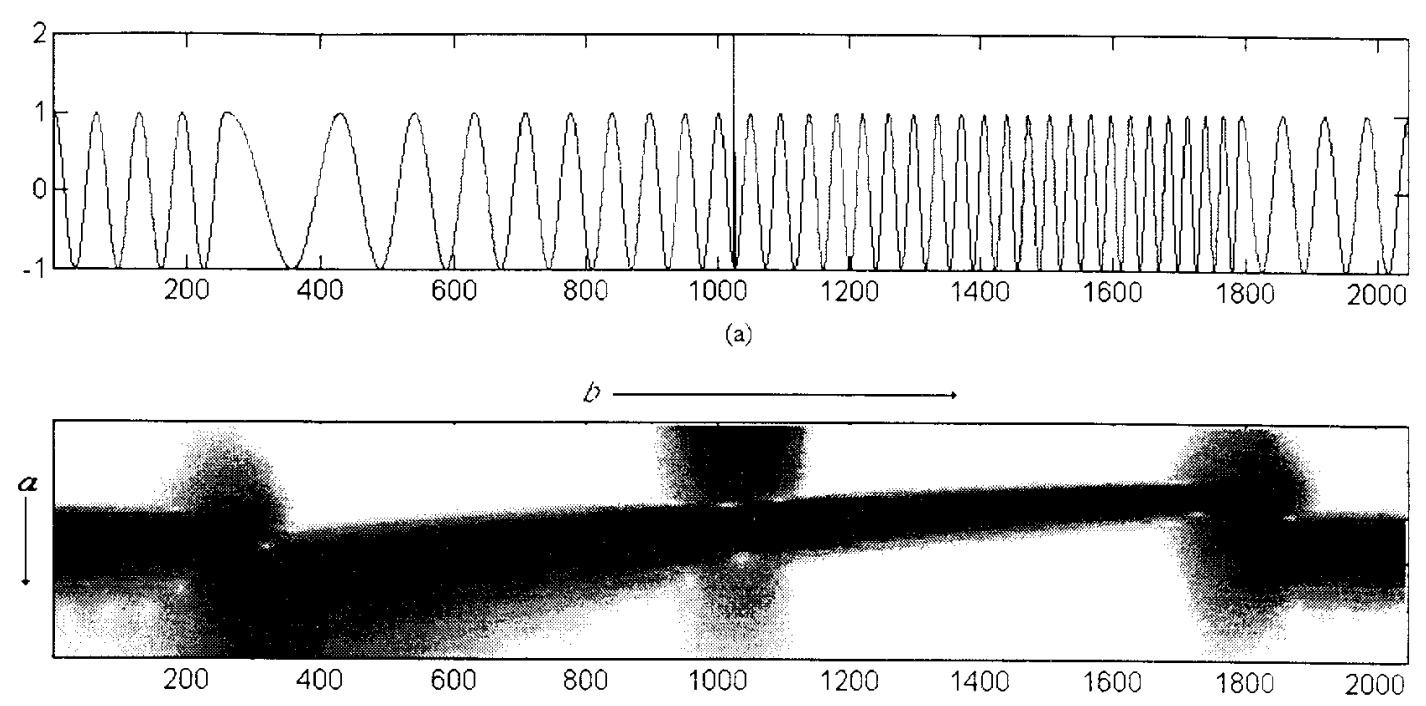

(b)

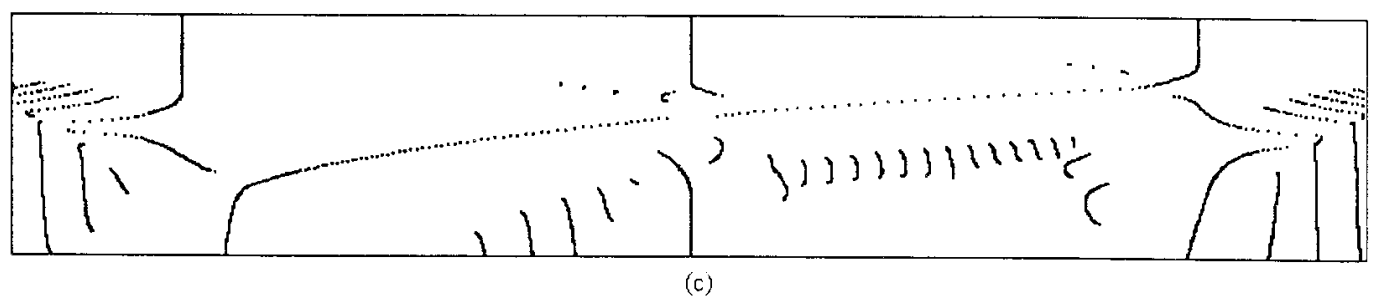

Figura (3.4): Transformada de Gabor do sinal (a).

Finalmente, a Figura 3.5 apresenta a transformada em wavelets do sinal do exemplo, usando uma wavelet de Morlet (veja o Capítulo 5). A análise também é feita em termos do módulo da transformada, assumindo-se as mesmas convenções de representação gráfica. Embora um resultado semelhante ao da transformada de Gabor possa ser percebido, a propriedade de largura de banda relativa das wavelets causa um efeito que pode ser visto nesse exemplo. A wavelet realiza uma espécie de "zoom" em torno das singularidades, com sua resposta mais forte afunilando em torno delas na medida que se caminha para as pequenas escalas. Essa propriedade é utilizada no algoritmo de detecção de vértices desenvolvido no Capítulo 5. 

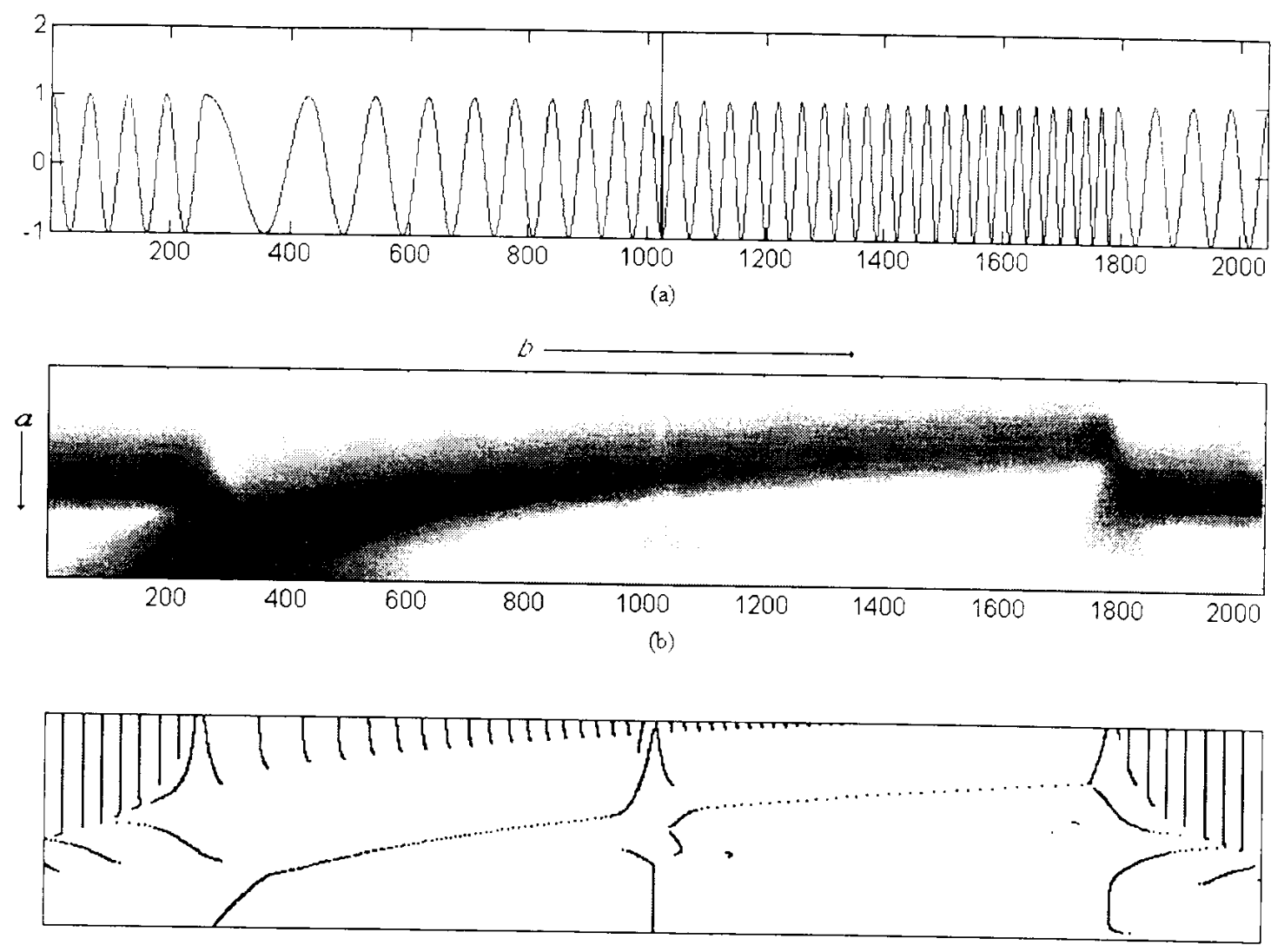

(c)

Figura (3.5): Transformada em wavelets do sinal (a) (usando Morlet).

\subsection{ANÁlise dAS TRANSFORMADAS MULTI-ESCALA}

1 ma vez que o sinal tenha sido representado por uma transformada multiescala, diferentes métodos podem ser usados na extração de informação sobre a forma a partir dessa representação. Abaixo são apresentadas brevemente algumas das principais técnicas para a análise automática dos planos espaço-escala, tempo-escala e tempo-freqüência, nas quais os algoritmos de análise de contornos são baseados:

- Máximos, Mínimos e Zeros Locais: Desde os trabalhos de David Marr [Marr \& Hildreth, 1980; Marr, 1982], essa é uma das abordagens mais exploradas para a análise de transformadas multi-escala. A idéia básica dessa abordagem fundamentase no fato de que alguns pontos dos sinais são mais importantes que outros (como vértices em contornos ou bordas em imagens), sendo que uma transformada multiescala apropriada responde localmente de maneira máxima a esses pontos dominantes. Exemplos desse tipo de comportamento são o detector de bordas de Marr-Hildreth [Marr \& Hildreth, 1980] e o comportamento das transformadas multiescala apresentadas na Seção 3.4 deste capítulo. Dependendo do problema, a busca pode ser por máximos, mínimos (por exemplo, Richards e colaboradores procuram 
por mínimos de curvatura em regiões côncavas, argumentando que, de acordo com a percepção humana de formas, tais pontos definem uma divisão natural da forma em partes [Richards et al., 1986]) ou cruzamentos por zero (o espaço-escala de curvatura desenvolvido por Mokhtarian e Macworth baseia-se na busca por pontos de inflexão no contorno, caracterizados por zeros na curvatura [Mokhtarian \& Mackworth, 1986; Mokhtarian \& Mackworth, 1992]);

- Sintonização ou Seleção Apropriada de uma Escala de Observação: Pode-se analisar a resposta da transformada para uma escala pré-fixada $a_{0}$, o que equivaleria a analisar a resposta de um filtro linear (definido pelo núcleo da transformada multi-escala) ao sinal de entrada. Tal abordagem é adotada, por exemplo, em problemas de segmentação de texturas em imagens [Bovik et al., 1990; Dunn et al., 1994; Dunn \& Higgins, 1995; Reed \& Wechsler, 1990], compartilhando as mesmas vantagens e problemas desses métodos. $\mathrm{O}$ maior problema dessa abordagem reside na dificuldade de se sintonizar corretamente os parâmetros, ou seja, de como escolher corretamente a escala de análise. Como será mostrado no Capítulo 6 , o experimento de classificação de células ganglionares mostrou que a energia de dobramento multi-escala podia fornecer o melhor e um dos piores resultados como medida de classificação dependendo da escala escolhida, o que ilustra a importância da realização de uma escolha correta da escala. Uma abordagem inicialmente simples seria identificar as escalas com resposta mais forte em valores absolutos [Reed \& Wechsler, 1990]. Tal abordagem pode ser empregada de maneira direta na caracterização de escalas naturais, de maneira análoga à abordagem apresentada na Seção 5.7, consistindo de uma generalização do método global baseado em FD's de Rosin e Venkatesh [Rosin \& Venkatesh, 1993]. Um outro problema que deve ser resolvido nesta abordagem é que a magnitude da resposta a cada filtro pode variar bastante, principalmente tendo-se em vista que a energia dos FD's de formas normais concentra-se, geralmente, nas baixas freqüências (ver Seção 2.6.5). Se as respostas de filtros de diferentes freqüências devem ser comparadas, deve-se normalizar as saídas dos filtros para que todas tenham a mesma energia de saída. Tal normalização é particularmente importante na análise por projeção explicada a seguir;

- Projeções sobre os Eixos do Tempo e da Escala: Uma maneira simples e direta de análise de uma transformada multi-escala consiste na projeção de seus valores sobre os eixos do tempo e da escala. No caso da projeção sobre o eixo da escala, o resultado possui ligação direta com a transformada de Fourier, se não houver a aplicação do processo de normalização explicado no item anterior,uma vez que a capacidade da transformada de localizar os eventos no domínio do tempo é perdida na projeção. Os máximos locais da projeção resultante podem ser usados na detecção de escalas naturais globais do contorno, em uma abordagem análoga ao trabalho de Rosin \& Venkatesh, 1993. Por outro lado, a projeção sobre o eixo do tempo pode revelar quais instantes carregam maior energia do sinal através das diferentes escalas. Tais pontos definem os pontos dominantes do contorno. Uma terceira abordagem para a análise do contorno por projeções consiste na realização de projeções ponderadas, por exemplo, ponderando-se as escalas da projeção no eixo do tempo 
pela energia total daquela escala. A análise de contornos pelos métodos de energia introduzidos no Capítulo 6 baseia-se nesta abordagem.

Para finalizar esta seção, vale notar que as três abordagens não são excludentes, no sentido que algoritmos envolvendo combinações desses métodos podem ser desenvolvidos. Assim, pode-se, por exemplo, identificar as linhas de máximos verticais da transformada multi-escala, normalizar a resposta de cada escala e projetá-las sobre o eixo do tempo para cálculo de pontos dominantes. Os próximos capítulos apresentam métodos de análise de formas baseados nessas idéias. 


\section{Capítulo 4 - Caracterização de Contornos através do Curvograma}

Concurrently with some of the early developments of quantum theory, Albert Einstein deeply re-examined the very basis of Newtonian gravity and finally, in 1915, came up with a revolutionary new theory which provided a totally different picture: his general theory of relativity. Now, gravity was no longer to be a force at all, but it was represented as a kind of curvature of the very space (actually spacetime) in which all the other particles and forces were to be housed. 


\section{Caracterização de Contornos através do CURVOGRAMA}

\subsection{INTRODUÇÃO}

1 ste capítulo introduz um conjunto de métodos para análise multi-escala de formas baseados na estimação da curvatura digital de um dado contorno. A idéia básica da abordagem apresentada neste capítulo é a da extração de um diagrama multi-escala da curvatura, denominado curvograma [Cesar \& Costa, 1995a; Cesar \& Costa, 1995b; Cesar \& Costa, 1996b; Cesar \& Costa, 1996e]. Como já foi explicado anteriormente, a estimação da curvatura em contornos digitais apresenta dois problemas principais: a inexistência de uma fórmula analítica que descreva contornos quaisquer e a necessidade da estimação de derivadas numéricas. O primeiro problema é resolvido a partir da transformada de Fourier do contorno, através da aplicação da propriedade das derivadas de Fourier. Essa propriedade permite a estimação de $u^{(j)}(t)$ a partir da transformada de Fourier $U(s)$ de $u(n)$. Já o segundo problema é tratado através da filtragem passa-baixas do sinal, o que permite a generalização do método para uma abordagem multi-escala. Novas soluções são apresentadas para um problema tradicional na filtragem gaussiana de contornos, a chamada contração ("shrinking") do contorno. Finalmente, este capítulo apresenta uma série de informações sobre a implementação numérica dos métodos desenvolvidos, incluindo a avaliação da precisão do método por meio de uma técnica baseada em curvas B-spline cúbicas. É importante comentar aqui que, posteriormente ao desenvolvimento do método apresentado neste capítulo, o autor tomou conhecimento de um trabalho relacionado desenvolvido por Baroni \& Barletta, 1992, em que a série de Fourier é utilizada para estimação da curvatura de contornos. Por outro lado, a incorporação do paradigma multi-escala através da filtragem gaussiana, incluindo as ferramentas para normalização e tratamento do problema de contração de contornos, essenciais para a definição do curvograma e da precisão da estimação da curvatura, não constam daquele trabalho.

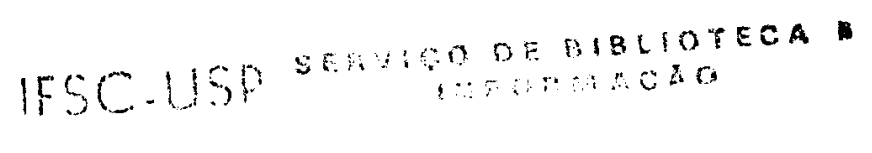




\subsection{Curvograma}

\subsubsection{Cálculo da Curvatura através da Transformada de Fourier}

$\Longrightarrow$ eja $C(t)=(x(t), y(t))$ a representação paramétrica de uma curva, em que o parâmetro $\mathrm{t}$ define uma parametrização por tamanho de arco (veja a Seção 2.3). A curvatura $k(t)$ da curva $C(t)$ pode ser definida pela fórmula:

$$
k(t)=\frac{\dot{x}(t) \ddot{y}(t)-\ddot{x}(t) \dot{y}(t)}{\left(\dot{x}(t)^{2}+\dot{y}(t)^{2}\right)^{3 / 2}}
$$

A Seção 2.3 apresenta mais detalhes relacionados à derivação da fórmula acima. Assim, a equação da curvatura envolve o cálculo das duas primeiras derivadas das funções $x(t)$ e $y(t)$. Sejam $X(f)$ e $Y(f)$ as respectivas transformadas de Fourier (Equação 2.7) dos sinais $x(t)$ e $y(t)$. As transformadas de Fourier das derivadas $\dot{x}(t)$, $\dot{y}(t), \ddot{x}(t)$ e $\ddot{y}(t)$ podem ser estimadas através da aplicação da propriedade da derivada de Fourier para funções de banda limitada [Papoulis, 1962] (Equação 2.11), isto é

$$
\begin{array}{r}
\dot{X}(f)=i 2 \pi f X(f) \\
\dot{Y}(f)=i 2 \pi f \dot{Y}(f) \\
\ddot{X}(f)=-(2 \pi f)^{2} X(f) \\
\ddot{Y}(f)=-(2 \pi f)^{2} \dot{Y}(f)
\end{array}
$$

em que $\dot{X}(f), \dot{Y}(f), \ddot{X}(f)$ e $\ddot{Y}(f)$ denotam as transformadas de Fourier de $\dot{x}(t)$, $\ddot{x}(t), \dot{y}(t)$ e $\ddot{y}(t)$ respectivamente, e não a derivada em relação à variável $f$. Assim, a aplicação da referida propriedade da derivada seguida da transformada inversa de Fourier (Equação 2.8) permite o cálculo da curvatura através da aplicação da Equação 4.1 em termos das transformadas de Fourier dos sinais $x(t)$ e $y(t)$, isto é:

$$
\begin{aligned}
& \dot{x}(t)=F^{-1}\{\dot{X}(f)\} \\
& \dot{y}(t)=F^{-1}\{\dot{Y}(f)\} \\
& \ddot{x}(t)=F^{-1}\{\ddot{X}(f)\} \\
& \ddot{y}(t)=F^{-1}\{\ddot{Y}(f)\}
\end{aligned}
$$


A aplicação das Equações 4.2 e 4.3 permite a obtenção da expressão da curvatura (Equação 4.1) em termos das transformadas de Fourier de $x(t)$ e $y(t)$. Primeiro, tem-se que:

$$
\begin{aligned}
\dot{x}(t) \ddot{y}(t)-\ddot{x}(t) \dot{y}(t)= & F^{-1}\{\dot{X}(f)\} F^{-1}\{\ddot{Y}(f)\}-F^{-1}\{\ddot{X}(f)\} F^{-1}\{\dot{Y}(f)\} \\
= & F^{-1}\{i 2 \pi f X(f)\} F^{-1}\left\{-(2 \pi f)^{2} Y(f)\right\} \\
& -F^{-1}\left\{-(2 \pi f)^{2} \ddot{X}(f)\right\} F^{-1}\{i 2 \pi f Y(f)\} \\
= & -i(2 \pi)^{3}\left(F^{-1}\{f X(f)\} F^{-1}\left\{f^{2} Y(f)\right\}-F^{-1}\left\{f^{2} X(f)\right\} F^{-1}\{f Y(f)\}\right)
\end{aligned}
$$

Em seguida, verifica-se que:

$$
\begin{aligned}
\left(\dot{x}(t)^{2}+\dot{y}(t)^{2}\right)^{3 / 2} & =\left(F^{-1}\{\dot{X}(f)\}^{2}+F^{-1}\{\dot{Y}(f)\}^{2}\right)^{3 / 2} \\
& =\left(F^{-1}\{i 2 \pi f X(f)\}^{2}+F^{-1}\{i 2 \pi f Y(f)\}^{2}\right)^{3 / 2} \\
& =\left((i 2 \pi)^{2}\left(F^{-1}\{f X(f)\}^{2}+F^{-1}\{f Y(f)\}^{2}\right)\right)^{3 / 2} \\
& =(i 2 \pi)^{3}\left(F^{-1}\{f X(f)\}^{2}+F^{-1}\{f Y(f)\}^{2}\right)^{3 / 2}
\end{aligned}
$$

Substituindo as duas últimas expressões na Equação 4.1, e devido ao fato de que $i^{3}=-i$, conclui-se que a expressão final da curvatura em termos das transformadas direta e inversa de Fourier dos sinais $x(t)$ e $y(t)$ é dada por:

$$
k(t)=\frac{F^{-1}\{f X(f)\}(t) F^{-1}\left\{f^{2} Y(f)\right\}(t)-F^{-1}\left\{f^{2} X(f)\right\}(t) F^{-1}\{f Y(f)\}(t)}{\left[\left(F^{-1}\{f X(f)\}(t)\right)^{2}+\left(F^{-1}\{f Y(f)\}(t)\right)^{2}\right]^{3 / 2}}
$$

\subsubsection{Cálculo da Curvatura a partir de $u(t)$}

1 formulação acima pode ser desenvolvida a partir do sinal complexo $u(t)$ definidas como:

(Equação 2.2) e de suas derivadas em relação ao parâmetro $t$, as quais são

$$
\begin{aligned}
& \dot{u}(t)=\dot{x}(t)+i \dot{y}(t) \\
& \ddot{u}(t)=\ddot{x}(t)+i \ddot{y}(t)
\end{aligned}
$$


Seguindo um raciocínio análogo, as transformadas de Fourier de $\dot{u}(t)$ e $\ddot{u}(t)$ são definidas em função de $U(f)$, isto é:

$$
\begin{gathered}
\dot{U}(f)=i 2 \pi f U(f) \\
\ddot{U}(f)=-(2 \pi f)^{2} U(f)
\end{gathered}
$$

Tem-se assim que:

$$
\begin{aligned}
& \dot{u}(t)=\mathrm{F}^{-1}\{\dot{U}(f)\} \\
& \ddot{u}(t)=\mathrm{F}^{-1}\{\ddot{U}(f)\}
\end{aligned}
$$

Pode-se facilmente verificar que:

$$
\dot{u}(t) \ddot{u}^{*}(t)=\dot{x}(t) \dot{y}(t)+\ddot{x}(t) \ddot{y}(t)-i(\dot{x}(t) \ddot{y}(t)-\ddot{x}(t) \dot{y}(t))
$$

A parte imaginária da Equação 4.8 coincide (a menos de uma multiplicação por -1) com o numerador da formula da curvatura (Equação 4.1). Além disso, a relação:

$$
|\dot{u}(t)|^{3}=\left(\sqrt{\dot{x}(t)^{2}+\dot{y}(t)^{2}}\right)^{3}=\left(\dot{x}(t)^{2}+\dot{y}(t)^{2}\right)^{3 / 2}
$$

eqüivale ao denominador da referida Equação 4.1. Assim, substituindo-se as Equações 4.8 e 4.9 na Equação 4.1, tem-se:

$$
k(t)=\frac{-\operatorname{Im}\left\{\dot{u}(t) \ddot{u}^{*}(t)\right\}}{|\dot{u}(t)|^{3}}
$$

A Equação 4.10 permite que o cálculo da curvatura seja feito diretamente a partir dos sinais complexos $\dot{u}(t)$ e $\ddot{u}(t)$. A propriedade da derivação de Fourier pode ser 
aplicada novamente em relação ao sinal $u(t)$, como foi feito com os sinais reais $x(t)$ e $y(t)$, de maneira a obter uma expressão da curvatura em função da transformada de Fourier $U(f)$ de $u(t)$. Assim, pode-se estimar a curvatura de uma forma digital a partir de seus descritores de Fourier $U(s)$. Porém, no caso de dados discretizados e ruidosos, características típicas encontradas em aplicações de análise de formas, a aplicação direta da Equação 4.10 apresenta um problema sério: a derivação age como um filtro passaaltas no espectro do sinal, aumentando a influência do ruído e comprometendo a estimação da curvatura. Tal problema pode ser controlado através da incorporação de um filtro passa-baixas no cálculo dos espectros das derivadas das funções, como será explicado na Seção 4.2.4. A Seção 4.2.3 trata de alguns aspectos particularmente importantes relacionados à implementação da derivada numérica por meio das propriedades de Fourier que foram aplicadas nessa seção.

\subsubsection{Implementação Numérica das Expressões de Curvatura}

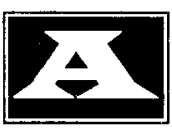

implementação numérica das equações apresentadas na seção anterior envolve uma série de cuidados relacionados à correta interpretação da estimação da transformada contínua de Fourier e sua inversa (Equações 2.7 e 2.8) através da transformada discreta de Fourier e sua inversa ( Equações 2.12 e 2.13). É importante notar que os cuidados apresentados nesta seção são fundamentais para o êxito da aplicação dos métodos introduzidos nesta tese, visto que a implementação -geralmente mais eficiente- de tais métodos com o auxílio de algoritmos da FFT fornece resultados que devem ser interpretados corretamente. Um exemplo simples será discutido para o melhor entendimento dos conceitos discutidos. Assim, será elucidada a obtenção numérica, através da propriedade da derivada de Fourier, da derivada da seguinte função:

$$
g(t)=\cos (2 t)+\operatorname{sen}\left(t^{2}\right)
$$

O gráfico de $g(t)$, que consiste na soma de um chirp linear e um quadrático, é apresentado na Figura 4.1 (a). O sinal $g(t)$ foi amostrado em 256 pontos, em que $t \in$ $[0,2 \pi)$, isto é $N=256$ e o intervalo de amostragem $T=2 \pi / N$.

O primeiro cuidado a ser tomado deve-se ao fato de que a transformada discreta de Fourier, da maneira como é geralmente definida, resulta na representação da segunda parte do período da transformada de Fourier do sinal, seguida da primeira parte [Brigham, 1974], o que pode ser conferido na Figura 4.1 (b). Vale lembrar que a transformada de Fourier de um sinal discretizado é periódica, daí o significado de primeira e segunda partes do período da transformada. A Figura 4.1 (b) apresenta o módulo $|G(s)|$ da transformada de $g(t)$ calculada pela Equação 2.14, a qual define $s=0, \ldots, N-1$. O período montado corretamente de $G(s)$ pressupõe a correta ordenação dessas duas partes fornecidas pela transformada discreta de Fourier, o que é mostrado na Figura 4.1 (c). Essa operação de ordenação das partes do período é 
equivalente à operação de fft shift, comumente aplicada para se mostrar a transformada de Fourier de imagens, o que faz com que a origem do eixo da freqüência seja localizado no centro da representação. Dessa maneira, tem-se que a variável $s$ fica redefinida como $s=-$ floor $\left(\frac{N}{2}\right), \ldots, 0, \ldots, N-$ floor $\left(\frac{N}{2}\right)-1$, em que floor $(x)$ é a tradicional função de truncamento que retorna o maior inteiro menor ou igual a $x$. Além disso, o gráfico da Figura 4.1 (c) também apresenta a terceira preocupação que deve ser tomada, preocupação essa devida à relação entre $s$ e $f$, as variáveis das transformadas discreta (Equação 2.14) e contínua (Equação 2.7), visto que a propriedade da derivada é definida em função da transformada contínua do sinal. A resposta a essa preocupação é encontrada por meio da correta interpretação da transformada discreta de Fourier, tornando-se explícita na formulação da transformada expressa pelas Equações 2.12 e 2.13 , isto é, $f=s / N T$. Assim, antes da aplicação da propriedade da derivada (Equação 2.11), deve-se tomar cuidado no cálculo dos valores de $f$. A Figura 4.1 (c) já indica essa mudança de variáveis, em que o gráfico apresentado é $|U(f)|$ em função de $f$. O cálculo da primeira derivada envolve a multiplicação de $U(f)$ por uma reta definida por (i $2 \pi f$ ), a qual também aparece na Figura 4.1 (c), porém normalizada graficamente para que pudesse ser percebida. 


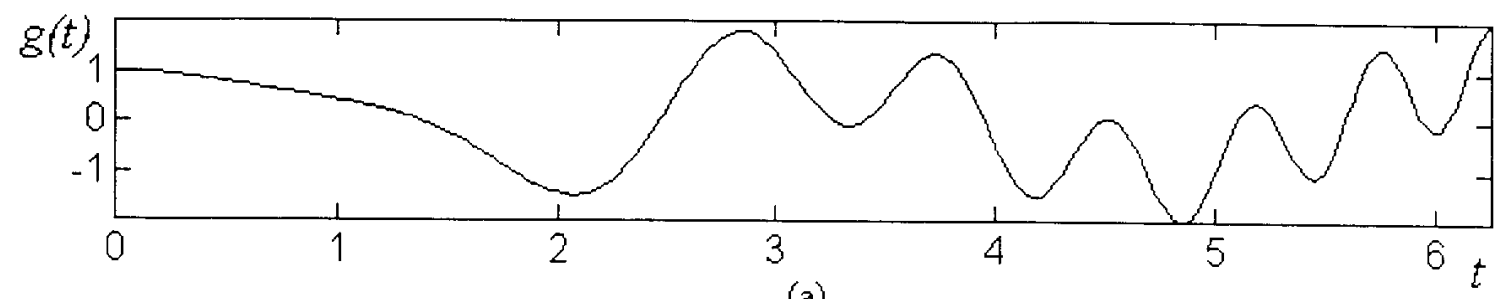

(a)

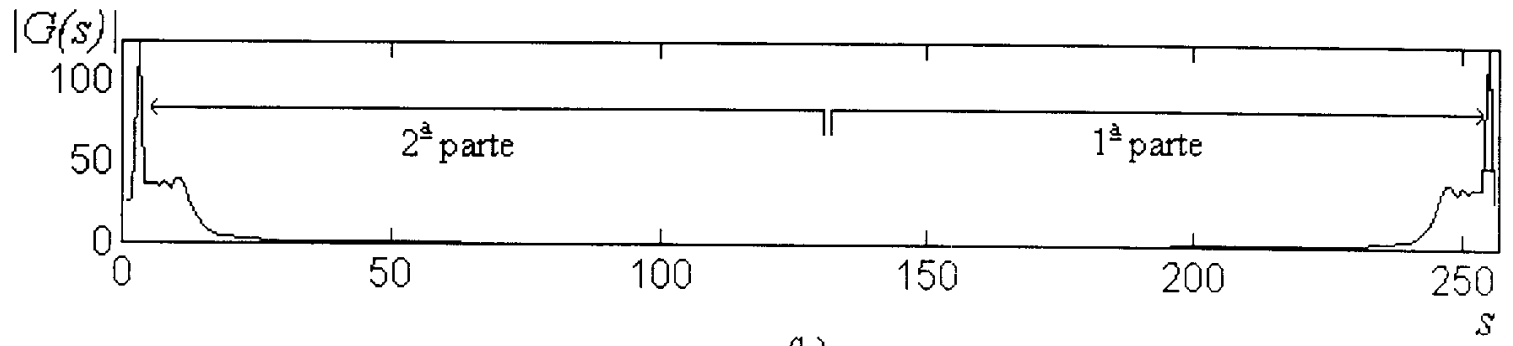

(b)
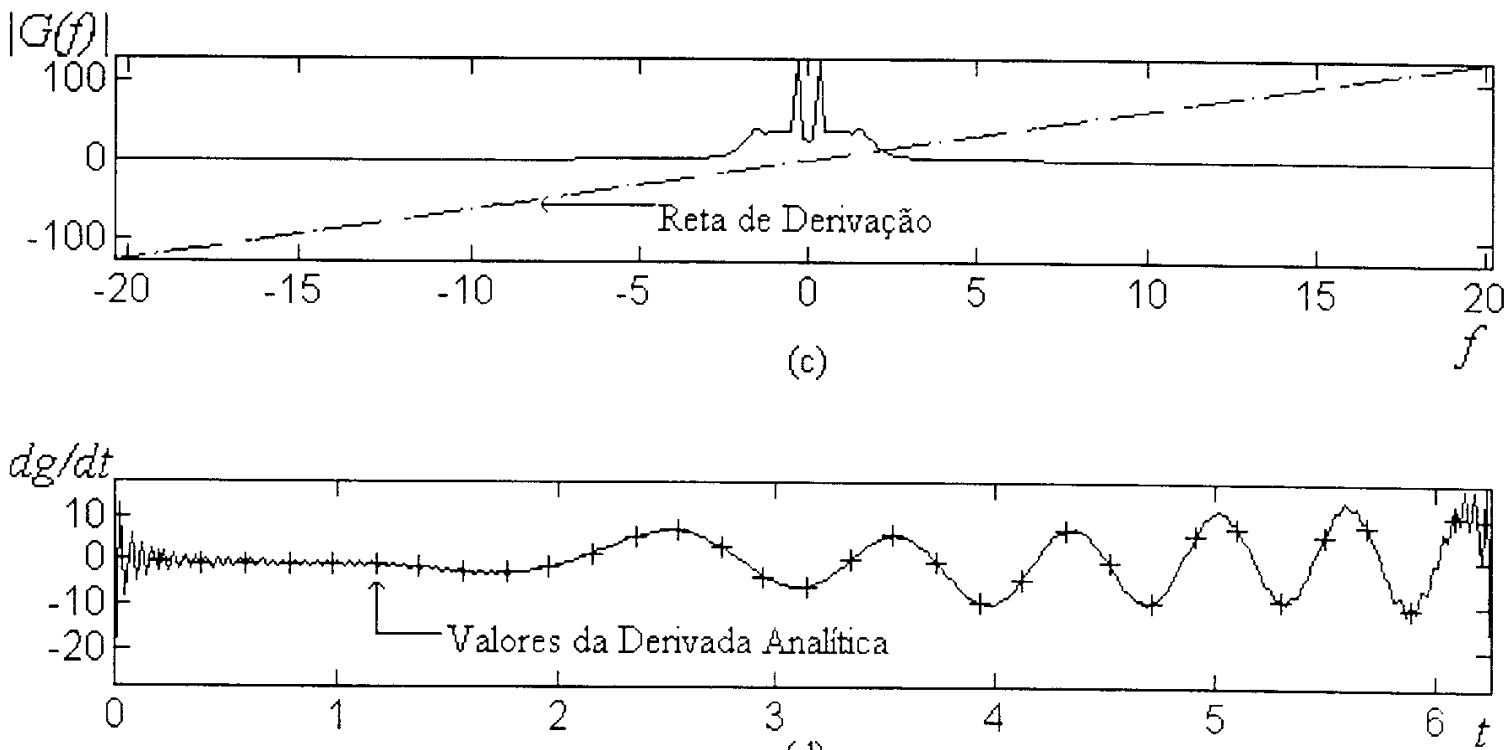

(d)

Figura (4.1): Exemplo de diferenciação numérica pela transformada de Fourier.

O cálculo da derivada prossegue com o "redobramento" de (i $2 \pi f) U(f)$, para que os coeficientes da transformada fiquem na ordem normalmente tratada pela transformada discreta de Fourier e sua inversa, isto é, a segunda parte do período seguida da primeira, e a aplicação da transformada inversa. A Figura 4.1 (d) apresenta o sinal obtido como sendo a derivada de $g(t)$. É fácil verificar que: 


$$
\frac{d g}{d t}(t)=-2 \sin (2 t)+2 t \cos \left(t^{2}\right)
$$

Alguns valores analíticos de $d g / d t$ foram calculados a partir da expressão acima e mostrados no gráfico da Figura 4.1 (d), tendo sido denotados por "+". Pode-se facilmente notar a boa aproximação fornecida pela propriedade da derivada, com exceção da oscilação próxima aos extremos do sinal, oscilação essa devida aos efeitos de bordas decorrentes do fato de o sinal não ser periódico. Tais efeitos são mínimos em sinais periódicos.

O código em linguagem script do Matlab para a implementação desse experimento é apresentado abaixo.

function deriva;

$\%$ definicao das constantes iniciais

$$
\begin{aligned}
& N=256 ; \\
& n=0:(N-1) ; \\
& T=2 * p i / N ;
\end{aligned}
$$

$\%$ funcao $g(t)$ amostrada

$g=\cos \left(2^{*} n * T\right)+\sin \left(\left(n^{*} T\right) .^{\wedge} 2\right)$

$\%$ transformada discreta de Fourier atraves dafft

$G=f f t(g)$;

$\%$ preparacao para desdobramento da fft

$$
\begin{aligned}
& N 2=\text { floor }(N / 2) ; \\
& N 1=N-1 ; \\
& s=-N 2:(N 1-N 2) ; \\
& G=f f t \operatorname{hift}(G) ;
\end{aligned}
$$

\section{$\%$ deriva}

$$
d G=\left(i * 2 * p i *\left(s /\left(N^{*} T\right)\right)\right) .{ }^{*} G ;
$$

\% unshift da transformada da derivada $d G=f f t u n s h i f t(d G)$ 


\section{$\%$ Calculo da derivada pela transformada inversa de Fourier}

$$
d g=i f f t(d G) \text {; }
$$

O Apêndice 1 discute um outro aspecto igualmente importante para a implementação das técnicas discutidas neste capítulo.

É importante ressaltar um último ponto que concerne à implementação numérica discutida nesta seção, a qual procurou explicar a diferença entre os parâmetros $s$ e $f$ e sua correta interpretação. Por outro lado, as próximas seções mostram que a filtragem gaussiana dos contornos acarreta a perda de energia dos sinais. Os métodos de prevenção à contração apresentados neste capítulo tentam compensar essa perda de energia, ajustando-a arbitrariamente em função da energia do sinal inicial. Em consequiência desse processo, a aplicação da propriedade da derivada utilizando a variável $s$ ou $f$ tornase indiferente, visto que a relação linear existente entre elas $(f=s / N T)$ desaparece se a energia final dos sinais for normalizada. Isso porque, como será explicado na Seção 4.2.5, a energia final do sinal filtrado é normalizada para que coincida com a energia do sinal original, não importando que tipo de normalização seja adotado antes da normalização final da energia. Por outro lado, isso não anula a importância da discussão apresentada nesta seção, visto ser fundamental a correta compreensão da aplicação da propriedade da derivada de Fourier.

\subsubsection{Filtragem Gaussiana e o Esquema Multi-Escala}

07 mbora a discussão desta seção seja centrada no sinal complexo $u(t)$, os resultados derivados nesta seção também podem ser obtidos analogamente para os sinais reais $x(t)$ e $y(t)$.

Como já mencionado de maneira introdutória no Capítulo 3, existem diferentes formas de se abordar o problema levantado no final da Seção 4.2.1, sendo agrupadas nesta tese sob o nome de diferenciação numérica [Weiss, 1993; Weiss, 1994]. Esse tópico possui importância fundamental para diferentes problemas de visão computacional como análise de formas e detecção de bordas, podendo ser estudado sob a perspectiva da teoria da regularização [Poggio et al., 1985; Grossmann, 1988; Duncan et al., 1991; Weiss, 1994] . O aumento da influência do ruído devido ao processo de diferenciação pode ser controlado por meio da incorporação de um mecanismo multiescala no processo de obtenção da curvatura. Com esse propósito, o processo de derivação através da aplicação da propriedade de Fourier é seguido da aplicação de um filtro passa-baixas gaussiano para que se possa controlar a influência das altas freqüências. O filtro gaussiano $G(f)$ pode ter sua largura de banda controlada através do parâmetro $\tau$, e a assunção desse parâmetro como uma variável permite a incorporação do dito mecanismo multi-escala através da aplicação de um banco de filtros gaussianos indexados pelo parâmetro $\tau$. No domínio do tempo, esse processo é equivalente à 
chamada descrição de um sinal pelo espaço-escala (veja o Capítulo 3), em que o sinal é convoluído com um conjunto de gaussianas, graças ao teorema da convolução de Fourier e ao fato de a transformada de Fourier de uma gaussiana ser uma outra gaussiana (ver Seção 2.5), isto é:

$$
g(t)=\frac{1}{a \sqrt{2 \pi}} \exp \left(\frac{-t^{2}}{2 a^{2}}\right) \Leftrightarrow G(f)=\exp \left(\frac{-(2 \pi)^{2} f^{2}}{2 \tau^{2}}\right), \tau=1 / a
$$

A discussão apresentada no final da Seção 4.2.3 também se aplica à definição utilizada para a função gaussiana, a qual pode ser formulada de diferentes maneiras, incluindo a utilização de diferentes normalizações. $O$ fato de que a energia final do sinal é normalizada no final da filtragem multi-escala (o que será explicado na Seção 4.2.5) implica que qualquer uma das diferentes formulações da gaussiana pode ser adotada. Em particular, pode-se desejar que o banco de filtros gaussianos tenha área constante no dominio da freqüência, o que leva à seguinte definição do par de gaussianas:

$$
G(f)=\frac{1}{\tau \sqrt{2 \pi}} \exp \left(\frac{-f^{2}}{2 \tau^{2}}\right)
$$

Nesse contexto, a variável a se relaciona com a escala analisada, enquanto $\tau=1 /$ a se relaciona com a largura de banda do filtro, estando os dois conceitos ligados de maneira dual. Assim, a aplicação de um filtro gaussiano freqüencial de largura de banda $1 / a$ está relacionada à obtenção de um sinal suavizado observado na escala $a$. Uma família de curvas suavizadas pode ser obtida variando-se o parâmetro de escala $a$ e definindo-se uma família de filtros $G_{l / a}(f)$ indexados por esse parâmetro, isto é:

$$
G(f)=G_{1 / a}(f)
$$

A Figura 4.2 mostra o conjunto de filtros e a relação entre a variável de escala $a$ e a freqüência $f$. Cada filtro $G_{l / a}(f)$ é uma gaussiana centrada na origem do eixo de freqüência e de largura dependendo da largura de banda $\tau=1 / a$. A Figura 4.2 (a) apresenta o gráfico de alguns filtros (de diferentes larguras de banda) em função da freqüência $f$, ao passo que a Figura 4.2 (b) mostra o banco de filtros como uma imagem, em que o eixo vertical representa a largura de banda do filtro, o eixo horizontal representa a freqüência e $G_{1 / a}(f)$ é codificado pelos níveis de cinza (valores aumentando do preto para o branco). Ambas as imagens mostram que, na medida que a largura de 


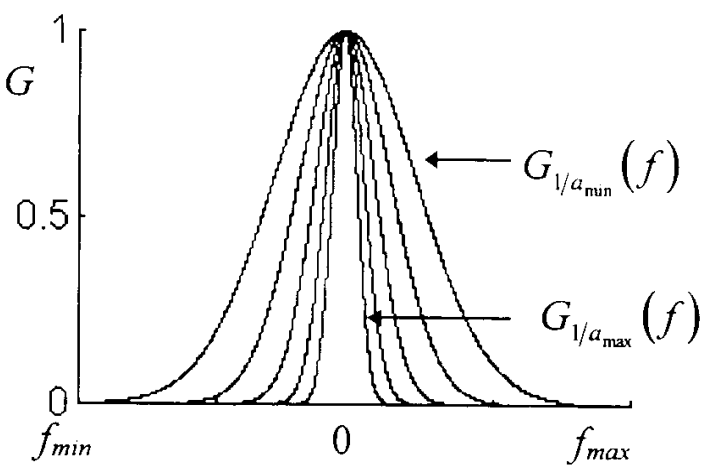

(a)

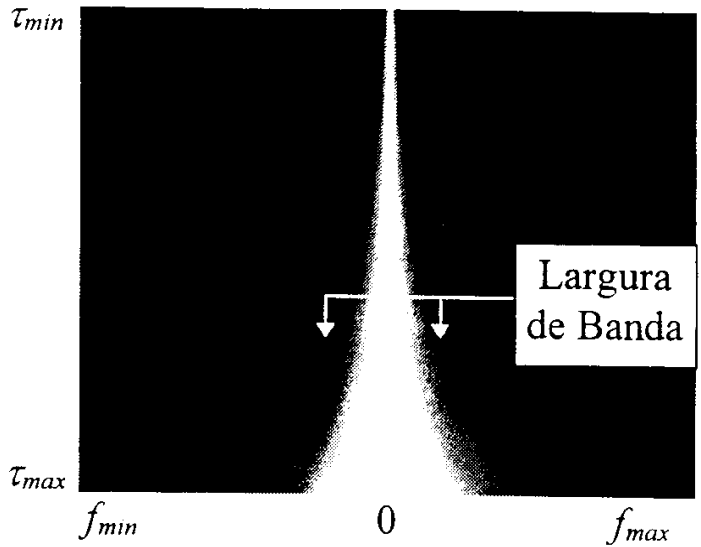

(b)

Figura (4.2): Esquema do banco de filtros gaussianos.

banda aumenta (e a escala $a$ diminui), uma porção maior do espectro é levada em consideraçào.

Em seguida, a família de curvas suavizadas $\hat{u}(t, a)$ é definida filtrando-se $U(f)$ pelo banco de filtros $G_{l / a}(f)$ seguido da aplicação da transformada inversa de Fourier:

$$
\widehat{u}(t, a)=u * g_{a}(t)=\mathrm{F}^{-1}\left\{U_{1 / a}(f)\right\}=\mathrm{F}^{-1}\left\{U(f) G_{1 / a}(f)\right\}
$$

Assim, $U_{l, a}(f)$ denota o espectro de $U(f)$ filtrado por $G_{l / a}(f)$. De maneira análoga, as expressões multi-escala das derivadas de $u(t)$ podem ser definidas filtrando-se os respectivos espectros pelo banco de filtros $G_{l, a}(f)$ :

$$
\begin{aligned}
& \overline{\dot{u}}(t, a)=\dot{u} * g_{a}(t)=\mathrm{F}^{-1}\left\{\dot{U}_{1 / a}(f)\right\}=\mathrm{F}^{-1}\left\{\dot{U}(f) G_{1 / a}(f)\right\} \\
& \overline{\ddot{u}}(t, a)=\ddot{u} * g_{a}(t)=\mathrm{F}^{-1}\left\{\ddot{U}_{1 / a}(f)\right\}=\mathrm{F}^{-1}\left\{\ddot{U}(f) G_{1 / a}(f)\right\}
\end{aligned}
$$

em que $\dot{U}(f)$ e $\ddot{U}(f)$ são definidos pelas Equações 4.4 e 4.5 , respectivamente. 


\subsubsection{Soluções para o problema de contração do contorno}

filtragem gaussiana de sinais modifica a amplitude da representação espectral de contornos [Cesar \& Costa, 1996e], implicando no efeito de contração dessas curvas na medida que a escala do filtro gaussiano aumenta (ou diminui, dependendo da normalização adotada) [Cesar \& Costa, 1996e; Marshall, 1989; Lowe, 1988; Lowe, 1989; Oliensis, 1993; Sapiro \& Tannenbaum, 1995]. Diferentes métodos para solucionar esse inconveniente foram propostos na literatura (veja o trabalho de Sapiro \& Tannenbaum, 1995, para uma revisão detalhada desse problema). Duas soluções distintas, introduzidas em [Cesar \& Costa, 1996e] e [Cesar \& Costa, 1997a], serão apresentadas a seguir.

\subsubsection{Prevenção à contração por conservação de energia}

Supondo-se que a forma encontra-se centrada na origem e, portanto, $U(0)=0$, define-se a energia total do contorno $u(t)$ por:

$$
E=\int|U(f)|^{2} d f
$$

A energia $E$ é modificada pelo processo de filtragem de $U(f)$ por $G_{l / a}(f)$, sendo que a energia do contorno filtrado é definida por:

$$
E(a)=\int\left|U_{1 / a}(f)\right|^{2} d f
$$

A perda total de energia durante o processo de filtragem pode ser corrigida através da introdução do coeficiente $\Omega(a)$ :

$$
\Omega(a)=\sqrt{\frac{E}{E(a)}}
$$

Em seguida, o coeficiente $\Omega(a)$ deve multiplicar os sinais $\widehat{u}(t, a), \hat{\dot{u}}(t, a)$ e $\hat{\dot{u}}(t, a)$, de modo que a energia do contorno reconstruído seja a mesma do contorno original, gerando-se os sinais:

$$
u(t, a)=\hat{u}(t, a) \Omega(a)
$$




$$
\begin{aligned}
& \dot{u}(t, a)=\hat{\dot{u}}(t, a) \Omega(a) \\
& \ddot{u}(t, a)=\hat{\ddot{u}}(t, a) \Omega(a)
\end{aligned}
$$

Particularmente, $u(t, a)$ contém uma série de versões suavizadas do sinal $u(t)$, em que $u\left(t, a_{0}\right)$, para $a_{0}$ fixo, é uma versão suavizada de $u(t)$ obtida pela convolução desse sinal com uma gaussiana de escala $a$. Na medida que $a$ varia, $u(t, a)$ define a evolução de $u$, sendo que os diagramas que mostram essa evolução são denominados morfogramas.

Como será ilustrado mais adiante, essa técnica simples de compensação de energia fornece bons resultados. Por outro lado, deve-se observar que esse esquema de prevenção à contração do contorno funciona bem apenas porque a maior porção da energia de contornos típicos se concentra nas baixas frequêencias (veja Seção 2.6.5). Caso contrário, a atenuação da energia das altas freqüências acarretaria um efeito de degradação consideravelmente maior, inviabilizando a aplicação do esquema de compensação de energia.

\subsubsection{Prevenção à contração por conservação de perímetro}

Uma alternativa à preservação de energia apresentada anteriormente é preservação do perímetro da curva original. Tal restrição baseia-se em uma interpretação física segundo a qual o processo de suavização do contorno original $u(t)$ é encarado como um processo de desdobrar um arame inicialmente dobrado no formato do contorno original. Tal interpretação é explorada pelo conceito de energia de dobramento (Capítulo 6). Para ser realista em termos físicos, o processo de desdobramento do contorno original deve preservar o perímetro $L$ do contorno original, visto que um arame não deve encolher quando está sendo desdobrado. $O$ perímetro $L$ de $u(t)$ é definido por:

$$
L=\int|\dot{u}(t)| d t
$$

O cálculo do perímetro para curvas discretas pode ser feito estimando-se a primeira derivada por diferenças sucessivas:

$$
L=\sum_{n=0}^{N-1}|u(n)-u(n-1)|
$$

Uma outra alternativa é a estimativa do perímetro a partir de $\dot{u}(n)$, o qual pode ser calculado a partir dos descritores de Fourier de $u(n)$ em conjunto com a aplicação da 
propriedade da derivada de Fourier (Equações 4.4 e 4.6). A expressão de estimativa do perímetro a partir de $\dot{u}(n)$ é dada por:

$$
L=\frac{2 \pi}{N} \sum_{n=o}^{N-1}|\dot{u}(n)|
$$

De maneira similar, o perímetro $L(a)$ da curva suavizada $u(t, a)$ é definido como:

$$
L(a)=\int|\dot{u}(t, a)| d t
$$

podendo ser calculado através do método de diferenças finitas ou pelo sinal $\dot{u}(n, a)$, isto é:

$$
L(a)=\sum_{n=o}^{N-1}|\hat{u}(n, a)-\hat{u}(n-1, a)|
$$

ou ainda

$$
L(a)=\frac{2 \pi}{N} \sum_{n=0}^{N-1}|\hat{\dot{u}}(n, a)|
$$

O fator de normalização $P(a)$ dependente da escala $a$ é definido como:

$$
P(a)=\frac{L}{L(a)}
$$

O fator $P(a)$ é definido pela razão entre os perímetros da curva original $u(t)$ e cada curva suavizada $u(t, a)$. De maneira análoga à prevenção da contração por conservação de energia apresentada nas Equações 4.13, 4.14 e 4.15, define-se:

$$
\begin{aligned}
& u(t, a)=\hat{u}(t, a) P(a) \\
& \dot{u}(t, a)=\hat{\dot{u}}(t, a) P(a)
\end{aligned}
$$




$$
\ddot{u}(t, a)=\hat{\ddot{u}}(t, a) P(a)
$$

\subsubsection{O Curvograma}

A s expressões multi-escala corrigidas de $\dot{u}(t, a)$ e $\ddot{u}(t, a)$ (Equações $4.17 \mathrm{e}$ 4.18), em conjunto com a expressão complexa da curvatura $k(t)$ dada pela Equação 4.10, permitem a definição do curvograma como:

$$
k(t, a)=\frac{-\operatorname{Im}\left\{\dot{u}(t, a) \ddot{u}^{*}(t, a)\right\}}{|\dot{u}(t, a)|^{3}}
$$

A função $k(t, a)$ expressa a curvatura do contorno analisado em termos de um conjunto de escalas de análise. A Figura 4.3 apresenta um contorno enquanto que a Figura 4.4 apresenta o curvograma associado. Nesse diagrama, o eixo horizontal está associado ao parâmetro $b$ enquanto que o eixo horizontal está associado ao parâmetro $a$, conforme discutido no Capítulo 3. Note que o curvograma apresenta uma resposta mais forte afunilando-se em torno dos pontos equivalentes aos vértices do contorno. Para pequenas escalas, o curvograma responde a detalhes mais finos do contorno, como a região de oscilação senoidal. $\mathrm{Na}$ medida que a escala aumenta, o curvograma torna-se insensivel a esses detalhes, refletindo informações mais globais da forma. Os resultados apresentados neste capitulo apresentam um curvograma visualizado como uma superfície, de maneira alternativa à visualização de transformadas multi-escala como

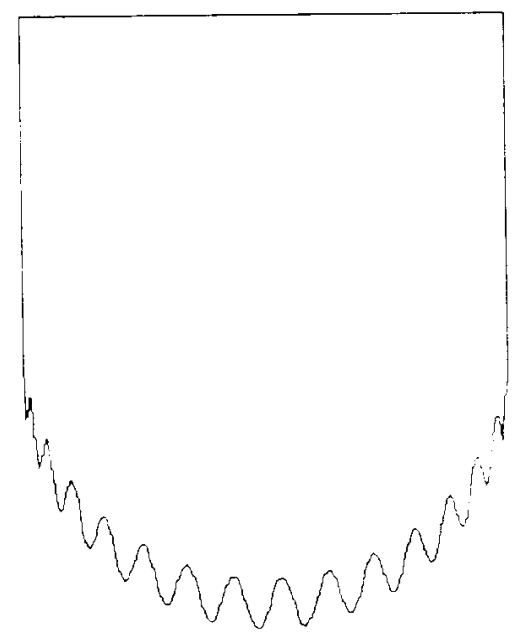

Figura (4.3): Contorno contendo dois cantos e um padrão periódico local.

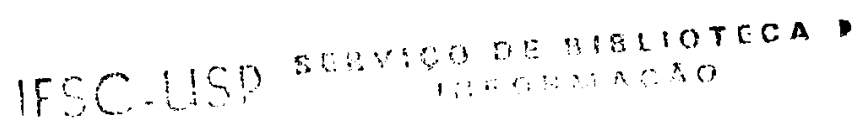




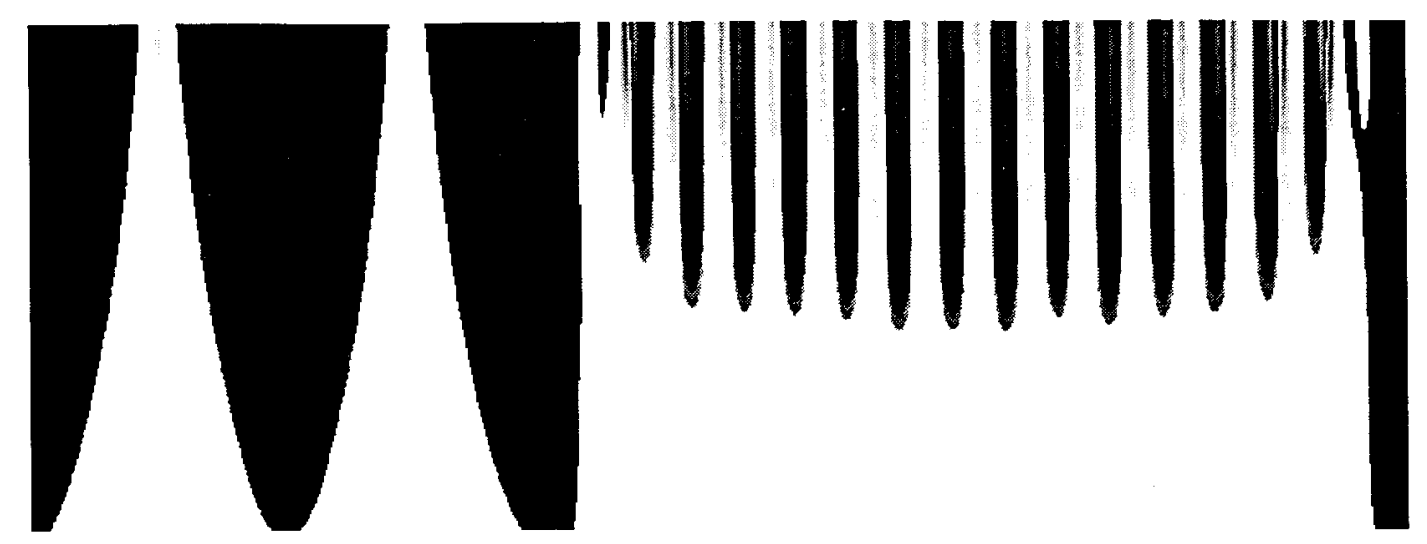

Figura (4.4): Curvograma da Figura 4.3.

imagens, como neste exemplo.

As seções subseqüentes, a última seção do próximo capítulo e o Capítulo 6 discutem diversas propriedades e ferramentas de análise de formas que podem ser obtidas a partir do curvograma.

Tal representação multi-escala pode ser obtida por meio de caminhos alternativos à filtragem gaussiana (a qual está relacionada com o modelo de evolução da equação do calor), como através da definição de evoluções de curva baseadas em outras equações a derivadas parciais [Kimia et al., 1992; Kimia et al., 1995; Sapiro \& Tannenbaum, 1993] ou por modelos baseados em dilatação-erosão morfológicas [Sapiro et al., 1993; Boomgaard \& Smeulders, 1994].

\subsubsection{Discretização do Parâmetro de Escala}

Diferentes esquemas de discretização do parâmetro de escala a podem ser desenvolvidos. Esta seção apresenta um deles como exemplo.

O esquema descrito em seguida baseia-se no programa que implementou as técnicas usadas nos experimentos de neuromorfometria relatados no Capítulo 6 . $\mathrm{O}$ programa desenvolvido toma 3 parâmetros de entrada: o número de escalas $S$, e os valores mínimo e máximo da variável de largura de banda $\tau_{\min } \mathrm{e} \tau_{\max }$. Um índice auxiliar aux é definido pela seguinte equação:

$$
\operatorname{aux}_{l}=(\sqrt{2}), \quad l=1, \ldots, S
$$

A equação acima utiliza as potências da raiz quadrada de 2 , ao inés das potências de 2 diretamente, como é adotado em [Mokhtarian \& Macworth, 1992], para obter-se uma amostragem mais fina. Seja $a u x_{\max }$ o maior valor de $a u x$. Então os valores discretos que a variável de largura de banda assume são definidos por: 


$$
\tau_{l}=\left(\frac{\tau_{\max }-\tau_{\min }}{a u x_{\max }-\sqrt{2}}\right)\left(a u x_{l}-\sqrt{2}\right)+\tau_{\min }
$$

Outros esquemas de discretização, como linear ou exponencial, podem ser facilmente derivados de maneira análoga.

\subsection{RESULTADOS EXPERIMENTAIS}

7 sta seção apresenta os resultados experimentais sobre o método de estimação digital de curvatura, avaliação da precisão do método e derivação da representação multi-escala de curvatura, ou seja, o curvograma. A gaussiana definida pela Equação 4.12 foi adotada nos experimentos apresentados nesta Seção.

A técnica de estimação de curvatura foi aplicada a diversas formas obtidas de imagens reais e sintéticas, sendo seus resultados apresentados a seguir. No primeiro caso, o contorno gerado sinteticamente, o qual é composto por um arco de circunferência de raio 16 complementado por 3 arestas de um quadrado, pode ser visto na Figura 4.5(a). A Figura 4.5(b) apresenta os sinais $x$ e $y$ correspondentes a esse contorno. Considerando que a fórmula analítica do arco de circunferência que compõe esse contorno é conhecida, os valores teóricos para a curvatura ao longo do contorno podem ser determinados. De fato, a curvatura ao longo do arco de circunferência é de $1 / 16=0.0625$, pois a curvatura de uma circunferência é dada pelo inverso de seu raio; a curvatura se anula ao longo dos lados formados por linhas retas e forma duas singularidades nos dois vértices do contorno.

A Figura 4.5(c) mostra o contorno reconstruido utilizando-se $27 \%$ dos primeiros descritores de Fourier do contorno original, o que eqüivale a dizer que os descritores de Fourier foram filtrados por uma janela quadrada que cobria $27 \%$ da transformada de Fourier do contorno. A curvatura estimada pelo método descrito na Seção 4.2.2 é apresentada na Figura 4.5(d). O efeito de oscilação de alta freqüência ("ripple") devido à filtragem com a janela retangular na região correspondente ao arco de circunferência é tão intenso que o valor da curvatura nessa região é completamente afetado. Esse efeito advém do fato de que a filtragem dos descritores de Fourier por uma janela quadrada eqüivale à convolução do contorno original com uma função $\operatorname{sinc}(t)=\operatorname{sen}(t) / t$, que é a transformada inversa de Fourier da janela quadrada. As oscilações da função sinc afetam a estimação digital da curvatura. No entanto, os picos de alta curvatura correspondentes aos vértices do contorno são claramente identificados. Esse exemplo ilustra a limitação da utilização de uma simples janela quadrada, comumente adotada em diferentes artigos sobre descritores de Fourier em que os autores guardam apenas alguns primeiros coeficientes.

$\mathrm{O}$ efeito da aplicação de uma janela gaussiana sem a compensação de energia para $\tau=32$ é ilustrado nas Figuras 4.5(e) e (f), as quais representam o contorno reconstruído 
e a respectiva curvatura estimada. A eficiência da filtragem com a janela gaussiana pode ser facilmente verificada: a curvatura na região correspondente ao arco de circunferência é constante, anulando-se nas regiões correspondentes aos segmentos de reta e criando picos de máximos locais nos pontos correspondentes aos vértices do contorno. Entretanto, a curvatura média na região do arco de circunferência é 4.9764 e não 1/16, como era esperado. A razão para essa distorção, como discutido anteriormente, é a contração do contorno implicada pela filtragem gaussiana. O contorno reconstruído e a curvatura após a aplicação da técnica de correção de energia discutida na Seção 4.2 .5 são apresentados nas Figuras 4.5(g) e $(\mathrm{h})$, respectivamente. A nova curvatura média na região da circunferência é de 0.06203 , bastante próxima, portanto, do valor teórico (uma diferença da ordem de $0.1 \%$ ). As Figuras 4.6(a) e (b) apresentam a primeira e a segunda derivadas dos sinais $x$ e $y$, respectivamente. 


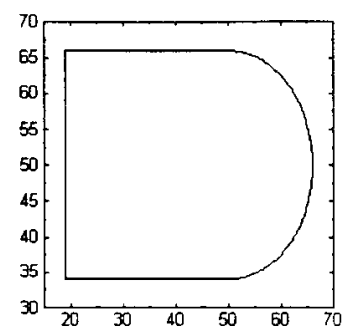

(a)

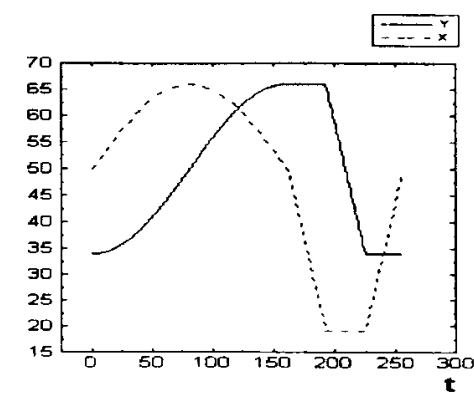

(b)
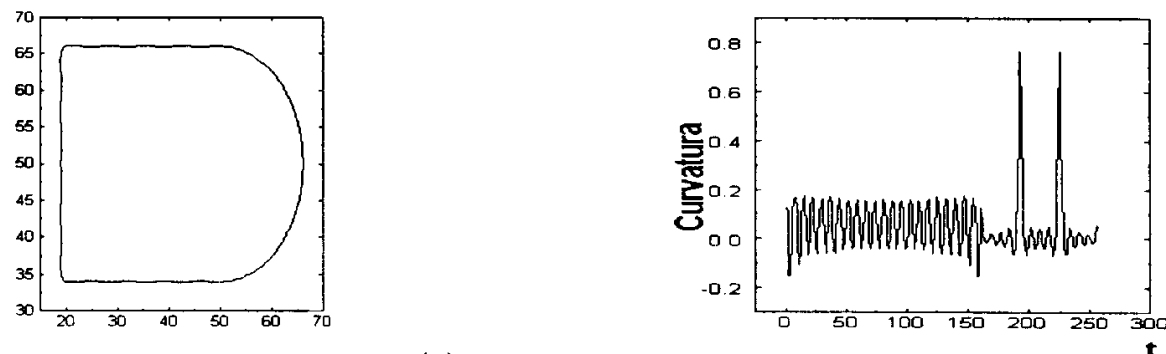

(c)

(d)

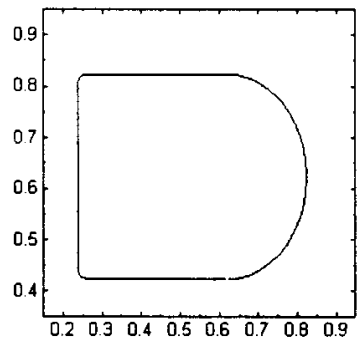

(e)

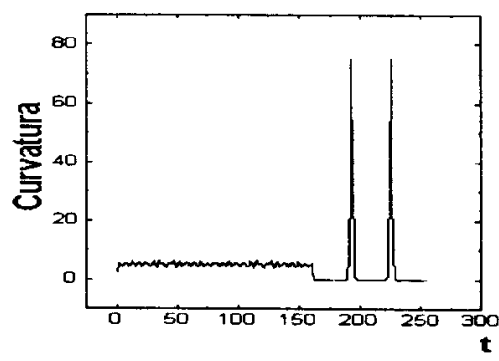

(f)

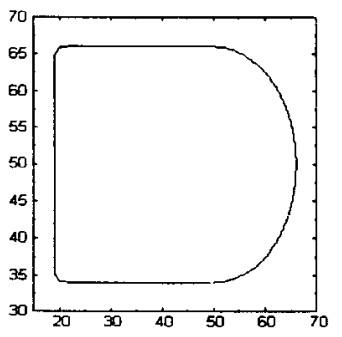

(g)

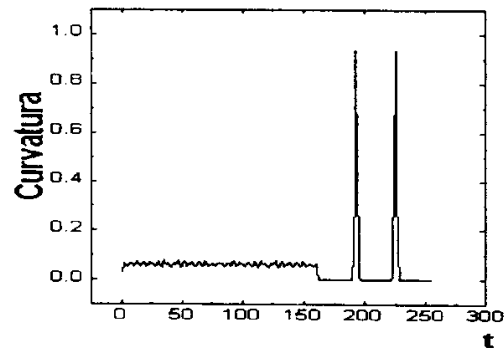

(h)

Figura (4.5): Resultados da estimação digital da curvatura de uma forma sintética.

Os efeitos da abordagem multi-escala são agora discutidos na série de resultados apresentados na Figuras 4.7(a)-(d), os quais foram obtidos para $\tau=4,8,16$ e 32, respectivamente. Todos esses sinais foram normalizados pela técnica de compensação de energia. É importante notar que, embora diferentes valores do parâmetro $\tau$ levem a diferentes perdas de energia no processo de filtragem, o fator de normalização $\Omega$ ainda funciona com sucesso. A Tabela 4.1 mostra a evolução da energia filtrada, o erro médio quadrático (EMQ) entre o contorno reconstruído (com e sem compensação de energia) e 

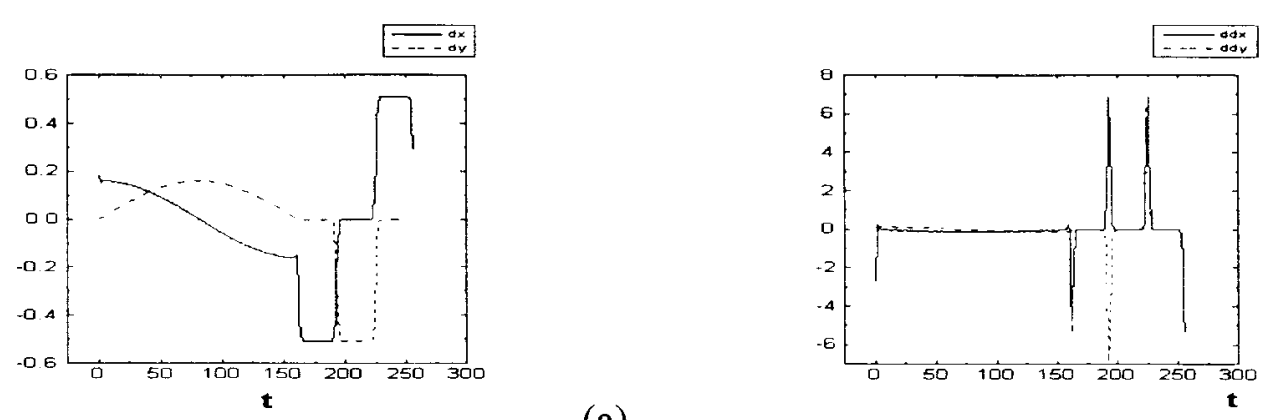

(a)

Figura (4.6): Primeira e segunda derivadas dos sinais $x$ e $y$ vistos na Figura 4.5(b).

o original, e $\Omega$ para os diferentes valores de $\tau$. Note que a energia filtrada diminui ao passo que o EMQ sem a normalização por energia aumenta quando $\tau$ aumenta. Esse fenômeno deve-se ao fato de que, embora o contorno reconstruído seja mais semelhante (no formato) ao original, ele possui menos energia (tendo, portanto, sofrido maior contração). Em outras palavras, o contorno reconstruído contrai-se mais com o aumento de $\tau$. Esse fenômeno ocorre devido à gaussiana adotada (Equação 4.12), a qual diminui em altura quando $\tau$ aumenta (veja a Figura 4.8), implicando em uma menor magnitude para as freqüências mais baixas. Esse problema é corrigido com sucesso através do uso do fator de normalização de energia, como pode ser verificado através de uma rápida análise dos valores dos EMQ na Tabela 4.1.

A Figura 4.7(a) mostra a curvatura para $\tau=4$ e os sinais reconstruídos. É importante notar que os picos de curvatura dos vértices se sobrepõem entre si devido à suavização demasiada. As Figuras 4.7(b) e (c) mostram a curvatura e os sinais reconstruídos para $\tau=8$ e $\tau=16$, nas quais os vértices podem ser corretamente identificados. Além disso, a curvatura permanece constante na região correspondente à semi-circunferência e quase nula nas regiões correspondentes aos segmentos de reta. Para $\tau=16$ a curvatura na região da semi-circunferência começa a oscilar, um fenômeno que se mostra de forma mais acentuada para $\tau=32$ (Figura 4.7(d)). 


\begin{tabular}{l|llll} 
& $\tau=\mathbf{4}$ & $\tau=\mathbf{8}$ & $\tau=\mathbf{1 6}$ & $\tau=\mathbf{3 2}$ \\
\hline $\begin{array}{l}\text { Energia Original (x) } \\
\text { (parte real) }\end{array}$ & $2.651 \mathrm{E}+03$ & $2.651 \mathrm{E}+03$ & $2.651 \mathrm{E}+03$ & $2.651 \mathrm{E}+03$ \\
$\begin{array}{l}\text { Energia Original (y) } \\
\text { (parte imaginária) }\end{array}$ & $2.655 \mathrm{E}+03$ & $2.655 \mathrm{E}+03$ & $2.655 \mathrm{E}+03$ & $2.655 \mathrm{E}+03$ \\
$\begin{array}{l}\text { Energia Filtrada (x) } \\
\text { (parte real) }\end{array}$ & 26.141 & 6.578 & 1.647 & 0.412 \\
$\begin{array}{l}\text { Energia Filtrada (y) } \\
\text { (parte imaginária) }\end{array}$ & 26.277 & 6.593 & 1.65 & 0.413 \\
$\begin{array}{l}\text { EMQ (x) } \\
\text { (parte real) }\end{array}$ & 46.381 & 48.928 & 50.209 & 50.85 \\
$\begin{array}{l}\text { EMQ (y) } \\
\text { (parte imaginária) }\end{array}$ & 46.399 & 48.956 & 50.239 & 50.881 \\
$\begin{array}{l}\text { EMQ (x normalizado) } \\
\text { (parte real) }\end{array}$ & 1.156 & 0.413 & 0.153 & 0.061 \\
$\begin{array}{l}\text { EMQ (y normalizado) } \\
\text { (parte imaginária) }\end{array}$ & 0.958 & 0.341 & 0.123 & 0.046 \\
$\Omega_{x}$ & 10.071 & 20.077 & 40.119 & 80.219 \\
(parte real) & 10.051 & 20.067 & 40.113 & 80.216 \\
$\Omega_{y}$ & & & \\
(parte imaginária) & & & & \\
\hline
\end{tabular}

Tabela (4.1): Tabela com resultados do erros médios quadráticos (EMQ) com e sem a normalização por compensação de energia.

A Figura 4.9 apresenta o primeiro experimento que ilustra a capacidade do método de tratar com contornos de imagens reais. A Figura 4.9(a) mostra o contorno de um caractere, enquanto na Figura 4.9(b) pode-se ver o contorno reconstruído depois da filtragem passa-baixas gaussiana para $\tau=8$. A Figura 4.9(c) apresenta a curvatura estimada para $\tau=8$, na qual pode-se perceber que os vértices puderam ser corretamente identificados. O método é capaz de identificar o ponto de curvatura máxima dentro da região arredondada, além de discriminar corretamente as regiões côncavas e as convexas em termos do sinal da curvatura.

Dentro do contexto da representação gráfica da curvatura multi-escala (ver Seção 3.4), uma das maneiras de visualizá-la é como uma superfície. Assim, o curvograma do contorno da Figura 4.9(a) é apresentado na Figura 4.9(d), sendo um detalhe mais próximo desse mesmo curvograma visto na Figura 4.9(e). 


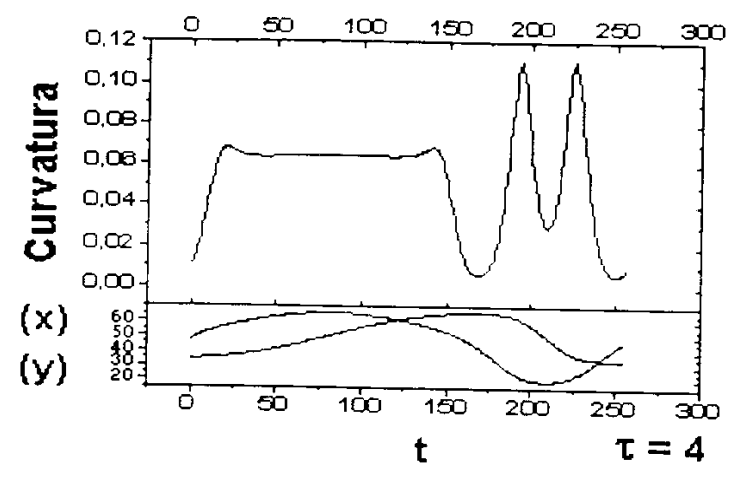

(a)

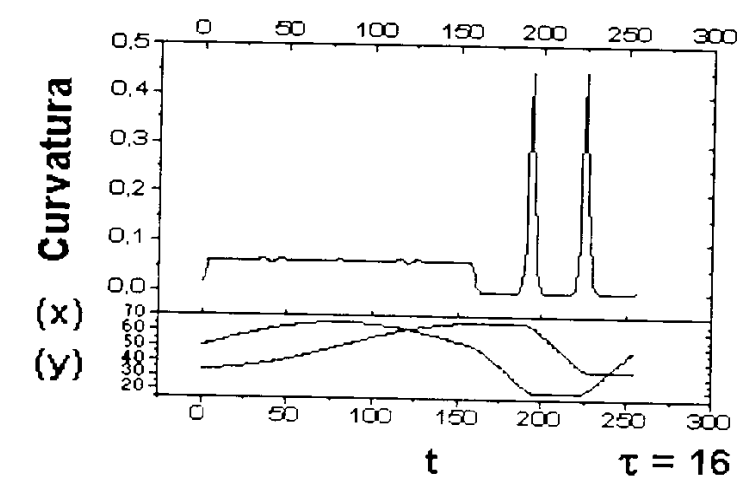

(c)

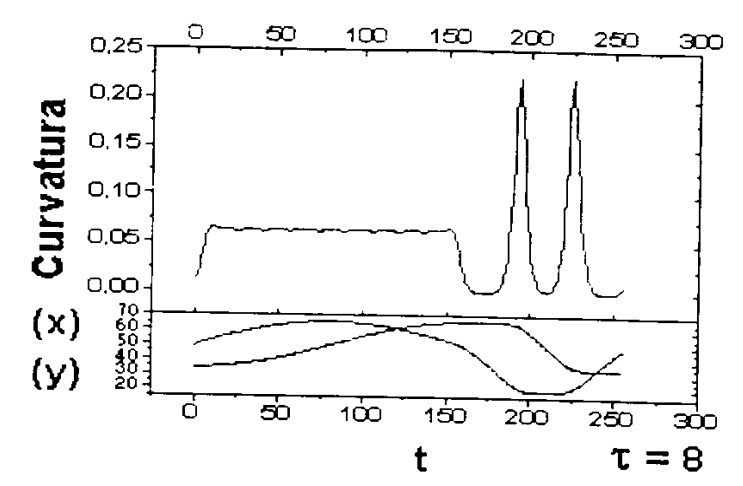

(b)

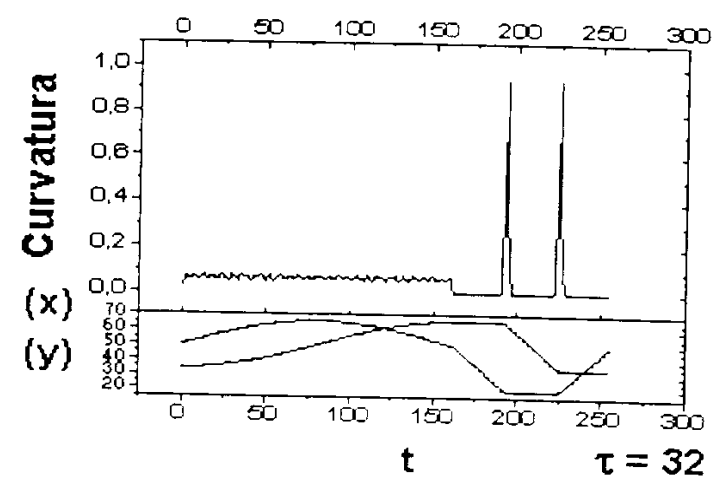

(d)

Figura (4.7): Efeitos da abordagem multi-escala no cálculo da curvatura.

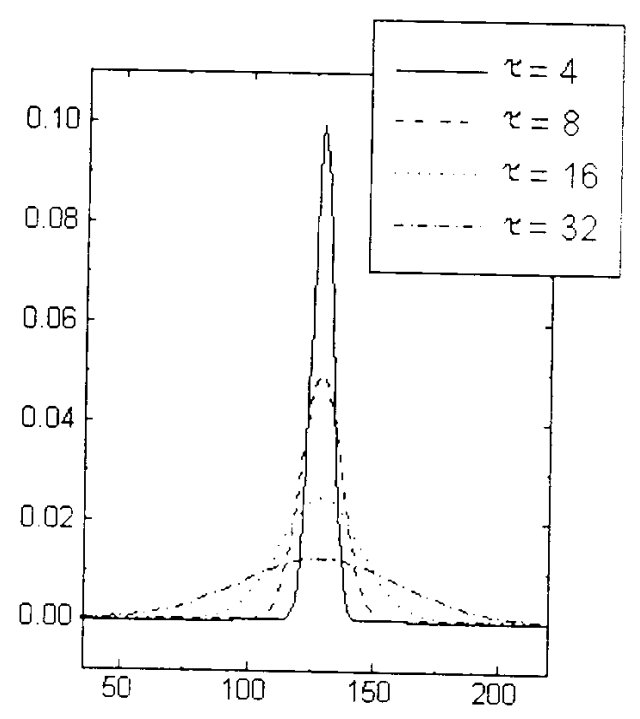

Figura (4.8): Algumas gaussianas de diferentes escalas. 


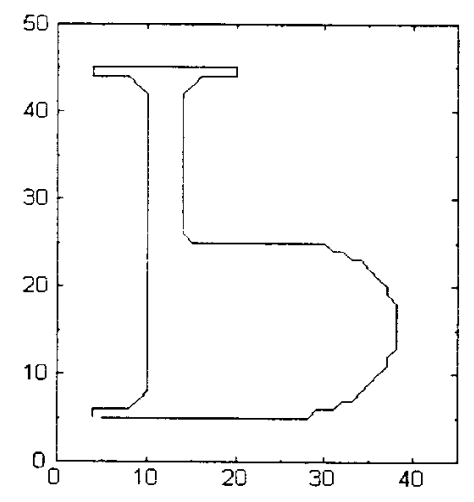

(a)

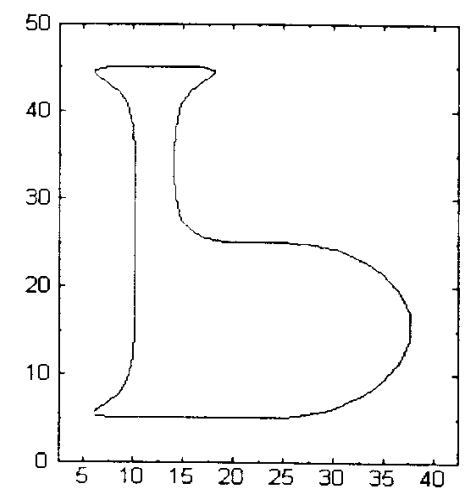

(b)

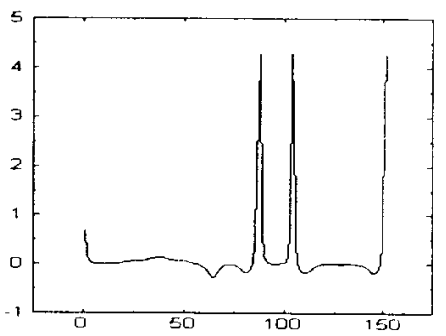

(c)

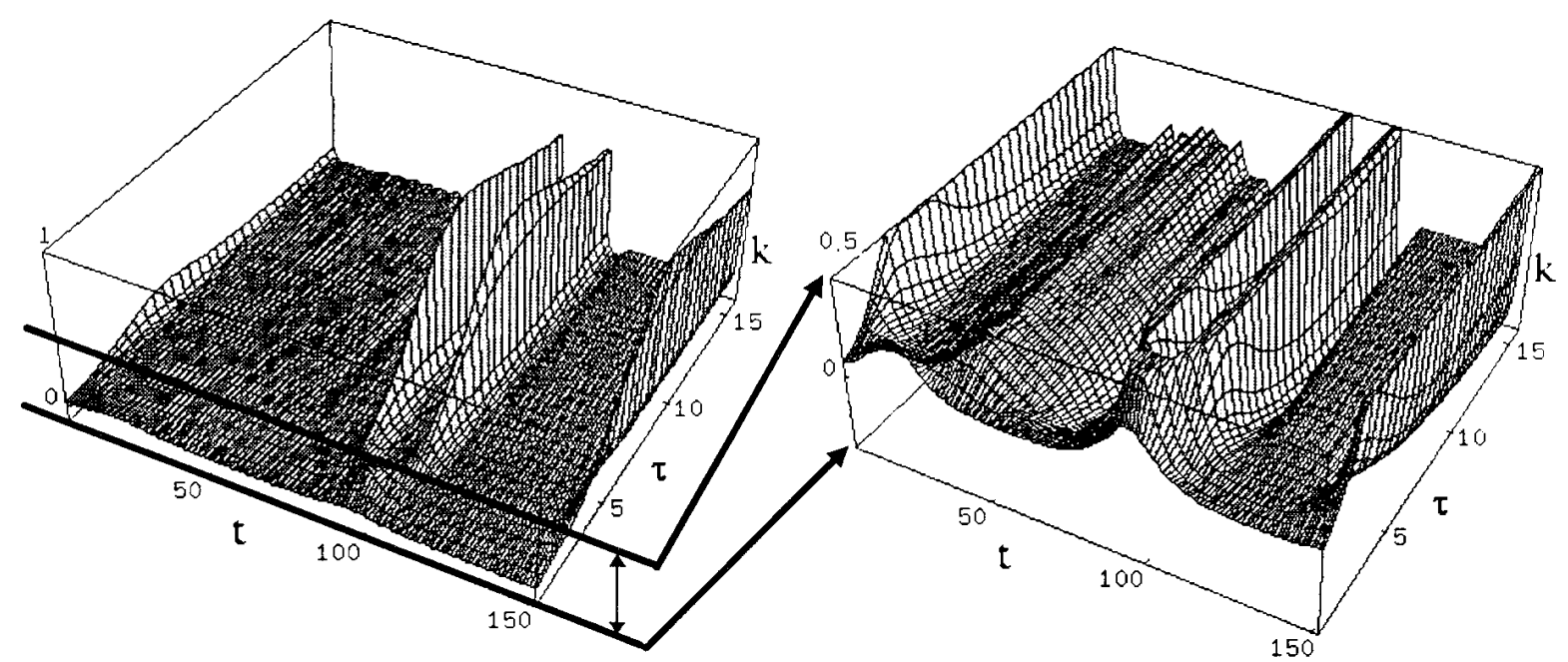

(d)

(e)

Figura (4.9): Exemplo da análise multi-escala de curvatura, incluindo o curvograma de um contorno real. 


\subsubsection{Avaliação da Precisão do Método}

omo já foi comentado antes, um aspecto para o qual procurou-se prestar uma atenção especial é o desempenho da técnica no que concerne à sua precisão na estimação da curvatura. O exemplo da Figura 4.5(a) já ilustra um dos testes que foram realizados nessa direção; da mesma forma, serão apresentados experimentos adicionais que avaliam, de maneira mais extensiva e completa, a precisão do método.

O próximo experimento discute o efeito das altas freqüências na estimação da

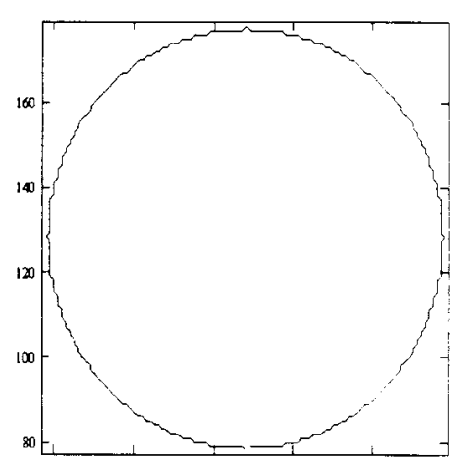

(a)

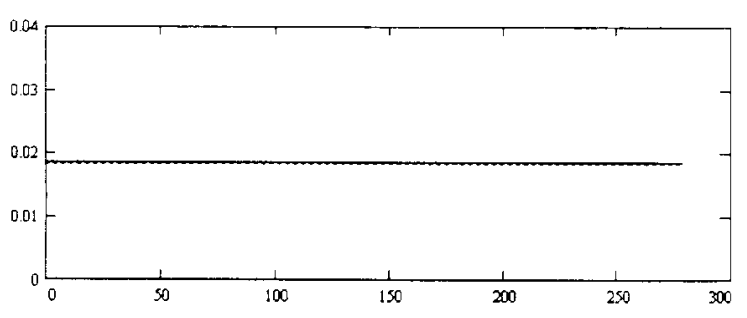

(b)

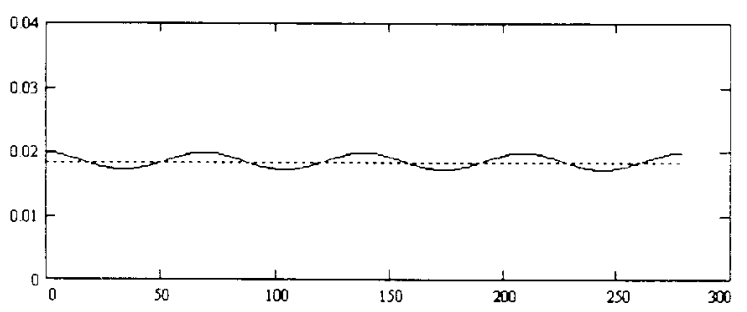

(d)

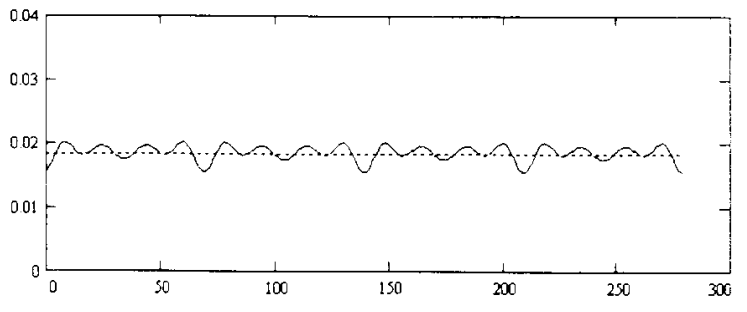

(f)

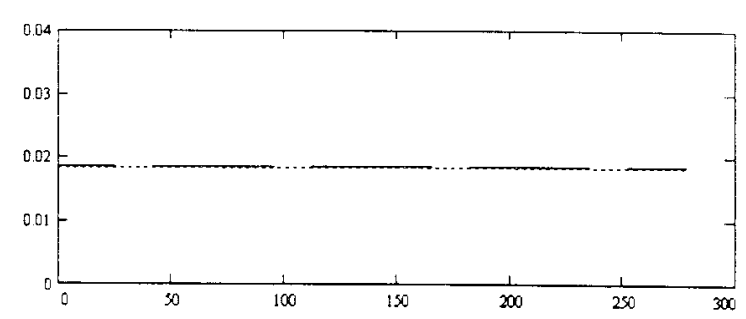

(c)

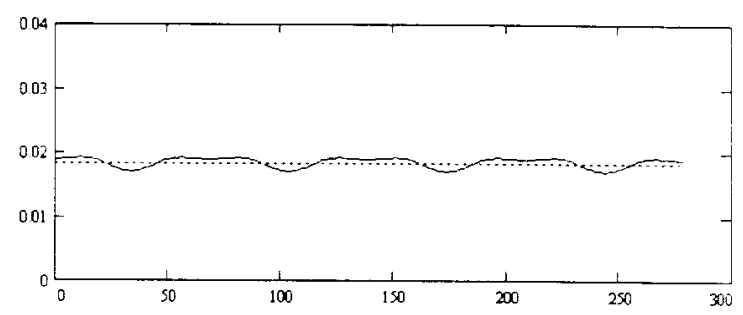

(e)

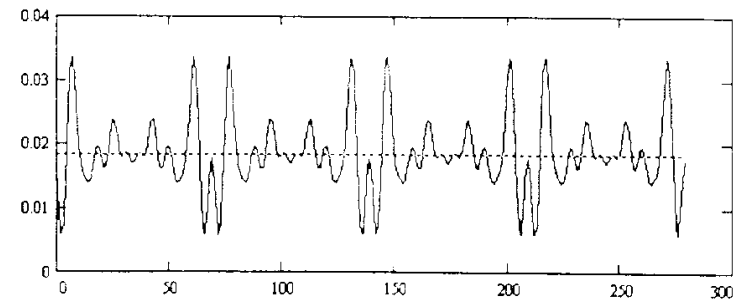

(g)

Figura (4.10): Estimação digital da curvatura de uma circunferência. 
curvatura. A Figura 4.10(a) mostra os resultados da estimação da curvatura de uma circunferência digital de raio igual a 50, o que significa que sua curvatura é igual a $1 / 50=0.02 \mathrm{em}$ todos os pontos. É importante notar que a circunferência foi obtida a partir de uma imagem digital, sendo corrompida com o tipo de ruído básico provindo de discretização. A série de gráficos vistos nas Figuras 4.10(b)-(g) mostra a curvatura analítica traçada em pontilhado e a curvatura estimada em escalas decrescentes. Na medida que a escala de observação diminui, a curvatura multi-escala começa a responder para as pequenas imperfeições da circunferência discreta, oscilando em torno da curvatura analítica 0.02 , o que reafirma a precisão do método. É também importante perceber que o efeito de contração do contorno, que deveria aumentar a curvatura, é completamente corrigido pela técnica de compensação de energia.

O próximo experimento trata da estimação da curvatura em formas livres, as quais modelam de maneira mais legitima as formas comumente encontradas em imagens reais. $O$ fato de ser impossível de se obter o valor exato da curvatura de contornos de imagens reais, a qual deve ser necessariamente usada como referência para uma comparação quantitativa, motivou a elaboração de uma série de testes em termos de uma curva gerada por B-splines [Mortenson, 1985]. Em primeiro lugar, um contorno foi gerado interativamente através da definição de uma série de pontos de controle ao longo do plano cartesiano. Uma vez que as B-splines são expressas em termos de expressões polinomiais analíticas, é possível o cálculo da curvatura exata em cada ponto ao longo do contorno. Uma curva B-spline é gerada a partir de uma combinação de uma série de funções "blending" $B_{j, r}$ a partir de um conjunto de pontos de controle $p_{j}$ [Mortenson, 1985]:

$$
C(t)=\sum_{j=1}^{n} p_{j} F B_{j, r}(t)
$$

em que $t$ é o parâmetro, $F B_{j, r}$ é a j-ésima função base de grau $r$-l e $p_{j}$ é o j-ésimo ponto de controle. Uma curva B-spline pode ser vista como a composição de um conjunto de segmentos de curva, sendo cada segmento determinado por um subconjunto seqüencial de pontos de controle e pelo grau da B-spline. Em particular, para as B-splines cúbicas $(r=4)$, tem-se que cada segmento $p_{j}(t)$ da curva pode ser reescrito na seguinte forma matricial:

$$
p_{j}(t)=\frac{1}{6}\left[\begin{array}{llll}
t^{3} & t^{2} & t & 1
\end{array}\right]\left[\begin{array}{cccc}
-1 & 3 & -3 & 1 \\
3 & -6 & 3 & 0 \\
-3 & 0 & 3 & 0 \\
1 & 4 & 1 & 0
\end{array}\right]\left[\begin{array}{c}
p_{j-1} \\
p_{j} \\
p_{j+1} \\
p_{j+2}
\end{array}\right]
$$


em que $p_{j}(t)=\left(x_{j}(t), y_{j}(t)\right), \quad 0 \leq t<1, \quad i=1,2, \ldots, n-2$. Essa expressão pode ser reescrita como:

$$
\begin{aligned}
& p_{j}(t)=\frac{1}{6}\left[\begin{array}{llll}
\left(-t^{3}+3 t^{2}-3 t+1\right) & \left(3 t^{3}-6 t^{2}+4\right) & \left(-3 t^{3}+3 t^{2}+3 t+1\right) & \left(u^{3}\right)
\end{array}\right]\left[\begin{array}{c}
p_{j-1} \\
p_{j} \\
p_{j+1} \\
p_{j+2}
\end{array}\right]= \\
& =\frac{1}{6}\left[\left(-t^{3}+3 t^{2}-3 t+1\right) p_{j-1}+\left(3 t^{3}-6 t^{2}+4\right) p_{j}+\left(-3 t^{3}+3 t^{2}+3 t+1\right) p_{j+1}+\left(t^{3}\right) p_{j+2}\right]
\end{aligned}
$$

A expressão acima define a forma paramétrica de cada segmento da curva Bspline de maneira bastante simples. Relembre que as derivadas de cada segmento de curva são definidas como:

$$
\begin{aligned}
& \dot{p}_{i}(u)=\left(\dot{x}_{i}(u), \dot{y}_{i}(u)\right) \\
& \ddot{p}_{i}(u)=\left(\ddot{x}_{i}(u), \ddot{y}_{i}(u)\right)
\end{aligned}
$$

A partir da expressão de $p_{j}(t)$ pode-se concluir facilmente que:

$$
\begin{aligned}
& \dot{p}_{j}(t)=\frac{1}{6}\left[\left(-3 t^{2}+6 t-3\right) p_{j-1}+\left(9 t^{2}-12 t\right) p_{j}+\left(-9 t^{2}+6 t+3\right) p_{j+1}+\left(3 t^{2}\right) p_{j+2}\right] \\
& \ddot{p}_{j}(u)=\frac{1}{6}\left[(-6 t+6) p_{j-1}+(18 t-12) p_{j}+(-18 t+6) p_{j+1}+(6 t) p_{j+2}\right]
\end{aligned}
$$

As expressões acima, em conjunto com a fórmula da curvatura dada pela Equação 4.1 permitem o cálculo analítico da curvatura de uma curva B-spline cúbica. Criou-se programa que aceita como entrada um conjunto de pontos de controle que são marcados pelo usuário sobre uma janela gráfica. Em seguida, o programa gera a curva B-spline cúbica correspondente com os dados em precisão de ponto-flutuante, a sua versão amostrada sobre uma imagem digital e os valores da curvatura analítica calculados conforme explicado nesta seção. É importante observar que a discretização espacial necessária para que o contorno fosse processado numericamente fez com que a curvatura digital estimada pelo novo método introduzido neste trabalho fosse comparada com a curvatura do ponto mais próximo da curva contínua. A avaliação quantitativa da precisão 


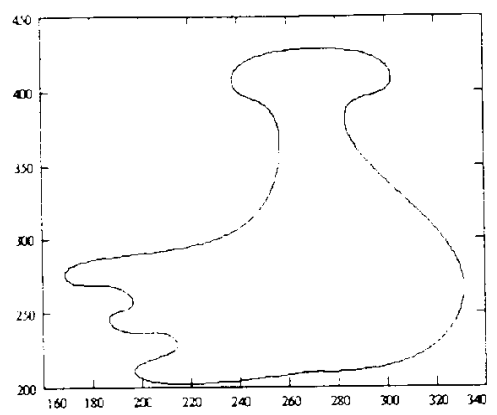

(a)

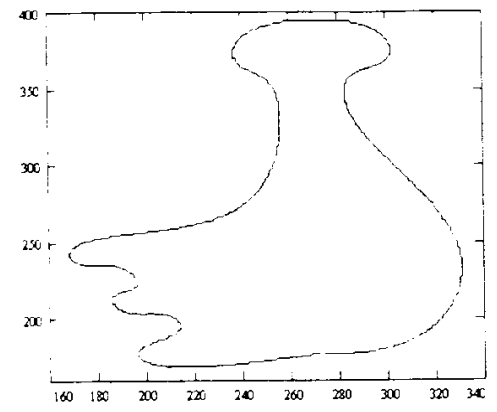

(b)

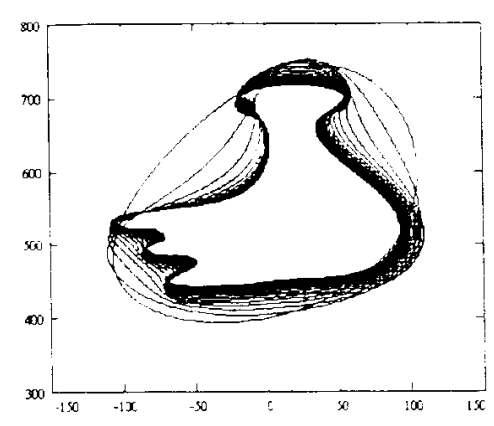

(c)

Figura (4.11): Curva B-spline usada para experimento do curvograma. da técnica foi realizada com auxílio do contorno apresentado na Figura 4.11(a), cuja versão amostrada pode ser observada na Figura 4.11(b). A Figura 4.11(c) mostra o morfograma (veja a Equação 4.13) da B-spline.

A curvatura analítica dessa curva B-spline é apresentada na Figura 4.12(a), enquanto a curvatura estimada é apresentada na Figura 4.12(b) $(\tau=40)$. Como pode ser visto claramente, o método é capaz de estimar com sucesso a curvatura analítica a partir da versão amostrada da curva. De fato, os maiores erros ocorrem nos picos de alta curvatura, devido à suavização provinda da filtragem gaussiana. Esse fato é melhor visualizado no gráfico da Figura 4.12(c), no qual as duas curvaturas, analítica e estimada, foram sobrepostas e uma região desse gráfico foi ampliada (na região do pico de curvatura positiva para $n$ entre 70 e 100). Barras de erros foram acrescentadas entre as duas curvaturas, deixando claro que o erro aumenta em torno do pico mas não inviabiliza a capacidade do método de detectar vértices, uma vez que a curvatura estimada também detecta tais pontos dominantes como máximos locais de grande magnitude.

Diferentes medidas de erros foram usadas para avaliar a precisão do método de estimação digital de curvatura. Essas medidas podem ser vistas na série de diagramas apresentados nas Figuras 4.13(a)-(d). A Figura 4.13(a) apresenta a evolução do EMQ em função de $\tau$, a qual indica que o EMQ é otimizado para $25<\tau<45$. Valores menores da largura de banda do filtro (portanto, escalas maiores: $\tau=1 / a$ ) tendem a suavizar demasiadamente os pequenos detalhes do contorno, enquanto valores maiores não atenuam suficientemente o ruído presente nas altas freqüências. $O$ erro quadrático pontoa-ponto ao longo do sinal da curvatura é apresentado na Figura 4.13(b), enquanto o erro quadrático relativo ${ }^{9}$ ponto-a-ponto é mostrado na Figura 4.13(c), indicando claramente um bom desempenho. As maiores taxas de erro, como já foi comentado, se encontram em torno dos pontos de alta curvatura. Finalmente, a Figura 4.13(d) apresenta o gráfico da correlação entre as curvaturas esperada e estimada, ilustrando a alta correlação entre ambas em torno das escalas com melhor desempenho.

\footnotetext{
${ }^{9}$ O erro relativo foi calculado como sendo |(curvatura_esperada - curvatura_estimada)/ curvatura_esperada
} 


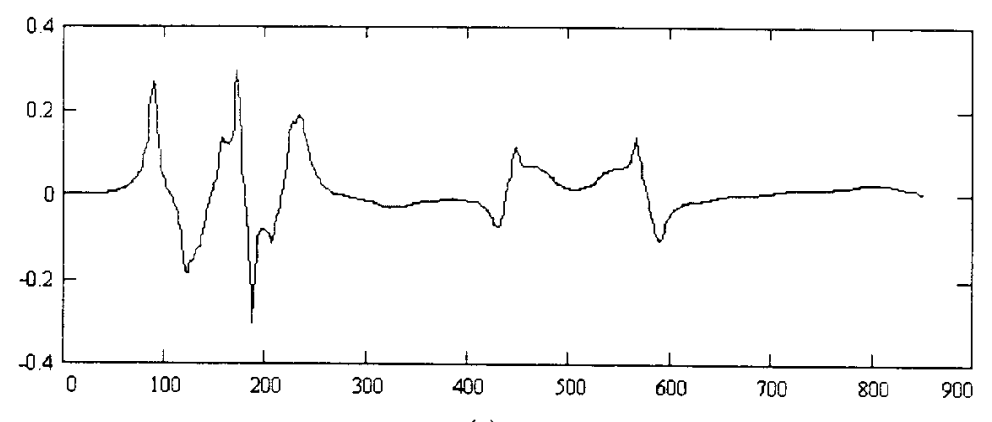

(a)
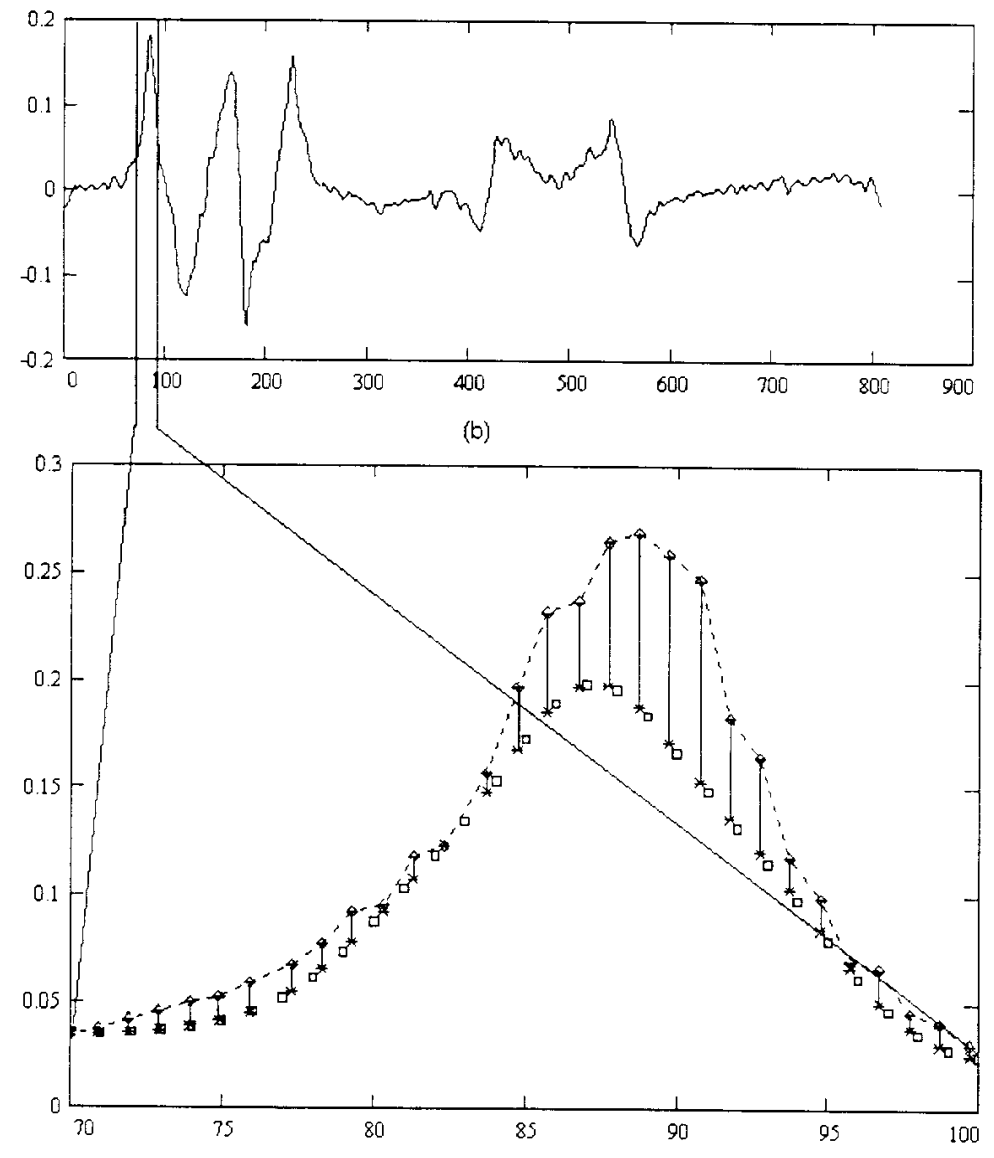

(c)

Figura (4.12): Curvatura analítica, estimada e barra de erros entre as duas. 


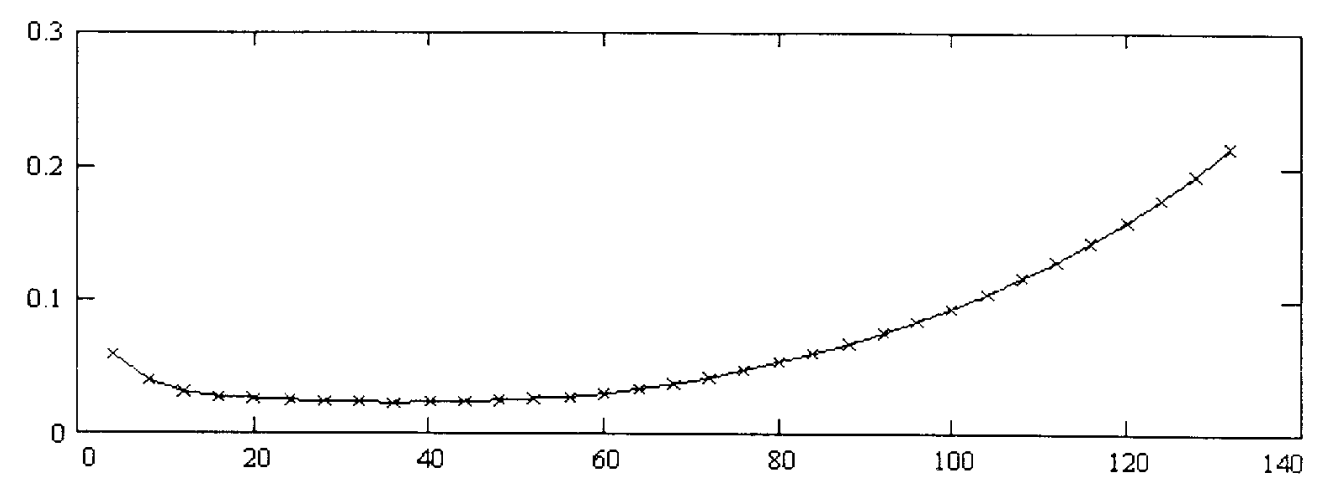

(a)

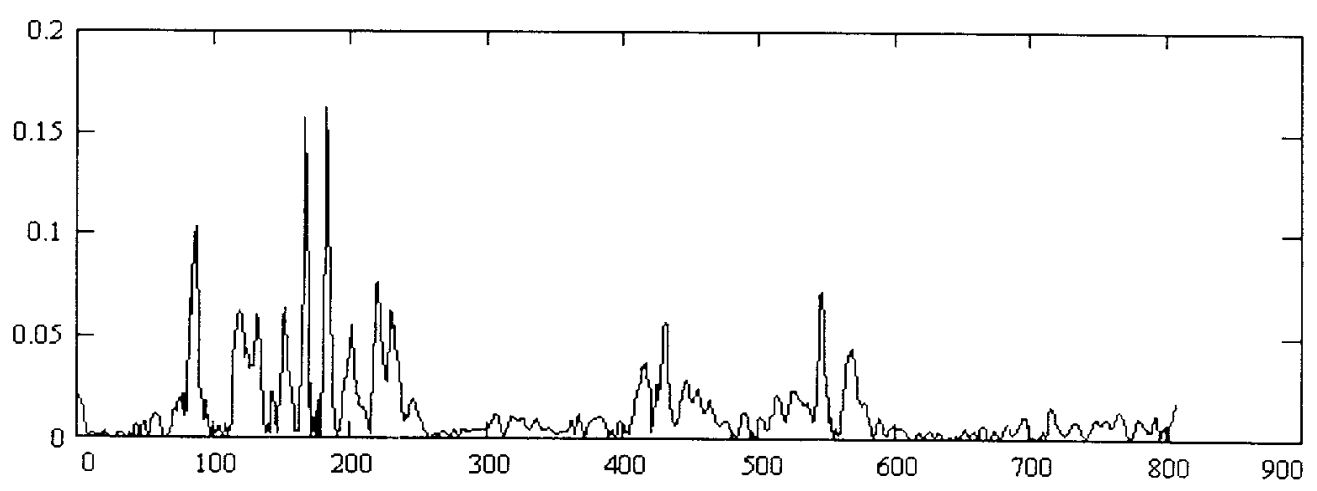

(b)

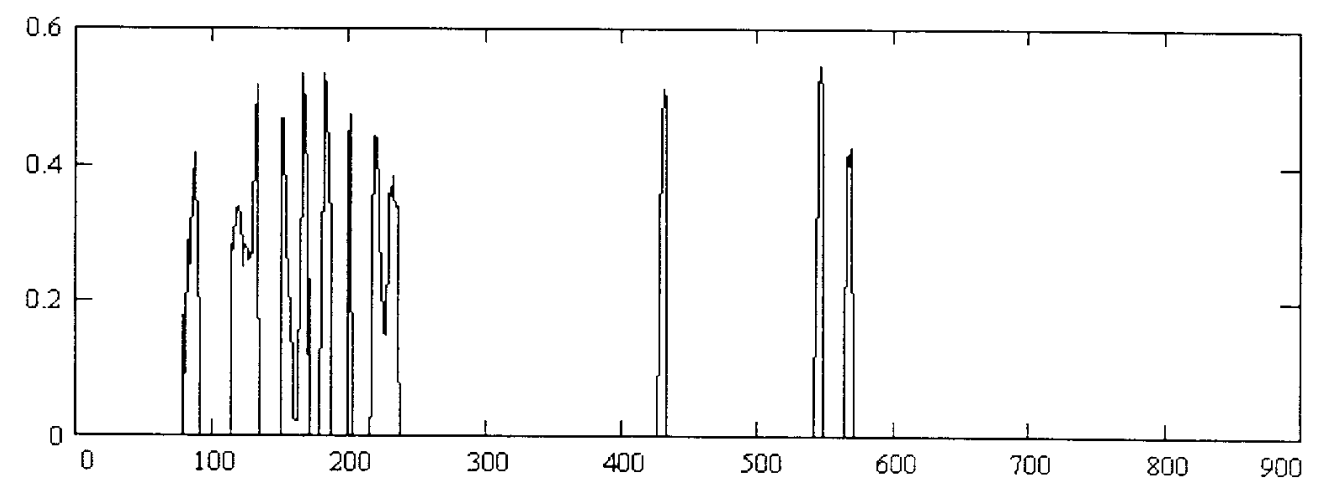

(c)

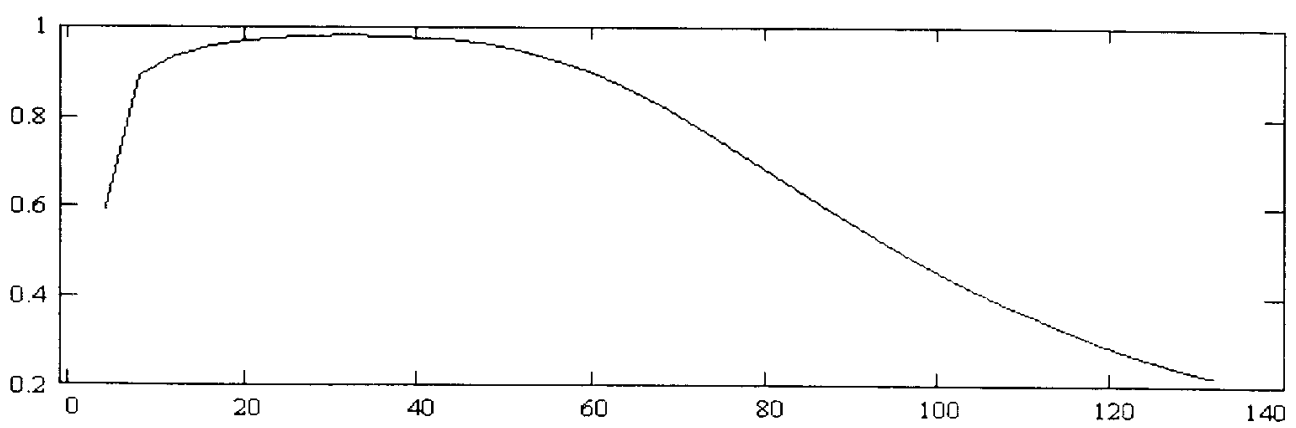

(d)

Figura (4.13): Série de medidas de erros entre a curvatura analítica e a estimada. 


\subsubsection{Detecção de Vértices}

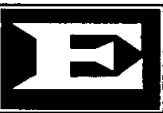

sta seção ilustra a capacidade do método de estimação de curvatura para a detecção de pontos dominantes.

A detecção de vértices pode ser realizada escolhendo-se uma escala apropriada a partir do curvograma, seguido de uma busca por máximos locais do valor absoluto de curvatura. O Capítulo 7 utiliza essa técnica na geração semi-automática de dendrogramas, apresentado detalhes mais específicos sobre sua implementação. A técnica proposta foi aplicada ao contorno extraído da imagem real apresentada na Figura 4.14. Esse contorno contém 1479 pontos, tendo sofrido distorções típicas devido à iluminação não-uniforme e contendo uma série de diferentes características geométricas como vértices e segmentos retos e curvos. Com o intuito de avaliar o método, os resultados foram comparados com os resultados da detecção de vértices por uma outra técnica. Assim, a Figura 4.14(b) apresenta os resultados de detecção de vétices pela técnica proposta em [Medioni \& Yasumoto, 1987], enquanto que a Figura 4.14(a) apresenta os resultados utilizando a técnica descrita nesta tese. Deve ser observado que a técnica proposta em [Medioni \& Yasumoto, 1987] depende de vários parâmetros, e o resultado apresentado na Figura 4.14(b) foi obtido a partir da melhor configuração obtida pelo autor para esses parâmetros. Uma comparação desses resultados ilustra que a técnica apresentada nesta tese apresentou melhores resultados.

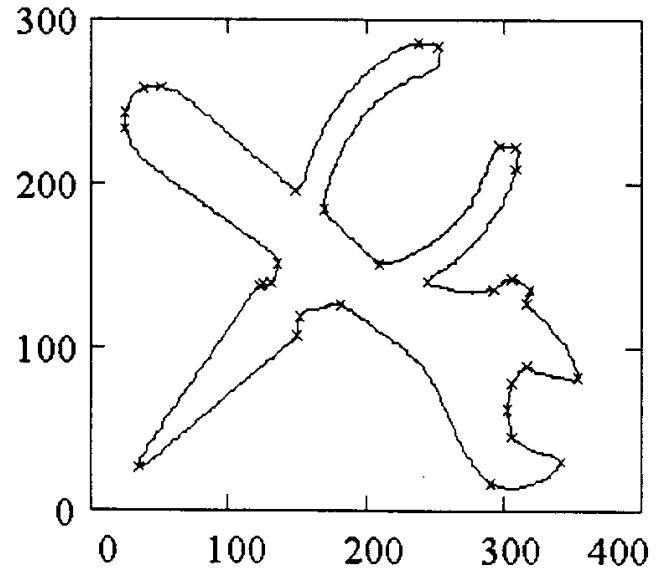

(a)

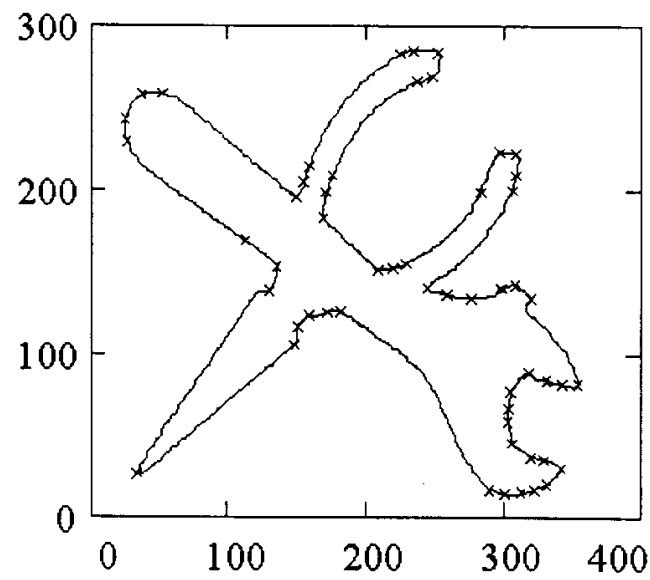

(b)

Figura (4.14): (a) Detecção de vértices usando o método desta tese; (b) Detecção de cantos usando o método proposto em [Medioni \& Yasumoto, 1987]. 


\section{Capítulo 5 - Análise de Formas usando Wavelets}

O que o mar sim aprende do canavial: a elocução horizontal do seu verso; a geórgica de cordel, ininterrupta, narrada em voz e silêncio paralelos. O que o mar não aprende do canavial: a veemência passional da preamar; a mão-de-pilão das ondas na areia, moída e miúda, pilada do que pilar.

O que o canavial sim aprende do mar: o avançar em linha rasteira da onda o esparaiar-se minucioso, de líquido, alagando cova a cova onde se alonga. O que o canavial não aprende do mar: o desmedido do derramar-se da cana; o comedimento do latifúndio do mar, que menos alastradamente se derrama.

João Cabral de Melo Neto, O Mar e o Canavial, 1962-65.

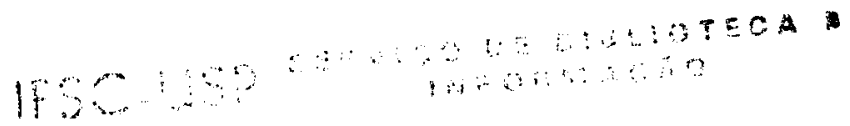




\section{ANÁlise de Formas usando WaVELETS}

\subsection{INTRODUÇÃO}

-

Capítulo 4 apresentou o primeiro esquema de caracterização multi-escala de contornos desenvolvido nesta tese, ou seja, aquele baseado no curvograma. Este capítulo dá continuidade ao trabalho introduzindo a representação- $W$, um novo conceito de representação e análise multi-escala de contornos baseado na transformada contínua em wavelets. Assim, este capítulo inclui a definição da representação- $W$, as propriedades que a tornam útil para a análise de formas, alguns dos principais tipos de wavelets que podem ser adotados e as informações que podem ser extraídas a partir do contorno. Este capítulo introduz ainda, de maneira análoga à representação- $W$, a transformada de Gabor de um contorno, ilustrando como esse tipo de transformada tempo-freqüuência também pode ser usada em análise de formas. Na verdade, esse tipo de transformada apresenta resultados bastante semelhantes aos da transformada em wavelets com a wavelet de Morlet, uma vez que ambas diferem apenas em relação ao fato de que o envelope do núcleo da transformada de Gabor permanece constante ao longo do eixo da freqüência, enquanto o da wavelet de Morlet se adapta, possuindo maior resolução temporal para análise de altas freqüências. Essa semelhança entre as duas transformadas ilustra que a transformada de Gabor é mais adequada para a análise de padrões periódicos locais que possam ocorrer ao longo do contorno.

\subsection{Considerações Preliminares}

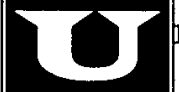

m novo método de análise multi-escala de formas utilizando a transformada contínua $1 \mathrm{D} \mathrm{em}$ wavelets foi introduzido pelo autor desta tese e colaboradores em [Antoine et al., 1996] e complementado em [Antoine et al., 1997], a partir de uma sugestão preliminar desenvolvida em [Campos et al., 1994]. O novo método se baseia na detecção de características da forma através da análise da chamada representação- $W$ ("W-representation"), definida como a transformada contínua em wavelets da curva parametrizada que define o contorno de interesse (veja o Capítulo 2). A representação- $W$ é especialmente útil para análise de formas em visão devido aos fundamentos matemáticos da teoria das wavelets que fornecem diversas propriedades geralmente requeridas pelos esquemas de representação de formas. Diferentes tipos de informação 
podem ser extraídos dos contornos através da representação- $W$ e este capítulo apresenta métodos para:

1. Deteç̧ão de vértices e outros pontos dominantes;

2. Caracterização de escalas naturais;

3. Análise fractal de curvas.

A eficiência desses algoritmos deve-se ao fato de que a transformada em wavelets é especialmente adequada para:

- Detecção e caracterização de singularidades em sinais [Grossmann, 1988; Mallat \& Hwang, 1992];

- Extração de freqüências instantâneas [Torrésani, 1995];

- Análise fractal e multifractal de sinais [Arnèodo et al., 1995; Holschneider, 1995; Muzy et al., 1994].

$\mathrm{Na}$ verdade, dois pontos merecem ser enfatizados sobre as considerações apresentadas na Seção 1.4: (1) estruturas importantes nas formas estão geralmente associadas a eventos transientes do objeto; (2) eventos diferentes podem ocorrer em escalas diferentes. Vale notar que tais considerações podem ser estendidas para o problema geral de visão [Koenderink, 1984; Marr, 1982], de processamento de sinais e de imagens [Mallat, 1989; Meyer, 1992; Witkin, 1983]. A teoria das wavelets tornou-se uma ferramenta matemática natural para tratar esses problemas, unificando diversas abordagens desenvolvidas separadamente [Mallat, 1996]. Essa teoria já foi aplicada a uma grande variedade de problemas como à análise fractal [Arnèodo et al., 1995; Holschneider, 1995], à compressão e análise de imagens [Rioul \& Vetterli, 1991], à detecção de bordas [Grossmann, 1988; Mallat \& Hwang, 1992], à discriminação de texturas [Mallat, 1996] e à modelagem de campos receptivos [Costa, 1995b; Gaudart et al., 1993]. Particularmente no caso de representação e análise de formas, as wavelets foram aplicadas para a codificação de contornos [Chassery \& Waku, 1993; Chuang \& Kuo, 1996; Kashi et al., 1996; Wunsch \& Laine, 1995] (geralmente wavelets discretas ortonormais), detecção de vértices diretamente sobre a imagem 2D [Antoine et al., 1993; Chen et al., 1995] ou a partir da representação tangencial da curva [Lee et al., 1993; Lee et al., 1995; Nakamura \& Yoshida, 1994], e geração de descritores para reconhecimento de objetos [Tieng \& Boles, 1995; Tieng \& Boles, 1997a; Tieng \& Boles, 1997b]. Uma característica atrativa da representação tempo-escala das wavelets reside em sua habilidade em discriminar eventos transientes no sinal, evitando que modificações locais afetem toda a representação. Tal característica é altamente desejável para a análise de formas, em que diferentes fatores, como oclusão parcial, podem afetar localmente a configuração da forma. Um dos principais problemas com representações globais de formas, como os descritores de Fourier, é que tais eventos afetam a representação como um todo. 
Em um certo sentido, pode-se concluir que a representação- $W$ consiste em uma abordagem unificada para todos esses problemas clássicos em análise de formas. Este capítulo também discute diferentes propriedades da transformada em wavelets que são úteis para a análise de contornos. Além disso, algoritmos para a análise da representação$W$ a partir de seu esqueleto, isto é, as linhas de máximos locais do módulo da representação- $W$, são introduzidos.

\subsection{A REPRESENTAÇÃO-W}

eja $u(t)$ o sinal complexo representando um contorno, em que $t$ define uma parametrização por tamanho de arco da curva correspondente (ver Seção 2.3). A representação- $W$ de $u(t)$ é definida como a transformada contínua em wavelets desse sinal, isto é [Kaiser, 1994]:

$$
\begin{aligned}
U[\psi, u](b, a)=U_{\psi}(b, a) & =\frac{1}{\sqrt{a}} \int_{-\infty}^{\infty} \Psi^{*}\left(\frac{1-b}{a}\right) u(t) d t \\
& =\sqrt{a} \int_{-\infty}^{\infty} \Psi^{*}(a f) \hat{u}(f) e^{i 2 \pi f t} d f
\end{aligned}
$$

em que $b \in \mathbb{R}$ representa o parâmetro de translação, enquanto que $a>0$ é o parâmetro de dilatação da transformada contínua em wavelets. $O$ espaço de parâmetros é definido como o semi-plano superior do $\mathbb{R}^{2}, H H=\{(b, a) \mid b \in \mathbb{R}, a>0\}$. A wavelet analisadora $\psi(t)$ deve ser de média nula, o que corresponde à condição de admissibilidade simplificada. Tal condição garante a existência de uma fórmula de reconstrução exata definida por:

$$
u(t)=c_{\psi} \int_{-\infty}^{\infty} \int_{-\infty}^{\infty} a^{-1 / 2} U_{\psi}(b, a) \psi\left(\frac{t-b}{a}\right) \frac{d b d a}{a^{2}}
$$

em que a constante de normalização $c_{\psi}$ depende apenas da wavelet analisadora [Rioul \& Duhamel, 1992].

A existência da fórmula de reconstrução definida pela Equação 5.3 significa que o sinal $u(t)$ é expandido, de maneira inversivel, em termos das wavelets $\psi_{(b, a)}(t)=a^{-1 / 2} \psi\left(a^{-1}(t-b)\right)$, as quais são cópias transladadas e escalonadas da wavelet analisadora (ou "wavelet mãe") $\psi$. 
Além da condição de admissibilidade, duas propriedades são usualmente requeridas das wavelets analisadoras: que elas sejam progressivas (isto é, $\psi(f)$ deve ser real e $\psi(f)=0, f \leq 0)$ e que possuam um certo número de momentos nulos, isto é:

$$
\int t^{j} \psi(t) d t=0, \quad j=0,1, \ldots, K
$$

A razão para se requerer a propriedade dos momentos nulos é a seguinte: a wavelet $\psi(t)$ e sua transformada de Fourier $\psi(f)$ devem ser bem localizadas em seus respectivos domínios (respeitando-se o princípio da incerteza). Combinando isto com o fato de que a transformada contínua em wavelets (Equação 5.1) representa uma convolução do sinal $u(t)$ com uma função de média zero, pode-se notar que a transformada leva a uma análise com largura de banda relativamente constante, $\Delta f / f=$ constante, fazendo com que a transformada em wavelets seja especialmente bem adaptada para a análise de singularidades. A imposição de momentos nulos acarreta um melhoramento dessa análise, visto que a transformada torna-se "cega" a polinômios de graus menores ou iguais a $K$, particularmente às partes regulares do sinal.

A representação- $W$ possui as seguintes propriedades interessantes sob o ponto de vista de análise de formas [Kashi et al., 1996; Mokhtarian \& Mackworth, 1992]:

1. Unicidade: Já que a transformada em wavelets pode ser invertida, a representação- $W$ de uma forma é única, e duas formas diferentes possuem representações- $W$ diferentes, acarretando implicações importantes do ponto de vista de reconhecimento de formas;

2. Invariância a transformações geométricas: A partir do princípio da superposição e das propriedades de covariância da transformada contínua em wavelets [Holschneider, 1995], pode-se mostrar que a representação- $W$ é invariante às seguintes transformações geométricas:

- Translação: A translação de um objeto na imagem por um vetor $\underline{v}=\left(x_{0}, y_{0}\right)$ eqüivale à soma da constante complexa $z=x_{0}+i y_{0}$ ao sinal $u(t)$. Essa operação não afeta a representação- $W$ (exceto pelas diferenças de amostragem na grade e pré-processamento para a extração da curva), pois:

$$
U[\psi, u(t)+z]=U[\psi, u(t)]+U[\psi, z]=U[\psi, u(t)], \quad z \in \mathbb{C}
$$

- Escalonamento: O escalonamento homogêneo (ou isotrópico) de uma forma por uma constante $C$ altera a magnitude e a parametrização de $u(t)$. Nesse caso, a representação- $W$ é covariante a essa transformação, visto que: 


$$
U\left[\psi, c_{1} u\left(t / c_{2}\right)\right](b, a)=c_{1} U[\psi, u(t)]\left(b / c_{2} . a / c_{2}\right), c_{1}, c_{2} \in \mathbb{R}^{+}
$$

Se a parametrização por tamanho de arco for adotada, então $c=c_{1}=c_{2}$ e o fator de magnificação $C$ pode ser estimado (ver Capítulo 6).

- Rotação: A rotação de um objeto na imagem por um ângulo $\theta$ geralmente acarreta duas alterações na representação da forma pelo sinal complexo $u(t)$. Em primeiro lugar, o sinal $u(t)$ é multiplicado por $e^{i \theta}$, seguido de uma translação na parametrização por uma constante $t_{0}$ (em virtude de uma mudança na origem da parametrização e à adoção de um novo ponto inicial a partir do qual o contorno do objeto é extraído). Essas transformações fazem com que a representação- $W$ seja alterada da seguinte maneira:

$$
U\left[\psi, e^{i \theta} u\left(t-t_{0}\right)\right](b, a)=e^{i \theta} U[\psi, u(t)]\left(b-t_{0}, a\right), \quad t_{0} \in \mathbb{R}, \theta \in[0,2 \pi)
$$

3. Tolerância a modificações locais na forma: Se uma wavelet de suporte compacto for empregada, então modificações locais na forma afetarão apenas localmente a representação- $W$ (mais especificamente, dentro do cone de influência). Essa propriedade é particularmente importante para o caso em que oclusões parciais venham a ocorrer. Tal propriedade é uma das vantagens da representação- $W$ em relação a representações globais como os descritores de Fourier.

4. Eficiência e facilidade de implementação: A computação da representação- $W$ envolve o cálculo de convoluções uni-dimensionais circulares (uma vez que contornos fechados geram sinais periódicos), que podem ser consideradas operações padrão para os pesquisadores em processamento de imagens e sinais. Além disso, é importante enfatizar que o conjunto de convoluções requerido para o cálculo da transformada em wavelets é altamente correlacionado em relação às escalas adjacentes, uma vez que as wavelets são obtidas por dilatação, fato este que pode ser aproveitado para uma melhoria na performance dos algoritmos que calculam a representação- $W$. Entretanto, apesar da existência de algoritmos rápidos para o cálculo da transformada em wavelets, vale notar que a representação- $W$ pode ser facilmente obtida a partir dos descritores de Fourier de um contorno e da aplicação da versão discretizada da Equação 5.2. Em outras palavras, é suficiente calcular a versão discretizada da transformada de Fourier da wavelet analisadora, multiplicá-la pelos descritores de Fourier do contorno a ser analisado e calcular a transformada inversa de Fourier (via FFT). 


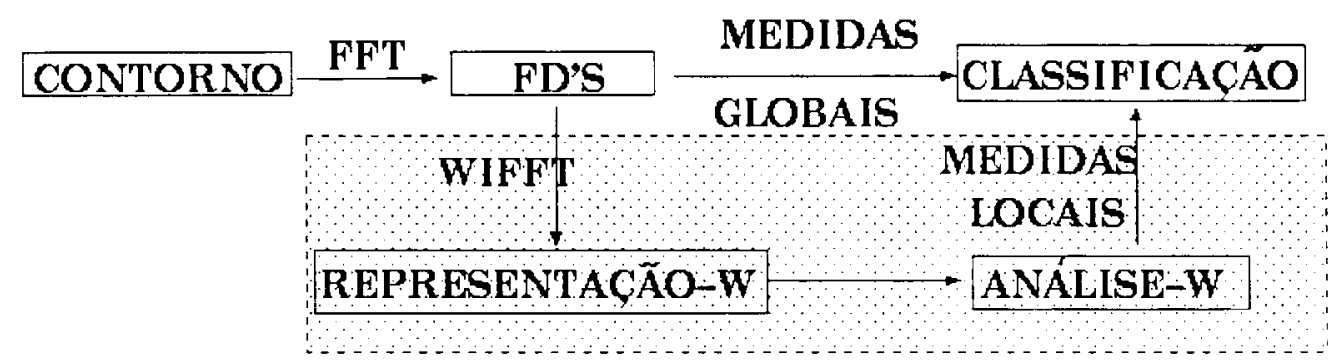

Figura (5.1): Arquitetura de um sistema de análise de formas usando características globais (FDs) e locais.

A Figura 5.1 apresenta a arquitetura de um sistema de classificação que adota o cálculo da representação- $W$ explicado, em que a aplicação da Equação 5.2 utilizando FFT inversa é denotada por WIFFT. É bem conhecido que os descritores de Fourier representam um dos métodos de representação de formas mais usados, possuindo, ao mesmo tempo, a vantagem de ser facilmente implementável e a desvantagem de falhar na descrição de eventos locais no contorno. Portanto, a arquitetura apresentada na Figura 5.1 possui a qualidade de incorporar as vantagens dos descritores de Fourier, fornecendo um mecanismo para a detecção de eventos locais importantes no contorno e solucionando, assim, um grande problema de representações globais de formas.

O cálculo da representação- $W$ de um contorno típico possuindo em torno de 1000 pontos, para 512 escalas, leva aproximadamente 15 segundos em uma estação Digital AlphaStation 200 (multi-usuário e "time-sharing"). Por outro lado, é importante salientar que a detecção de algumas características importantes (como vértices) pode ser realizada em uma versão bem mais sub-amostrada (na variável de escala a) da representação- $W$, e que bons resultados experimentais foram obtidos amostrando-se o parâmetro $a$ em 16 pontos. Em tal caso, a representação- $W$ pode ser calculada em menos de 1 segundo. A arquitetura discutida apresenta ainda a vantagem adicional de permitir a extração paralela de diferentes características locais e diferentes wavelets analisadoras, que podem ser integradas pelo procedimento de reconhecimento. É também importante comentar alguns aspectos ligados à amostragem do parâmetro de escala em relação aos três métodos de análise de formas que serão introduzidos neste capítulo (deteç̧ão de pontos dominantes, caracterização de escalas naturais e análise fractal).

Já foi observado que, embora a determinação dos parâmetros envolvidos na estimação da transformada contínua em wavelets (ou seja, as escalas mínima e máxima e o número de amostras no parâmetro $a$ da transformada) não seja crítica, alguns cuidados devem ser tomados, principalmente no caso da análise fractal. A análise de objetos fractais envolve, em um certo sentido, a análise de um conjunto de estruturas auto-similares (de uma maneira determinística ou estatística) através de diferentes escalas. Além disso, para objetos construídos com um número finito de iterações, o que é o caso de qualquer experimento numérico, tais estruturas 
fractais ocorrem em um domínio limitado de escalonamento, e a informação associada à estrutura fractal do objeto deve ser medida dentro dessa região de escalonamento. Nos experimentos que foram realizados, os parâmetros foram definidos de maneira que as wavelets de escalas menores cobrissem, aproximadamente, 5 pontos (o que significa que a wavelet centrada em $u\left(t_{0}\right)$ pode "enxergar" o trecho da curva entre $u\left(t_{0-2}\right)$ e $\left.u\left(t_{0+2}\right)\right)$, enquanto as wavelets de escalas maiores cobrissem entre $1 / 4$ e $1 / 3$ do contorno. Em relação ao número de pontos amostrados ao longo do eixo $a$, os experimentos de análise fractal foram realizados com 128 ou 256 pontos amostrados, enquanto os outros dois casos (detecção de pontos dominantes e escalas naturais) puderam ser resolvidos com um número menor de pontos (em torno de 64). Porém, o aumento do número de amostras em geral permite um melhoramento na precisão dos resultados, um fato que deve ser levado em consideração na implementação final, juntamente com outras características práticas, como o sistema computacional disponível e o tamanho dos contornos.

\subsection{Escolha da WAVELet ANalisadora}

omo pode ser percebido a partir de sua definição, a transformada em wavelets é determinada unicamente a partir da escolha da wavelet analisadora $\psi$. Esta seção apresenta e discute dois exemplos de wavelets comumente usadas em análise de sinais: uma wavelet definida como uma derivada da função gaussiana e a wavelet de Morlet.

\subsubsection{As Derivadas da Gaussiana}

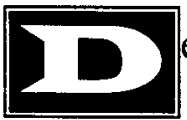

entro do contexto de deteç̧ão de bordas, David Marr introduziu a segunda derivada da gaussiana como um filtro para a localização dos cruzamentos por zero referentes a bordas em diferentes escalas na imagem [Marr \& Hildreth, 1980]. O filtro introduzido por Marr é hoje usado como uma das wavelets mais populares, conhecida como wavelet de Marr ou chapéu mexicano:

$$
\psi_{g}^{(2)}(t)=(2 \pi)^{-1 / 2}\left(t^{2}-1\right) e^{-t^{2} / 2} \Leftrightarrow \psi_{g}^{(2)}(f)=-(2 \pi f)^{2} e^{-f^{2} / 2}
$$

Esta é uma wavelet real e não-progressiva, possuindo dois momentos nulos e não respondendo, portanto, a componentes constantes e/ou lineares do sinal (daí sua eficiência na análise de singularidades).

Uma generalização bastante explorada em análise de sinais é a de tomar uma derivada arbitrária da gaussiana como wavelet [Grossmann et al., 1989; Arnèodo et al., 1995]: 


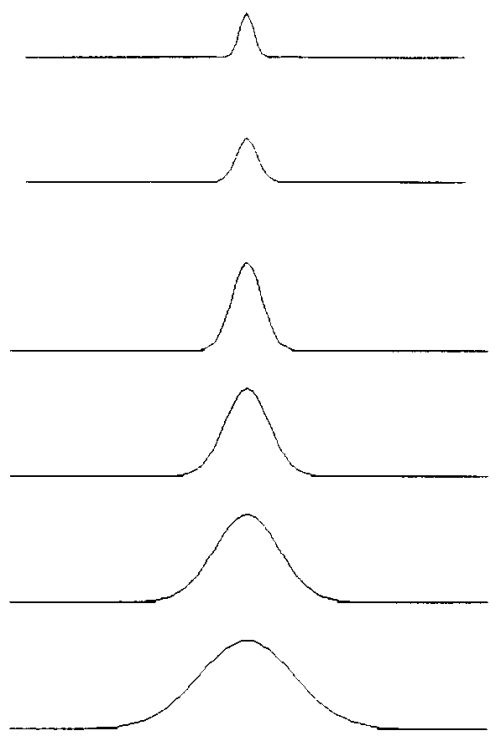

(a)

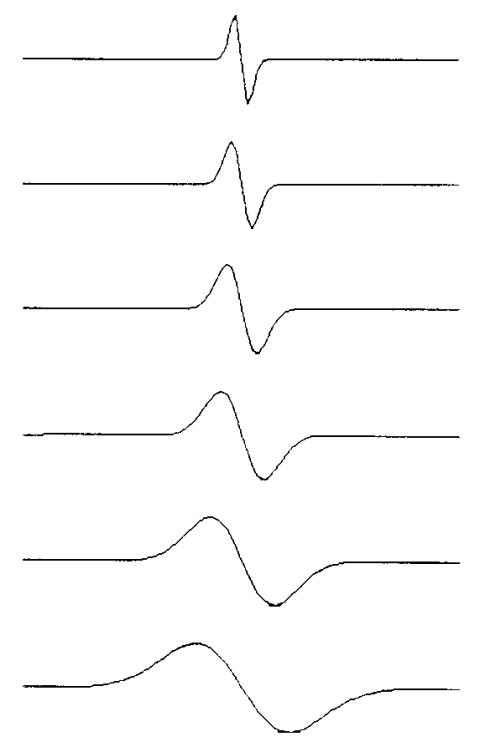

(b)

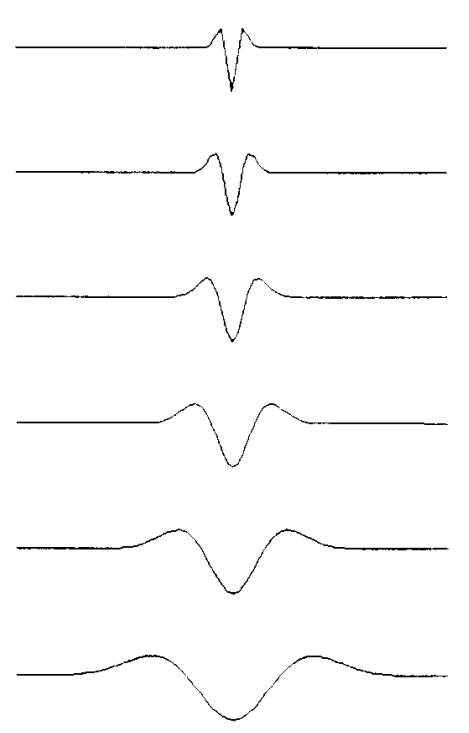

(c)

Figura (5.2): (a) Gaussianas em diferentes escalas, e suas respectivas primeira (b) e segunda (c) derivadas.

$$
\psi_{g}^{(j)}(t)=\frac{d^{j} g(t)}{d t^{j}} \Leftrightarrow \psi_{g}^{(j)}(f)=(i 2 \pi f)^{j} g(f)
$$

A Figura 5.2 apresenta a gaussiana, sua primeira e segunda derivadas para uma série de diferentes escalas. A wavelet $\psi_{g}^{(j)}$ definida pela Equação 5.5 possui $j$ momentos nulos, isto é:

$$
\int t^{p} \psi_{g}^{(j)}(t) d t=0, \quad 0 \leq p \leq j
$$

Essa família de wavelets tem sido aproveitada intensamente para a análise de regularidade de sinais em problemas como análise multifractal em sinais de turbulência e seqüenciamento de moléculas de DNA [Arnèodo et al., 1995]. Este trabalho faz uso extensivo dessa família de wavelets para detecção de vértices e análise fractal. Denotando-se por $u^{(j)}(t)$ a derivada de ordem $j$ do sinal $u(t)$, tem-se a relação:

$$
U\left[\psi_{g}^{(j)} ; u\right]=a^{j} U\left[\psi_{g} ; u^{(j)}\right]
$$



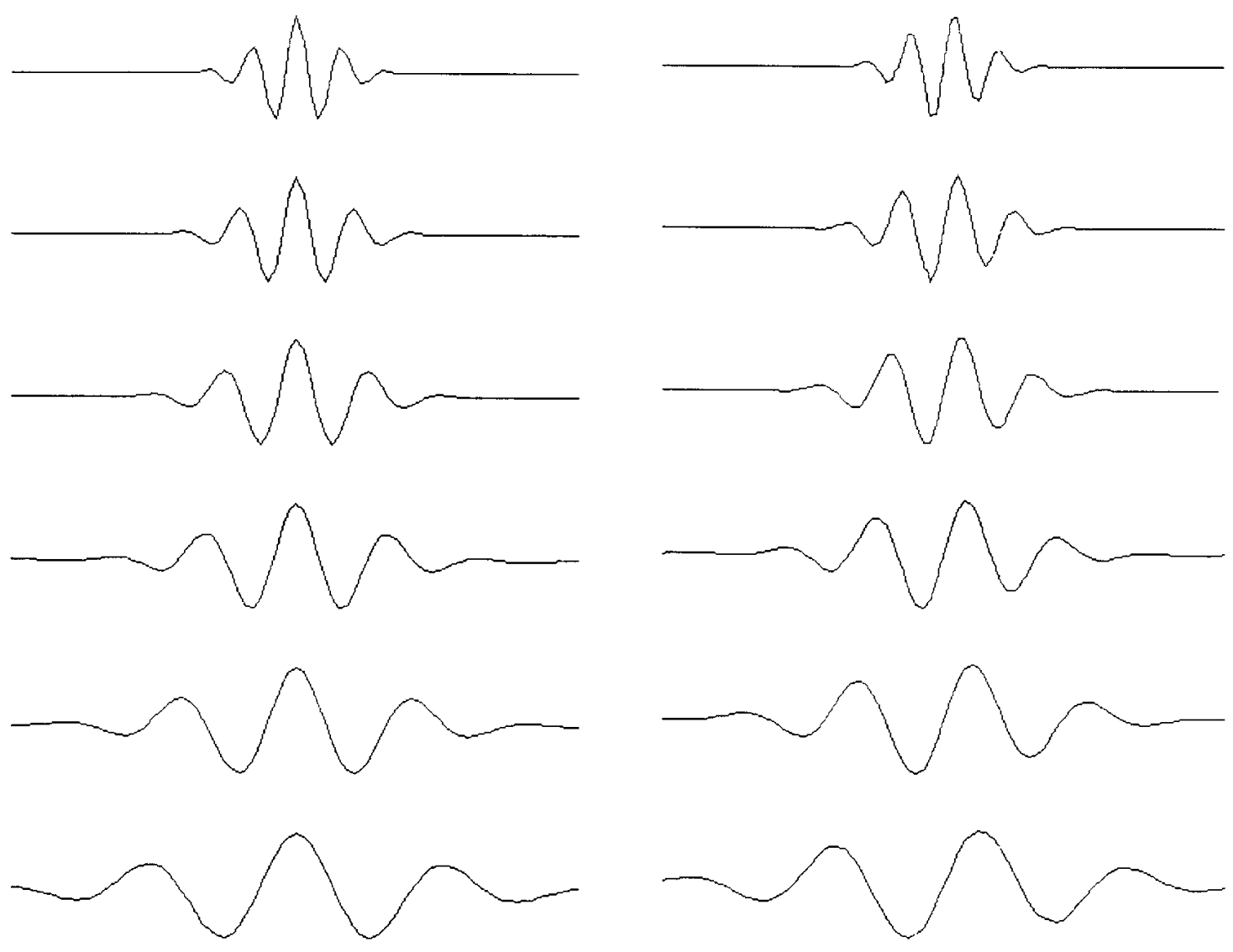

(a)

(b)

Figura (5.3): Wavelet de Morlet em diversas escalas: parte real (a) e imaginária (b).

indica que a análise de $u(t)$ por meio da transformada que utiliza a wavelet $\psi_{g}^{(j)}$ fornece informações sobre a regularidade de $u(t)$ até a ordem $j$.

\subsubsection{A Wavelet de Morlet}

4. primeira wavelet (introduzida no contexto da teoria das wavelets) foi criada por J. Morlet para problemas em prospecção de óleo, tendo sido definida como uma gaussiana modulada por uma exponencial complexa:

$$
\psi_{M}(t)=e^{i 2 \pi f_{0} t} e^{-t^{2} / 2}+\eta(t)
$$


O termo de correção $\eta$ é necessário pois somente a gaussiana modulada não verifica a condição de admissibilidade. Por outro lado, para $f_{0}$ grande o bastante (aproximadamente $\left.\left(2 \pi f_{0}\right)>5.5\right)$, esse termo é numericamente desprezível. Embora essa wavelet não seja progressiva, as componentes de freqüências negativas são muito menores que as positivas [Holschneider, 1995]. Essa wavelet é especialmente aplicada na análise de sinais oscilantes, uma vez que ela é muito bem localizada em frequiência. Suas versões dilatadas podem ser vistas como filtros passa-faixas de largura $1 / a$. A Seção 5.7 discute a noção de escalas naturais em termos de padrões periódicos locais em uma curva, sugerindo que a análise tempo-freqüência seja melhor adaptada para esse tipo de problema. A wavelet de Morlet, assim como a transformada de Gabor, fornece um bom filtro para essa aplicação, uma vez que ela é localizada de maneira ótima simultaneamente nos domínios do tempo e da freqüência. A Figura 5.3 apresenta as partes real e imaginária da wavelet de Morlet em uma série de diferentes escalas.

\subsection{ANÁLISE DE FORMAS A PARTIR DA REPRESENTAÇĀO-W}

2 mbora existam diferentes maneiras de se analisar os resultados obtidos pela transformada contínua em wavelets (veja o artigo introdutório de Grossmann, Kroland-Martinet e Morlet para uma boa revisão [Grossmann et al., 1989]), faz-se importante desenvolver algoritmos de análise automática da representação- $W$ para aplicações em análise de formas. Uma vez que a representação- $W$ assume, geralmente, valores complexos, ela pode ser analisada a partir de sua representação polar, definida por:

$$
U(b, a)=M(b, a) e^{i \varphi(b, a)}
$$

em que:

$$
M(b, a)=|U(b, a)| \quad \text { e } \quad \varphi(b, a)=\arg (U(b, a))
$$

A Figura 5.4 ilustra a derivação da representação- $W$ para um contorno em forma de "L". A parametrização $u(t)$ foi obtida percorrendo-se o contorno a partir do vértice superior esquerdo da forma. A representação- $W$ é visualizada como duas imagens criadas a partir do módulo $M(b, a)$ e da fase $\varphi(b, a)$ de $U(b, a)$, em que a wavelet adotada é o chapéu mexicano (Equação 5.4). Nesse caso, a transformada em wavelets pode ser associada à velocidade de difusão com a escala da wavelet como variável de tempo e com as condições iniciais dadas pelo contorno original. Uma outra forma comum de análise da transformada contínua em wavelets consiste no escalograma (análogo ao espectrograma da transformada de Fourier janelada), que representa a distribuição de 


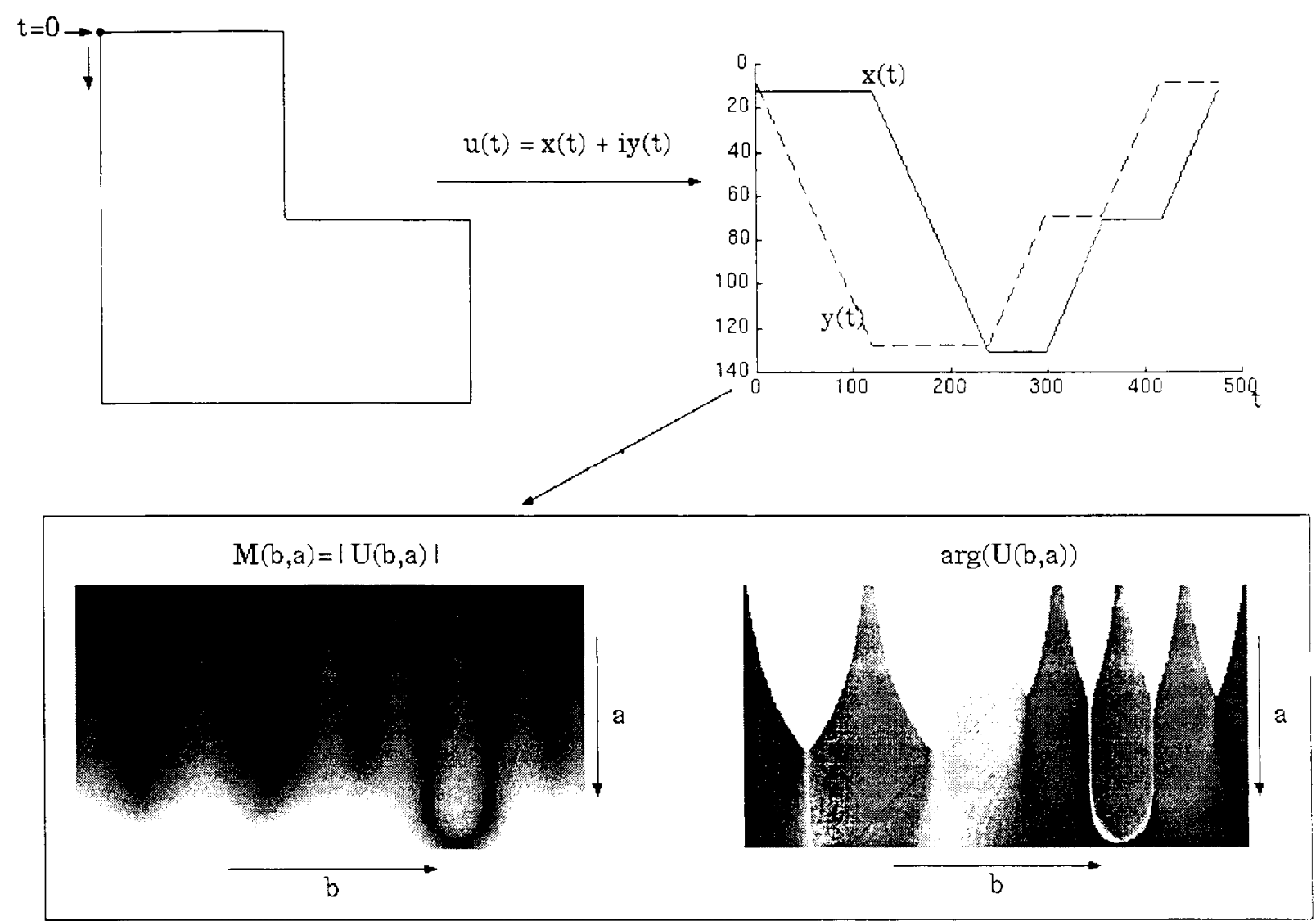

Figura (5.4): Esquema geral da representação- $W$. Nas representações gráficas deste capitulo, as cores claras codificam os maiores valores do módulo das transformadas.

energia do sinal sobre o plano tempo-escala $/ H I[$ [Rioul \& Vetterli, 1991], sendo definido como $M(b, a)^{2}$.

A informação presente na representação- $W$ é redundante, sendo, portanto, desnecessário guardar todos os coeficientes da transformada para a caracterização da curva. Na verdade, a caracterização pode ser feita a partir dos máximos locais do módulo $M(b, a)$, o que representa uma maneira muito útil de se tratar com a redundância, o ruído e outros problemas em aplicações reais. Este capítulo explora a representação por máximos locais no desenvolvimento de algoritmos para a resolução de 3 problemas importantes em análise de formas: deteç̧ão de pontos dominantes, definição de escalas naturais locais e análise fractal.

\subsection{DETECÇÃO DE VÉRTICES}

4. transformada em wavelets é uma boa ferramenta para a detecção e análise de singularidades em sinais [Mallat $\&$ Hwang, 1992]. Em particular, se um sinal $u(t)$ possuir uma singularidade em $t=t_{0}$, então o módulo de sua transformada em 
wavelets admite um linha de máximos locais verticais que converge para $t_{0}$ quando $a$ tende a zero [Mallat \& Hwang, 1992]. O conceito matemático comumente utilizado para a caracterização de singularidades de funções é o expoente de Hölder (também chamado de coeficiente de Lipschitz), o qual quantifica a "força" da singularidade [Arnèodo et al., 1995]. Suponha que o sinal $u(t)$ possua uma singularidade em $t_{0}$, e que sua expansão de Taylor em torno desse ponto seja dada por:

$$
x(t)=x\left(t_{0}\right)+\left(t-t_{0}\right) x^{(1)}\left(t_{0}\right)+\ldots+\frac{\left(t-t_{0}\right)^{j}}{j !} x^{(j)}\left(t_{0}\right)+R\left|\left(t-t_{0}\right)\right|^{h\left(t_{0}\right)}
$$

em que $R$ é uma constante e, em geral, $j \leq h\left(t_{0}\right) \leq j+1$. Assim, pode-se pensar que o expoente de Hölder $h\left(t_{0}\right)$ está associado ao primeiro termo singular da expansão de Taylor do sinal, implicando que $x$ é $j$ vezes derivável, mas não é $j+1$. Além disso, uma segunda conclusão que se pode facilmente obter é que quanto maior o expoente de Hölder, mais fraca é a singularidade e, nesse sentido, o expoente de Hölder é uma medida de regularidade da função. Dessa maneira, se $h\left(t_{0}\right)=0$, então a função é descontínua em $t_{0}$; se $h\left(t_{0}\right)=1$, então a função é contínua mas não derivável em $t_{0}$; se $h\left(t_{0}\right)=2$, então a função é contínua, possui a primeira mas não possui a segunda derivada em $t_{0}$; e assim por diante. O poder das wavelets para analisar singularidades de funções reside no fato de que, se $x(t)$ possui uma singularidade em $t_{0}$ cujo expoente de Hölder é dado por $h\left(t_{0}\right)$, então a transformada em wavelets $X[\psi, x](b, a)$ admite uma linha de máximos locais que tende a $b=t_{0}$, quando $a$ tende a zero, e que o módulo da transformada ao longo dessa linha se comporta da seguinte maneira:

$$
|X[\psi, x](b, a)| \sim a^{h\left(x_{0}\right)}
$$

com a restrição de que $\psi$ tenha $J$ momentos nulos e $h\left(t_{0}\right)<J$.

A Figura 5.5 apresenta quatro funções com tipos diferentes de singularidades em $t_{0}=0$, o módulo da transformada em wavelets, as linhas de máximos locais e o comportamento do módulo da transformada ao longo de uma linha de máximos em função da escala (log-log plot). Particularmente, o ajuste de uma linha reta nesse gráfico do módulo ao longo de uma linha de máximos permite a estimação do expoente de Hölder, indicado nos gráficos, através da inclinação da reta ajustada. Os quatro sinais singulares, de cima para baixo, são um delta de Dirac (descontínua), uma função escada (descontínua), a função $u(t)=t, t \geq 0$ (contínua mas não derivável) e a função $x(t)=2 t+|t|^{2.5}$ (contínua e derivável, com coeficiente de Hölder igual a 2.5). Os resultados ilustram a capacidade da 
transformada de estimar corretamente os expoentes de Hölder. A Seção 5.8 irá retomar essa discussão dentro do contexto de análise fractal. 

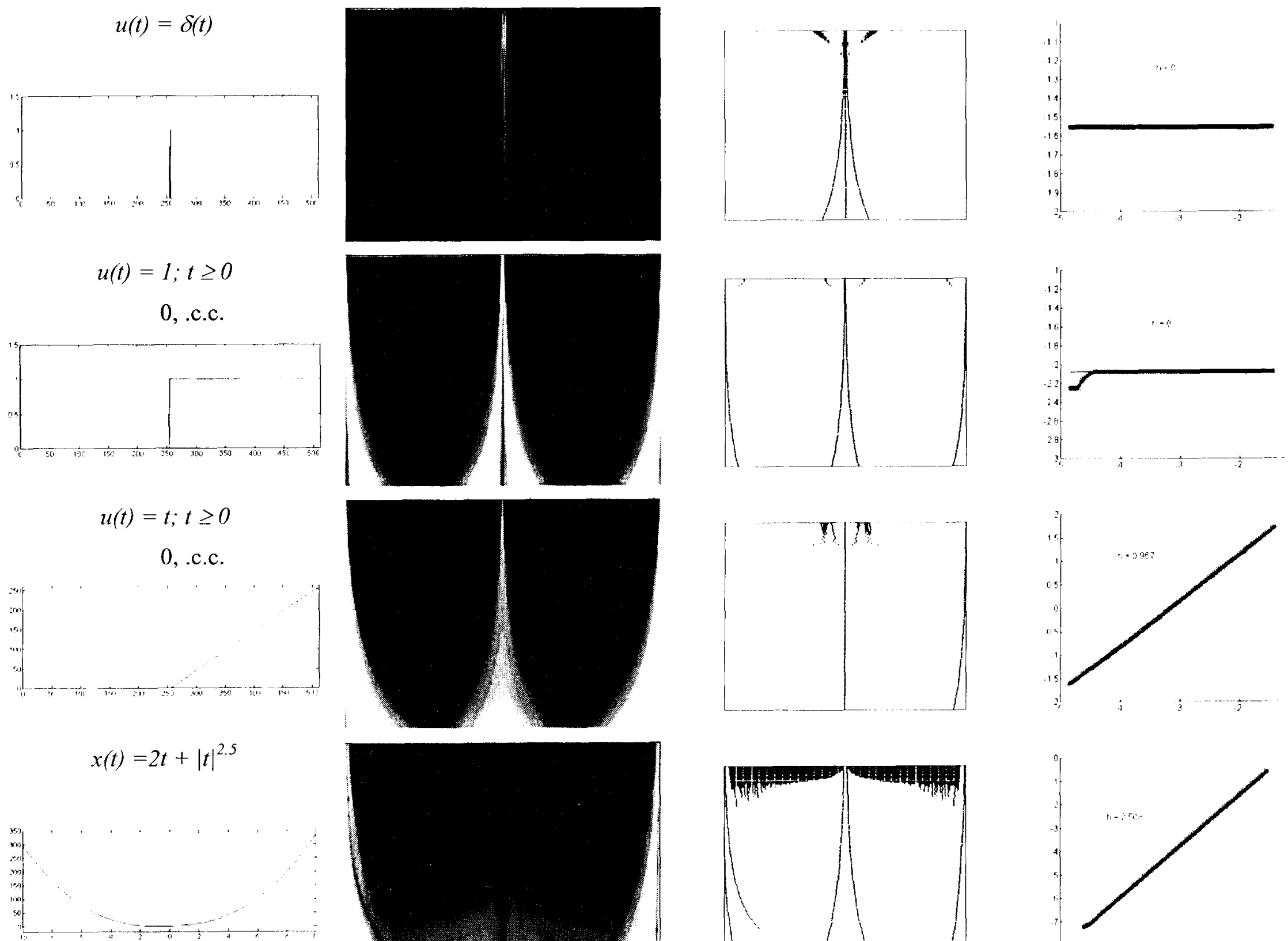

Figura (5.5): Detecção de singularidades e estimação do expoente de Hölder usando a transformada em wavelets. 


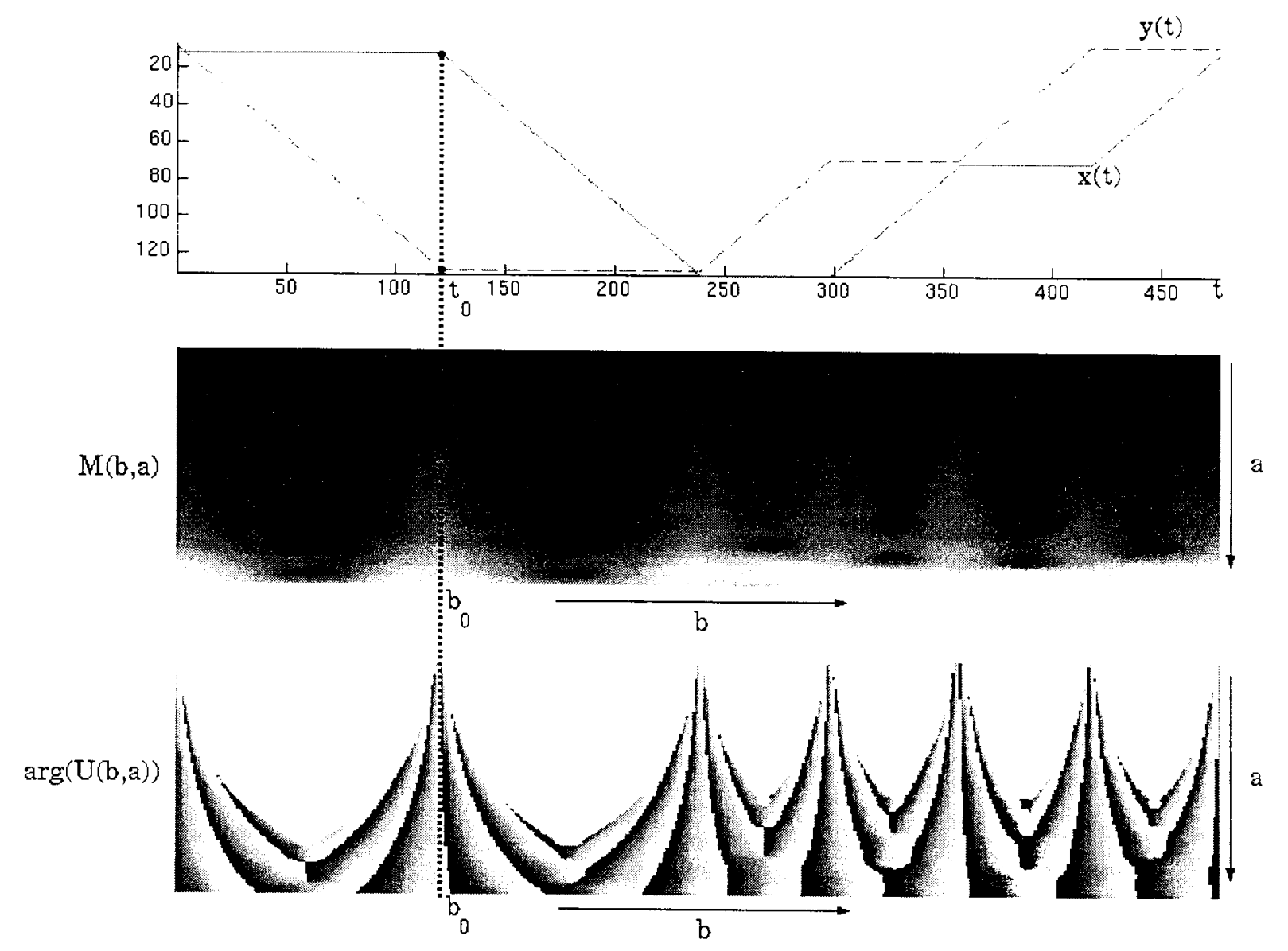

(a)

(b)

Figura (5.6): Esquema de detecção de vértices através do módulo e da fase da transformada em wavelets.

Como um vértice pode ser associado a uma singularidade na representação paramétrica $u(t)$, é natural que as linhas de máximos locais verticais da representação- $W$ sejam utilizadas para a deteç̧ão desses pontos dominantes do contorno. A Figura 5.6 ilustra como o módulo e a fase da representação- $W$ respondem "apontando", ou seja, realizando um "zoom" em torno de um dos vértices do contorno em forma de "L", indicado por $t_{0}$ na figura.

A Figura 5.7(a) apresenta as linhas de máximos verticais da representação- $W$ em questão. A Figura 5.7(b) apresenta as duas imagens sobrepostas, isto é, as linhas de máximos sobre $M(b, a)$. Esses máximos correspondem não só à resposta da transformada a pontos dominantes do contorno, mas também a ruídos e outras características não importantes da curva. Portanto, os pontos dominantes são detectados pelas linhas de máximos verticais da representação- $W$, mas nem toda linha de máximos corresponde necessariamente à assinatura de um ponto importante do contorno. A idéia básica do 

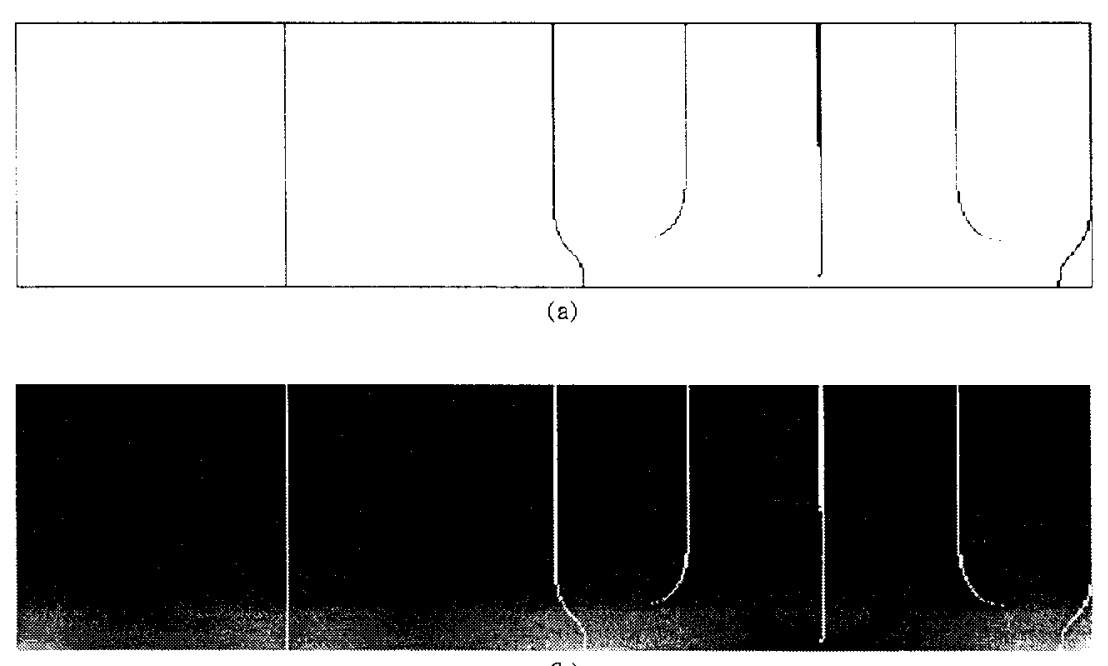

(b)

Figura (5.7): Linhas de máximos da transformada em wavelets do contorno em forma de $\mathrm{L}$ e as linhas sobrepostas ao módulo da transformada.

algoritmo de detecção de vértices reside na identificação de linhas mais relevantes no conjunto de linhas de máximos da representação- $W$. Esses conceitos são agora formalizados com as seguintes definições:

- Definição 5.1 (Ponto de Máximo Local Vertical): Um ponto $\left(b_{0}, a_{0}\right) \in \mathbb{H} /$ é dito ser um ponto de máximo local vertical se $\exists \varepsilon>0 \mid M\left(b_{0}, a_{0}\right)>M\left(b, a_{0}\right), \forall b \in\left(b_{0}-\varepsilon\right.$, $\left.b_{0}\right)$ e $M\left(b_{0}, a_{0}\right) \geq M\left(b, a_{0}\right), \forall b \in\left(b_{0}, b_{0}+\varepsilon\right)$, ou ainda se $\exists \varepsilon>0 \mid M\left(b_{0}, a_{0}\right) \geq$ $M\left(b, a_{0}\right), \forall b \in\left(b_{0}-\varepsilon, b_{0}\right)$ e $M\left(b_{0}, a_{0}\right)>M\left(b, a_{0}\right), \forall b \in\left(b_{0}, b_{0}+\varepsilon\right)$.

- Definição 5.2 (Linha de Máximos Verticais): Uma linha $L_{v}=\{(b, a) \in \mathbb{H}\} \quad \dot{e}$ denominada uma linha de máximos verticais se todo ponto $\left(b_{0}, a_{0}\right) \in L_{v}$ for um ponto de máximo local vertical.

- Definição 5.3 (Esqueleto Vertical): O conjunto de todas as linhas de máximos verticais, denotado por $\left\{L_{v}\right\}$, é chamado esqueleto vertical da representação-W.

A detecção das linhas correspondentes a pontos dominantes no contorno é realizada atribuindo-se uma medida de relevância $f\left(L_{v}\right)$ a cada linha do esqueleto vertical da representação- $W$, seguido de uma operação de limiarização do esqueleto baseada em $f\left(L_{v}\right)$. Assim, se $f\left(L_{v}\right)>T$, em que $T$ é o limiar definido a priori, e a linha de máximos $L_{v}$ tende para $b_{0}$, quando $a \rightarrow 0$ (isto é, pequenas escalas), então $u\left(b_{0}\right)$ é tomado como ponto dominante. A medida de relevância $f\left(L_{v}\right)$ adotada neste trabalho deriva do conceito de tempo de vida no espaço-escala [Lindeberg, 1993], sendo definida como a diferença dos 


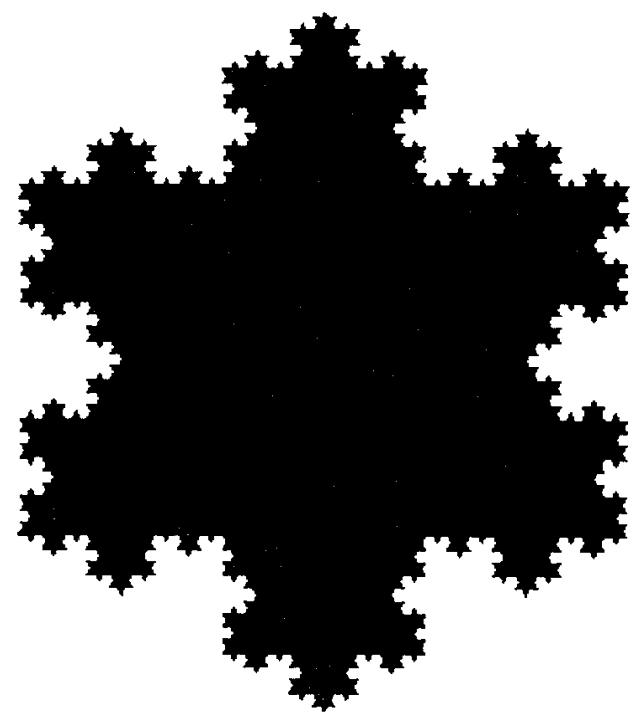

Figura (5.8): Forma definida pela curva triádica de Koch.

logaritmos das escalas inicial e final da linha de máximos. Suponha que a linha $L_{v}$ comece no ponto $\left(b_{0}, a_{0}\right) \in \mathbb{H} /$ e termine no

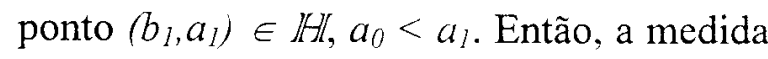
de relevância $f\left(L_{v}\right)$ é definida como sendo:

$$
f\left(L_{v}\right)=\log a_{1}-\log a_{0}
$$

Uma vez que todas as linhas de máximos que definem os vértices começam em $a_{0}=a_{m i n}$, em que $a_{m n n}$ é a menor escala de análise da representação- $W$, a medida de relevância pode ser redefinida como:

$$
f\left(L_{v}\right)=\log a_{l}
$$

Medidas alternativas como o tamanho da linha de máximos ou a integral de $M(b, a)$ sobre a linha também podem ser usadas e, embora não exista nenhuma razão $a$ priori para se escolher um dos possíveis critérios, foi observado empiricamente que o tempo de vida do espaço-escala definido acima geralmente discrimina melhor entre os verdadeiros pontos dominantes e o ruído. Na verdade, um exemplo simples é capaz de ilustrar como os eventos importantes no plano tempo-escala normalmente ocorrem em uma escala logarítmica, o que é geralmente assumido.

A Figura 5.8 apresenta uma curva triádica de Koch que foi analisada pelo esquema da representação- $W$. Quatro diferentes medidas de relevância foram testadas: o tempo de vida do plano tempo-escala, definido pela Equação 5.6; o tamanho ou comprimento de arco da linha de máximos; a integral do módulo da representação- $W$ sobre a linha de máximos; e a maior escala da linha de máximos. O tamanho da linha de máximos é calculado como sendo o número de pontos (discretos) que compõem a versão discreta da linha de máximos. Como será ilustrado, o esquema de discretização do parâmetro de escala, que pode ser linear ou logarítmico [Grossmann et al., 1989], cumpre um papel particularmente importante para a adoção do tamanho da linha como medida de relevância. A Figura 5.9(a)-(c) apresenta os sinais $x(t)$ e $y(t)$ definidos pela curva de Koch, o esqueleto vertical correspondente obtido através de um esquema de discretização logarítmica do parâmetro de escala e o esqueleto obtido por discretização linear, respectivamente. Como pode-se ver, embora os mesmos limites mínimo e máximo para as escalas tenham sido adotados em ambos os casos, os dois esqueletos resultantes são muito diferentes, o que é refletido diretamente no tamanho de cada linha de máximos. A Figura $\mathbf{5 . 1 0}$ apresenta os resultados para cada medida de relevância, cujos nomes são indicados em cada gráfico. Os dois primeiros indicam que o tempo de 


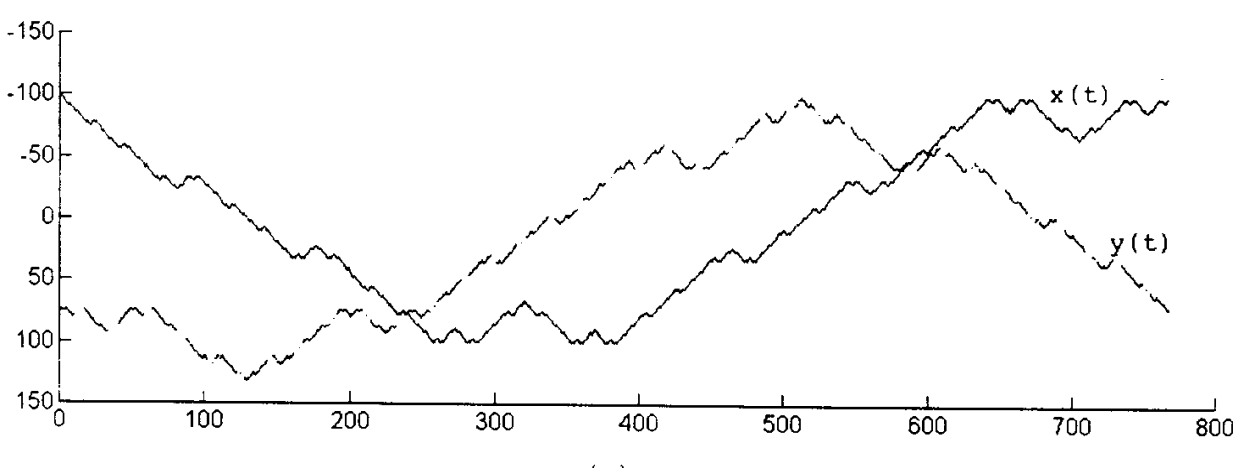

(a)

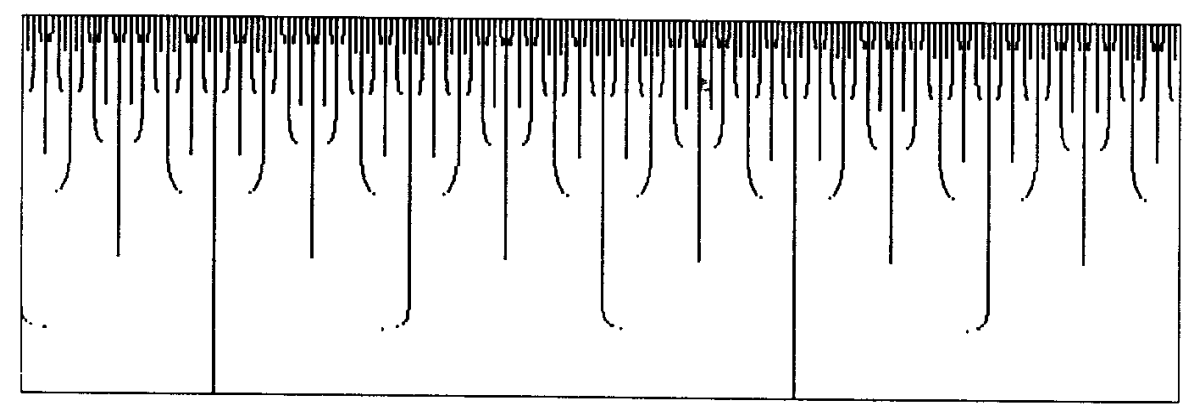

(b)

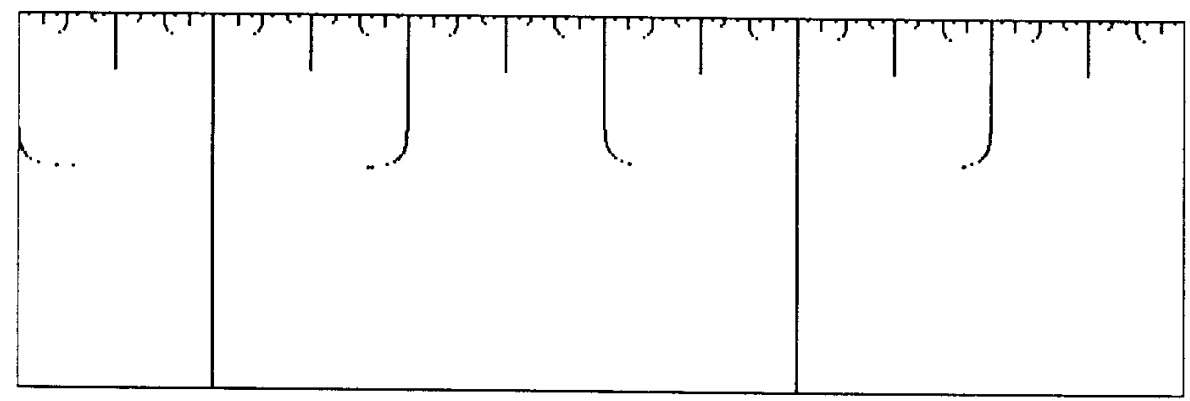

(c)

Figura (5.9): Sinais $x$ e $y$ e esqueletos verticais da curva de Koch.

vida e o tamanho das linhas no caso de amostragem logarítmica são equivalentes, refletindo a evolução das diferentes singularidades ao longo das escalas. As outras medidas enfatizam acentuadamente as singularidades de grande escala, mas mal detectam as singularidades restantes. Finalmente, é importante observar que o critério do tempo de vida é independente do esquema de discretização do parâmetro de escala, sendo, também, mais fácil de calcular, razões essas que indicam que o tempo de vida é a medida de relevância mais apropriada. 

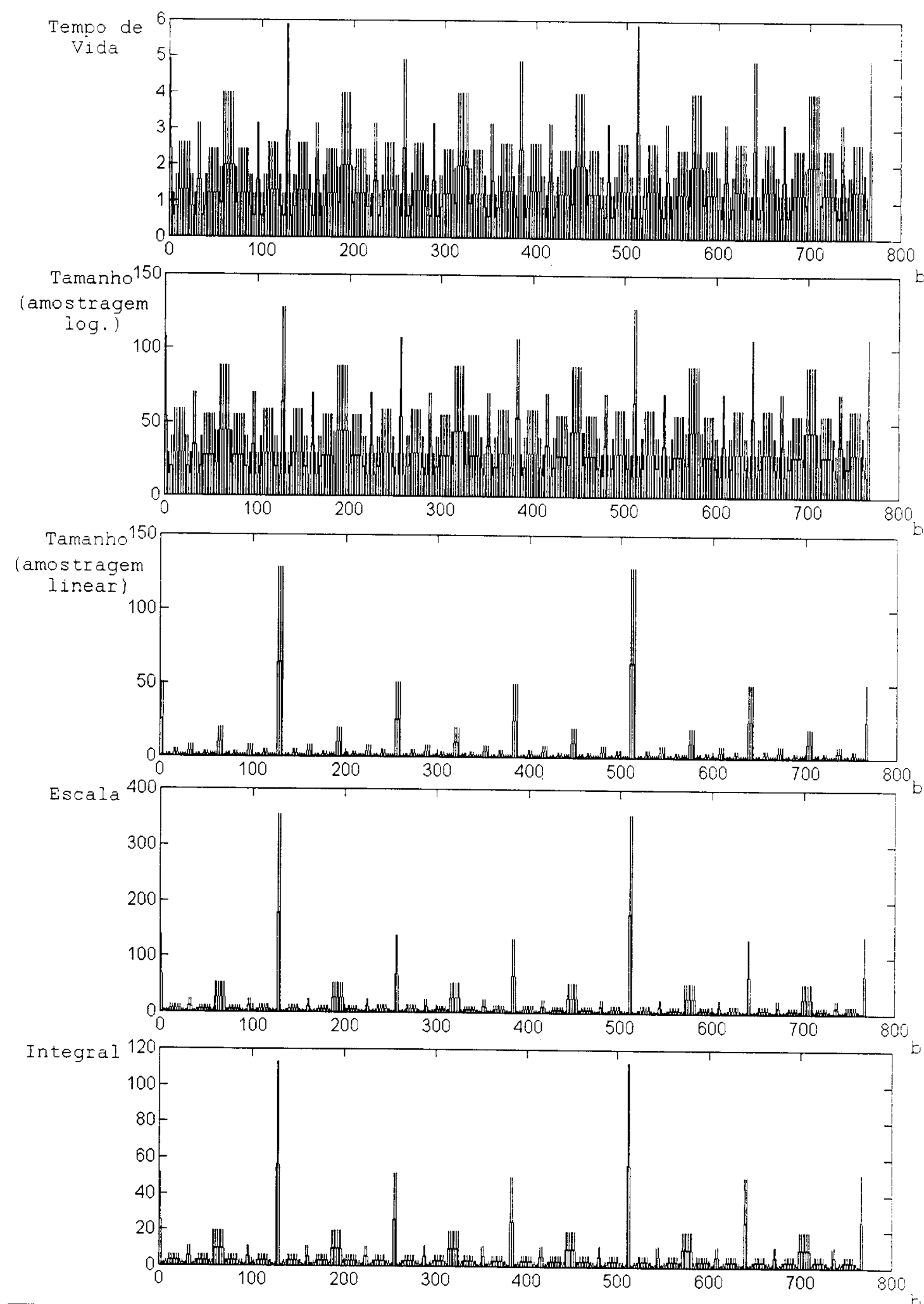

Figura (5.10): Medidas de relevância para as linhas de máximos verticais. 


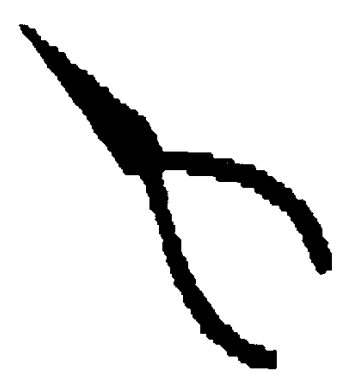

Figura (5.11): Silhueta de um alicate, usada em um experimento.

$\mathrm{O}$ algoritmo foi testado em um conjunto de objetos obtidos de imagens reais. sendo sua capacidade de identificar corretamente pontos perceptualmente importantes no contorno ilustrada através dos resultados obtidos. A Figura 5.11 apresenta a silhueta de um alicate, enquanto os esqueletos de sua representação- $W$, antes e depois da limiarização pela medida de relevância, são mostrados na Figura 5.12. Os pontos dominantes detectados pelo método de limiarização do esqueleto vertical da representação- $W$ foram marcados com um asterisco sobre o contorno original e são mostrados na Figura 5.13(a), que também mostra os pontos dominantes marcados sobre os sinais $x(t)$ e $y(t)$.

O mesmo procedimento foi aplicado à silhueta de um garfo de churrasco, sendo o seu resultado apresentado na Figura 5.13(b). As imagens dos dois objetos foram

Esqueleto

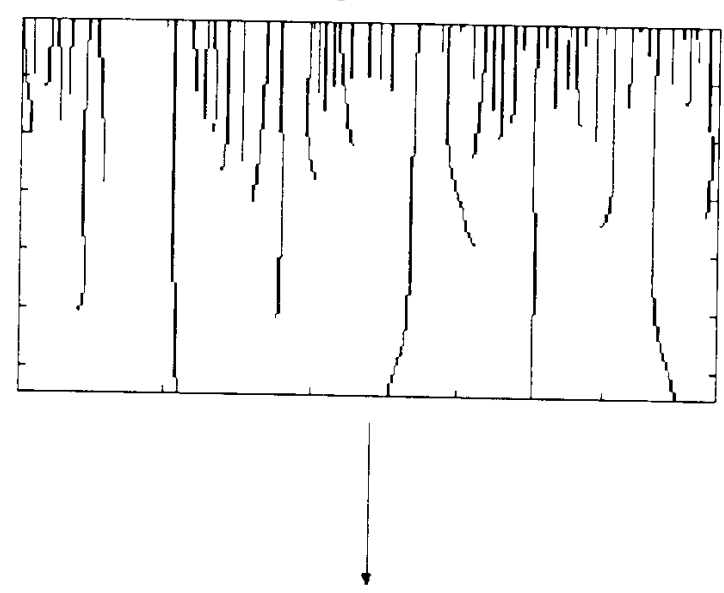

Esqueleto Limiarizado

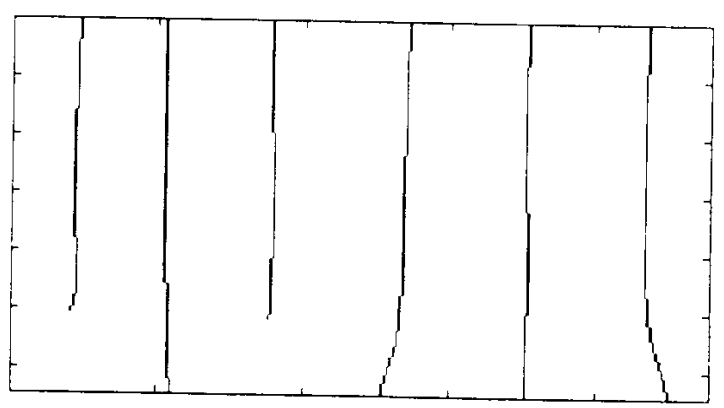

Figura (5.12): Esqueleto antes e depois da limiarização pela medida de relevância. sobrepostas e distorcidas. fazendo com que os objetos sofram de oclusão parcial e escalonamento não-homogêneo, simulando os efeitos típicos de distorção em imagens. Esse tipo de transformação geométrica introduz dificuldades a serem tratadas por sistemas de visão computacional, uma vez que propriedades básicas de formas são severamente afetadas. $\mathrm{Na}$ verdade, um experimento interessante de psicofísica seria testar o grau de distorção que curvas podem sofrer ainda sendo percebidas como representando o "mesmo objeto". Por outro lado, tais distorções implicam dificuldades adicionais a sistemas de reconhecimento baseado em modelos, pois tais sistemas geralmente dependem do particionamento do contorno: os pontos de segmentação (e, conseqüentemente, os segmentos) podem ser detectados erroneamente, prejudicando a fase de casamento entre a forma de entrada e o modelo armazenado na base de dados [Tsang et al., 1994] . Portanto, o detector de pontos dominantes deve ser o mais robusto possível para esse tipo de distorções geométricas, com 

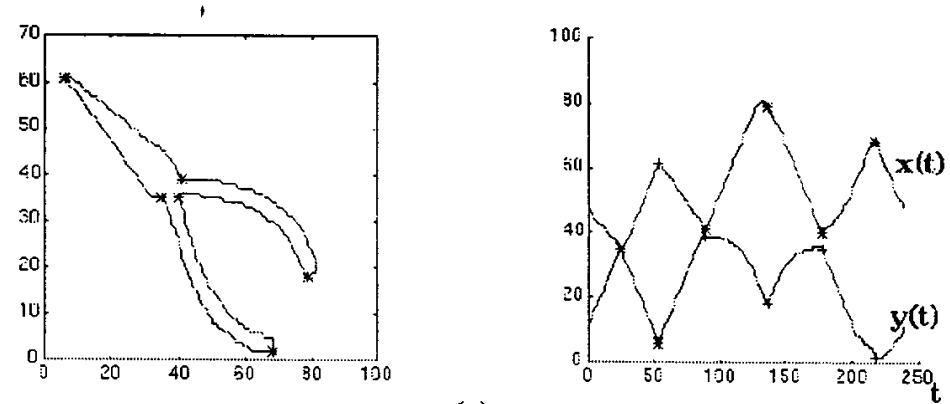

(a)
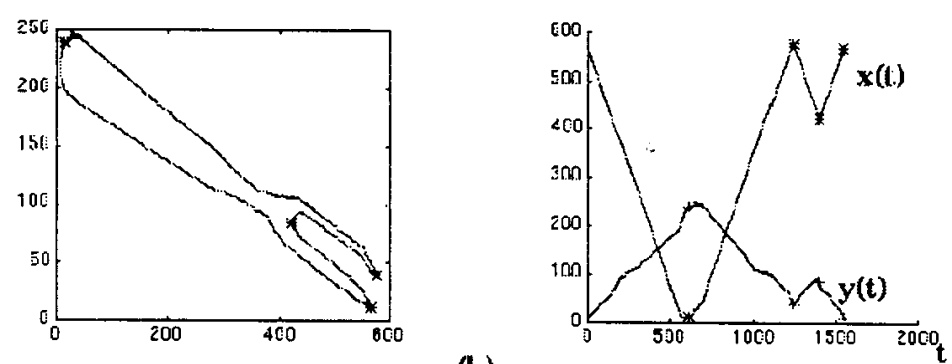

(b)
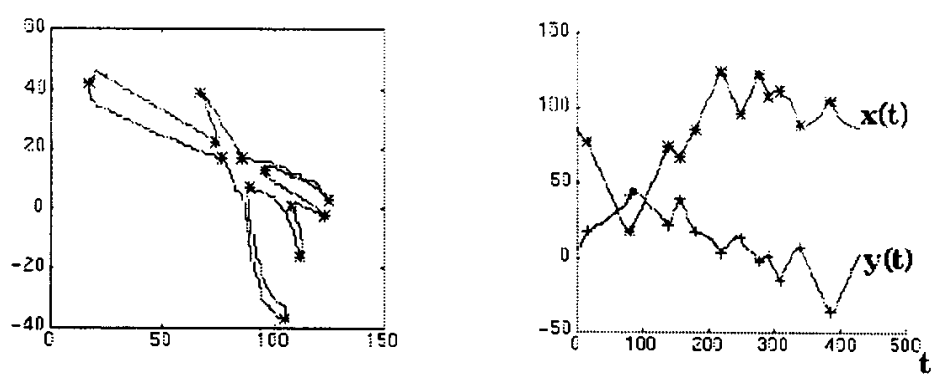

(c)

Figura (5.13): Resultados de detecção de pontos dominantes através da representação- $W$.

o propósito de evitar tais inconsistências entre os segmentos do modelo e os do objeto a ser reconhecido. O contorno dos objetos distorcidos e sobrepostos foi analisado pelo método de deteç̧ão de pontos dominantes por wavelets, sendo seu resultado apresentado na Figura 5.13(c). É importante notar que, apesar das diferenças nas imagens, os pontos característicos permaneceram consistentes no contorno distorcido. Os pontos dominantes adicionais devem-se às junções entre os dois objetos, que são concavidades geralmente identificadas quando duas superficies se interpenetram, o que é de importância central na teoria de segmentação de formas de W. Richards e D.D. Hoffmann [Richards et al., 1986].

O algoritmo introduzido detecta vértices como sendo descontinuidades em uma das derivadas da curva. Embora existam pontos dominantes devidos a singularidades na função de curvatura e não em derivadas da curva, argumenta-se que tais singularidades não são tão comuns em contornos discretizados extraídos de objetos reais. Um exemplo típico de uma curva é a astróide, cuja versão paramétrica é dada por $c(t)=\left(\cos ^{3} t\right.$, 
$\operatorname{sen}^{3} t$ ) (veja a Figura 2.4). Essa curva possui 4 singularidades nos pontos em que sua primeira derivada se anula, apesar do fato de todas as suas derivadas serem contínuas. No entanto, uma versão discretizada dessa curva foi gerada em uma imagem digital, seu contorno extraído, sendo que o método de detecção de vértices por wavelets foi capaz de detectar os vértices com sucesso.

A abordagem de segmentação de contornos por wavelets pode ser resumida pelo seguinte algoritmo:

\section{0 - Algoritmo para detecção de pontos dominantes a partir da representação- $W$}

1 - Detectar todas as linhas de máximos verticais, ou seja, o esqueleto vertical;

2 - Calcule a medida de relevância de cada linha do esqueleto;

3 - Selecione todas as linhas de máximos que possuem medida de relevância maior que um determinado limiar previamente especificado;

4 - Determine os pontos $b_{k}$ para os quais cada linha selecionada no passo 3 convirja;

5- Tome $u\left(b_{k}\right)$ como os pontos dominantes de $u(t)$;

6 - Fim.

\subsection{ESCALAS NATURAIS E FREQÜÊNCIAS LOCAIS}

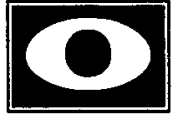

conceito de escalas naturais explorado nesta seção relaciona-se com a definição de pontos dominantes de contornos, permitindo a definição de uma partição natural do contorno. Esta é vista como um processo de segmentação do contorno de forma que os pontos de cada segmento compartilhem um conjunto de características significativas comuns. Para melhor esclarecer os significados de "partição natural" e "características significativas comuns", apresenta-se a Figura 5.14 que exibe 3 formas com seus respectivos pontos dominantes indicados por setas. A Figura 5.14(a) mostra um quadrado com os quatro vértices indicados como pontos dominantes. Nesse caso, os pontos em cada segmento (isto é, cada lado do quadrado) compartilham a propriedade de apresentarem a mesma orientação. A Figura 5.14(b) mostra um círculo com três segmentos de textura senoidal acrescentados radialmente à sua fronteira, sendo que as setas indicam os pontos dominantes que delimitam esses três segmentos. Para o caso dessa forma, a frequiência de cada textura senoidal define a propriedade comum compartilhada pelos pontos de cada segmento. Finalmente, a Figura 5.14(c) também apresenta um círculo com três texturas senoidais radiais, mas dessa vez revelando a mesma frequiência e amplitudes diferentes, o que define a partição natural (como indicado pelas setas) em que os pontos de cada segmento compartilham a mesma amplitude. É importante notar que diferentes partições podem ser definidas para cada forma, como por exemplo através de detecção de vértices seguida de uma aproximação poligonal do círculo da Figura 5.14(c). Porém, argumenta-se que a aplicação de critérios alternativos (em detrimento de métodos mais tradicionais em visão, como a detecção de 
pontos de alta curvatura), como freqüência local ou modulação de amplitude, leva a segmentações mais significativas do contorno. Além disso, é importante salientar que a percepção de padrões periódicos - geralmente transientes, isto é, padrões que se repetem um número limitado de vezes em uma cena ou objeto - que compõem o estímulo visual acaba por definir uma situação em que o conceito de "escalas naturais" aparece de maneira evidente. O experimento descrito por Attneave em 1954 e explicado no Capítulo 1 fornece subsídios psicofísicos para essa argumentação.

Baseada nas considerações acima, uma nova abordagem para a identificação de regiões do contorno contendo informação freqüencial constante ou coerente e para a subsequente caracterização de escalas naturais de objetos foi introduzida em [Antoine et al., 1996; Antoine et al., 1997]. A idéia básica dessa abordagem é a de que a repetição de um padrão em uma determinada região do contorno define uma escala natural do objeto. Essa idéia foi enfatizada pelos pesquisadores De Valois e De Valois como uma importante informação visual que deve ser explorada por sistemas biológicos de visão:

\section{"Visual stimuli are periodic}

If the visual world were spatially periodic, there would clearly be a major advantage to spatial frequency encoding and/or analysis, as opposed to encoding in terms of the spatial location of such features such as edges or bars of different widths. (...) A large proportion of visual stimuli are in fact spatially periodic, and one can readily identify a number of physical and biological principles that might account for such periodicities.(...)"

[De Valois \& De Valois, 1990, pg 337]

Vale notar que tal interpretação pode ser conferida à abordagem baseada nos descritores de Fourier desenvolvida por [Rosin \& Venkatesh, 1993]. Entretanto, tal

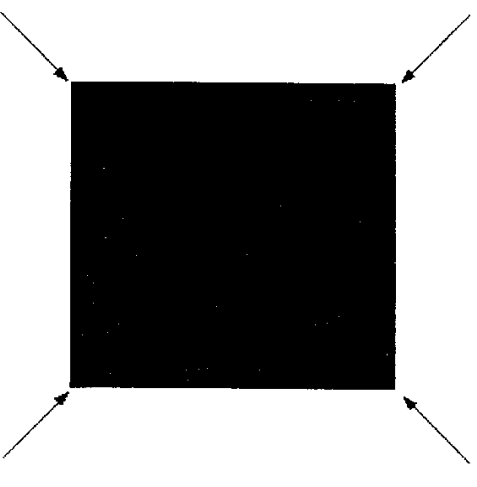

(a)

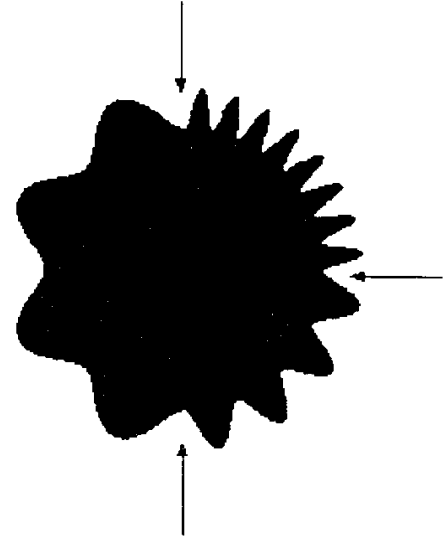

(b)

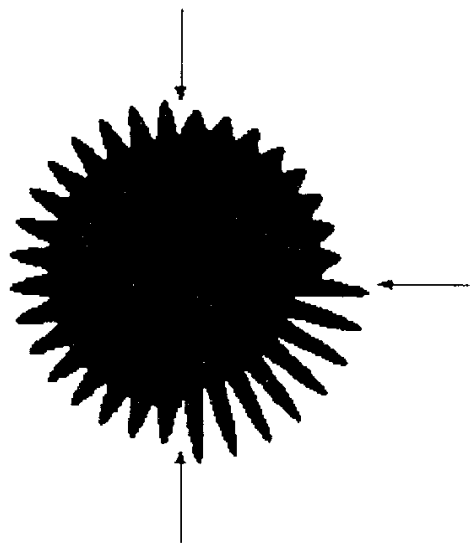

(c)

Figura (5.14): Três tipos diferentes de partições naturais de formas. 


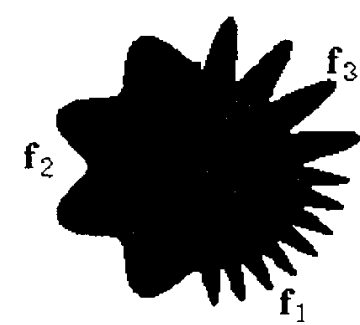

Figura (5.15): Círculo com 3 tipos diferentes de textura senoidal.

abordagem global, visto que se baseia em análise de Fourier, não é adaptada para a caracterização de estímulos periódicos transientes que se estendam apenas por poucos ciclos. Essa é, na verdade, uma situação em que a análise por wavelets mostra sua força através de sua capacidade de tratar eventos transientes em sinais.

Seja a representação $u(t)$ de uma circunferência com três texturas senoidais (de freqüências $f_{j}, j=1,2,3$ ) acrescentadas radialmente. A Figura 5.15 apresenta uma circunferência criada a partir dessa definição, enquanto a Figura 5.17 mostra os sinais $x(t)$ e $y(t)$ correspondentes. Como foi comentado no início desta seção, essa forma possui 3 partes ou segmentos perceptualmente naturais, definidas pela freqüência de cada textura senoidal.

Visto que $\psi_{M}(a 2 \pi f)$ é uma gaussiana centrada em $f_{d} / a$, a transformada $U(b, a)$ possui 4 linhas de máximos horizontais. Esse conjunto de linhas, denominado esqueleto horizontal, fornece a decomposição em escalas naturais da circunferência modulada. A representação- $W$ da circunferência com textura é mostrada na Figura 5.17 (magnitude e fase). A resposta da representação- $W$ é intensificada quando a wavelet analisadora é sintonizada às freqüências locais apropriadas. Além disso, a representação- $W$ também indica (através dos pontos de máximo vertical e das linhas de fase constante, um dos casos denotado por $b_{0}$ e $t_{0}$ na figura) os pontos de transição entre as freqüências, ilustrando, novamente, a propriedade de "zoom" da transformada. Assim, as escalas naturais podem ser caracterizadas pelas linhas de máximos horizontais de $M(b, a)$, da mesma maneira que as linhas de máximos verticais localizam pontos dominantes no contorno (veja Seção 5.6). É importante notar que esse tipo de partição do contorno não

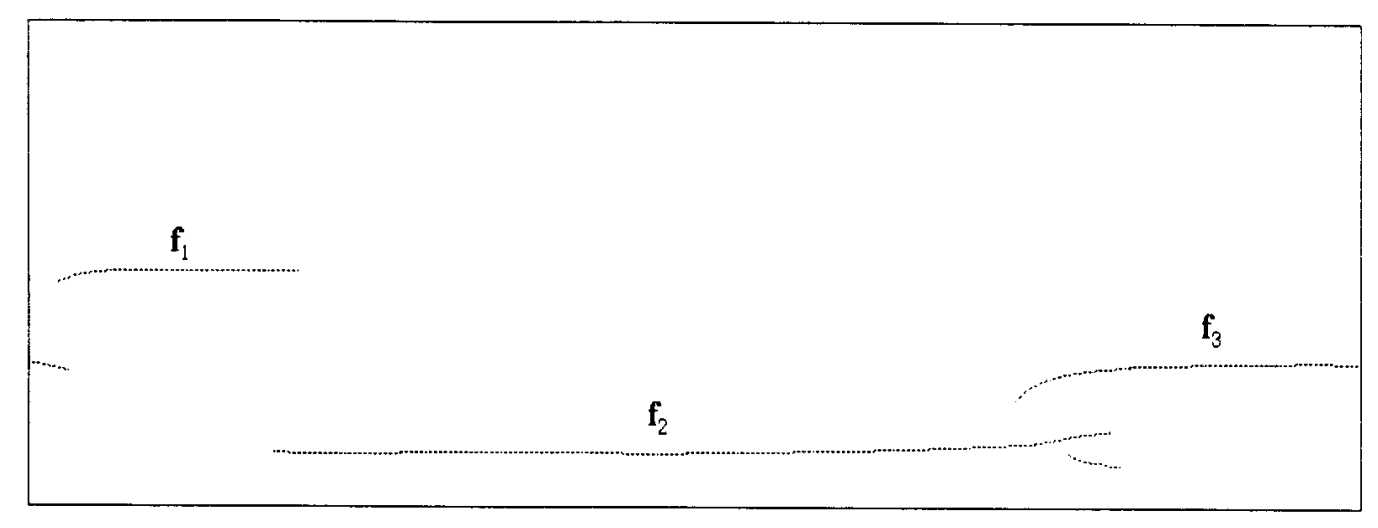

Figura (5.16): Esqueleto horizontal da representação- $W$ do círculo mostrado na Figura 5.15. 


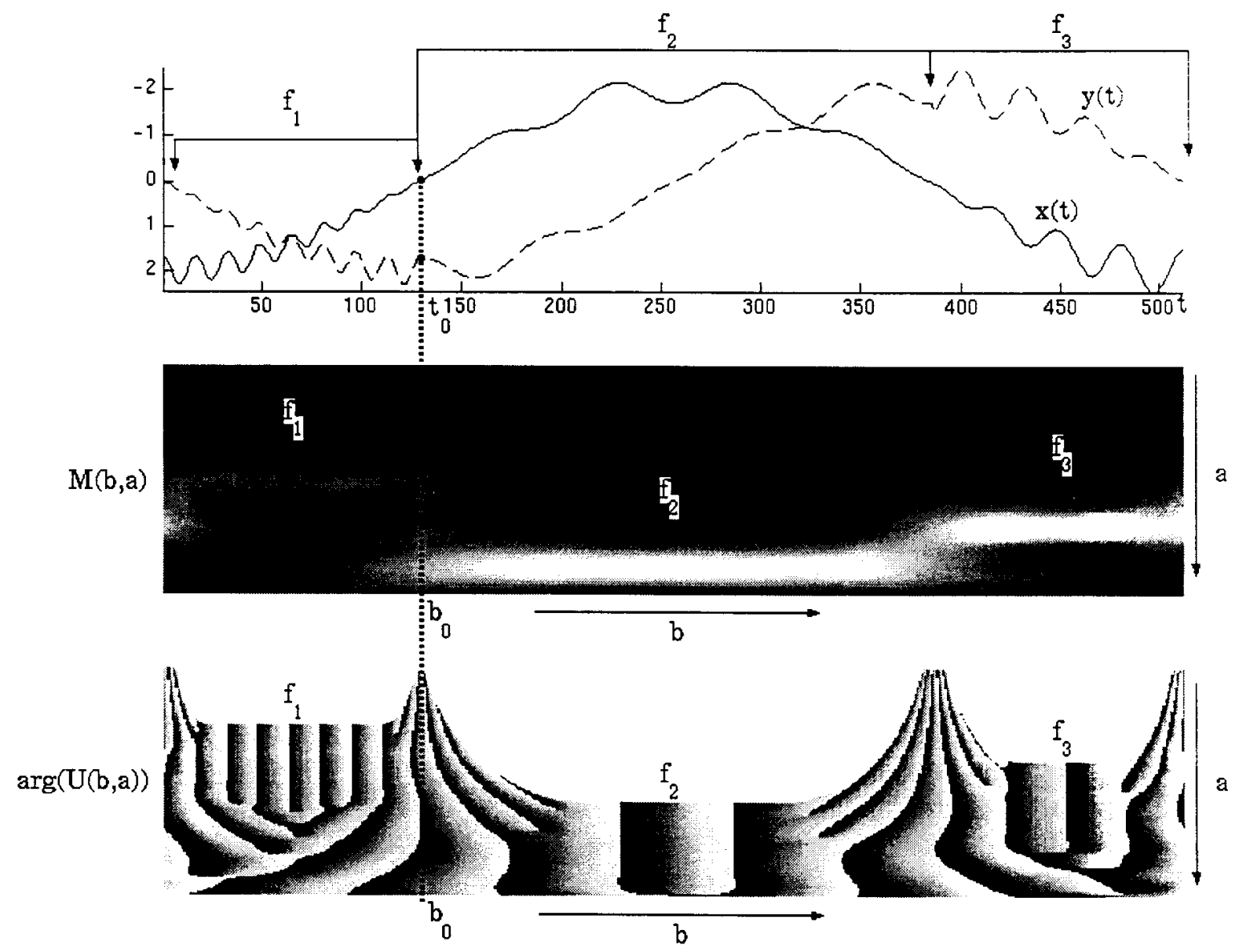

(a)

(b)

Figura (5.17): Esquema de detecção de escalas naturais e de pontos de transição entre padrões periódicos por meio do módulo e da fase da representação- $W$.

pode ser feito por métodos clássicos de análise de curvatura (como por máximos, mínimos ou cruzamentos por zero), a menos que procedimentos mais globais de análise sejam empregados. Tal situação deve-se ao fato de que a característica percebida (isto é, a textura senoidal) é fruto não só de propriedades locais (como curvatura), mas de uma interação entre pontos de regiões do contorno (isto é, organização de características locais, repetição periódica de um padrão, modulação, etc.).

A partição do contorno é dada pelo esqueleto horizontal, em que cada linha de máximos horizontais é a assinatura de uma escala natural da curva (veja a Figura 5.16). Esses conceitos são definidos no mesmo sentido da detecção de vértices.

- Definição 5.4 (Ponto de Máximo Local Horizontal): Um ponto $\left(b_{0}, a_{0}\right) \in H^{\prime}$ é dito ser um ponto de máximo local horizontal se $\exists \varepsilon>0 \mid M\left(b_{0}, a_{0}\right)>M\left(b_{0}, a\right), \forall a \in\left(a_{0}\right.$ - 
$\left.\varepsilon, a_{0}\right)$ e $M\left(b_{0}, a_{0}\right) \geq M\left(b_{0}, a\right), \forall a \in\left(a_{0}, a_{0}+\varepsilon\right)$, ou ainda se $\exists \varepsilon>0 \mid M\left(b_{0}, a_{0}\right) \geq$ $M\left(b_{0}, a\right), \forall a \in\left(a_{0}-\varepsilon, a_{0}\right)$ e $M\left(b_{0}, a_{0}\right)>M\left(b_{0}, a\right), \forall a \in\left(a_{0}, a_{0}+\varepsilon\right)$.

- Definição 5.5 (Linha de Máximos Horizontais): Uma linha $L_{h}=\{(b, a) \in \mathbb{H}\}$ é denominada uma linha de máximos horizontais se todo ponto $\left(b_{0}, a_{0}\right) \in L_{h}$ for um ponto de máximo local vertical.

- Definição 5.6 (Esqueleto Horizontal): O conjunto de todas as linhas de máximos horizontais, denotado por $\left\{L_{h}\right\}$, é chamado esqueleto horizontal da representação- $W$.

Para ilustrar como esses conceitos podem ser aplicados em imagens reais, o contorno do saca-rolhas apresentado na Figura 5.18(a) foi analisado por meio da representação- $W$. A região em espiral do saca-rolhas é um exemplo típico de um padrão periódico transiente que caracteriza uma escala natural dessa forma. Três pontos dominantes estão indicados sobre o contorno na Figura 5.18, correspondendo às extremidades inicial e final do padrão em espiral (pontos A e C na Figura 5.18) e à singularidade da ponta do saca-rolhas (ponto $B$ na Figura 5.18). As linhas de máximos horizontais da representação- $W$ foram sobrepostas a $M(b, a)$ dessa representação, sendo a imagem resultante apresentada na Figura 5.18(b). A representação- $W$ apresenta uma resposta mais forte na região identificada por um retângulo na Figura 5.18. Essa imagem também identifica as extremidades da linha de máximos horizontais associada aos pontos $\mathrm{A}, \mathrm{B}$ e $\mathrm{C}$ do contorno. É ainda interessante notar que a linha de máximos horizontais aumenta em frequêencia (isto é, diminui em escalas) ao se aproximar da singularidade $\mathrm{B}$.

Existe um ponto importante que deve ser enfatizado sobre esta seção: a contribuição original da tese não é a introdução do conceito de frequêencia local, o qual é bem conhecido e vem sendo usado há anos em diferentes aplicações (veja, por exemplo [Delprat, 1992; Delprat et al., 1992; Torrésani, 1992; Torrésani, 1995]), mas sim mostrar que esse conceito pode ser aproveitado na resolução de um problema importante de análise de formas que vem recebendo recentemente atenção crescente, ou seja, as escalas naturais [Rosin, 1992; Rosin \& Venkatesh, 1993; Garcia \& Fdez-Valdivia, 1994; Garcia et al., 1995]. Nesse sentido, tal contribuição é muito mais conceitual do que pragmática: a discussão e os exemplos incluídos neste capítulo introduzem um novo conceito a propósito do que vem a ser uma escala natural, esta sendo definida como a escala na qual deve-se sintonizar a wavelet para que se possa perceber melhor um determinado padrão periódico que ocorra na borda do objeto em questão. Além disso, argumenta-se que a transformada contínua em wavelets, bem como a transformada de Gabor, como será discutido, é uma ferramenta apropriada para a detecção e caracterização dessas escalas naturais. De fato, este trabalho fornece exemplos que ilustram essas idéias, como o exemplo do saca-rolhas, que foi incluído para mostrar uma escala natural real 

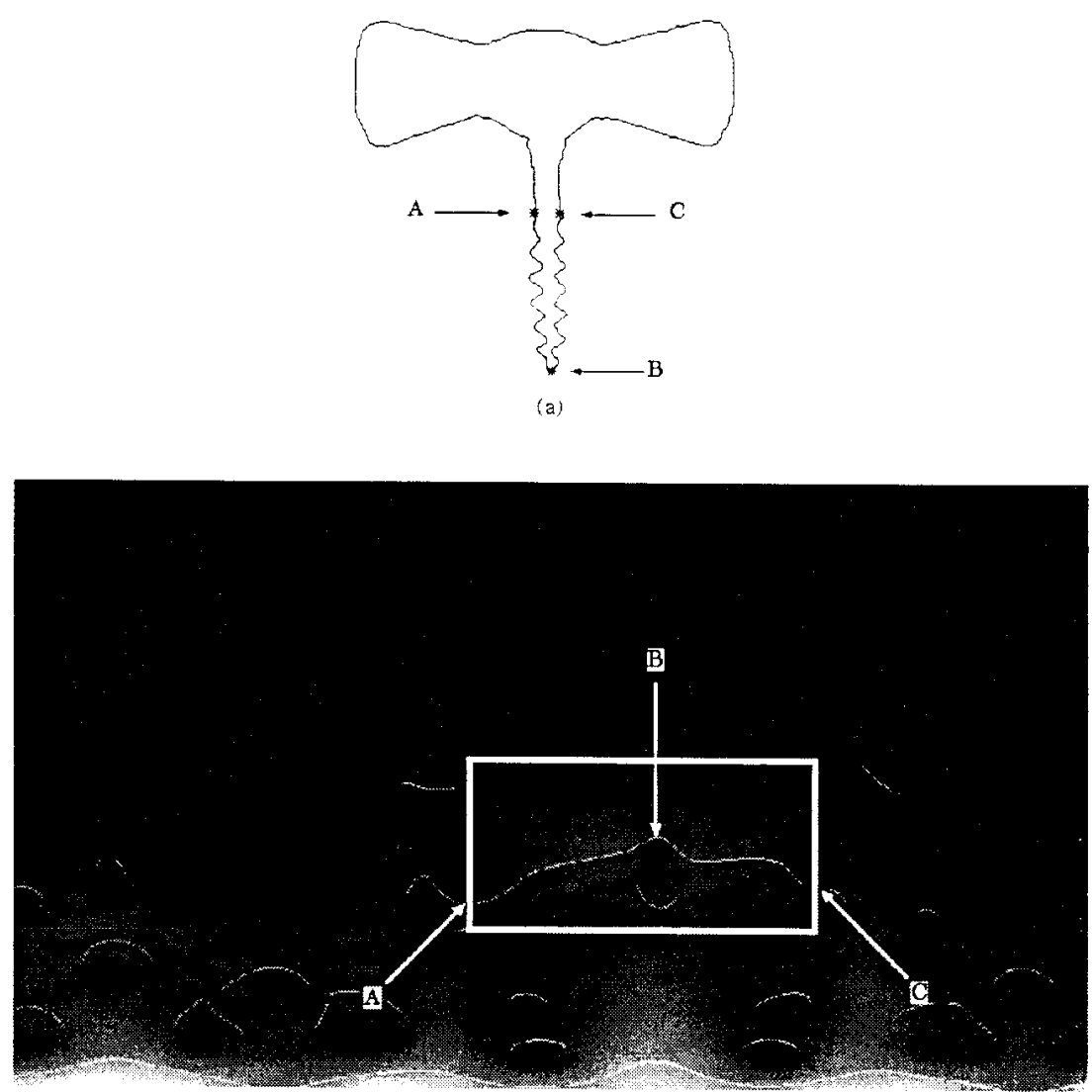

(b)

Figura (5.18): Exemplo da ocorrência de um padrão periódico local em um objeto real e sua respectiva detecção pela representação- $W$.

ocorrendo em um objeto real, como um complemento para o exemplo da circunferência com textura senoidal.

Um tópico que deve ainda ser pesquisado futuramente é o do desenvolvimento de algoritmos robustos para a extração dos pontos de transição entre os padrões periódicos. Enquanto o algoritmo de detecção de vértices pode ser aplicado para a segmentação do contorno da circunferência com textura, o que pode ser conferido na Figura 5.17, infelizmente esse não é o caso para formas de imagens reais em geral. É um fato conhecido que a abstração de verdadeiras linhas espectrais de ruído presente no plano tempo-escala (ou tempo-freqüência) não é um problema simples (veja, por exemplo, [Delprat, 1992]), sendo que diversos métodos já foram propostos para essa tarefa (como, por exemplo, algoritmos baseados em "snakes", isto é, modelos de contornos ativos), embora sem um maior sucesso geral.

Finalmente, existe ainda um último ponto essencial a ser comentado. Embora métodos completamente automáticos sejam importantes em diferentes situações, como em algumas áreas de robótica, eles não são a única meta da pesquisa em visão 
computacional. Métodos semi-automáticos estão presentes em diferentes situações práticas nas quais os problemas são resolvidos interativamente pelo computador e pelo ser humano.

Em suma, esta seção encerra uma contribuição conceitual à pesquisa em análise de formas, a definição e detecção de escalas naturais em termos de freqüências, e, embora os métodos completamente automáticos robustos que possam ser aplicados na segmentação de contornos ainda devam ser pesquisados e desenvolvidos futuramente, os conceitos introduzidos podem ser aplicados em análise semi-automática de formas.

\subsection{ANÁLISE FRACTAL}

0 omo foi discutido anteriormente, a representação- $W$ permite a construção de bons algoritmos de deteç̧ão de vértices em contornos. Uma curva fractal pode ser vista como uma curva não-diferenciável, com vértices em toda sua extensão. Portanto, uma vez que a transformada em wavelets é eficiente na análise de medidas e/ou sinais, a análise fractal de curvas a partir da representação- $W$ passa a ser um caminho natural a ser trilhado. $\mathrm{O}$ gráfico de uma função não diferenciável [Arnèodo et al., 1995, Feder, 1988], curvas auto-similares como as construções de Koch [Tricot, 1993] e a silhueta de mapas de países [Mandelbrot, 1982] são exemplos de curvas fractais. As Seções 5.6 e 5.7 introduziram algoritmos para a detecção de características (vértices e escalas naturais, respectivamente) em contornos. Esta seção, por sua vez, discute maneiras de extração de informação relacionada à análise fractal a partir da representação- $W$. Deve ser salientado que a parametrização $u(t)$ da curva original desempenha um papel central nesta seção, pois os resultados dependem da parametrização escolhida.

\subsubsection{Análise Fractal usando a Transformada Contínua em Wavelets}

$\mathbf{\theta}$ sta seção revisa brevemente os principais conceitos de análise fractal por meio de wavelets, baseando-se principalmente nos trabalhos desenvolvidos pelo "Grupo de Bordeaux", liderado por Alain Arnèodo [Arnèodo et al., 1995]. Os livros de Mathias Holschneider [Holschneider, 1995] e Arnèodo [Arnèodo et al., 1995] fornecem maiores detalhes e resultados rigorosos. Dentro desse contexto, os desenvolvimentos desta tese buscam generalizar os resultados já existentes para o caso de curvas paramétricas para aplicações em análise de formas. Tendo isso em vista, adota-se a definição da transformada em wavelets apenas nesta seção:

$$
U[\psi, u](b, a)=U_{\psi}(b, a)=\frac{1}{a} \int_{-\infty}^{\infty} \Psi^{*}\left(\frac{t-b}{a}\right) u(t) d t
$$




$$
=\frac{1}{2 \pi} \int_{-\infty}^{\infty} \Psi^{*}(a \omega) \hat{u}(\omega) e^{i \omega t} d \omega
$$

Uma medida fractal $\mu$ pode, geralmente, ser caracterizada por um conjunto de expoentes ou dimensões locais. A extração de tais expoentes pode ser realizada através do método de contagem de caixas ("box-counting"), isto é, o expoente no ponto $x_{0} \in$ supp $\mu$ (suporte da medida) é definido por

$$
\mu\left(B_{x_{0}}(\varepsilon)\right) \sim \varepsilon^{\alpha\left(x_{0}\right)}
$$

em que $B_{x_{0}}(\varepsilon)$ é uma bola centrada em $x_{0}$ e de diâmetro $\varepsilon$, e $\mu\left(B_{x_{0}}(\varepsilon)\right)$ é sua medida, definida por:

$$
\mu\left(B_{x_{0}}(\varepsilon)\right)=\int B_{x_{0}}(\varepsilon) d \mu
$$
wavelets:

Essa definição pode ser generalizada dentro do espírito da transformada em

$$
T[\psi, \mu](b, a)=\int \psi\left(\frac{\mathrm{x}-\mathrm{b}}{\mathrm{a}}\right) d \mu
$$

em que a wavelet analisadora $\psi$ pode ser vista como uma caixa generalizada. Nesse sentido, a Equação 5.7 pode ser vista como uma transformada em wavelets da medida, $T[\psi, \mu]\left(b=x_{0}, \varepsilon\right)$, em que a wavelet analisadora $\psi$ relaciona-se com a caixa $B$. O expoente local $\alpha\left(x_{0}\right)$ é dado por:

$$
\alpha\left(x_{0}\right)=\lim _{a \rightarrow 0^{+}} \frac{\ln T[\psi, \mu]\left(b=x_{0}, a\right)}{\ln a}
$$

Essa generalização é interessante por 3 motivos principais: 
1. Os máximos locais do módulo $|T|$ fornecem uma partição natural da medida que pode ser usada na construção de uma função de partição para análise multi-fractal;

2. Usando uma função contínua como wavelet analisadora, os problemas provenientes de descontinuidades da caixa da Equação 5.7 são eliminados;

3. O comportamento singular da medida pode ser dissimulado por algum comportamento regular. Tal componente regular pode ser extraído utilizando-se uma wavelet com um número suficiente de momentos nulos.

A Equação 5.8 também fornece uma ponte entre a análise fractal de uma medida e a análise fractal de uma distribuição. Seja $u(x)=\mu([0, x])$ a função de distribuição da medida $\mu$. Então, exceto pela normalização, a definição 5.8 pode ser vista como a transformada contínua em wavelets da função $u$, em que a wavelet analisadora é a derivada de $\psi$, isto é:

$$
T[\psi, \mu](b, a)=T\left[\psi^{(1)}, u\right](b, a)=\frac{1}{a} \int \psi^{(1)}\left(\frac{\mathrm{x}-\mathrm{b}}{\mathrm{a}}\right) u(x) d x
$$

Essa definição não é restrita a funções $u$ que derivem de uma medida, podendo ser usada para análise de regularidade de uma função $u$. Seja a função $u$ Lipschitz em $x_{0}$ :

$$
\left|u(x)-P_{n}\left(x-x_{0}\right)\right| \leq C\left|x-x_{0}\right|^{h\left(x_{0}\right)}
$$

em que $P_{n}$ é um polinômio de ordem $n$. Seja $\psi^{(l)}$ a wavelet analisadora com $N=n+1$ momentos nulos. Tem-se que:

1. Deteç̧ão: Existe uma linha de máximos verticais $L_{\nu}$ que converge para $x_{0}$;

2. Caracterização: Ao longo dessa linha $L_{v}$, o módulo da transformada em wavelets comporta-se de acordo com a seguinte lei:

$$
\left|T\left[\psi^{(1)}, u\right]\left(b \in L_{v}, a\right)\right| \sim a^{h\left(x_{0}\right)}
$$


Portanto, a transformada em wavelets pode ser usada no estudo de regularidade de funções (ou, de forma mais geral, de distribuições; veja a discussão na Seção 5.6). Uma vez que o esqueleto vertical de $T[\psi, \mu]$ fornece uma partição natural da medida, o esqueleto de $T\left[\psi^{(l)}, u\right]$ fornece uma partição natural da função $u$. Nesse sentido, de maneira análoga ao caso da análise multifractal de uma medida (estatística de expoentes locais $\alpha$ ), uma análise multifractal também pode ser realizada em uma distribuição (estatística do expoente de Hölder $h$ ). Tal abordagem foi aplicada a diferentes problemas como análise de sinais de turbulência e seqüências de ADN [Arnèodo et al., 1995; Muzy et al., 1994].

\subsubsection{Curvas Exatamente Auto-Similares}

1 ma curva exatamente auto-similar $\Gamma$ é a união de $N$ cópias transladadas, rotacionadas e dilatadas de si mesmas [Tricot, 1993]:

$$
\Gamma=\bigcup_{j=1}^{N} F_{j}(\Gamma)
$$

em que os $F_{j}$ representam aplicações afins do plano. Aplicações $f_{j}$ podem ser associadas a $F_{j}$ da seguinte maneira [Tricot, 1993]:

$$
u\left(f_{j}(t)\right)=F_{j}(u(t))
$$
verificam:

Uma vez que $\Gamma$ é a imagem de um intervalo $I$ a partir de $u$, as aplicações $f_{j}$

$$
\boldsymbol{I}=\bigcup_{j=1}^{N} f_{j}(\boldsymbol{I})
$$

As funções $f_{j}$ não são definidas unicamente e dependem da escolha da parametrização. Uma conseqüência disso é que a função $u$ não reflete necessariamente a estrutura da curva $\Gamma$. Em outras palavras, a curva $\Gamma$ define diferentes medidas sobre o intervalo $I$, o que leva à procura da definição de uma parametrização natural $u(t)$. Sejam $\rho_{j}$ os fatores de dilatação das aplicações $F_{j}$, e $D$ a dimensão fractal da curva. Uma parametrização natural [Tricot, 1993; página 201] é definida por:

- A medida ou o tamanho de um arco é igual ao tempo passado sobre ele. (P.1)

- A medida do $\operatorname{arco} F_{j}(\Gamma)$ é $\rho_{j}^{D}$. (P.2)

- A medida do arco $F_{j l}\left(\ldots\left(F_{j k}(\Gamma)\right) \ldots\right)$ é $\left(\rho_{j l} \ldots \rho_{j k}\right)^{D}$. (P.3)

Nesse caso, os fatores de dilatação $\lambda_{\mathrm{j}}$ de $f_{j}$ são dados por $\rho_{j}^{D}$. 
Tomando o caso da curva triádica de Koch como exemplo, os fatores de dilatação $F_{i}$ são dados por $\rho=1 / \sqrt{3}$ e sua dimensão fractal é $\log 4 / \log 3$. Portanto, no caso da parametrização natural e $\boldsymbol{I}=[0,1]$ tem-se que $\rho^{D}=1 / 2$ e $u$ verifica a relação 5.10. A partir da representação $u$, adotando-se a parametrização natural, a dimensão fractal de uma curva pode ser obtida a partir da definição de tamanho local [Tricot, 1993], isto é:

$$
T(t, a)=\operatorname{size}(u(t-a), u(t+a))
$$

que se comporta como:

$$
T(t, a) \approx a^{l / D}
$$

A função "size" da Equação 5.11 inclui diferentes equações equivalentes [Tricot, 1993], sendo a distância entre os pontos $u(t-a)$ e $u(t+a)$ a mais simples, isto é:

$$
T(t, a)=|u(t+a)-u(t-a)|
$$

Recordando a abordagem de medidas explorada anteriormente, seria interessante definir a função $T(t, a)$ como o módulo da representação- $W$ de $u(t)$, e o esqueleto vertical correspondente como uma partição escala-espaço natural da curva $\Gamma$. A transformada em wavelets da curva $\Gamma$ é definida pelas Equações 5.1 e 5.2. Em uma parametrização natural $u(t), \lambda_{l}$ é igual a $\rho_{l}^{D}$, de maneira que espera-se que o módulo da transformada se comporte ao longo de uma linha de máximos como $\alpha=1 / D$. Esse resultado não-rigoroso é análogo (para a transformada em wavelets) ao teorema de Tricot que indica $T(t, a) \sim a^{1 / D}$ para o caso da parametrização natural. Assim, conjectura-se os seguintes resultados para o caso de uma parametrização natural de uma curva fractal $\Gamma$ :

1. Partição: a representação- $W$ de $\Gamma$ admite um esqueleto vertical que fornece uma partição natural da curva;

2. Caracterização: ao longo de uma linha de máximos verticais, o módulo da transformada em wavelets comporta-se como:

$$
M[\psi, u](b, a) \sim a^{1 / D}
$$

em que $D$ é a dimensão fractal de $\Gamma$. 

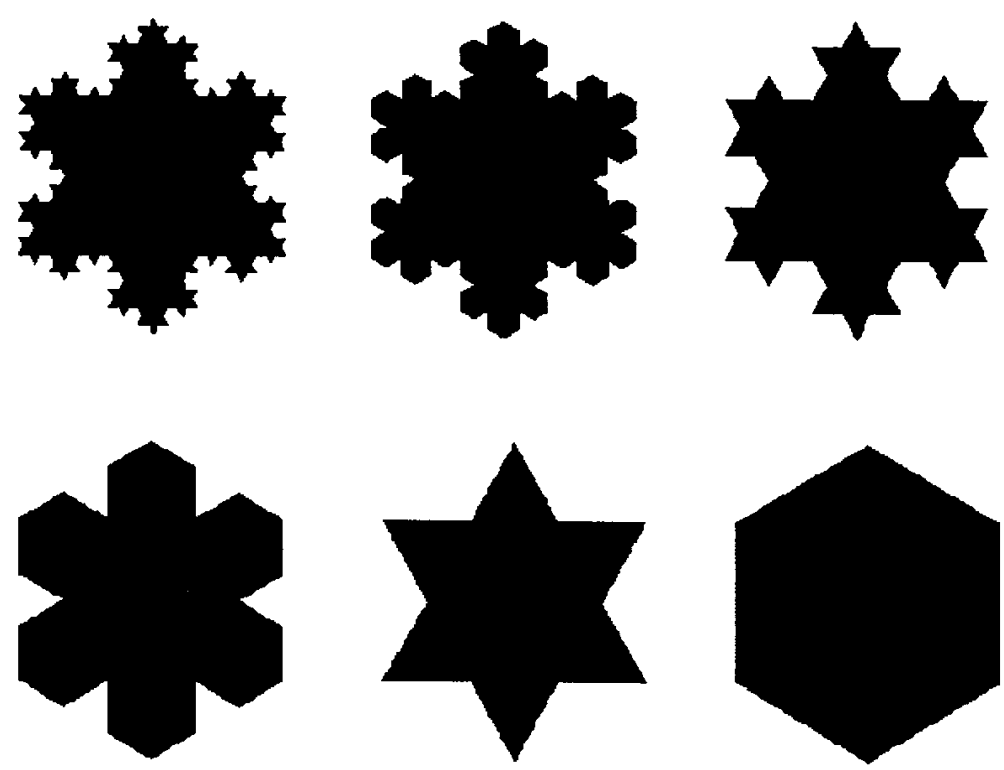

Figura (5.19): Aproximação poligonal multi-escala da curva de Koch que captura a lei de geração dessa curva.

\subsubsection{Exemplo: a curva triádica de Koch}

O esqueleto da representação- $W$ da curva de Koch é apresentado na Figura 5.9, evidenciando que a transformada em wavelets captura a regra de construção multi-escala auto-similar dessa curva. A aplicação do método de detecção de vértices desenvolvido na Seção 5.6 com diferentes valores de limiar fornece uma família de aproximações poligonais multi-escala da curva (veja a Figura 5.19). O gráfico de $M(b, a)$ ao longo de uma linha de máximos é apresentado na Figura 5.20 (escala logarítmica dos eixos). As oscilações de período log 4 são características da auto-similaridade da curva. No intervalo de fractalidade tem-se que $\log M(b, a)$ em função de $\log a$ é periódico de período log 4. Esse intervalo de escala é denominado região de escalonamento, sendo a inclinação de uma linha reta, ajustada manualmente a essa região, usada na estimação da dimensão fractal da curva de Koch $(\alpha=0.768 \approx 1 / D)$. 


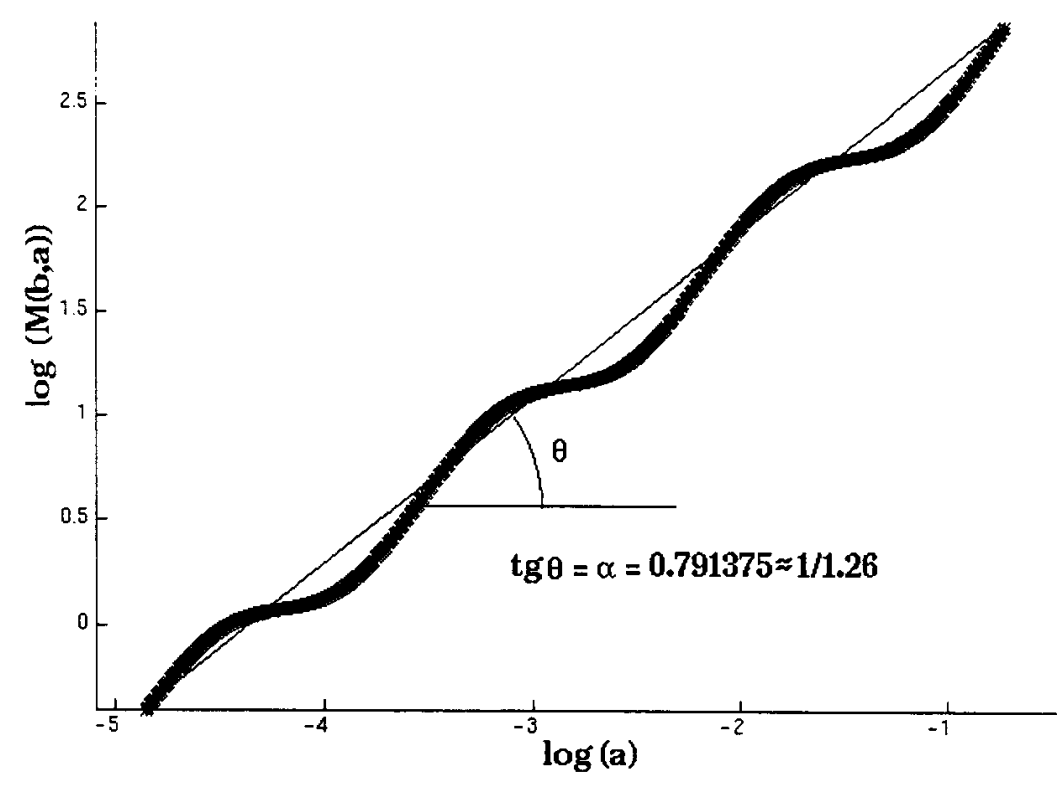

Figura (5.20): Gráfico do módulo da representação- $W$ ao longo de uma linha de máximos verticais (log-log plot).

\subsection{ANÁLISE DE FORMAS POR REPRESENTAÇÕES TEMPO-FREQÜÊNCIA} contornos de maneira análoga aos métodos desenvolvidos até então neste capítulo. $\mathrm{Na}$ verdade, a transformada de Gabor (isto é, a transformada de Fourier janelada com uma janela gaussiana) possui várias semelhanças com relação à transformada em wavelets usando a wavelet de Morlet, sendo, nesse sentido, melhor adaptada para análise de escalas naturais. No entanto, a transformada de Gabor também responde de maneira mais forte a vértices, embora a análise de singularidades seja melhor realizada utilizando-se uma das derivadas da gaussiana, por exemplo, a wavelet de Marr, como wavelet mãe. Uma outra característica que pode ser percebida através do estudo da literatura em análise tempo-escala e tempo-frequiência é que, em geral, a transformada de Gabor é bastante adotada para demonstrações algébricas. Uma das diferenças mais marcantes entre a transformada em wavelets e a transformada de Gabor (cujos núcleos são também chamados de gaborettes) é que, enquanto as gaborettes oscilam mais rápido para análise de altas frequiências e mais lentamente para a análise das baixas freqüências, as wavelets mudam apenas sua escala, mantendo constante o número de oscilações (veja a Figura 5.21). Essa característica explica uma das vantagens das wavelets em relação às gaborettes para análise de singularidades. 

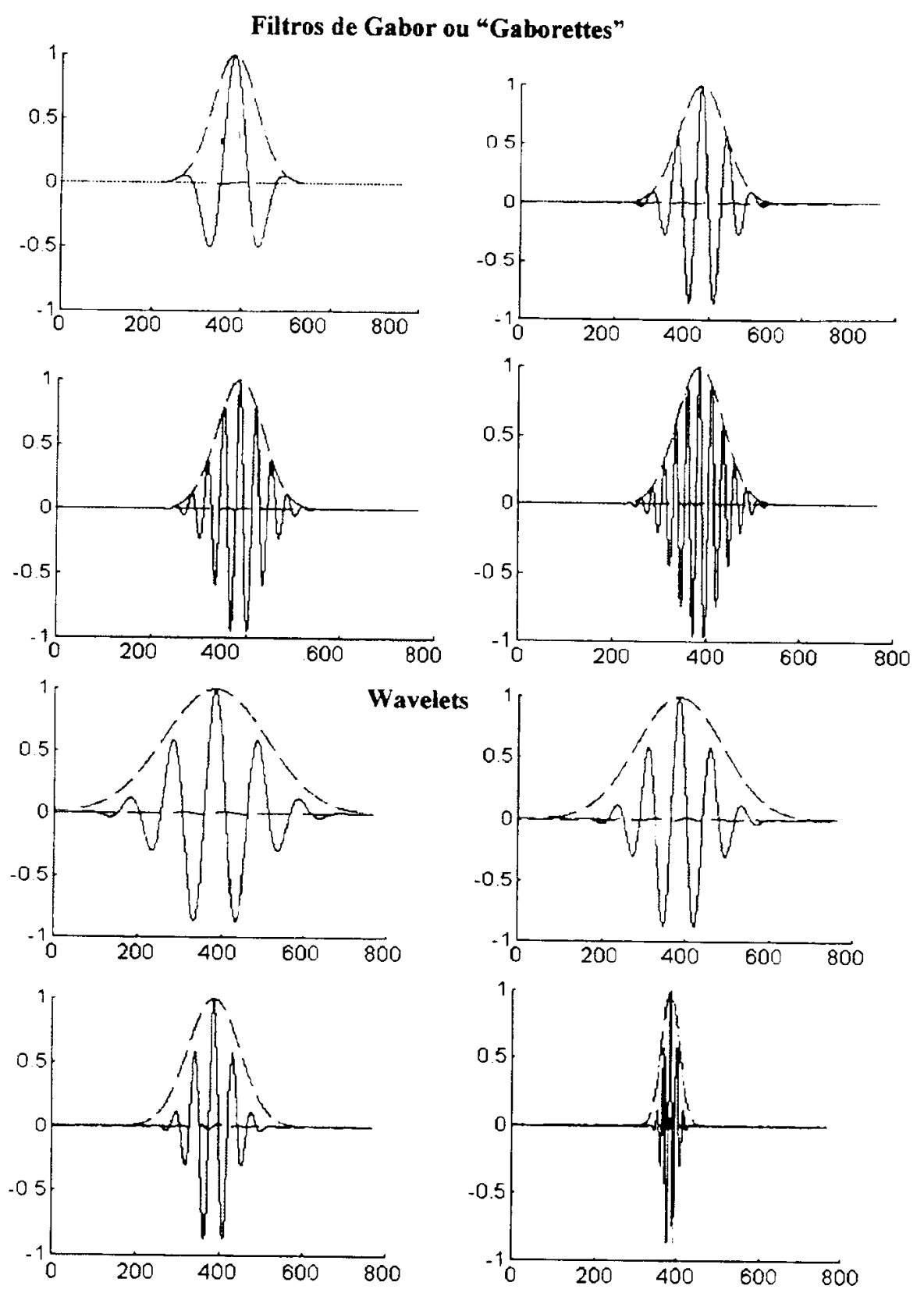

Figura (5.21): Conjunto de gaborettes e wavelets ilustrando as diferenças entre as duas abordagens. 


\subsubsection{A Transformada de Gabor de um Contorno}

transformada de Gabor $\mathrm{U}(b, f)$ de um contorno $u(t)$ é definida pelas seguintes equações:

$$
\begin{aligned}
U(b, f) & =\int_{-\infty}^{\infty} g^{*}(t-b) u(t) \mathrm{e}^{-i 2 \pi f t} d t \\
& =e^{-i 2 \pi f b} \int_{-\infty}^{\infty} G^{*}(v-f) U(v) e^{i 2 \pi f b} d v
\end{aligned}
$$

Pode-se pensar na transformada $U(b, f)$ como uma distribuição da energia freqüencial do sinal em função da evolução do tempo [Cohen, 1989]. O primeiro e mais clássico trabalho sobre caracterização tempo-freqüência de sinais foi proposto por $D$. Gabor meio século atrás [Gabor, 1946]. Em sua abordagem, Gabor propôs a decomposição de sinais por gaussianas moduladas por exponenciais complexas, as quais apresentam diversas qualidades como a obtenção de resultados ótimos sob o ponto de vista do princípio da incerteza [Daubechies, 1990; Gabor, 1946].

Uma breve análise da expressão da transformada janelada de Fourier permite a interpretação de uma linha da transformada, ou seja, $U\left(f_{0}, \tau\right)$ para a freqüência $f_{0}$ fixa, como sendo a resposta de um filtro passa-banda sintonizado à freqüência $f_{0}$. No caso da janela gaussiana, tais filtros são conhecidos como filtros de Gabor, possuindo diversas aplicações em visão computacional. Particularmente, pode-se citar a modelagem de resposta de células corticais [Marcelja, 1980] e, para a extensão 2D dessa teoria, a modelagem de campos receptivos 2D [Daugman, 1988], compressão de imagens [Daugman, 1988], segmentação de texturas [Bovik et al., 1990; Dunn et al., 1994; Dunn \& Higgins, 1995; Reed \& Wechsler, 1990] e agrupamento e organização de características em imagens no sentido da abordagem da psicologia Gestalt [Reed \& Wechsler, 1990]. É importante notar que, para o caso 2D, esses filtros apresentam um parâmetro adicional e igualmente importante, ou seja, a orientação [Daugman, 1988; Watson, 1987; Simoncelli et al., 1992; Freeman \& Adelson, 1991].

Como no caso da transformada contínua em wavelets, a aplicação de tal esquema de decomposição de sinais possui a desvantagem de a representação obtida ser altamente redundante devido ao fato de as funções da base não serem ortogonais [Bastiaans, 1980].

O próximo experimento ilustra a boa capacidade da transformada de Gabor em discriminar escalas naturais de objetos. Para essa finalidade, a circunferência com três texturas senoidais apresentada na Figura $\mathbf{5 . 1 5}$ foi analisada pela transformada de Gabor, que é mostrada na Figura 5.22 (módulo e fase). Essas transformadas estão sendo mostradas de maneira um pouco modificada: o parâmetro ao longo do contorno ainda é representado pelo eixo horizontal, mas o eixo vertical, que representa a variável de freqüência da transformada, inclui desde as menores freqüèncias negativas até as 


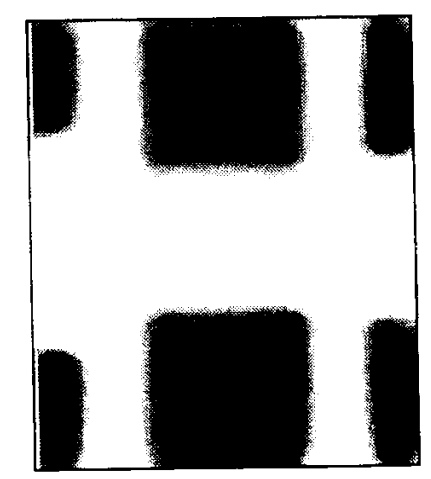

(a)

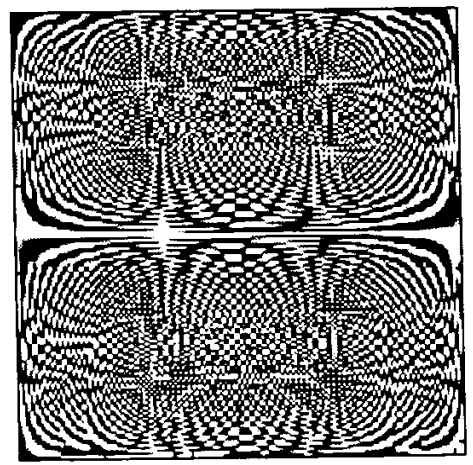

(b)

Figura (5.22): Transformada de Gabor (módulo e fase) da circunferência apresentada na Figura 5.15.

maiores positivas, crescendo de baixo para cima. Como pode-se perceber, o módulo da transformada responde mais fortemente quando essa estiver sintonizada corretamente em cada uma das freqüências locais responsáveis pelos três tipos de texturas da forma. Além disso, as faixas verticais de resposta mais forte correspondem aos pontos de transição entre as diferentes texturas.

Essa característica de responder mais fortemente nos pontos de transição entre as texturas permite a identificação automática desses pontos projetando-se o módulo da transformada sobre o eixo do tempo (horizontal, correspondendo ao parâmetro ao longo do contorno; veja a Seção 3.5). A Figura 5.23(a) apresenta o resultado da projeção, sendo que seus pontos de máximo local correspondem aos pontos de transição das três texturas, como é indicado na Figura 5.23(b).

Finalmente, o último experimento ilustra a importância da escolha da largura da

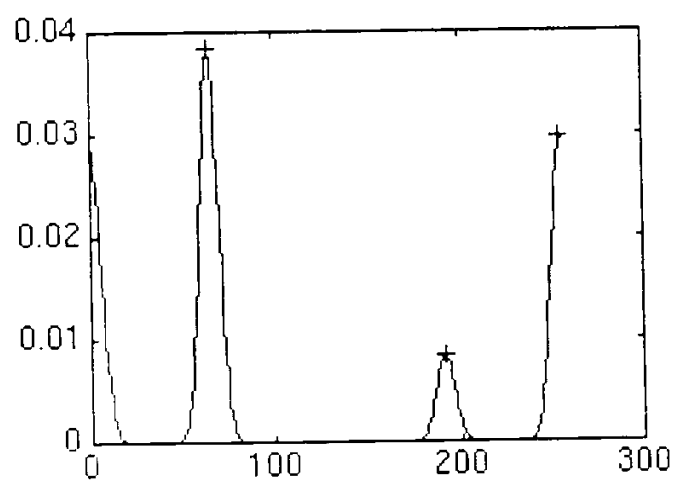

(a)

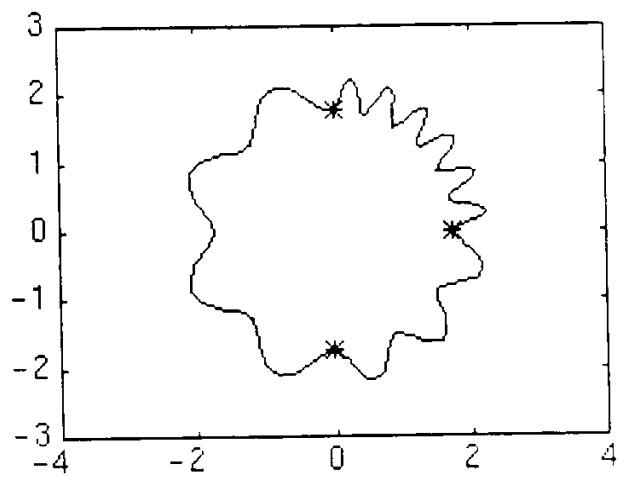

(b)

Figura (5.23): Projeção da transformada de Gabor da Figura 5.22 e os respectivos pontos de transição detectados corretamente. 
janela gaussiana da transformada de Gabor. Como uma breve análise direta indica, quanto menor o tamanho da janela $g$ da Equação 5.13, maior será a resolução no domínio do tempo, pois a transformada será capaz de discriminar eventos cada vez mais proximos. Mas, como já foi comentado, paga-se um preço por essa maior resolução: o princípio da incerteza implica que a resolução em freqüência diminui na medida que a resolução no tempo aumenta. A Figura 5.24 apresenta as respectivas transformadas de Gabor (módulo) da forma vista na Figura 5.15 para uma série de janelas de tamanho decrescente no domínio do tempo. Como pode-se perceber, na medida que a janela diminui de tamanho (maior resolução no tempo), as faixas correspondentes aos pontos de transição se estreitam em torno dos verdadeiros pontos dominantes, os quais podem ser localizados com maior precisão. Por outro lado, as faixas horizontais, correspondentes aos padrões periódicos locais, ficam cada vez menos precisas, o que reflete a perda de resolução freqüencial. 

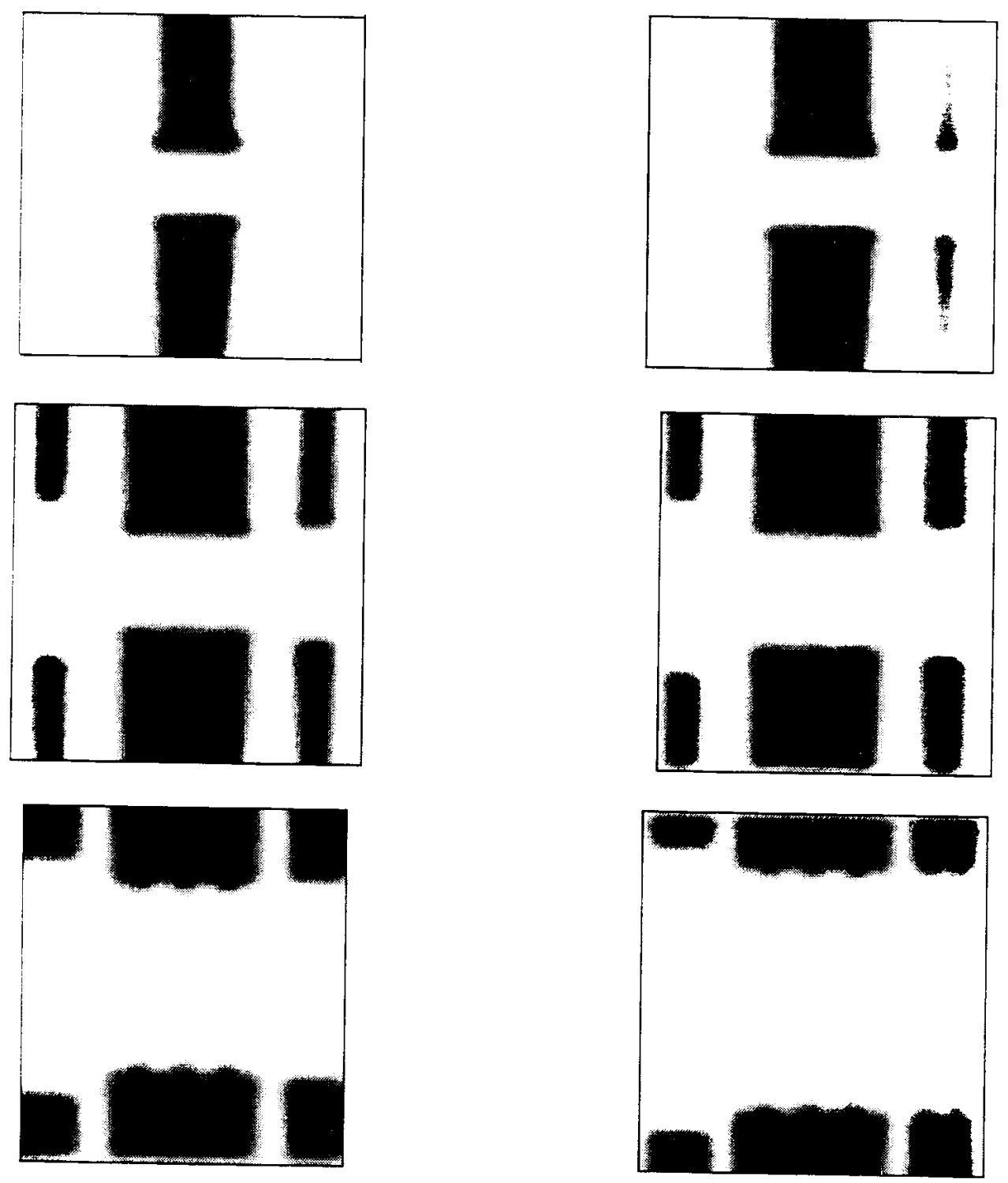

Figura (5.24): Série de transformadas de Gabor (módulo) da circunferência da Figura 5.15 para diferentes larguras da janela gaussiana da transformada. As larguras da janela do tempo diminuem de cima para baixo, da esquerda para direita. 


\subsection{CoMPARAÇÃo ENTRE AS REPRESENTAÇÕES MULTI-ESCALA}

7 sta seção apresenta um exemplo didático que ilustra as principais características que cada representação multi-escala discutida nesta tese possui. A Figura $\mathbf{5 . 2 5}$ mostra um contorno composto por 3 segmentos de reta, dois vértices e uma região semicircular acrescida de uma textura senoidal. Quatro diagramas de representações multiescala foram calculadas para esse contorno, a saber: o curvograma (Figura 5.26(a)); a representação- $W$ utilizando uma wavelet de Marr (módulo mostrado na Figura 5.26(b)); a representação- $W$ utilizando uma wavelet de Morlet (módulo mostrado na Figura 5.26(c)); e a transformada de Gabor do contorno (módulo mostrado na Figura 5.26(d)).

Uma comparação entre essas quatro representações, sob a luz das propriedades de cada uma discutidas neste capítulo e no anterior, permite que se resuma suas principais características da seguinte maneira:

- Curvograma: A principal vantagem do curvograma reside no fato de ser uma representação baseada em curvatura, uma das características mais importante no que concerne curvas bi-dimensionais. A observação da Figura 5.26(a) mostra que o curvograma detecta os vértices do contorno, afunilndo-se em torno deles na medida que a escala diminui. Além disso, o curvograma oscila na região do padrão periódico local até que a filtragem gaussiana elimina essas oscilações na medida que a escala aumenta. Em relação ao custo computacional, o curvograma é a representação mais cara em termos computacionais, uma vez que envolve o cálculo do equivalente a duas transformadas em wavelets, uma para a primeira derivada e outra para a segunda derivada do sinal;

- Representação- $W$ com a wavelet de Marr: Uma observação da Figura 5.26(b)

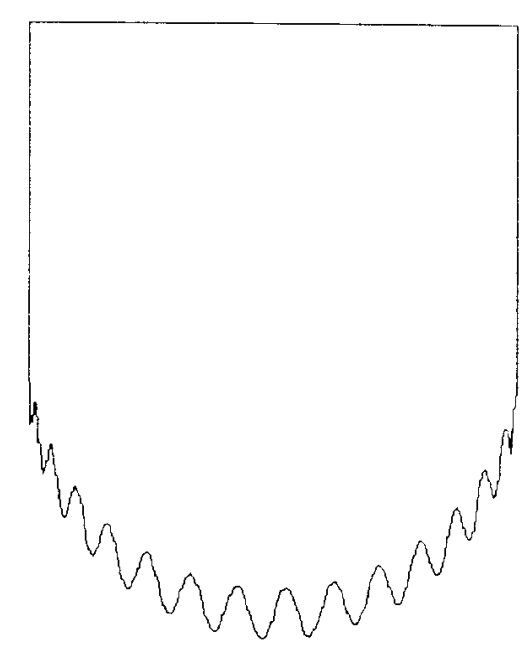

Figura (5.25): Contorno contendo dois cantos e um padrão periódico local. 
mostra uma grande semelhança entre essa representação e o curvograma, o que pode ser explicado pela natureza diferencial dessa wavelet. Essa representação possui duas vantagens em relação ao curvograma: é mais barata computacionalmente e carrega as propriedades da teoria das wavelets que podem ser utilizadas no desenvolvimento de outras ferramentas para análise de formas. Por outro lado, as excelentes propriedades da curvatura, presentes no curvograma, não podem ser exploradas nesta representação. Tanto o curvograma quanto a representação- $W$ com a wavelet de Marr podem ser usadas na detecção de vértices, embora o curvograma possa diferenciar regiões convexas de côncavas. Conjectura-se que a representação- $W$ também o possa com auxílio da informação de fase, embora esse seja um problema a ser pesquisado futuramente;

- Representação- $W$ com a wavelet de Morlet: Pode ser observada na Figura 5.26(c) e uma comparação dessa representação com as Figuras 5.26(b) e (d) mostra que ela é intermediária entre a representação- $W$ com a wavelet de Morlet e a transformada de Gabor do contorno. Assim, ela ainda apresenta a propriedade de "zoom" em torno dos vértices, embora de maneira menos explícita que a wavelet de Marr, ao mesmo tempo que responde de maneira mais forte horizontalmente em torno da frequêencia associada ao padrão periódico local;

- Transformada de Gabor do Contorno: Pode ser vista na Figura 5.26(c), possuindo a característica de boa detecção do padrão periódico local, de maneira semelhante à representação- $W$ com a wavelet de Morlet. No entanto, não possui a propriedade de "zoom" em torno dos vértices, limitando sua aplicação para esse tipo de problema. 

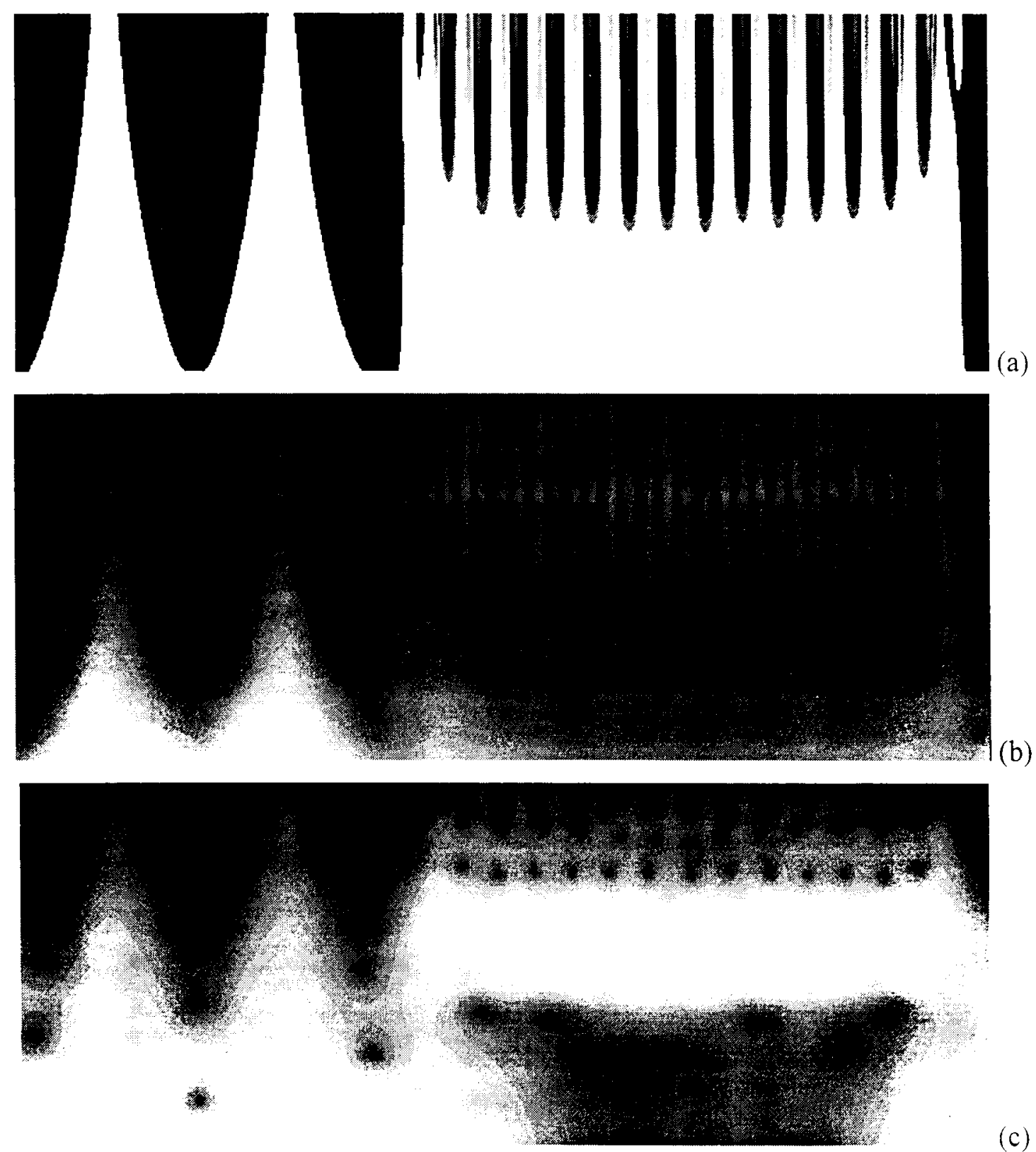

(c)

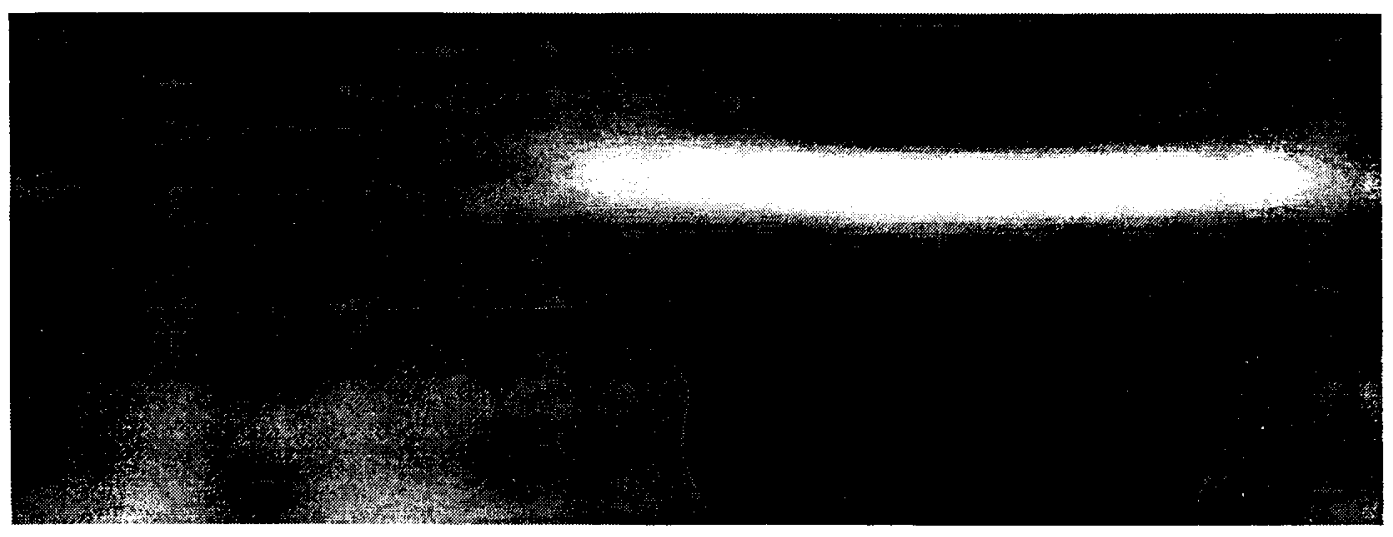

(d)

Figura (5.26): Representações multi-escala da forma da Figura 5.25. (a) Curvograma; (b) Representação- $W$ com a wavelet de Marr; (c) Representação- $W$ com a wavelet de Morlet; (d) Transformada de Gabor do contorno. Niveis de cinza mais claros codificam valores mais altos. 
As Figuras 5.27 e $\mathbf{5 . 2 8}$ ilustram como diferentes representações podem ser integradas para a resolução de problemas como detecção de padrões periódicos em formas. Como já foi comentado, o contorno da Figura 5.25 apresenta a região com uma textura periódica local que é bem detectada pela transformada de Gabor (assim como pela representação- $W$ com a wavelet de Morlet; veja as Figuras 5.26(c) e (d)). De fato, uma operação de limiarização nos coeficientes da transformada de Gabor (a original pode ser vista na Figura 5.26(d)) é capaz de selecionar praticamente apenas a região correspondente à região de oscilação periódica, como pode ser visto na Figura 5.27(a). $O$ esqueleto horizontal dessa representação limiarizada apresenta uma linha horizontal correspondendo à região do padrão periódico linha essa que pode ser vista na Figura 5.27(b) e (c). Por outro lado, como foi discutido, a transformada de Gabor não é uma boa ferramenta para localização com precisão de pontos dominantes, como é o caso dos pontos de transição entre as linhas retas e o padrão periódico da Figura 5.25. A representação- $W$ com a wavelet de Marr é uma ferramenta mais bem adaptada para essa tarefa, como indica o esqueleto vertical dessa representação, que pode ser visto na Figura 5.27(b). Uma operação de filtragem do esqueleto vertical em função do tempo de vida das linhas de máximos verticais, conforme explicado na seção de detecção de vértices deste capítulo, permite a identificação das linhas correspondentes aos pontos dominantes do contorno em questão, conforme pode ser observado na Figura 5.27(c). De fato, essa operação de filtragem do esqueleto vertical elimina as linhas correspondentes à região de oscilação do padrão periódico. Finalmente, os pontos de segmentação do contorno entre a região do padrão periódico e o restante podem ser obtidos a partir dos pontos de cruzamento entre os dois esqueletos, ou seja, o esqueleto horizontal da tranformada de Gabor e o esqueleto vertical filtrado da representação- $W$ com a wavelet de Marr. Os pontos de segmentação correspondentes a esses pontos de cruzamento são indicados na Figura 5.28. 

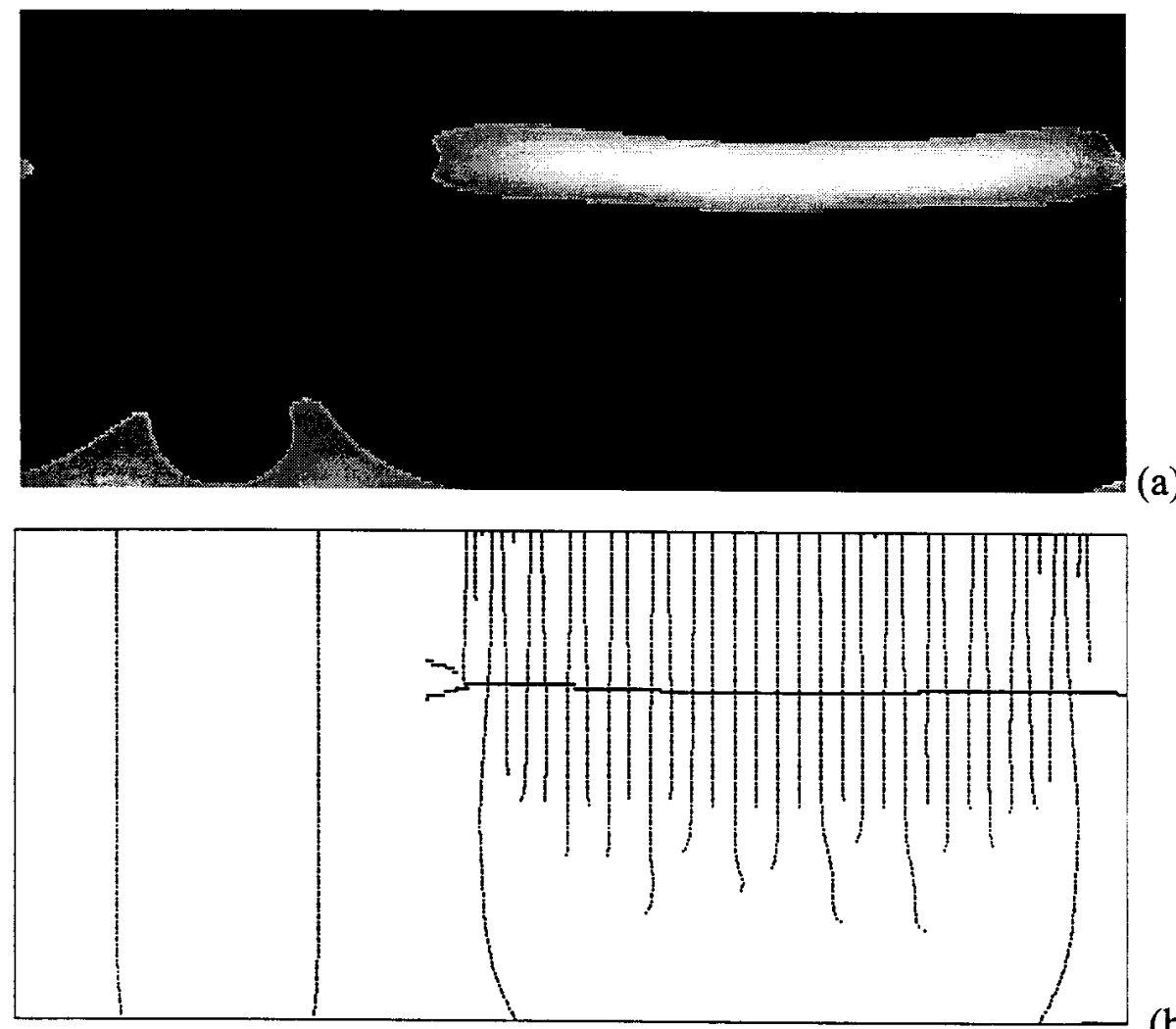

(b)

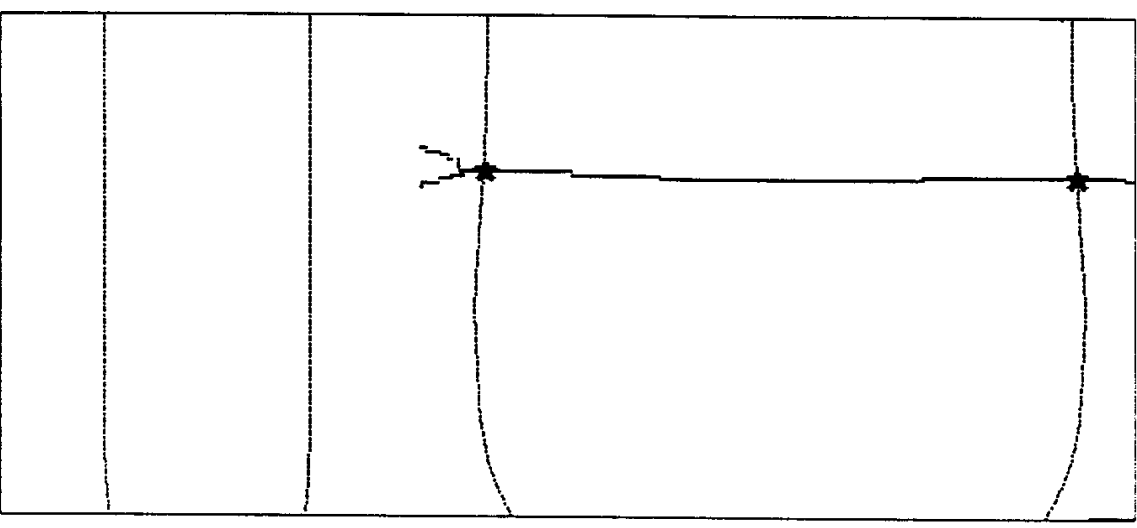

(c)

Figura (5.27): (a) Transformada de Gabor do contorno da Figura 5.25. O módulo da transformada de Gabor apresentada na Figura 5-26b foi limiarizado de modo que os coeficientes menores que um dado limiar foram anulados, resultando na transformada acima; (b) Sobreposição dos esqueletos horizontal da transformada de Gabor apresentada em (a) desta figura e do esqueleto vertical da representação- $W$ com a wavelet de Marr apresentada na Figura 5-26 (b); (c) Análogo ao (b), exceto que o esqueleto vertical foi limiarizado em função do tempo de vida das linhas de máximos, conforme explicado na seção de detecção de cantos. 


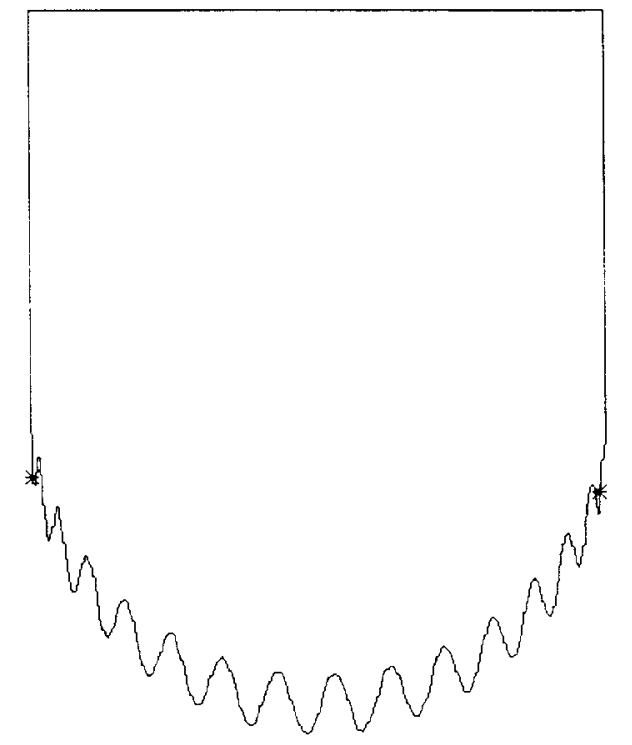

Figura (5.28): Os pontos de cruzamento dos esqueletos vertical e horizontal da Figura 5-28 (c) correspondem aos pontos de segmentação indicado nesta figura. 


\section{Capítulo 6 - Caracterização de Contornos Através de Energias Multi-Escala}

What is a government without energy? And what is a man without energy? Nothing - nothing at all. What is the grandest thing in "Paradise Lost" - the Arch-Fiend's terrible energy! What was the greatest feature in Napoleon's character? His unconquerable energy! Sum all the gifts that man is endowed with, and we give our greatest share of admiration to his energy. And today, if I were a heathen, I would rear a statue to Energy and fall down and worship it! 


\title{
6. Caracterização de Contornos através de ENERGIAS MULTI-ESCALA
}

\subsection{INTRODUÇÃO}

\begin{abstract}
Tos capitulos 4 e 5 foram introduzidas duas abordagens para a representação e análise multi-escala de contornos, incluindo algoritmos para deteç̧ão de determinadas características importantes para a análise de formas, como vértices e escalas naturais. Além disso, como já foi discutido em diferentes partes desta tese, a derivação de uma representação multi-escala de um contorno constitui apenas a metade da tarefa de análise de formas: resta a tarefa igualmente importante de análise da representação multi-escala para que as informações importantes em relação ao contorno sejam medidas. A detecção de vértices é um exemplo de um procedimento de análise da representação multi-escala. Este capítulo apresenta uma abordagem adicional de análise das novas representações a partir do conceito de energia multi-escala. Em particular, a energia de dobramento multi-escala, a qual pode ser calculada a partir do curvograma (veja o Capítulo 4) [Cesar \& Costa, 1996b, Cesar \& Costa, 1996f; Cesar et al., 1996g; Cesar \& Costa, 1997a], é introduzida e, em seguida, resultados experimentais são apresentados. De maneira análoga, a energia multi-escala de wavelets, calculada a partir da representação- $W$, é também introduzida. Essas medidas são exploradas dentro do contexto de classificação estatística de padrões, sendo que diversos experimentos de classificação automática de células ganglionares são relatados.
\end{abstract}

\subsection{ENERGIA DE DOBRAMENTO MULTI-ESCALA}

A energia de dobramento (ou energia de fronteira) é um conceito introduzido por I.T. Young e colaboradores [Young et al., 1974; Bowie \& Young, 1977] como uma medida global de forma para aplicações em análise e classificação de objetos. A energia de dobramento já foi aplicada com sucesso em problemas como análise do contorno do ventrículo esquerdo do coração [Duncan et al., 1991] e como um descritor de formas para o reconhecimento de objetos [Pernus et al., 1994]. Além disso, esse conceito originalmente proposto para aplicações baseadas no contorno da forma já foi 
generalizado para ser estimado diretamente na imagem em níveis de cinza [Vliet \& Verbeeck, 1993; Vliet, 1993] e objetos 3D. O número de diferentes trabalhos que relatam a aplicação com sucesso da energia de dobramento em problemas de análise de formas indica que ela já se tornou um descritor de formas clássico em visão computacional e reconhecimento de padrões [Pavlidis, 1980; Marshall, 1989; Castleman, 1996]. Desenvolvida a partir de conceitos de teoria da elasticidade, a energia de dobramento representa uma medida global que expressa a quantidade de energia necessária para transformar um dado contorno fechado em seu estado de menor energia, isto é, uma circunferência com o mesmo perímetro que o objeto original [Young et al., 1974]. Assim, a energia de dobramento é uma medida interessante para aplicações em classificação de formas, sendo invariante à translação, rotação e reflexão (transformações bidimensionais estão sendo consideradas aqui) e fornecendo uma medida de complexidade de formas. Em relação a formas relativas a objetos reais, como formas biológicas (por exemplo, membranas, neurônios, órgãos), a energia de dobramento apresenta uma interpretação física significativa em termos da energia que deve ser empregada na criação ou modificação do dito objeto. $\mathrm{Na}$ realidade, o possível relacionamento entre a energia de dobramento e o processo de crescimento do qual deriva a formação da forma biológica foi conjecturado no trabalho de J.E Bowie [Bowie \& Young, 1977]. Embora tal possibilidade não tenha sido investigada mais a fundo, é importante notar que esse possível relacionamento poderia ter implicações importantes em problemas de análise de formas biológicas, visto que a energia de dobramento poderia fornecer uma medida quantitativa sobre o processo físico de formação do objeto estudado. $O$ fracasso em se considerar tal relacionamento entre a medida de forma e o processo gerador do objeto em questão é um dos maiores problemas com alguns descritores comumente usados em neuromorfometria [Panico \& Sterling, 1995; Murray, $1995]$.

A energia de dobramento média é definida como a integral (ou soma, no caso discreto) do quadrado da curvatura ao longo do contorno, dividida pelo respectivo perímetro (ou número de pontos, no caso discreto), isto é:

$$
\widehat{B}=\frac{1}{N} \sum_{n=0}^{N-1} k(n)^{2}
$$

A versão multi-escala é obtida calculando-se a energia definida pela Equação 6.1 para cada curva que corresponde a cada escala distinta [Pernus et al., 1994], o que pode ser feito determinando-se a energia a partir do curvograma, isto é:

$$
\hat{B}(a)=\frac{1}{N} \sum_{n=0}^{N-1} k(a, n)^{2}
$$


É importante notar que a energia de dobramento definida dessa maneira depende da escala, visto que a curvatura é inversamente proporcional à escala da curva correspondente. Isso significa que a energia de dobramento definida pela Equação 6.2 está relacionada com a energia de uma circunferência com o mesmo perímetro do objeto analisado [Pernus et al., 1994]. Nos casos em que a invariância a escalonamento for requerida, a energia de dobramento deve ser normalizada, o que leva ao conceito de energia de dobramento multi-escala normalizada [Cesar \& Costa, 1996b: Cesar \& Costa, 1997a], definida como:

$$
B(a)=\frac{L^{2}}{N} \sum_{n=0}^{N-1} k(a, n)^{2}
$$

A energia definida pela Equação 6.3 é invariante a escalonamento da curva original, visto que o termo $L^{2}$ compensa o efeito do escalonamento na curvatura. Isso porque o escalonamento isotrópico por um fator $L$ de um objeto que inicialmente possui perímetro igual a 1 resulta no aumento de seu perímetro para $L$.

Finalmente, deve-se notar que a escolha da expressão da energia multi-escala (isto é, a versão sensível ou a invariante a escalonamento) depende da aplicação, a qual deve definir se a escala deve ser considerada ou não. No caso de aplicações em neuromorfometria, por exemplo, se o tamanho do neurônio for um parâmetro de discriminação importante, então a energia expressa pela Equação 6.2 deve ser usada. Caso contrário, se a análise deve proceder somente em termos da estrutura do neurônio, então a energia normalizada (Equação 6.3) deve ser aplicada. Todos os experimentos deste capítulo utilizam a definição da Equação 6.3, a qual será chamada simplesmente de energia de dobramento por questões de simplificação, podendo também ser referenciada pela sigla NMBE (do inglês "Normalized Multiscale Bending Energy").

\subsubsection{Interpretação da Energia de Dobramento}

^ energia de dobramento multi-escala de um contorno (Equação 6.3) é adotada como uma medida de complexidade de forma [Young et al., 1974; Castleman, 1996], apresentando resultados superiores aos de outras medidas desse gênero, como a razão entre o perímetro ao quadrado e a área ou a curvatura absoluta média do contorno [Bowie \& Young, 1977].

Os diagramas de energia de dobramento multi-escala são obtidos calculando-se a energia de dobramento para diferentes valores do parâmetro de escala $a$, fornecendo uma medida de complexidade de formas para cada escala de análise. Para pequenas escalas, isto é, pequenos valores de $a$, a curvatura é calculada em contornos que sofreram pouca suavização, retendo, conseqüentemente, grande parte dos detalhes de pequena escala. $\mathrm{Na}$ medida que a escala aumenta, esses detalhes são filtrados e a energia de dobramento começa a refletir a estrutura geral da forma. Pequenos detalhes, que são associados a 


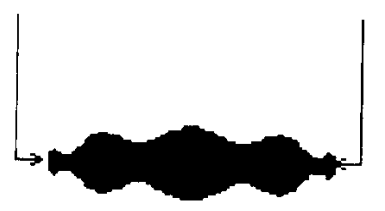

(a)

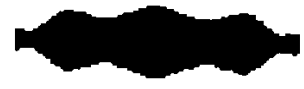

(b)

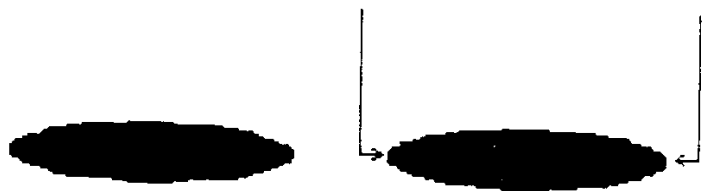

(c)

(d)

Figura (6.1): Evolução da elipse com textura através da filtragem multi-escala gaussiana com os pontos envolvidos no efeito de alta curvatura mascarada indicados.

altas freqüências, são filtrados antes de outras estruturas intermediárias, como grandes ramificações. Para grandes escalas, a energia de dobramento reflete a estrutura global do objeto, a qual é determinada pelas componentes de baixa freqüência da forma. $\mathrm{Na}$ medida que a escala aumenta ( $a$ aumenta), a largura de banda do filtro diminui ( $\tau$ diminui), sendo apenas as componentes de baixa freqüência conservadas.

É intuitivo pensar que a curvatura e, portanto, a energia de dobramento, devem diminuir na medida que a escala aumenta. De fato, a relação direta entre altas frequiências e altas curvaturas é geralmente aceita com naturalidade nas pesquisas em análise de contorno. Porém, a pesquisa sobre a energia de dobramento multi-escala levou a um contra-exemplo dessa conjectura, o qual pode representar uma situação de falha na capacidade de discriminação de complexidade de formas da energia de dobramento. Tal efeito, denominado efeito de alta curvatura mascarada, é discutido na próxima seção.

\subsubsection{Efeito de alta curvatura mascarada e algumas possíveis soluções}

eja $c(t)=(x(t), y(t))$ a equação paramétrica de uma elipse com uma textura senoidal acrescentada à sua borda, ou seja:

$$
\begin{aligned}
& x(t)=\xi_{1} \cos (t) \\
& y(t)=\xi_{2} \sin (t)+\xi_{3} \sin \left(\begin{array}{ll}
\varphi & t
\end{array}\right),
\end{aligned}
$$

em que $\varphi$ define uma textura senoidal vertical sobre a elipse. Um exemplo de tal forma é apresentado na Figura 6.1(a). Uma breve análise da Equação 6.4 indica que é possível definir-se uma circunferência se $\xi_{1}=\xi_{2}$ e $\xi_{3}=0$ ou uma elipse simples se $\xi_{1} \neq \xi_{2}$ e $\xi_{3}=$ 0 . Assumir-se-á que $\xi_{1}>\xi_{2}$, o que implica que a elipse de base é mais alongada na direção do eixo $x$ (veja a Figura 6.1). Os pontos de maior curvatura dessa elipse estão localizados nas extremidades laterais, como está indicado na Figura 6.1. Ajustar $\xi_{3} \neq 0$ faz com que a textura senoidal seja acrescentada ao contorno elíptico, uma operaçâo que faz com que a alta curvatura das extremidades laterais seja atenuada, como uma breve observação das Figuras 6.1(a) e (d) pode mostrar. Na medida que essa textura é filtrada 


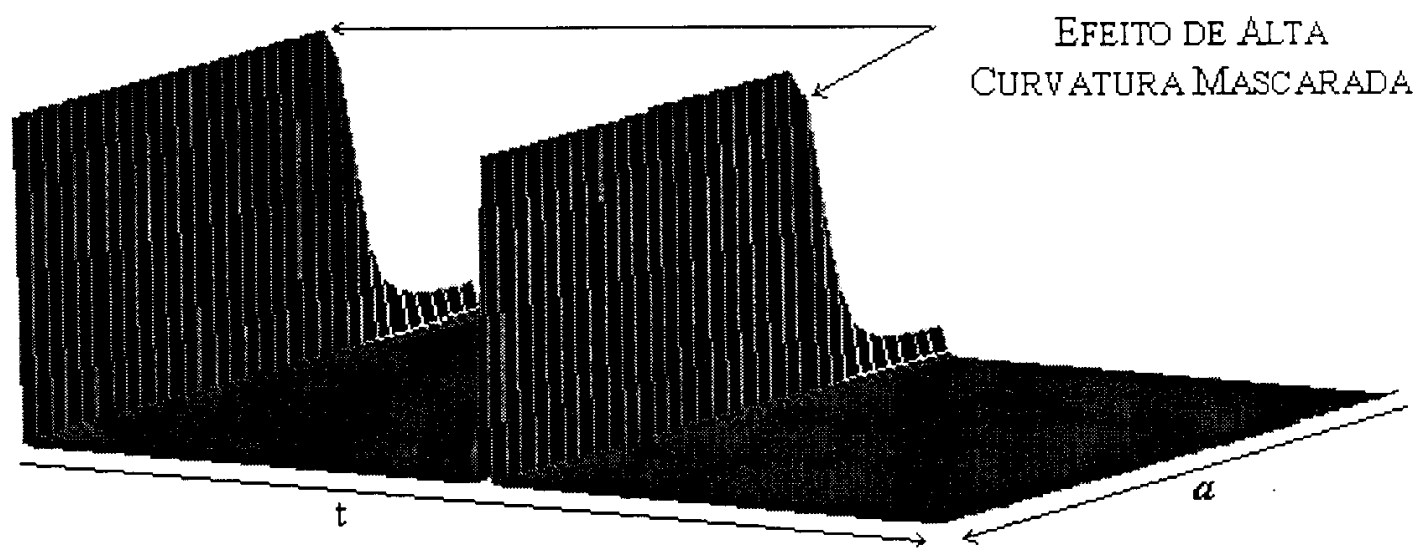

Figura (6.2): O curvograma da elipse com textura vista na Figura 6.1(a). Os pontos nos quais a curvatura aumenta com a escala, o que caracteriza o efeito de alta curvatura mascarada, são indicados na imagem.

pelo processo de convoluções com gaussianas de escalas crescentes, a curvatura aumenta nesses pontos laterais extremos. Esse efeito significa que, apesar do fato de as altas freqüências serem atenuadas durante o processo de filtragem multi-escala, a curvatura pode aumentar substancialmente em determinados pontos, dependendo apenas do alongamento da elipse, o qual pode ser caracterizado pelo raio $\xi_{2} / \xi_{1}$. Esse tipo de comportamento é ilustrado na Figura 6.2, a qual mostra o curvograma da elipse da Figura 6.1(a). Os pontos do curvograma que apresentam um aumento acentuado de curvatura estão indicados na figura, ao passo que a energia de dobramento para esse contorno é apresentada na Figura 6.3 (todos os gráficos da energia de dobramento são apresentados em log-log). Como pode-se perceber, existe um aumento acentuado da curvatura nessas extremidades, o que implica no aumento substancial na energia de dobramento, um efeito denominado efeito de alta curvatura mascarada. No caso desse exemplo específico, os seguintes valores de constantes foram adotados: $\xi_{1}=100 ; \xi_{2}=1$; $\xi_{3}=0.25 ; \varphi=9$; sendo que o contorno possui 128 pontos. $O$ raio $\xi_{2} / \xi_{1}=0.01$ indica que a elipse é 100 vezes mais alongada no eixo $x$. Para propósitos de apresentação, o eixo $x$ está mais comprimido do que o eixo $y$ na Figura 6.1. 
Dois importantes fatos decorrem do efeito da alta curvatura mascarada. Em primeiro lugar, o aumento da energia de dobramento nas escalas intermediárias pode significar a existência de "braços" alongados na forma. De fato, conjectura-se que essas estruturas apresentam um comportamento semelhante ao da elipse com textura. Embora esta suposição seja difícil de ser provada analiticamente devido à infinidade das possiveis configurações que tais estruturas podem assumir, diversos resultados experimentais observados extensivamente corroboram essa conjectura. Alguns desses experimentos são descritos na Seção 6.3.2. Esse fato significa que a energia de dobramento indica a presença de uma estrutura específica particularmente importante para percepção de formas: os braços alongados, os quais cumprem um papel central em uma teoria de análise de formas recentemente formulada [Kimia et al., 1995; Siddiqi \& Kimia, 1995]. Além disso, o efeito de alta curvatura mascarada carrega em si uma situação potencial de erro no que concerne à interpretação da energia de dobramento como uma medida de complexidade de formas. Intuitivamente, pode-se dizer que a forma da elipse com textura, vista na Figura 6.1 (a), é mais complexa do que a elipse simples da Figura 6.1(d). Porém, como foi visto, esse não é o caso do ponto de vista da energia de dobramento. Esse problema existe devido à alta curvatura presente nas extremidades laterais da elipse, a qual predomina em relação à curvatura do resto do contorno.

Uma maneira possível de se contornar esse problema apresenta-se por meio da ponderação da soma que define a energia de dobramento, de maneira que o efeito dos pontos problemáticos seja minimizado. Um exemplo de como isso pode ser feito é ordenando-se as curvaturas (ao quadrado) definidas ao longo do contorno em ordem crescente. As Figuras 6.4(c) e (e) mostram as curvaturas ordenadas dos contornos das Figuras 6.1(a) e (d), respectivamente, sendo que as curvaturas ao quadrado são apresentadas em escala logaritmica. A curvatura para a elipse com textura apresenta um aumento acentuado na porção final do gráfico devido aos pontos com altíssima

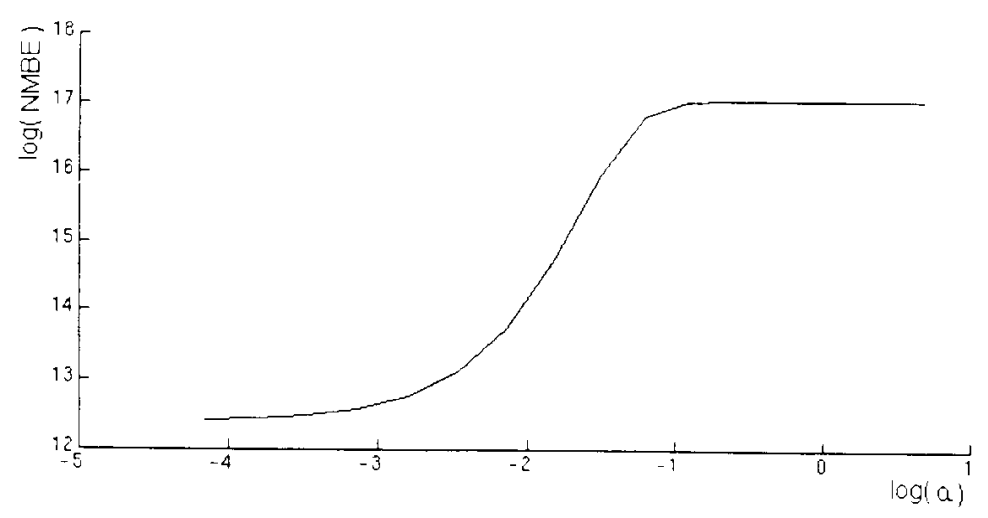

Figura (6.3): Energia de dobramento da elipse com textura vista na

Figura 6.1(a). 
curvatura. A soma ponderada pode ser realizada multiplicando-se as curvaturas ordenadas por uma gaussiana centrada no ponto médio do vetor ordenado (veja a Figura 6.4(a)) sendo que a nova energia de dobramento ponderada pode ser obtida somando-se a curvatura ponderada. As funções resultantes das Figuras 6.4(c) e (e) são mostradas nas Figuras 6.4(d) e (f), respectivamente, sendo estas menos afetadas pelas extremidades do vetor ordenado. Esse processo foi aplicado a todas as escalas da elipse com textura e a nova energia de dobramento é apresentada na Figura 6.4(b). É instrutivo comparar esse gráfico com aquele apresentado na Figura 6.3. A energia de dobramento ponderada indica que a forma da Figura 6.1(a) é mais complexa que a da Figura 6.1(d), o que coincide com a análise intuitiva. Entretanto, a despeito de tal resultado favorável, essa abordagem possui algumas desvantagens. Em primeiro lugar, ela introduz artefatos, tais como a definição da função de ponderação e sua influência na soma da energia, os quais devem ser analisados cuidadosamente; e, finalmente, a interpretação física da energia de dobramento, ligada à teoria de elasticidade, uma característica desejável e importante dessa medida, é, de certa maneira, distorcida. 


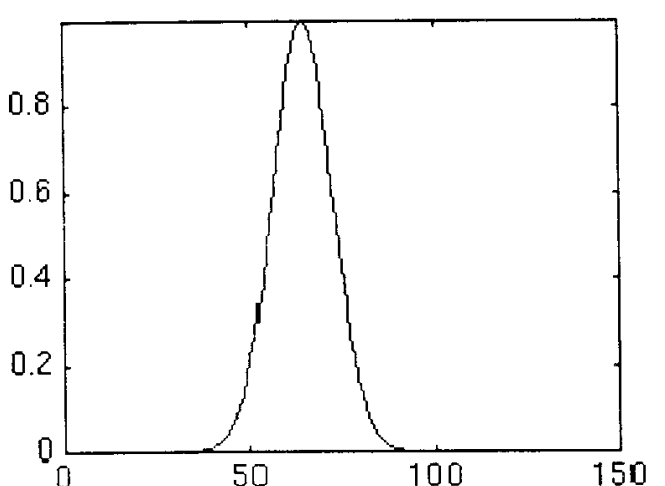

(a)
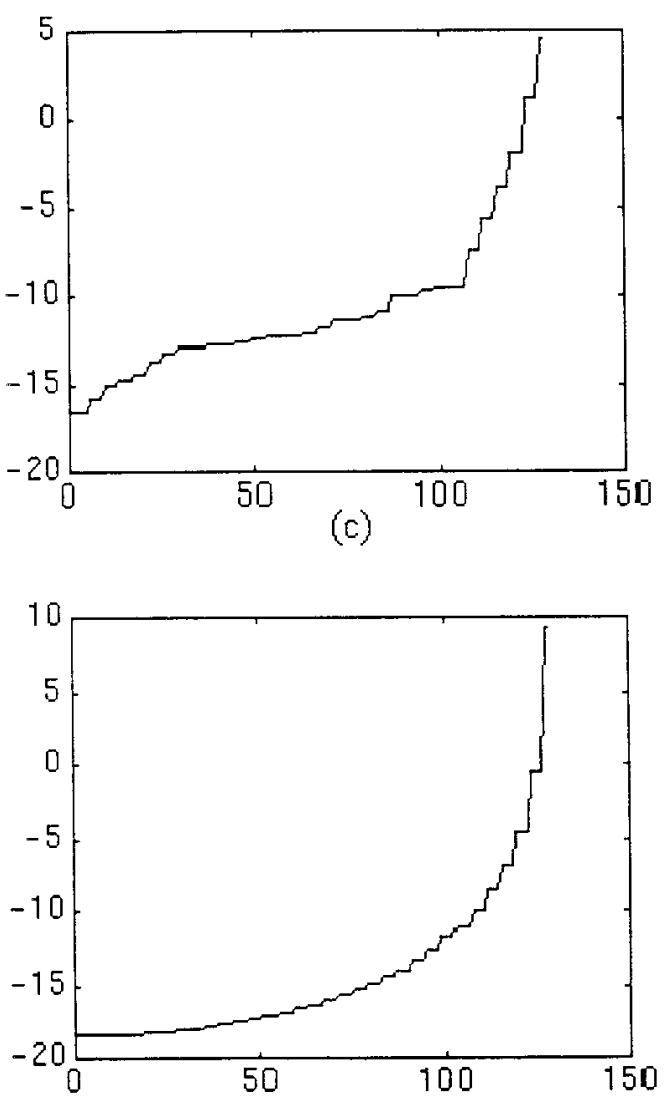

(e)

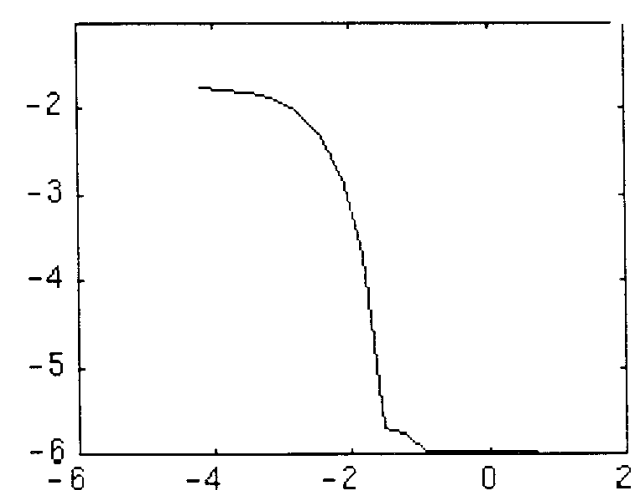

(b)

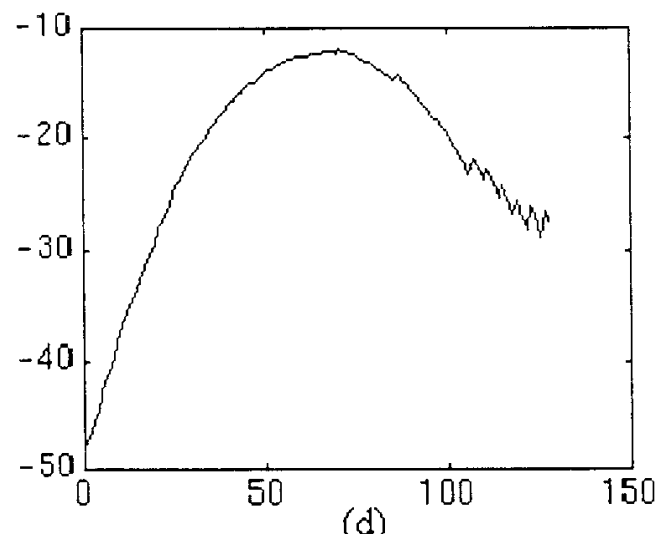

(d)

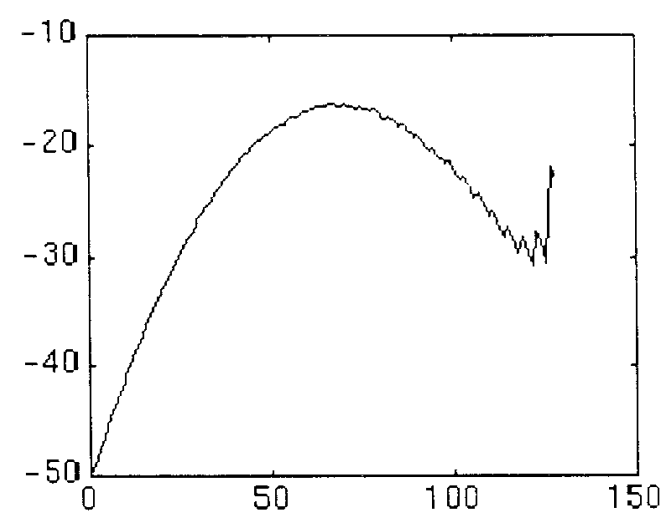

(f)

Figura (6.4): (a) Gaussiana usada como função de ponderação para a energia de dobramento modificada; (b) Nova energia de dobramento obtida pela soma ponderada das curvaturas ao quadrado; (c) curvaturas ordenadas da elipse com textura da Figura 6.1(a); (d) Curvaturas ordenadas da forma da Figura 6.1(a) ponderadas pela gaussiana; (e) Curvaturas ordenadas da forma da Figura 6.1(d); (f) Curvaturas ordenadas da forma da Figura 6.1(d) ponderadas pela gaussiana. 


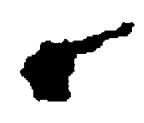

(a)

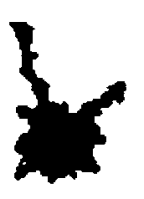

(e)

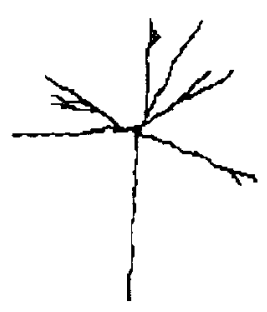

(i)

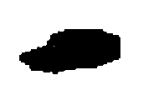

(b)

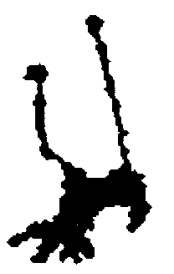

(f)

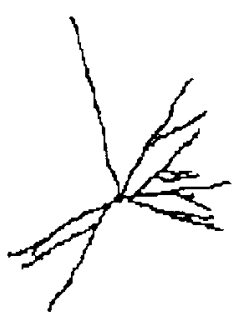

(j)

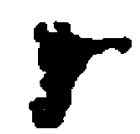

(c)

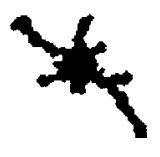

(g)

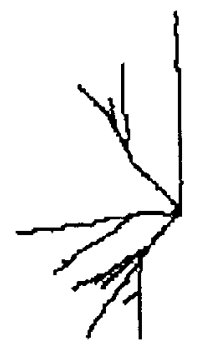

$(\mathrm{k})$

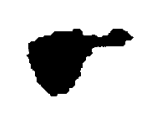

(d)

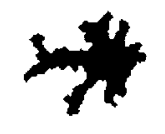

(h)

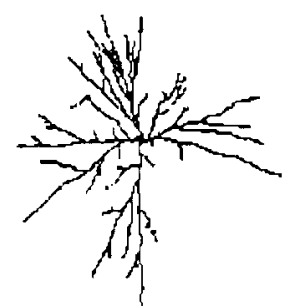

(1)

Figura (6.5): Diferentes formas biológicas usadas em experimentos de avaliação da energia de dobramento.

\subsection{NEUROMORFOMETRIA USANDO A ENERGIA DE DOBRAMENTO}

0 esquema de análise de formas baseado na energia de dobramento apresentado nesta tese foi aplicado à análise de complexidade geral de 12 células neurais apresentadas na Figura 6.5 (a) - (1). As formas na primeira linha (Figura 6.5 (a)-(d)) foram obtidas de imagens de cérebros de ratos. O tipo de preparado histológico usado nessas imagens enfatiza apenas o corpo celular, enquanto a árvore dendrítica é pobremente refletida. As formas na segunda linha provêem do córtex cerebral de camundongos (estágio embrionário). Finalmente, as formas da terceira linha são obtidas por modelos de geração de neurônios baseados em gramáticas formais.

O pré-processamento da imagem antes da extração do contorno foi basicamente o mesmo para todas as imagens. Estas foram segmentadas por limiar simples, seguido de filtragem mediana para supressão de ruído pontual. Uma vez que a célula foi segmentada, a operação de dilatação morfológica foi aplicada para dilatar regiões de 1 pixel de largura, regiões as quais poderiam acarretar singularidades artificiais (como auto-intersecção no contorno) que poderiam comprometer a eficácia do algoritmo. 

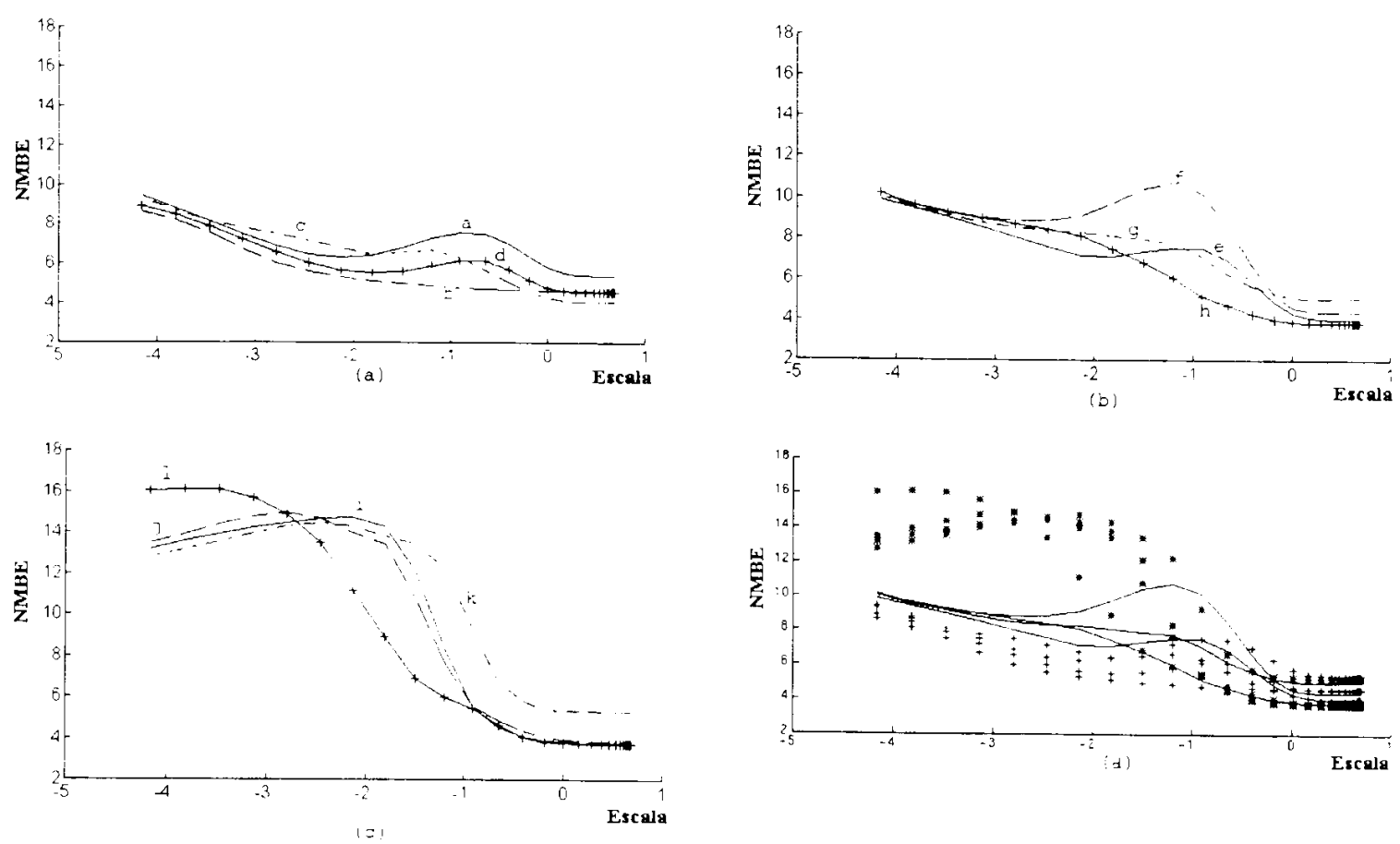

Figura (6.6): Energias de dobramento multi-escala para as células da Figura 6.5. (a), (b) e (c) correspondem, respectivamente, à primeira, segunda e terceira linhas da Figura 6.5, enquanto $(\mathrm{d})$ mostra uma sobreposição dos gráficos, em que "+" corresponde às células da primeira linha da Figura 6.5, "-" corresponde às células da segunda linha e "*" às células da terceira linha.

As formas da Figura 6.5 foram classificadas em três classes genéricas de complexidade, expressas pelas três respectivas linhas (classificação esta baseada no julgamento subjetivo do autor). A primeira, segunda e terceira linhas correspondem a neurônios com um grau baixo, médio e alto de complexidade, respectivamente. Deve-se observar que tal classificação baseia-se fortemente em detalhes de pequena escala. Os gráficos da energia de dobramento multi-escala normalizada para cada uma das três classes são apresentados, respectivamente, nas Figuras 6.6(a), (b) e (c) (o parâmetro de escala dos gráficos da energia de dobramento é apresentado em escala logarítmica), podendo ser vistos sobrepostos na Figura 6.6(d). Como pode ser notado, as formas da terceira linha da Figura 6.5 apresentam uma maior energia de dobramento, seguida pelas formas da segunda e da primeira linha (nesta ordem), o que corrobora a capacidade de discriminação de complexidade da energia de dobramento. É importante verificar que a energia de dobramento apresenta intersecções para algumas dessas diferentes formas, o que significa que a diferença relativa de complexidade entre as formas pode mudar em termos da evolução na escala. 


\subsubsection{Interpretando a Evolução em Escala da Energia de Dobramento}

1 ara mostrar como a energia de dobramento discrimina corretamente a complexidade das formas em termos da escala, vale analisar com maiores detalhes três formas que representam cada uma das classes de complexidade da Figura 6.5, tendo sido as formas das Figuras 6.5 (a), (e) e (l) escolhidas para esse propósito. A evolução de curva de cada uma dessas formas é mostrada nas Figuras 6.7(a), (b) e (c), nos diagramas denominados morfogramas, enquanto os respectivos diagramas de energia de dobramento são apresentados na Figura 6.8.
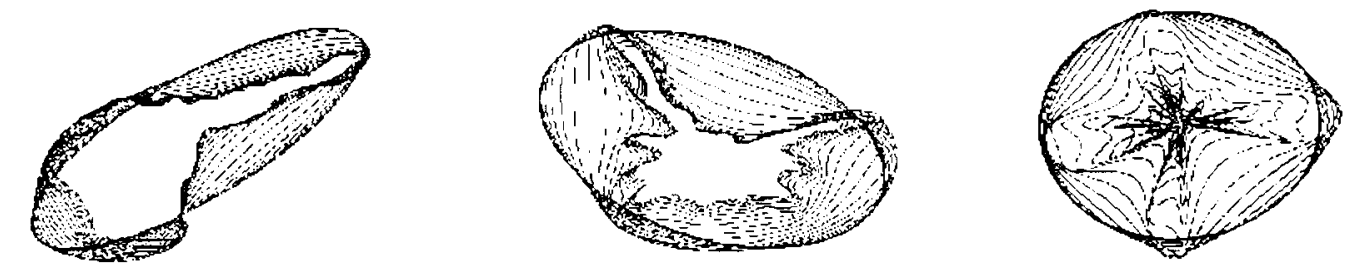

Figura (6.7): Morfogramas dos contornos das Figuras 6.5(a), (e) e (1).

A energia de dobramento relativa a pequenas escalas é maior para a forma da Figura 6.7(c), seguida pelas formas das Figuras 6.7(b) e (a), como esperado. Tal comportamento começa a se alterar a partir da escala $\sigma_{l}$ (indicado na Figura 6.8), a partir da qual a energia da forma da Figura 6.7(c) torna-se menor que a da Figura 6.7(b). O segundo ponto de interesse ocorre na escala $\sigma_{2}$, na qual a energia da forma da Figura 6.7(a) torna-se maior que a da Figura 6.7(b).

Para uma melhor compreensão do significado desses eventos, algumas das curvas

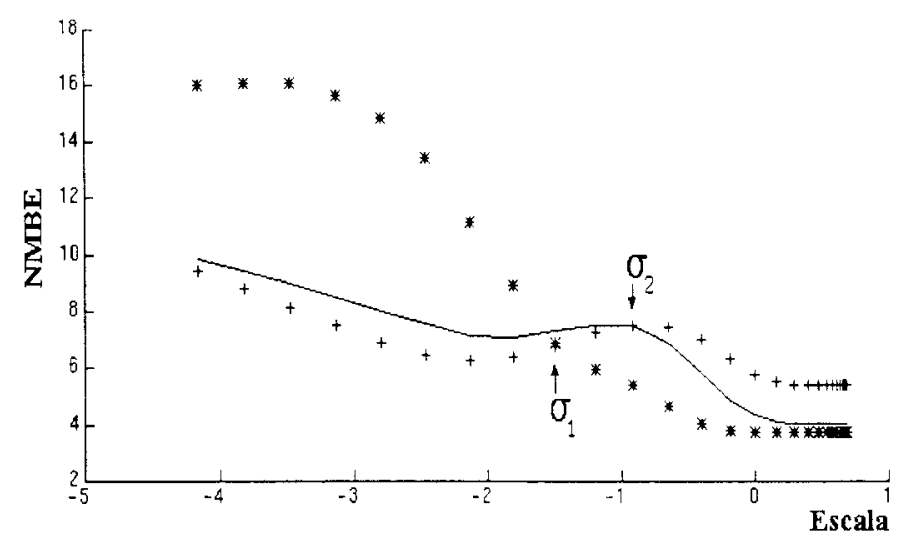

Figura (6.8): Energia de dobramento das Figuras 6.5(a) ("+"), (e) ("-") e (l) ("*").

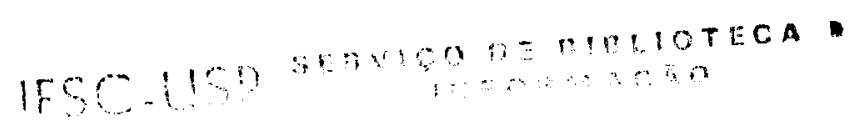




\begin{tabular}{lll}
\hline Contorno & "Aspect Ratio" original & "Aspect Ratio" final \\
\hline Figura 6.7(a) & 0.4727 & 0.3343 \\
Figura 6.7(b) & 0.7064 & 0.6466 \\
Figura 6.7(c) & 0.9083 & 0.8994 \\
\hline
\end{tabular}

Tabela (6.1): "Aspect ratios" dos contornos das Figuras 6.5(a), (e) e (1).

dos respectivos morfogramas são apresentadas na Figura 6.9. Na escala $\sigma_{l}$, as três curvas possuem basicamente a mesma complexidade. Por outro lado, a presença de duas protrusões agudas, com pontos de altíssima curvatura, contribui para o aumento acentuado da energia de dobramento da forma da Figura 6.7(b). Vale ainda notar que a forma da Figura 6.7(c) tende para um elipsóide mais rápido no domínio das pequenas escalas que as outras duas formas (perdendo, portanto, os detalhes de pequena escala mais rapidamente), o que é refletido pela energia de dobramento multi-escala. Esse fato também significa que essa forma possui informação substancial concentrada nas altas frequiências, visto que a largura de banda $\tau$ diminui na medida que a escala $\sigma$ aumenta. $\mathrm{Na}$ escala $\sigma_{2}$ da Figura 6.9, no qual a energia das formas das Figuras 6.7(a) e (b) é praticamente a mesma, a forma da Figura 6.7(b) perde uma de suas protrusões, enquanto as duas outras curvas sofrem poucas alterações, o que é refletido pela energia. A partir dessa escala, as três curvas tendem a elipsóides: a forma da Figura 6.7(c) tende a uma elipsóide menos alongada, seguida pelas formas das Figuras 6.7(b) e (a), as quais tendem a elipsóides mais alongadas em uma determinada direção. Isso significa que a ordem crescente de energia de contorno no estado final é (c), (b) e (a), fato este refletido pela energia de dobramento na escala mais alta.

A informação de grandes escalas está relacionada com uma medida de forma bastante popular e útil em vários casos: a retangularidade de uma forma, a qual pode ser

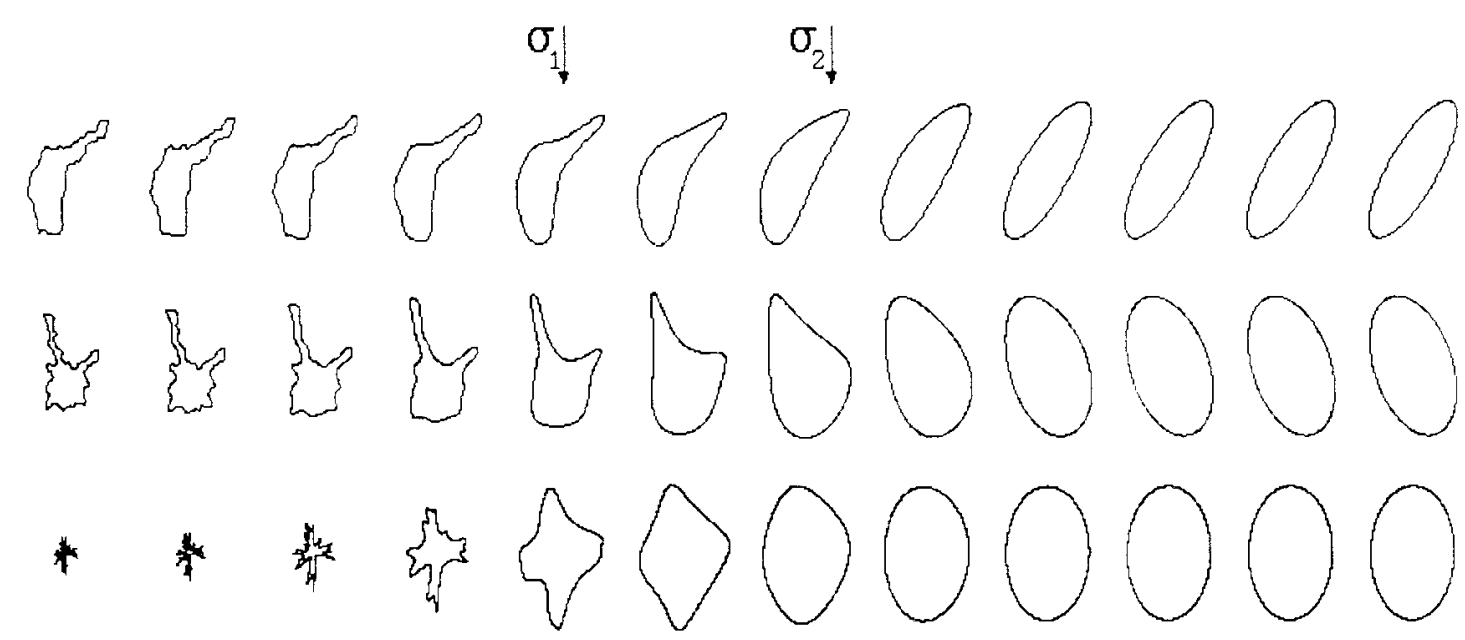

Figura (6.9): Detalhe da evolução dos contornos das Figuras 6.5(a), (e) e (1). 


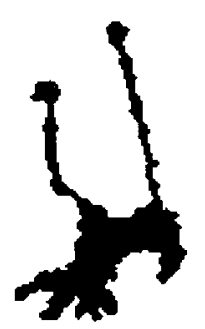

(a)

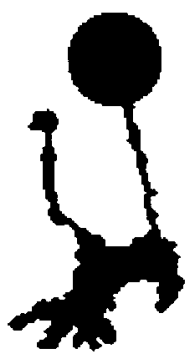

(b)

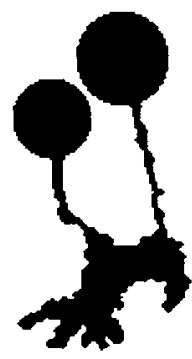

(c)

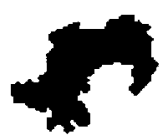

(d)

Figura (6.10): Formas do experimento que ilustra o efeito de alta curvatura mascarada.

medida pelo "aspect ratio". O menor retângulo envolvente de uma forma é definido como o retângulo de menor área que cobre completamente o objeto na imagem. $\mathrm{O}$ "aspect ratio" de uma forma é definido como a razão entre o menor e o maior lado do respectivo menor retângulo envolvente, sendo uma medida comumente associada ao alongamento do objeto em uma determinada direção. O "aspect ratio" assume máximo igual a 1 para formas como círculos e quadrados, decrescendo na medida que a forma é mais alongada em alguma direção específica. Considerando-se o caso de circunferências e elipses, pode-se verificar que o "aspect ratio" é inversamente proporcional à energia de dobramento, visto que esta assume seu mínimo quando aquele assume seu máximo. A Tabela 6.1 apresenta o "aspect ratio" das formas menos e mais suavizadas das Figuras 6.5(a), (e) e (l), em que pode-se observar que a energia de dobramento de grandes escalas pode ser usada para inferir a mesma informação que o "aspect ratio".

O menor retângulo envolvente de uma forma em uma imagem pode ser calculado facilmente rotacionando-se a forma em torno de seu centro de massa para uma série de ângulos entre 0 e $\pi / 2$. Para cada ângulo, o retângulo envolvente horizontal (isto é, um retângulo com dois de seus lados paralelos ao eixo $x$ ), o qual é definido pelo ponto mais alto à esquerda e pelo mais baixo à direita da curva rotacionada, é calculado. O retângulo de menor área é o próprio menor retângulo envolvente rotacionado pelo mesmo ângulo da curva, ângulo este que pode ser usado para estimar o principal eixo do objeto [Castleman, 1996]. A rotação do contorno em torno de seu centro de massa por um ângulo $\theta$ pode ser facilmente implementado transladando-se o centro de massa da curva para a origem do eixo de coordenadas, seguido da aplicação da seguinte equação:

$$
u_{r}(t)=u(t) e^{i \theta}
$$

em que $u_{r}(t)$ denota o contorno rotacionado. A translação do centro de massa do contorno para a origem pode ser feita subtraindo-se o as coordenadas do centro de massa da curva original, ou, alternativamente, calculando-se os descritores de Fourier do contorno, anulando-se o nível DC e recalculando-se a curva transladada. 


\subsubsection{Exemplo do Efeito de Alta Curvatura Mascarada}

-

próximo experimento ilustra o efeito da alta curvatura mascarada em relação à célula da Figura 6.5(f). Com a intenção de mostrar como a presença de protrusões agudas em um objeto é refletida por um aumento local na energia de dobramento multi-escala, a célula da Figura 6.5(f) foi editada para produzir 3 novas versões de si mesma, as quais são apresentadas na Figura 6.10. A célula original, mostrada na Figura 6.10(a), possui duas protrusões agudas que podem tomar a estrutura de "gargalos" acrescentando-se esferas em cima das respectivas extremidades, como nas Figuras 6.10(b) e (c). Coloca-se essas "luvas redondas" nas protrusões para evitar que o efeito de altíssima curvatura das extremidades possa aparecer. Finalmente, a Figura 6.10(d) foi obtida apagando-se as protrusões da célula original. Os diagramas de energia de dobramento dos quatro contornos são apresentados na Figura 6.11. O efeito de alta curvatura mascarada é capturado pela energia de dobramento de maneira mais acentuada para a forma da Figura 6.10(a). Para essa célula, a energia apresenta o aumento mais significativo nas escalas intermediárias. Tal efeito, que ocorre de maneira menos pronunciada na células das Figuras 6.10(b) e (c), praticamente desaparece na célula da Figura 6.10(d). É importante notar que a energia de dobramento nas pequenas escalas é praticamente a mesma para as quatro formas, devido ao fato de todas elas possuírem basicamente a mesma estrutura de complexidade em pequenas escalas. De fato, as diferenças estruturais entre as quatro formas são relativas a estruturas de escalas intermediárias (número de grandes protrusões, gargalos, etc., estruturas estas que possuem um papel central em teorias recentes de percepção de formas [Kimia et al., 1995; Siddiqi \& Kimia, 1995]) e grandes escalas (alongamento geral ou retangularidade), o que é sentido pela energia de dobramento.

Portanto, a evolução da energia de dobramento multi-escala normalizada em termos da escala de análise reflete 3 tipos distintos de informação estrutural sobre a forma analisada:

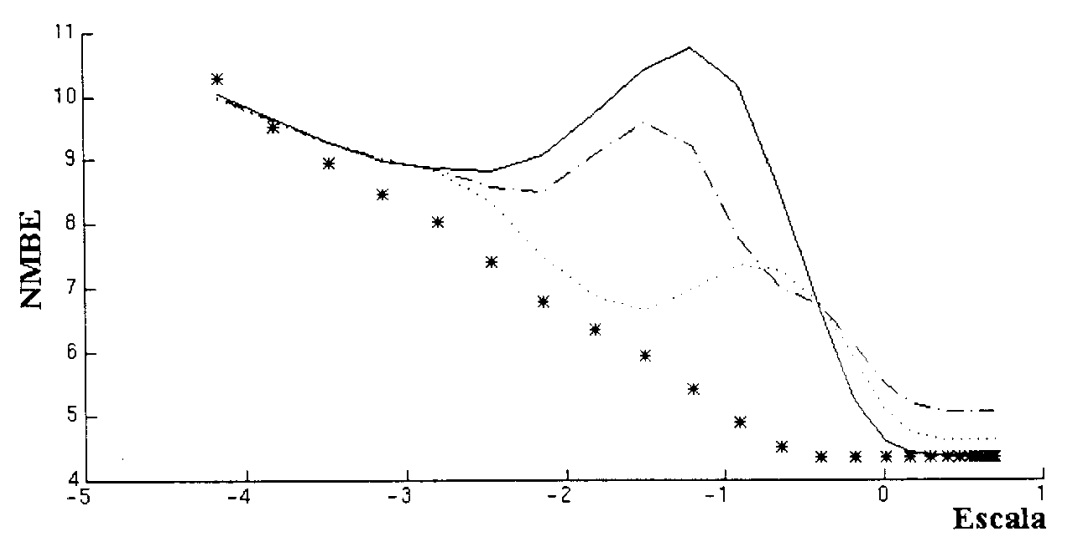

Figura (6.11): Energia de dobramento das formas da Figura 6.10 (a) ("-"), (b) ("“-.."), (c) (“...") e (d) (“*”). 


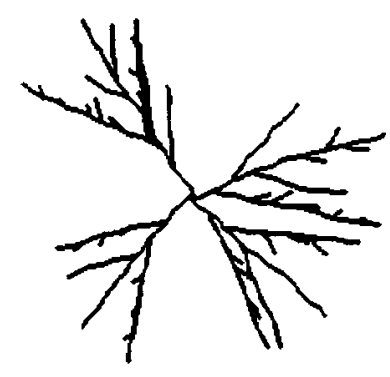

(a)

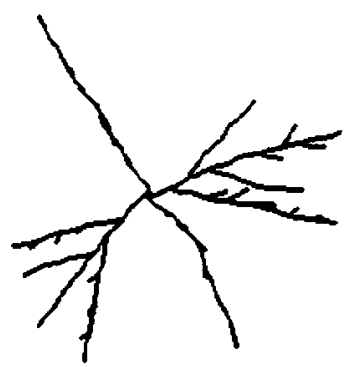

(c)

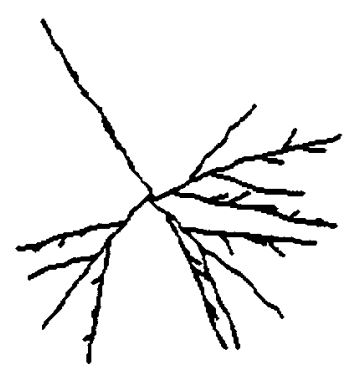

(b)

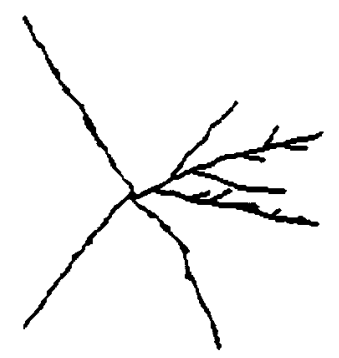

(d)

Figura (6.12): (a) Célula neural artificial; (b)-(d) Versões editadas da célula original, nas quais o padrão de ramificação de cada dendrito foi progressivamente apagado.

1. pequenas escalas: riqueza de ramificações locais;

2. escalas intermediárias: presença de grandes protrusões;

3. grandes escalas: alongamento da forma.

Para ilustrar essa interpretação da energia de dobramento, o seguinte experimento foi realizado. A célula neural (artificial) apresentada na Figura 6.12(a) foi editada de maneira que a ramificação local (de menor escala) fosse gradualmente apagada de um ramo dendrítico primário por vez (Figuras 6.12(b), (c) e (d)). Seguindo a interpretação e terminologia sobre o significado da energia de dobramento ao longo da evolução em escalas, a seqüência de formas das Figuras 6.12(a) $\rightarrow$ (d) apresenta:

1. quantidade decrescente de detalhes de pequenas escalas;

2. quantidade crescente de estruturas de escalas intermediárias, representadas pelos ramos dendríticos isolados e sem sub-ramificações, que atenuam o efeito de alta curvatura mascarada de maneira similar às "luvas redondas" do experimento anterior;

3. equivalência de estrutura de grandes escalas, uma vez que a retangularidade é, aproximadamente, a mesma para as quatro células. 


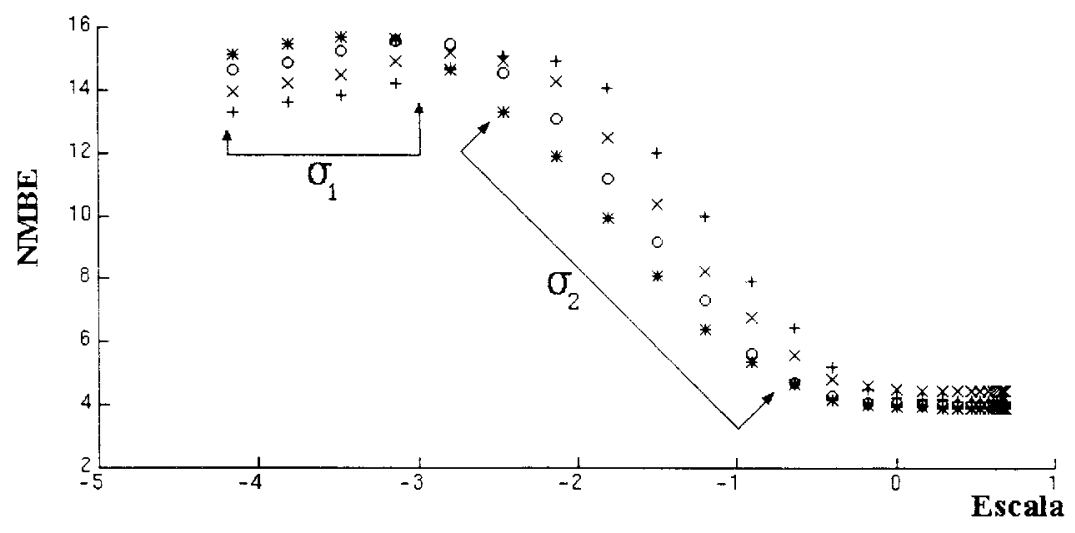

Figura (6.13): Energias de dobramento das células da Figura 6.12 (a) ("..."), (b) ("o"), (c) ("x") e (d) ("+").

A Figura 6.13 mostra a energia de dobramento para as quatro células, e a análise acima pode ser observada nesses diagramas. A energia nas pequenas escalas (indicado por $\sigma_{l}$ na Figura 6.13) classifica as formas na ordem (a) $\rightarrow$ (d). Para as escalas intermediárias (indicado por $\sigma_{2}$ na Figura 6.13), ocorre uma inversão dos valores da energia de dobramento, sendo as células classificadas na ordem (d) $\rightarrow$ (a). Finalmente, a energia de dobramento para as altas escalas é basicamente a mesma para as quatro células. 


\subsubsection{Tolerância a Transformações Geométricas}

$1 D$ ois experimentos foram realizados para ilustrar a invariância da energia de dobramento a transformações geométricas (bidimensionais) na imagem. No primeiro experimento, uma mesma célula sofreu uma série de transformações geométricas realizadas diretamente na imagem digital, ao passo que no segundo a transformação deu-se antes da aquisição da imagem.

A Figura 6.14 mostra uma série de células obtidas por 3 tipos de transformações 2D: escalonamento, reflexão e rotação. A primeira linha (Figuras 6.14(a)-(d)) apresenta as células escalonadas, obtidas pela aplicação da técnica de geração de pirâmides de imagens [Lindeberg, 1994; Burt \& Adelson , 1983], isto é, filtragem passa-baixas seguida de sub-amostragem. A ordem de magnitude de cada versão escalonada está indicada embaixo de cada célula das Figuras 6.14(a)-(d). As energias de dobramento dessas células aparecem no canto superior-esquerdo da Figura 6.15, em que se observa um bom grau de tolerância ao escalonamento das células, apesar das diferenças entre as quatro formas (diferenças devido à amostragem e à fase de pré-processamento e extraçào dos contornos). As maiores diferenças apontadas pela energia de dobramento ocorrem nas pequenas escalas, justamente onde os efeitos da amostragem e pré-processamento

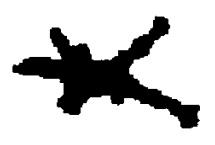

(a) (1.25)

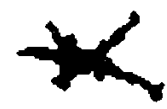

(e)

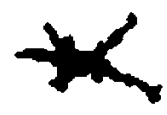

(i) $(0)$

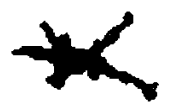

(b) (1)

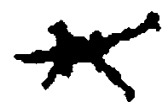

(E) (D)

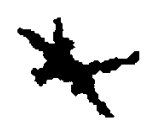

(j) (30)

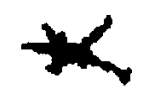

(c) $(0.75)$

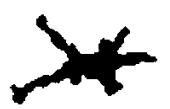

(g) $(R)$

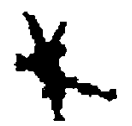

(k) $(60)$

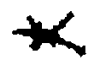

(d) $(0.5)$

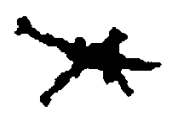

(h) (DR)

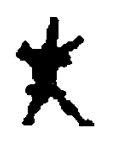

(1) (90)

Figura (6.14): Diferentes versões de uma mesma célula neural obtidas por transformações geométricas: (a)-(d) Escalonamento, com os fatores de escala indicados sob cada célula; (e)-(h) Reflexão, sendo que as células foram refletidas para baixo (indicado pela letra D), para a direita (indicado pela letra $\mathrm{R}$ ) e para baixo e para a direita (indicado pelas letras DR); (i)-(1) Rotação, no sentido horário, sendo que os ângulos de rotação em graus estão indicados sob cada célula. 

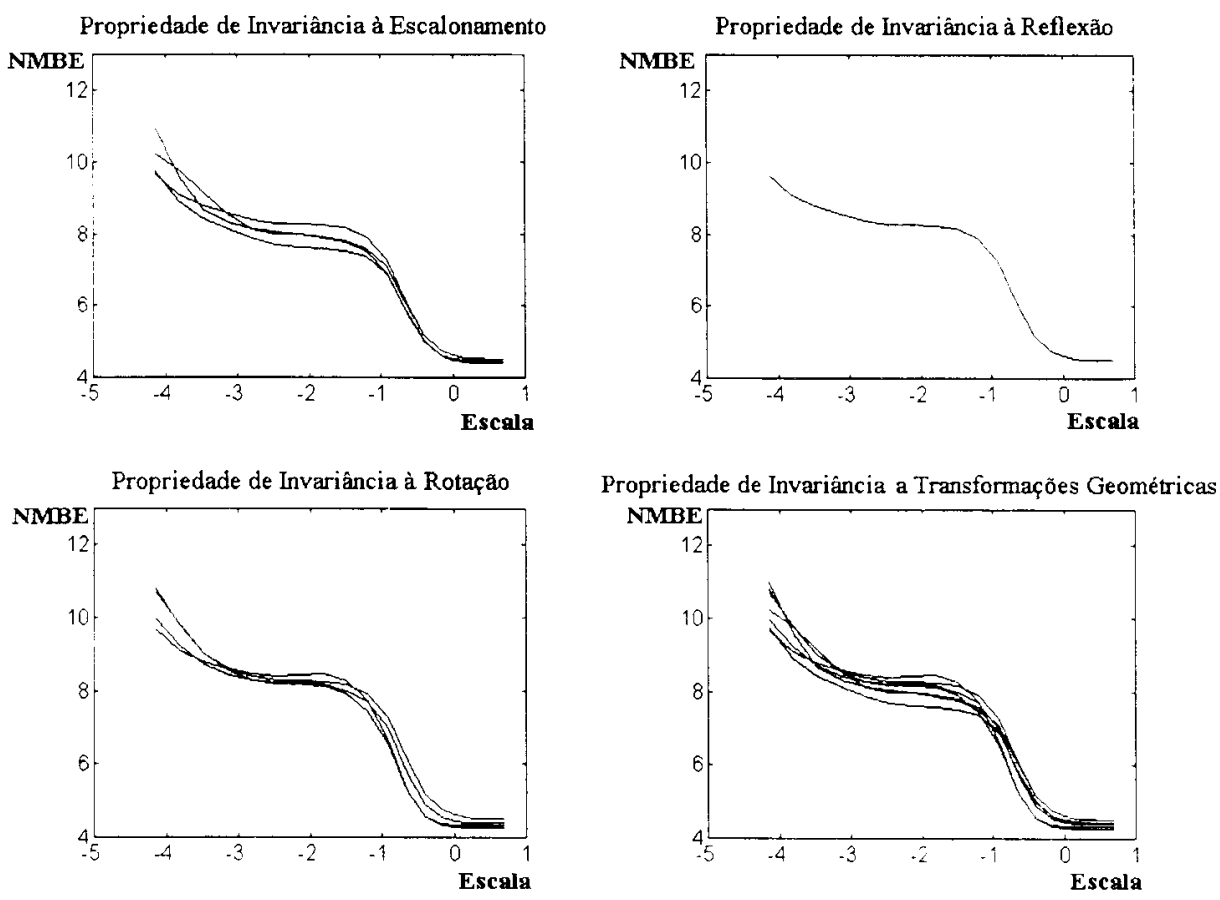

Figura (6.15): Energias de dobramento das formas vistas na Figura 6.14, ilustrando a tolerância a transformações geométricas. Todas as energias de dobramento foram sobrepostas no último gráfico de modo a mostrar como essa medida tem o mesmo comportamento para todas as versões da célula original.

são mais acentuados. Na medida que essas diferenças locais são filtradas com o aumento de escala, a energia de dobramento torna-se mais homogênea entre as quatro células, sendo o comportamento geral da evolução da energia ao longo das escalas praticamente o mesmo.

A segunda linha da Figura $6.14((\mathrm{e})-(\mathrm{h}))$ apresenta as versões obtidas por reflexão da célula original, isto é, reflexão em relação ao eixo $x$ (Figura 6.14(f), denotado por (D)); reflexão em relação ao eixo $y$ (Figura 6.14(g), denotado por (R)); e reflexão em relação aos eixo $x$ e $y$ (Figura 6.14(h), denotado por (DR)). As energias de dobramento dessas células são mostradas no canto superior-direito da Figura 6.15, sendo praticamente a mesma para todas as células. A energia é praticamente inalterada pela amostragem local e pré-processamento, visto que a operação de reflexão é isotrópica em relação à grade retangular que serve como estrutura básica da imagem digital.

Finalmente, a terceira linha da Figura 6.14 ((i)-(l)) mostra as versões rotacionadas no sentido horário por ângulos de $30^{\circ}, 60^{\circ}$ e $90^{\circ}$. A rotação de cada célula se fez baseada em um esquema de rotação $\rightarrow$ filtragem passa-baixas $\rightarrow$ segmentação por limiar, o que afeta a geometria local dos objetos, de maneira semelhante às transformações de escalonamento explicadas anteriormente. As energias de dobramento aparecem no canto inferior-esquerdo da Figura 6.15, em que se pode perceber uma boa tolerância em 


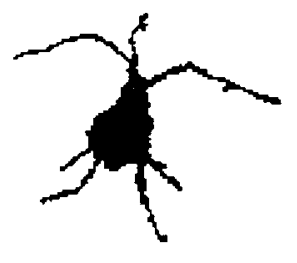

(a)

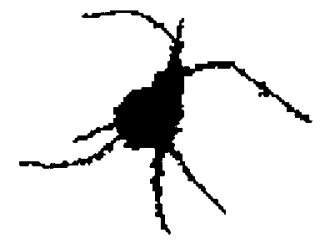

(b)

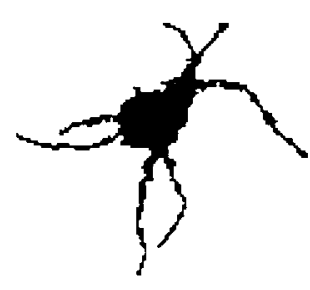

(c)

Figura (6.16): Versões rotacionadas e transladadas de um neurônio.

relação às diferenças das 4 células. As energias de dobramento de todas as células transformadas geometricamente são apresentadas no canto inferior-direito da Figura 6.15 .

No segundo experimento agora apresentado, testa-se a tolerância da energia de dobramento multi-escala a artefatos devidos à aquisição e pré-processamento de imagens. Diferentemente do anterior, neste experimento algumas características importantes da célula são fortemente afetadas em uma situação que imita condições reais de aplicações em laboratórios. Três imagens foram obtidas mudando-se a posição e orientação da mesma lâmina histológica no carro do microscópio. Isso significa que, embora a célula de interesse seja a mesma nas três imagens, diferenças importantes devido à translação, rotação, mudança de iluminação e foco nas várias regiões da imagem afetam a aquisição e o pré-processamento que dá origem ao contorno final. As 3 células são mostradas na Figura 6.16. Como pode ser visto, embora as células tenham, basicamente, a mesma forma, elas possuem algumas diferenças perceptíveis. As respectivas energias de dobramento são apresentadas na Figura 6.17, sendo que tais medidas apresentam um bom grau de tolerância aos artefatos acima comentados. Tais características indicam que, além do potencial para descrever características específicas em análise de formas baseada na interpretação humana, a energia de dobramento multiescala normalizada também pode ser usada como medidas de formas em procedimentos automáticos de reconhecimento de padrões, o que poderia ser aplicado, por exemplo, à contagem de células em preparados histológicos contendo centenas ou mesmo milhares

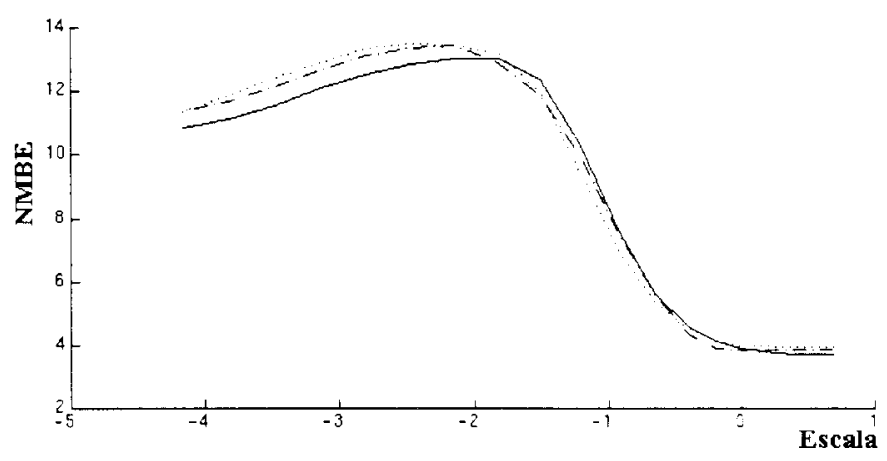

Figura (6.17): Energias de dobramento das células vistas na Figura 6.16(a)-(c), utilizando os seguintes respectivos estilos de gráfico: $(-),(--)$ e $(\cdots)$. 


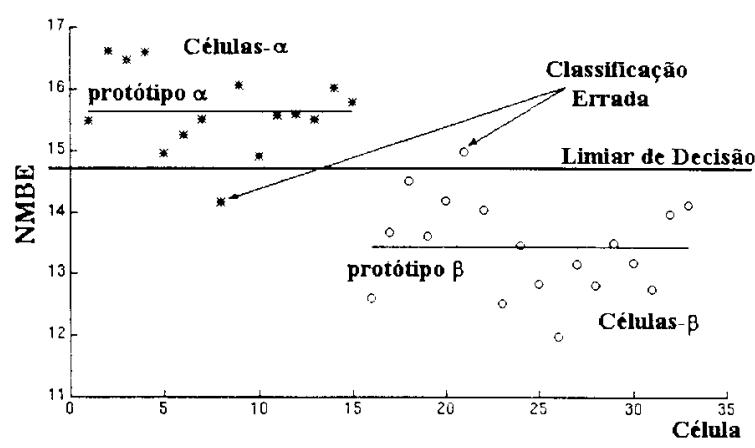

Figura (6.18): Resultados da aplicação da energia de dobramento na caracterização de células ganglionares (gato). As células $\alpha$ são representadas pelo símbolo "*”, ao passo que as células $\beta$ pelo símbolo "o". O protótipo para cada conjunto de medidas é definido como a média das energias de dobramento de cada classe. A linha de decisão é indicada como um limiar quase ótimo para discriminação entre as duas classes.

de neurônios.

Para exemplificar como a energia de dobramento pode ser usada como uma medida quantitativa em uma aplicação de caracterização de padrões, a energia de dobramento de 33 células ganglionares de gato foi calculada, sendo que 15 células eram da classe $\alpha$ (células mais complexas) e 18 da classe $\beta$ (células menos complexas). A Seção 6.5 apresenta uma análise mais elaborada sobre essas células ganglionares. A Figura 6.18 apresenta a distribuição das energias de dobramento de todas as células (para uma escala pequena fixa), na qual as células $\alpha$ são representadas por "*", enquanto as células $\beta$ são representadas por "o". O protótipo ou valor médio de cada classe também está indicado por uma linha reta no domínio de cada classe. Como pode ser visto, as células $\alpha$ apresentam um valor maior (na média) de energia de dobramento, o que reflete sua característica de forma subjetivamente mais complexa que as células $\beta$. De fato, tal diferença sugere um método simples de classificação entre células $\alpha$ e $\beta$ baseado em limiarização: células com energia maior que um determinado limiar devem ser classificadas como $\alpha \mathrm{e}$, caso contrário, como $\beta$. Um possível limiar está também indicado na Figura 6.18, o qual iria classificar erroneamente apenas duas células, o que representa claramente um bom desempenho levando-se em conta que apenas 1 característica foi usada. A Seção 6.5 apresenta maiores detalhes da utilização da energia de dobramento multi-escala (incluindo uma abordagem para escolha semi-automática de escalas) na classificação de neurônios.

\subsection{A ENERGIA MULTI-ESCALA NoRMALIZADA DE WAVELETS}

12 sta seção apresenta um método para extração de características de contornos análogo à energia de dobramento multi-escala. A energia multi-escala normalizada de wavelets é um sinal que descreve a energia média normalizada da 
representação- $W$ em função do parâmetro de escala $a$. O método introduzido aqui procura identificar, dentre as possíveis escalas de análise, quais são aquelas com maior potencial de discriminação entre as classes de formas. Assim, a energia multi-escala normalizada de wavelets é definida como:

$$
N M W E_{\psi}(a)=\frac{1}{K^{2}} \frac{1}{\mathrm{~L}} \int_{-\infty}^{\infty}\left|U_{\psi}(\mathrm{b}, \mathrm{a})\right|^{2} d b
$$

em que $K$ é uma constante de normalização que depende apenas do contorno original. $\mathrm{O}$ fator de normalização $1 / K^{2}$ é incluído para tornar o descritor invariante a escalonamento isotrópico da forma original, e diferentes constantes de normalização podem ser definidas, dependendo da aplicação. O tamanho do maior eixo do contorno, o qual pode ser calculado como sendo o maior lado o menor retângulo envolvente da forma (ver Seção 6.3.1) [Castleman, 1996, Cesar \& Costa, 1997a], foi usado como a constante de normalização $K$ nos experimentos apresentados nesta tese. Vale notar que a energia de wavelets é invariante a escalonamento isotrópico, rotação e translação do objeto na imagem, o que decorre das propriedades de covariância da transformada contínua em wavelets (ver Seção 5.3). A equação discreta da energia multi-escala normalizada de wavelets é dada por:

$$
N M W E_{\psi}\left(a_{j}\right)=\frac{1}{K^{2}} \frac{1}{N} \sum_{m=1}^{N}\left|U_{\psi}\left(b_{m}, a_{j}\right)\right|^{2}
$$




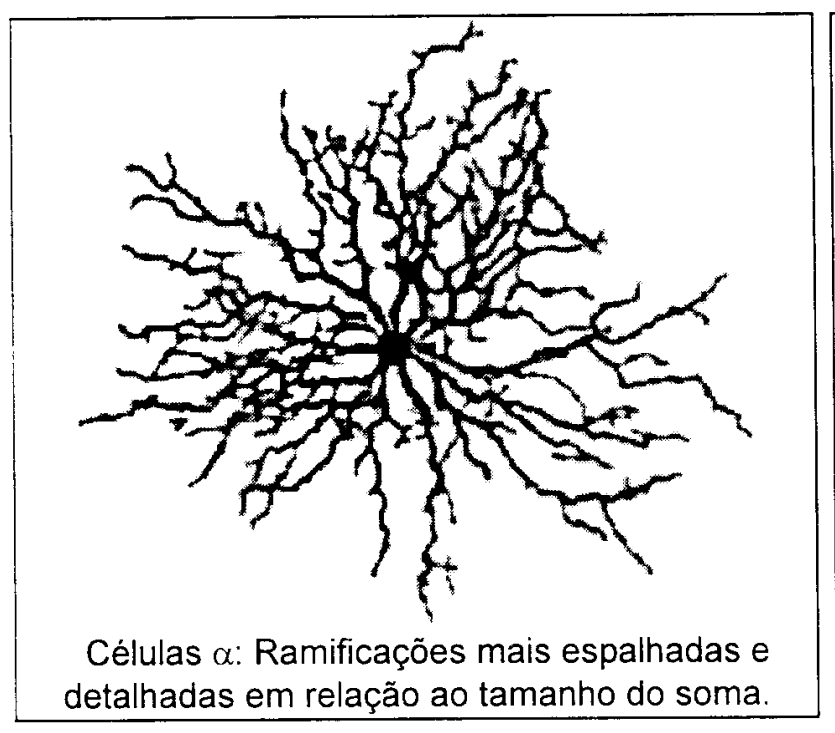

(a)

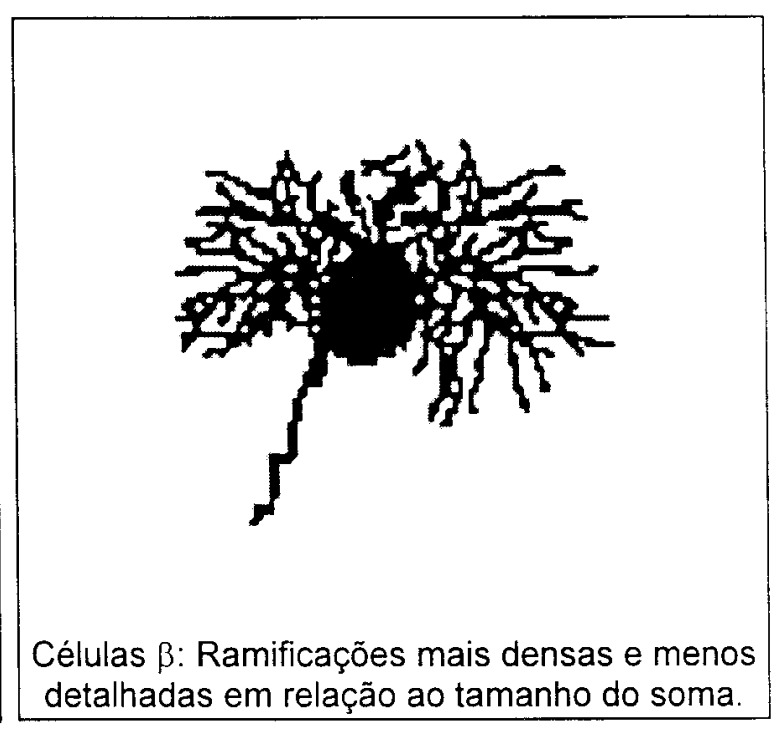

(b)

Figura (6.19): Protótipos de células ganglionares dos tipos $\alpha$ e $\beta$, ilustrando as principais características e diferenças estruturais entre essas duas classes morfológicas de células neurais.

\subsection{Classificação Automática de CÉlulas Ganglionares}

$\boldsymbol{O}$ principais resultados de classificação de neurônios apresentados neste rabalho baseiam-se na classificação de células pertencentes a duas classes morfológicas de células ganglionares da retina (gato), as classes $\alpha$ e $\beta$ (células pertencentes a essas classes serão denominadas células $\alpha$ e células $\beta$, respectivamente). Essas células (bem como as células $\gamma$, não incluídas aqui) têm sido estudadas nas últimas décadas, fornecendo um excelente exemplo de células neurais em que a relação entre morfologia e função foi identificada. De fato, três classes fisiológicas dessas células ganglionares foram identificadas, as células $X$, as células $Y$ e as células $W$ [Fukuda et al., 1984; Saito, 1983], tendo sido observado que as células Y (associadas com detecção de movimentos rápidos) apresentam a morfologia da classe $\alpha$, enquanto as células $X$ (que respondem a estímulos de pequenas escalas) possuem a morfologia da classe $\beta$, ambas possuindo campos receptivos do tipo "center-surround". Boycott e Wässle desenvolveram sua classificação das células $\alpha, \beta$ e $\gamma$ baseando-se no padrão de ramificação dos dendritos [Boycott \& Wässle, 1974]. As Figuras 6.19(a) e (b) apresentam dois protótipos de células $\alpha$ e $\beta$, respectivamente, em que se pode notar algumas das principais características morfológicas que diferenciam essas células: enquanto a célula $\alpha$ apresenta um padrão de ramificação mais espalhado, cobrindo uma maior região em relação ao tamanho do soma, a célula $\beta$ possui um padrão de ramificação mais denso, contendo um grau menor de detalhes de pequena escala. As células utilizadas nos experimentos de classificação são mostradas nas Figuras $6.20 \mathrm{e}$ 6.21 . 

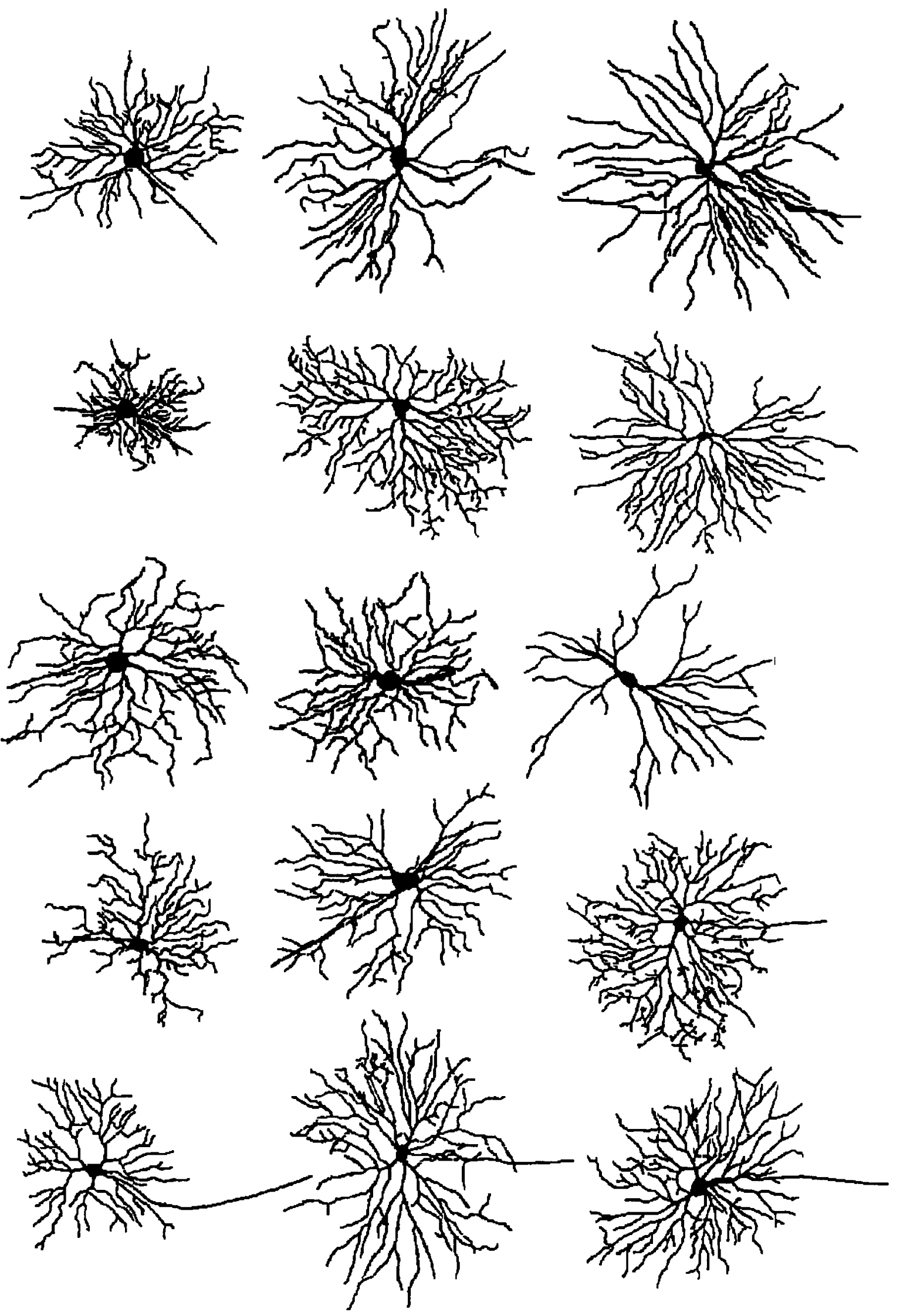

Figura (6.20): Células $\alpha$ usadas nos experimentos de classificação. 

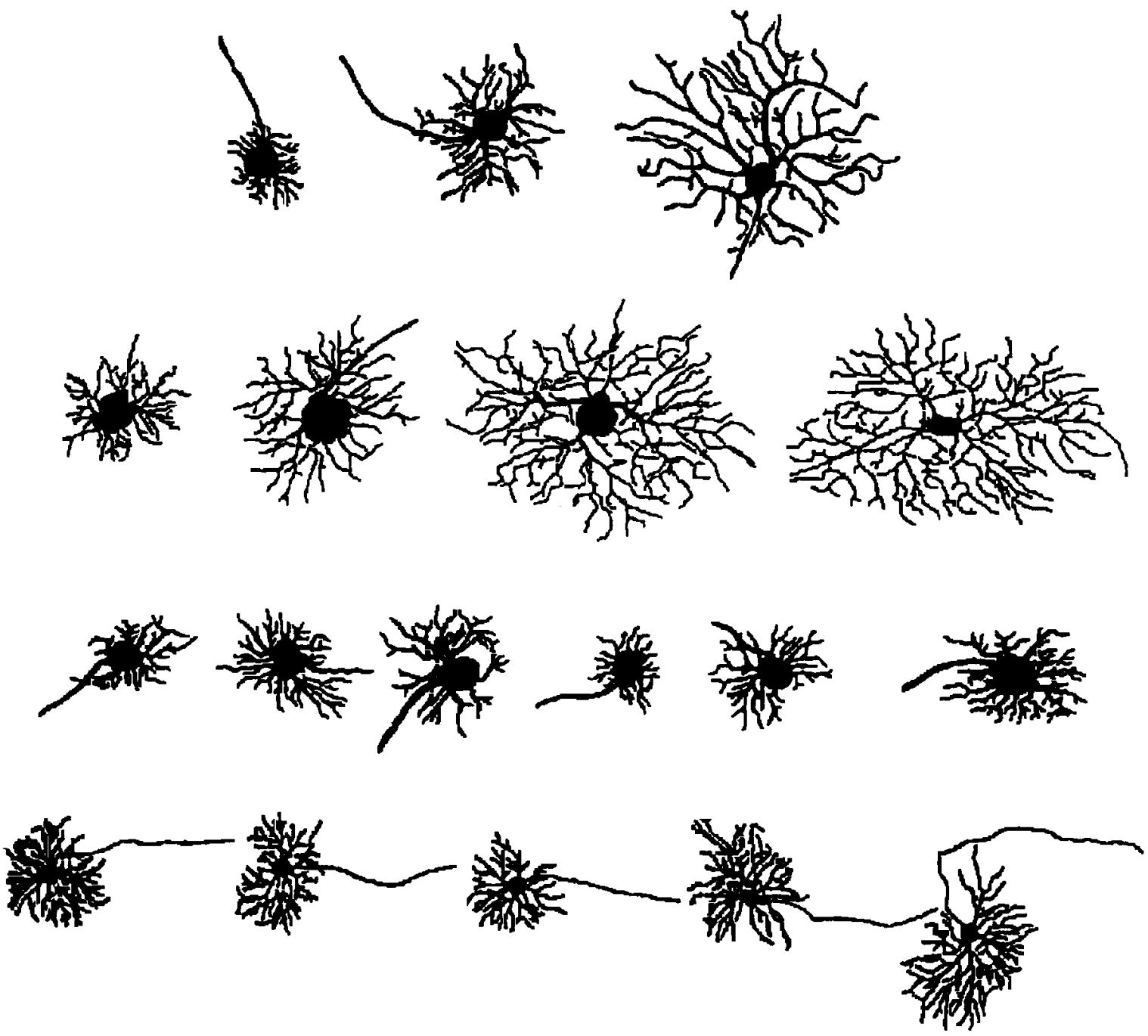

Figura (6.21): Células $\beta$ usadas nos experimentos de classificação.

As células da base de dados foram digitalizadas através de um "scanner" a partir de alguns trabalhos da literatura em neurociências, estando já classificadas pelos especialistas [Boycott \& Wässle , 1974; Fukuda et al., 1984; Kolb et al., 1981; Leventhal \& Schall, 1983; Saito, 1983]. A imagem de cada célula foi processada para a redução de ruídos (usualmente através de filtros medianos), tendo sido efetuada uma operação de dilatação morfológica em cada célula para a eliminação de singularidades falsas. Um problema que ocorre freqüentemente é o da presença de auto-intersecções dos dendritos, quando um pode cruzar ou tocar a si próprio ou um outro dendrito (veja a Figura 6.22(a)). Nesse caso, o algoritmo de extração de contorno não pode seguir dentro do buraco criado pela auto-intersecção dendrítica. A solução adotada para corrigir esse problema é permitir que o algoritmo entre no buraco artificial, percorra o contorno interno e continue a percorrer o contorno externo saindo próximo de onde entrou. Uma maneira simples de implementar esse processo é através da edição da imagem do neurônio para criar pequenas passagens para o algoritmo que percorre o contorno, de 


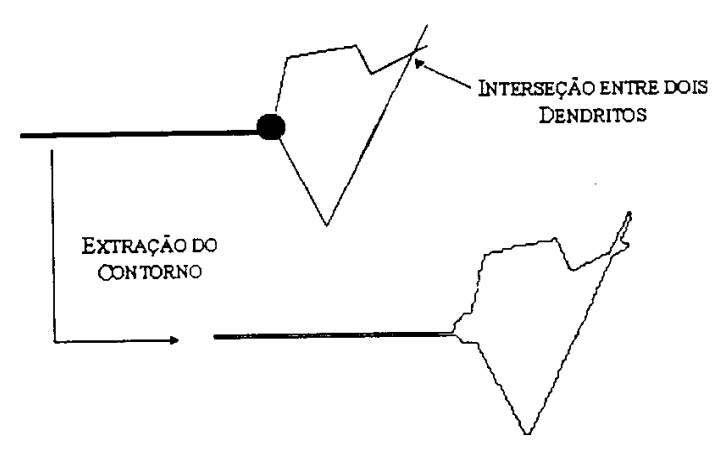

(a)

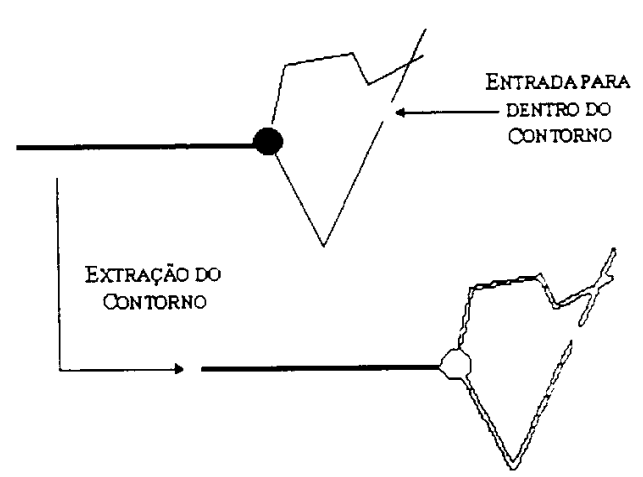

(b)

Figura (6.22): (a) Ilustração esquemática de uma auto-intersecção e o problema resultante na etapa de extração do contorno; (b) O contorno editado permite que o algoritmo de extração de contorno gere um contorno mais significativo em relação à forma do neurônio original.

maneira que ele possa entrar e sair do buraco artificial (veja a Figura 6.22(b)). Embora esse procedimento resulte em uma versão ligeiramente modificada do objeto original, argumenta-se que o contorno resultante representa basicamente as principais características da forma do neurônio original em relação a sua complexidade geral.

Cada célula foi editada para a eliminação dos efeitos de auto-intersecção, tendo sido extraído cada contorno, cada qual representado, em geral, por 1000 a 10000 pontos. A grande variedade no número de pontos de contorno para contorno implica duas dificuldades adicionais. Em primeiro lugar, torna-se mais dificil realizar as comparações entre eles. E em segundo lugar, os algoritmos de FFT geralmente requerem que o tamanho do sinal de entrada seja uma potência de 2 . O procedimento adotado para solucionar esses problemas é o de reamostrar todos os contornos (usando interpolação linear com resolução de sub-pixel), para que todos tenham o mesmo número final de pontos antes do processamento pelas transformadas, isto é, 8192 pontos. Embora alguns contornos tenham sido sub-amostrados por esse procedimento (aqueles que apresentavam mais que 8192 pontos, originalmente), pode-se observar experimentalmente que as versões sub-amostradas mantiveram a estrutura básica (incluindo os detalhes de pequena escala) que caracteriza a forma de cada neurônio.

Para melhor entender a maneira pela qual as transformadas multi-escala podem refletir o significado subjetivo de complexidade de forma, veja as Figuras 6.23 (a) e (c), as quais mostram duas células neurais artificiais. A célula da Figura 6.23(c), a mais complexa, apresenta um padrão de ramificação mais rico que o da célula da Figura 6.23(a), possuindo uma maior capacidade de cobertura espacial. Os sinais $x(t)$ e $y(t)$ de seus contornos são mostrados nas Figuras 6.23(b) e (d), respectivamente.

O módulo das respectivas representações- $W$ pode ser visto nas Figuras 6.24(a) e (b), indicando que o padrão de ramificação é refletido pela transformada multi-escala 
através do aparecimento de singularidades como função da escala de análise, o que permite a definição de aproximações poligonais multi-escala, como já foi discutido no Capítulo 5. Assim, o caráter mais complexo e rico da célula da Figura 6.23(c) pode ser inferido por meio da respectiva representação- $W$ através do aparecimento das novas estruturas na medida que a escala diminui, como está indicado na Figura 6.24(b).

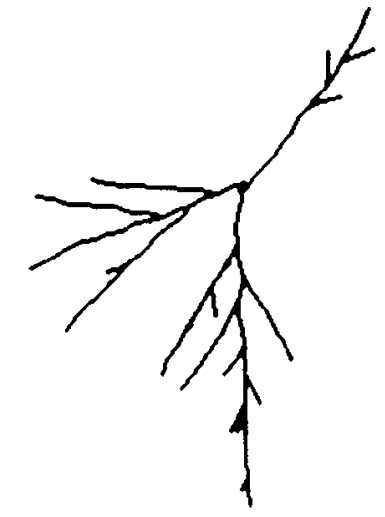

(a)

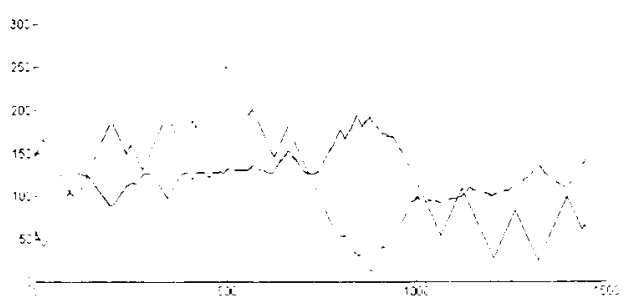

(b)

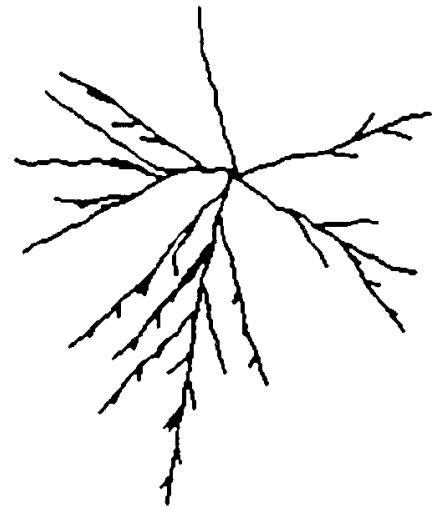

(c)

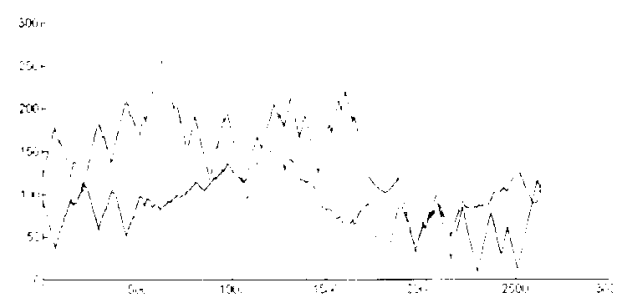

(d)

Figura (6.23): (a) e (c) apresentam duas células neurais artificiais, sendo a célula vista em (c) mais complexa que aquela vista em (a); (b) e (d) apresentam os respectivos sinais $x(t)$ e $y(t)$. 
$b$

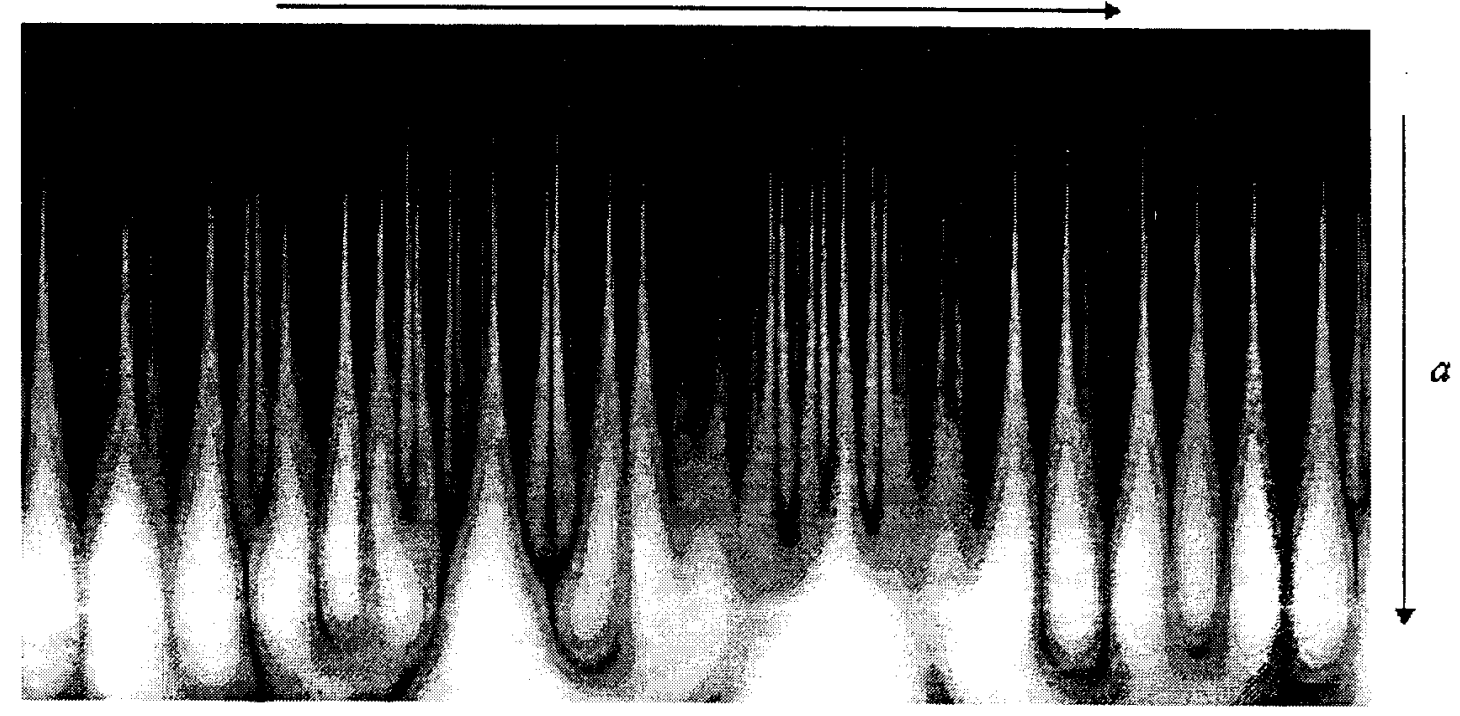

(a)

$b$

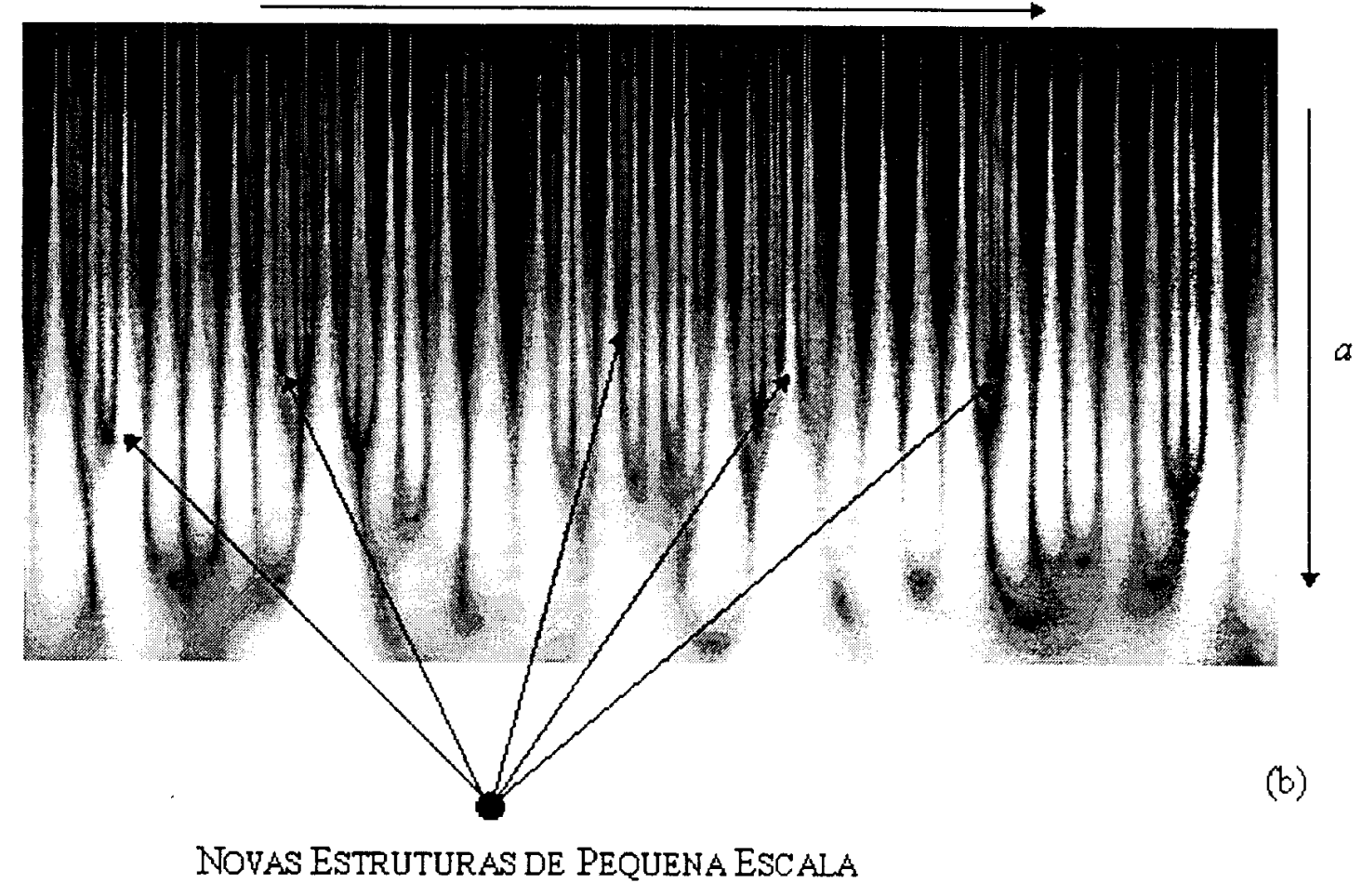

Figura (6.24): Módulo das representações- $W$ das células apresentadas na Figura 6.23. 
Baseando-se nessas considerações, uma série de experimentos de reconhecimento de padrões foi realizada. O conjunto de 33 células vistas nas Figuras 6.20 e 6.21, divididas em células $\alpha$ e $\beta$, foi usado como base de dados dos experimentos. Dessa base de dados, 5 células foram selecionadas aleatoriamente como conjunto de treinamento para os 2 classificadores estatísticos implementados, a saber, um classificador de $k$ vizinhos mais próximos e um classificador de máxima verossimilhança [Duda \& Hart, 1973; Fu, 1982; Castleman, 1996]. O modelo de densidade normal multivariada com probabilidade a priori igual para as duas classes foi adotado para o classificador de máxima verossimilhança. As seguintes 100 características foram medidas para cada célula:

- Dimensão fractal (DF): A dimensão fractal é denotada por $M_{\alpha, 1}(j)$ para a $j$-ésima célula $\alpha$ e por $M_{\beta, l}(j)$ para a $j$-ésima célula $\beta$;

- Energia de dobramento normalizada multi-escala (NMBE): A energia de dobramento foi calculada para 32 escalas diferentes, as quais são denotadas por $M_{\alpha, m}(j)$ para a $j$-ésima célula $\alpha$ e por $M_{\beta, m}(j)$ para a j-ésima célula $\beta$, com $m=2,3, \ldots, 33$. As energias de dobramento estão em ordem "coarse-to-fine", ou seja, a energia de maior escala corresponde a $m=2$, enquanto a energia para a menor escala corresponde a $m=33$;

- Diâmetro de Arborização Dendrítica (DAD): Foi estimado com base na informação relatada nos artigos originais, sendo denotado por $M_{\alpha, 34}(j)$ para a $j$-ésima célula $\alpha$ e por $M_{\beta, 34}(j)$ para a $j$-ésima célula $\beta$;

- Diâmetro do soma (DS): Também estimado com base nos trabalhos originais, é denotado por $M_{\alpha, 35}(j)$ para a $j$-ésima célula $\alpha$ e por $M_{\beta, 35}(j)$ para a $j$-ésima célula $\beta$;

- Energia multi-escala normalizada de wavelets (NMWE): A energia de wavelets também foi calculada para 30 escalas diferentes, as quais são denotadas por $M_{\alpha, m}(j)$ para a $j$-ésima célula $\alpha$ e por $M_{\beta, m}(j)$ para a $j$-ésima célula $\beta$, com $m=$ $36,37, \ldots, 65$. As energias de wavelets também são apresentadas em ordem "coarse-tofine", ou seja, a energia de maior escala corresponde a $m=36$, enquanto a energia para menor escala corresponde a $m=65$;

- Descritores de Fourier (FDs): Seja $U(s)$ a transformada discreta de Fourier do contorno $u(n)$, definida como:

$$
U(\mathrm{~s})=\frac{1}{N} \sum_{n=0}^{N-1} u(n) e^{-i \frac{2 \pi}{N} s t}, \quad s=-\frac{N}{2}+1, \ldots, \frac{N}{2}
$$

Um conjunto de descritores de Fourier invariantes a rotação, translação, deslocamento do parâmetro $n$ e escalonamento pode ser definido como $F D(s)=$ $|N F D(s)|$, em que: 


$$
N F D(s)=\left\{\begin{array}{cc}
0 ; & s=0 \\
U(s) / U(1) & s \neq 0
\end{array}\right.
$$

Os 30 descritores de Fourier $N F D(s)$ foram calculados para cada célula, sendo denotados por $M_{\alpha, m}(j)$ para a $j$-ésima célula $\alpha$ e por $M_{\beta, m}(j)$ para a $j$-ésima célula $\beta$, para $m=66.67, \ldots, 98$ :

- Descritor de Shen, Rangayyan e Desautels (FF): $N F D(s)$ é usado na definição do seguinte descritor de Fourier [Shen et al., 1994]:

$$
F F=\left[\sum_{s=-(N / 2)+1}^{N / 2}|N F D(s)| /|s|\right] / \sum_{s=-(N / 2)+1}^{N / 2}|N F D(s)|
$$

Esse descritor de formas foi usado por Shen et al., 1994, para a caracterização de calcificações mamográficas, tendo sido também incluído nos experimentos de classificação de células ganglionares. Assim, o descritor $F F$ é denotado por $M_{\alpha, 99(j)}$ para a $j$-ésima célula $\alpha$ e por $M_{\beta, 99}(j)$ para a $j$-ésima célula $\beta$;

- Energia de Fourier (EF): A última medida realizada para caracterização dos neurônios foi a energia de $N F D(s)$, definida por:

$$
E F=\sum_{s=-(N / 2)+1}^{N / 2} \mid N F D(s)^{2}
$$

Essa medida é denotada por $M_{\alpha, 100}(j)$ para a j-ésima célula $\alpha$ e por $M_{\beta \ldots 100}(j)$ para a $j$-ésima célula $\beta$.

Uma variação alternativa que também foi adotada é a de tomar o logaritmo de cada medida, o qual reduz os efeitos devidos à grande variação de magnitude entre as características. Outro tipo de normalização que também foi adotado é aquele baseado nos valores mínimo e máximo de cada medida das células da base de dados, para que o domínio de todas as características fosse entre 1 e $12^{10}$. O projeto de um classificador de padrões inclui a seleção, dentro de um conjunto de medidas possíveis, de um subconjunto mínimo de medidas não correlacionadas que melhor discrimine cada classe

\footnotetext{
${ }^{10}$ Esses valores foram escolhidos arbitrariamente, não existindo nenhuma razào especial a não ser a da padronizaçào dos dominios de cada medida.
} 
de padrões. Porém, isso é usualmente difícil na prática, pois envolve freqüentemente um conhecimento heurístico sobre a natureza particular do problema em questão. Por outro lado, algumas pistas podem ser fornecidas por técnicas de ordenação de características e aprendizado inicial por tentativa-e-erro [Castleman, 1996]. Neste trabalho, a distância de separação de classes [Castleman, 1996] foi aplicada a todas as medidas de toda a base de neurônios com o intuito de se ganhar "insight" sobre o potencial de discriminabilidade das 100 características explicadas anteriormente.

Sejam $\mu_{\alpha . m}$ e $\mu_{\beta, m}$ a média estimada da $m$-ésima característica das classes $\alpha$ e $\beta$, respectivamente; e sejam $\sigma_{\alpha, m}^{2}$ e $\sigma_{\beta, m}^{2}$ a variância estimada da $m$-ésima característica das classes $\alpha$ e $\beta$, respectivamente, para $m=1,2, \ldots, 100$. Esses valores podem ser estimados a partir das medidas realizadas sobre os elementos da base de dados da seguinte maneira:

$$
\begin{gathered}
\mu_{\alpha, m}=\frac{1}{N_{\alpha}} \sum_{j=1}^{N_{\alpha}} M_{\alpha, m}(j) \\
\mu_{\beta, m}=\frac{1}{N_{\beta}} \sum_{j=1}^{N_{\beta}} M_{\beta, m}(j) \\
\sigma_{\alpha, m}^{2}=\frac{1}{N_{\alpha}} \sum_{j=1}^{N_{\alpha}}\left(M_{\alpha, m}(j)-\mu_{\alpha, m}\right)^{2} \\
\sigma_{\beta, m}^{2}=\frac{1}{N_{\beta}} \sum_{j=1}^{N_{\beta}}\left(M_{\beta, m}(j)-\mu_{\beta, m}\right)^{2}
\end{gathered}
$$

em que $N_{\alpha}$ e $N_{\beta}$ denotam, respectivamente, o número de células $\alpha$ e $\beta$ na base de imagens. A distância de separação entre as classes $\alpha$ e $\beta$ para a $m$-ésima característica pode, então, ser definida como:

$$
D_{\alpha, \beta, m}=\frac{\left|\mu_{\alpha, m}-\mu_{\beta, m}\right|}{\sqrt{\sigma_{\alpha, m}^{2}+\sigma_{\beta, m}^{2}}}
$$

O potencial de discriminação de cada característica medida aumenta com $D_{\alpha, \beta, \mathrm{m}}$. A Figura 6.25 apresenta o gráfico de barras de $D_{\alpha, \beta, \mathrm{m}}$, com as respectivas características indicadas. Nesse experimento utilizou-se o logaritmo de cada característica, como foi comentado anteriormente. Como pode ser visto, as características que apresentam maior $D_{\alpha, \beta, m}$ correspondem às energias de dobramento para pequenas escalas, seguidas da energia em wavelets e o diâmetro dendrítico. As outras características apresentam uma performance visivelmente mais fraca. $O$ bom desempenho da energia de dobramento 


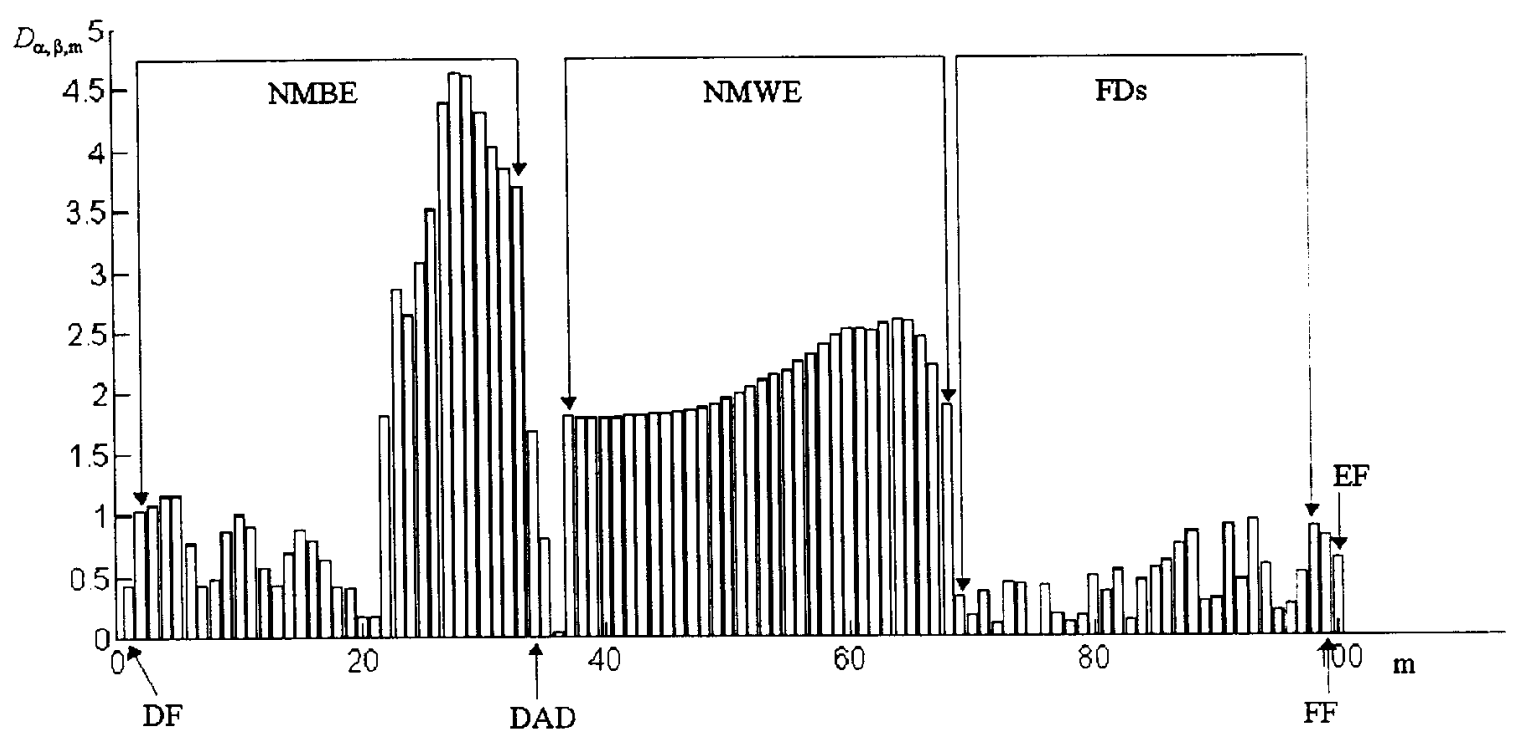

Figura (6.25): Distância de separação de classes para as diferentes características testadas na caracterização de células ganglionares.

para as pequenas escalas pode ser explicado visto que a arborização dendrítica das células $\alpha$ é mais esparsa que a das células $\beta$, especialmente se comparado com $o$ diâmetro do soma. Além disso, as células $\alpha$ possuem, em geral, um número maior de extremidades e segmentos de dendritos mais compridos e "tortinhos". Essa característica é observada na energia de dobramento de pequenas escalas, bem como na energia de wavelets, caracterizando a diferença de complexidade das duas classes de formas. Além disso, as energias adjacentes tendem a possuir valores similares de distância entre classes. Por outro lado, enquanto as energias de pequena escala exibem um bom potencial de discriminabilidade, as energias de escalas intermediárias e grandes apresentam um desempenho bem inferior. De fato, a energia de dobramento exibe algumas das menores distâncias entre classes, o que ilustra um fato importante sobre análise multi-escala de formas: embora os contornos sejam geralmente compostos por estruturas que ocorrem em diversas escalas, é importante identificar as boas escalas para análise. Esse problema está relacionado com as idéias de escalas naturais, discutidas nos Capítulos 2 e 5.

Como foi comentado, as energias multi-escala adjacentes possuem valores semelhantes de $D_{\alpha, \beta, m}$, sendo que uma breve análise desse fenômeno revela um fato importante para a classificação de padrões. Na verdade, a informação entre escalas vizinhas é altamente correlacionada e redundante, o que deve ser levado em consideração no processo de seleção de características que irão compor o vetor de entrada para o classificador estatístico. Assim, por exemplo, suponha que se deseja criar um vetor de características com duas componentes a partir da energia de wavelets das 33 células apresentadas nas Figuras 6.20 e 6.21. Em princípio, qual par deveria ser escolhido: uma energia de pequena escala e uma de grande ou duas energias de pequena 
escala? Tendo-se em vista somente a distância de separação de classes, a segunda opção parece ser mais apropriada que a primeira, visto que as energias para as pequenas escalas exibem maior distância que as das grandes escalas. Uma análise mais atenciosa, com o auxílio da Figura 6.26, revela a falácia desse raciocínio. De fato, a Figura 6.26 apresenta dois espaços de características, denotados por (NMWE(36), NMWE(63)) e (NMWE(62), NMWE(63)). Como pode ser facilmente notado, as características do espaço (NMWE(62), NMWE(63)) são altamente correlacionadas, indicando que uma delas deve ser eliminada do vetor de características, levando-se em consideração que a alta correlação entre duas medidas é um fato indesejável sob o ponto de vista de classificação estatística de padrões.

Baseado nessas considerações, foi realizada uma série de experimentos para classificação das células $\alpha$ e $\beta$ e avaliação das medidas de complexidade introduzidas neste trabalho. Assim, as seguintes medidas foram avaliadas: (1) a energia de dobramento apresentando a menor distância de separação de classes, denotada por $\mathbf{N M B E}_{\mathbf{w}}$; (2) a energia de dobramento apresentando a maior distância de separação de classes, denotada por $\mathrm{NMBE}_{\mathbf{0}}$; (3) a energia de wavelets apresentando a maior distância de separação de classes, denotada por NMWE $\mathbf{N}_{\mathbf{0}}$; (4) o descritor de Shen, Rangayan e Desautels, denotado por FF; (5) a melhor energia de dobramento e a melhor energia de wavelets, denotadas por $\mathrm{NMBE}_{\mathbf{0}}$ e $\mathrm{NMWE}_{\mathbf{0}} ;(6)$ a melhor energia de dobramento e o diâmetro da arborização dendrítica, denotados por $\mathbf{N M B E}_{\mathbf{0}}$ e $\mathbf{D A D}$.

A Figura 6.27 apresenta os espaços dessas características. Nos casos (1)-(4), em que os vetores de características possuem apenas uma componente, as características são traçadas em função da célula neural. Assim, as 33 células foram ordenadas, sendo as 15 células $\alpha$ apresentadas primeiramente, tendo sido representadas pelo eixo horizontal dos gráficos exibidos nas Figuras 6.27(a)-(d), enquanto as respectivas características são representadas pelos eixos verticais. Nesses casos, a classificação pode ser implementada através da definição de um limiar ótimo que diferencie as células $\alpha$ das células $\beta$. Um limiar sub-ótimo escolhido por inspeção está indicado em cada um dos gráficos. Nos casos (5) e (6), vistos nas Figuras 6.27(e) e (f), os vetores de características possuem 2

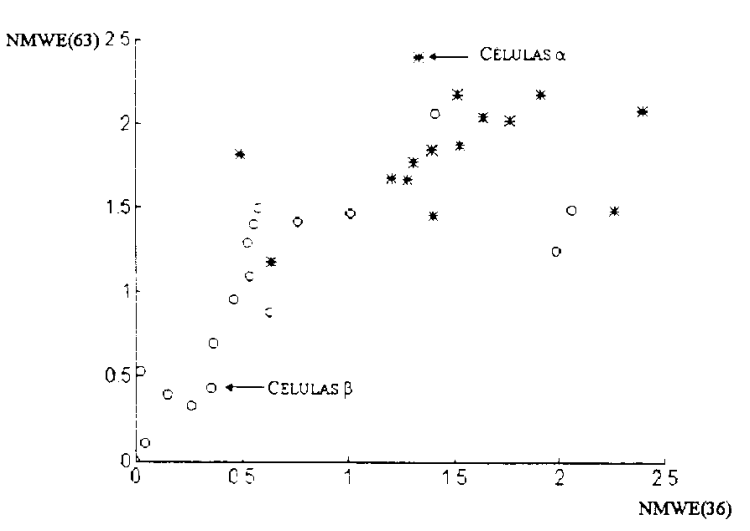

(a)

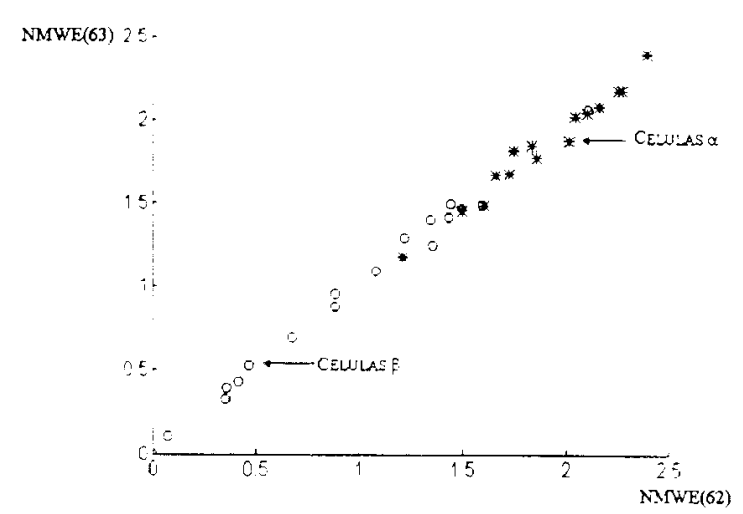

(b)

Figura (6.26): Distribuições indicando a alta correlação entre características extraídas de energias multi-escala adjacentes. 

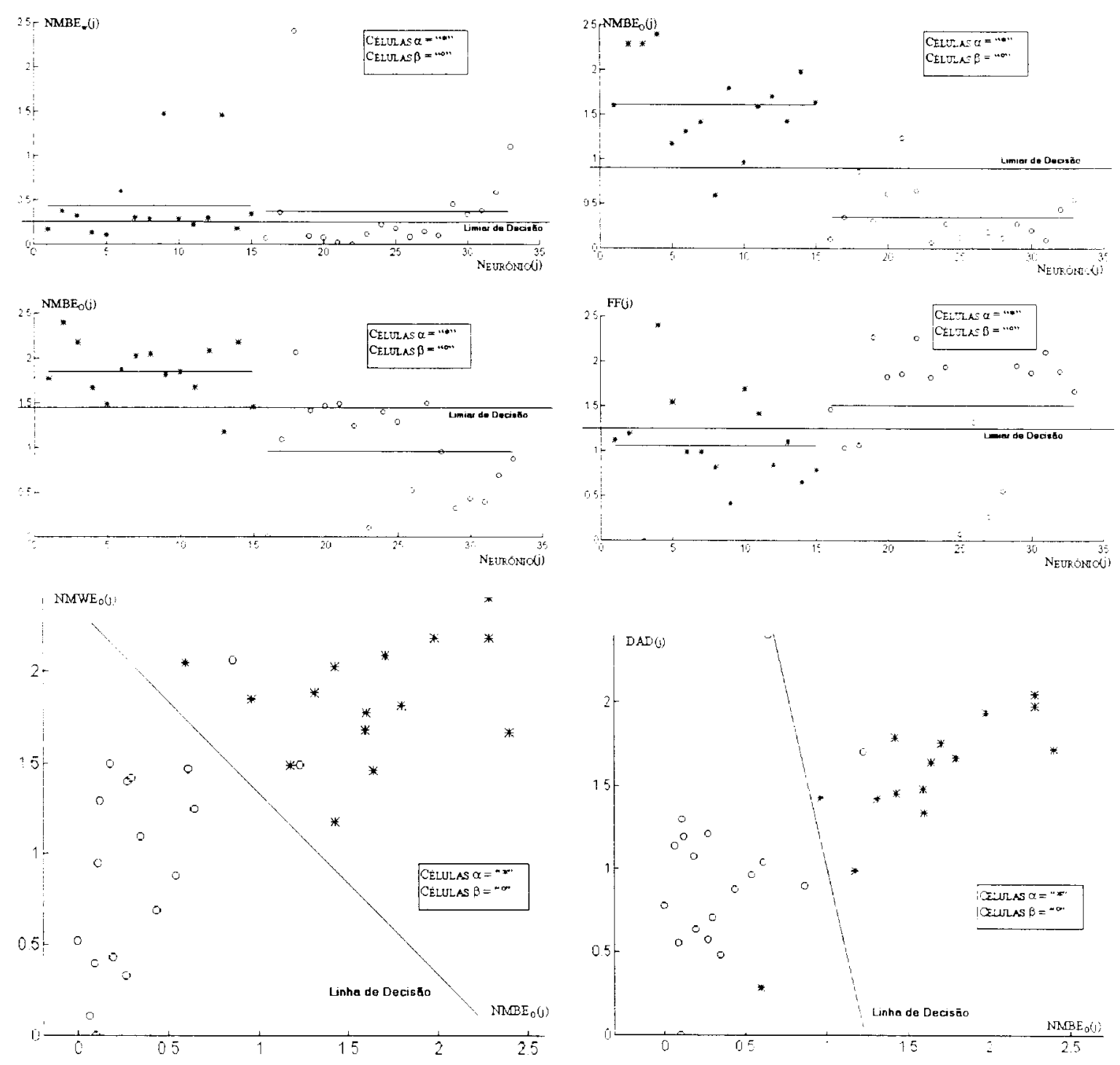

Figura (6.27): Distribuições dos diferentes vetores de características avaliados para classificação das células ganglionares $\alpha$ e $\beta$.

componentes, as quais são representadas pelos dois eixos cartesianos. A classificação, nesse caso, pode ser implementada através da definição de uma linha de decisão dividindo o plano em dois semi-planos, um para cada tipo de célula. Também nesse caso, uma linha de decisão sub-ótima escolhida por inspeção está indicada em cada um dos gráficos. A taxa de acertos dessas regiões lineares de classificação para cada vetor de características é apresentada na Tabela 6.2, indicando o bom desempenho das energias multi-escala ótimas.

Um dos fatores que explicam o bom desempenho das energias multi-escala é a presença de um número maior de extremidades nas células $\alpha$, como pode ser conferido no gráfico da Figura 6.28. Tais extremidades formam singularidades no sinal $u(t)$, 
implicando em respostas mais acentuadas por parte das transformadas multi-escala e uma maior energia para as células $\alpha$.

Experimentos de classificação automática de células usando dois classificadores estatísticos clássicos, um classificador por $k$-vizinhos mais próximos e um classificador de máxima verossimilhança foram realizados sorteando-se aleatoriamente 5 células de cada classe para formar o conjunto de treinamento dos classificadores. Um conjunto de taxa de acerto é apresentado na Tabela 6.3, corroborando a análise feita em relação ao bom esempenho das energias multi-escala para a caracterização de complexidade de formas. Como pode ser observado na tabela, os resultados não variaram muito em função do classificador estatístico utilizado. Além disso, na média, a melhor energia de dobramento $\left(\mathrm{NMBE}_{0}\right.$ ) apresentou os melhores resultados individualmente, embora a média de acertos tenha crescido quando essa característica foi usada juntamente com a NMWE ou a DAD.

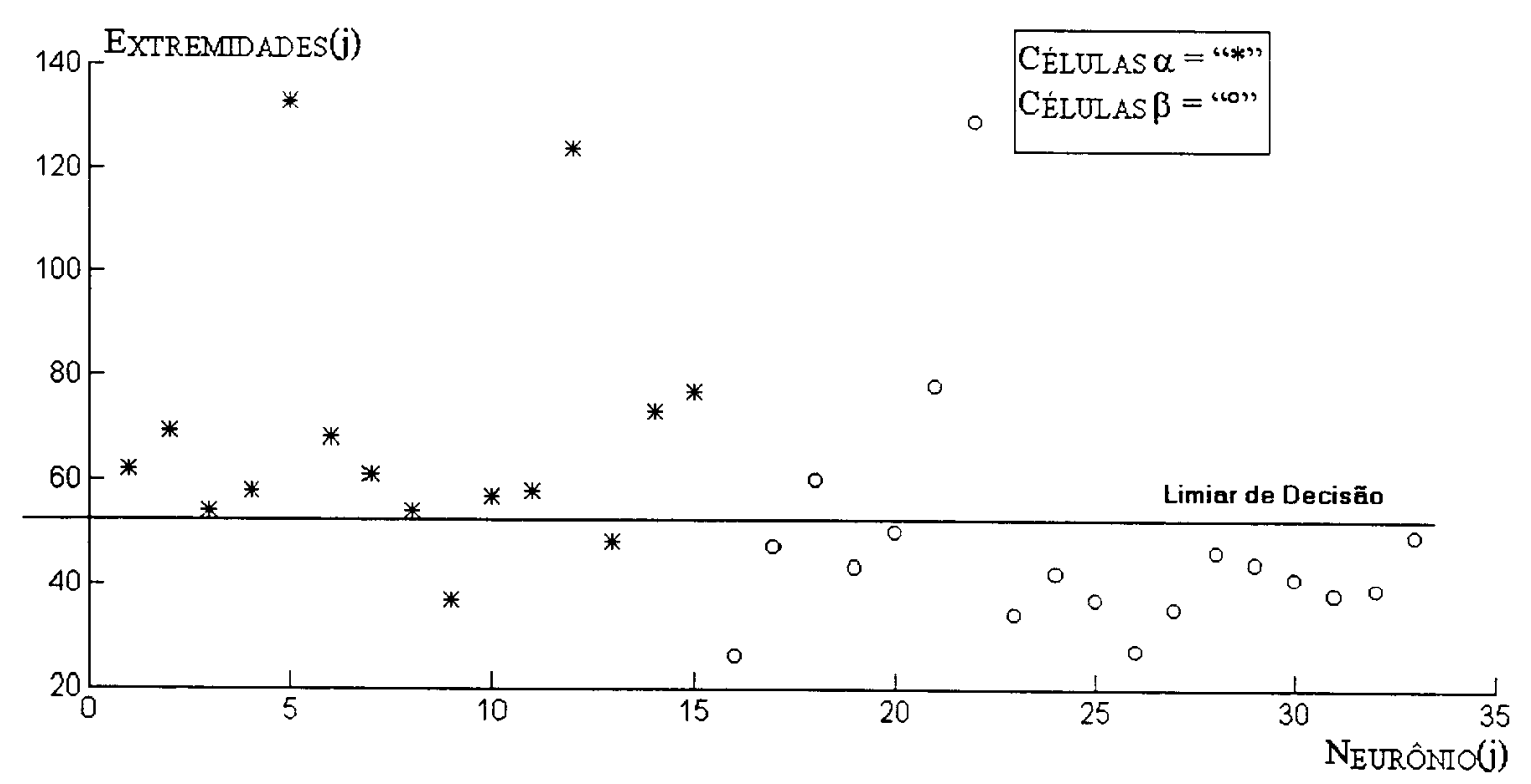

Figura (6.28): Distribuições do número de pontas em função dos neurônios. 


\begin{tabular}{|l|c|c|c|}
\hline Característica/Célula & $\alpha$ & $\beta$ & Média \\
\hline NMBE $_{\mathbf{w}}$ & $67 \%$ & $61 \%$ & $64 \%$ \\
\hline NMBE $_{\mathbf{0}}$ & $93 \%$ & $94 \%$ & $93.5 \%$ \\
\hline NMWE $_{\mathbf{0}}$ & $93 \%$ & $78 \%$ & $85.5 \%$ \\
\hline FF & $73 \%$ & $72 \%$ & $72.5 \%$ \\
\hline NMBE $_{\mathbf{0}}$ X NMWE & $100 \%$ & $89 \%$ & $94.5 \%$ \\
\hline NMBE $_{\mathbf{0}}$ X DAD & $93 \%$ & $94 \%$ & $93.5 \%$ \\
\hline
\end{tabular}

Tabela (6.2): Classificação correta das células ganglionares baseada na separação linear dos "clusters" de cada vetor de características .

É importante notar que complexidade de forma não é a única característica que pode ser usada por neurocientistas na classificação de células $\alpha$ e $\beta$, existindo outras características como o diâmetro da arborização dendrítica em função da excentricidade ou informação fisiológica da célula que são normalmente utilizadas. A meta dos experimentos desta seção não é a classificação das células ganglionares em si, mas mostrar que as energias multi-escala podem ser aproveitadas como descritores de complexidade robustos em problemas de análise de formas em geral e, particularmente, em neuromorfometria.

\begin{tabular}{|l|c|c|c|c|c|c|}
\hline & \multicolumn{3}{|c|}{ k-Vizinhos } & \multicolumn{3}{c|}{ Máxima Verossimilhança } \\
\hline Característica / Célula & $\alpha$ & $\beta$ & Média & $\alpha$ & $\beta$ & Média \\
\hline $\mathrm{NMBE}_{\mathrm{w}}$ & $40 \%$ & 53.84 & $47 \%$ & $90 \%$ & $0 \%$ & $45 \%$ \\
\hline $\mathrm{NMBE}_{\mathrm{o}}$ & $90 \%$ & $92 \%$ & $91 \%$ & $90 \%$ & $92 \%$ & $91 \%$ \\
\hline $\mathrm{NMWE}_{0}$ & $80 \%$ & $92 \%$ & $86 \%$ & $80 \%$ & $92 \%$ & $86 \%$ \\
\hline $\mathrm{FF}$ & $90 \%$ & $54 \%$ & $72 \%$ & $90 \%$ & $54 \%$ & $72 \%$ \\
\hline $\mathrm{NMBE}_{0} \mathrm{X} \mathrm{NMWE}$ & $93 \%$ & $89 \%$ & $91 \%$ & $100 \%$ & $94 \%$ & $97 \%$ \\
\hline $\mathrm{NMBE}_{\mathrm{o}} \mathrm{X} \mathrm{DAD}$ & $100 \%$ & $92 \%$ & $96 \%$ & $90 \%$ & $92 \%$ & $91 \%$ \\
\hline
\end{tabular}

Tabela (6.3): Resultados de classificação das células ganglionares. 


\section{Capítulo 7 - Geração Semi-Automática de Dendrogramas}

(...) Mais si vous raisonnez comme un neurophysiologiste banal, qui vous dit que le neurone n'a que deux états, un état excité et un état inhibé, un état de repos et un état excité, vous n'irez évidemment pas très loin. Mais tout le monde reconaîtra que dire que le neurone n'a que deux états résulte d'une simplification extraordinaire! Le neurone est un objet très compliqué, dont l'espace représentatif des états a certainement une dimension considérable. Les neurophysiologistes ont examiné une bestiole qui s'appelle l'aplysie. Je ne sais pas si c'est un céphalopode ou un mollusque qui vit dans les eaux du port de Marseille ou quelque part sur les rivages de la Provence. Ils ont constaté qu'il n'y avait que six ou huit neurones dans le systeme nerveux de cet animal, et ils ont dit: "Enfin! II n'y a que six ou huit neurones! Nous allons enfin comprendre comment fonctionne le système nerveux." Et ils ont constaté que cet animal a un comportement aussi compliqué, je ne dirais pas qu'un homme, mais très compliqué, et on ne peut pas en rendre compte simplement par une petite combinatoire n'impliquant que six ou huit neurones susceptibles de prendre un très petit nombre d'états. (...)

René Thom - Prédire n'est pas Expliquer, 1991 


\section{Geração Semi-Automática de DendRogramas}

7 ste capítulo introduz uma nova abordagem para caracterização de células neurais através da geração semi-automática de dendrogramas, os quais são estruturas de dados que descrevem diferentes aspectos globais associados à natureza ramificada nos dendritos dos neurônios. Em particular, os dendrogramas gerados por essa nova abordagem representam a estrutura ramificada dos neurônios em termos do tamanho dos segmentos de cada dendrito. $O$ novo método, que baseia-se na segmentação de contornos em função do curvograma (Capítulo 4) e em análise sintática de formas, facilita bastante a tarefa cansativa e demorada da extração de dendrogramas, tradicionalmente realizada por operadores humanos. Este capítulo ainda inclui diversos resultados experimentais que corroboram as qualidades da nova técnica.

\subsection{INTRODUÇÃO}

D

entre as diferentes abordagens para caracterização de células neurais, o dendrograma [Costa, 1997; Poznanski, 1992; Schutter \& Bower, 1994; Turner et al., 1995; Velte \& Miller, 1995] possui uma importância especial devido ao tipo de informação que ele explicita. Basicamente, os dendrogramas são árvores binárias que representam o padrão de arborização dendrítica dos neurônios, com nós que correspondem a cada ponto de ramificação nessas arborizações. Deve-se observar que árvores binárias são suficientes para representar tais arborizações, visto ser estatisticamente impossível o acontecimento de uma ramificação tripla, não importando quão próximos possam estar os novos ramos. Além disso, ramificações triplas que eventualmente ocorram na prática, devido à natureza discreta de imagens amostradas, podem ser tratadas como sendo duas ramificações duplas mais simples adotando-se arbitrariamente que as ramificações de um lado (por exemplo, o esquerdo, veja a Figura 7.1) vêm antes das do outro lado. Os dendrogramas também têm sido estendidos para incluir informação adicional sobre as estruturas neurais, sendo representada nas próprias arestas da árvore binária. Os tipos de informações adicionais podem incluir o tamanho e o diâmetro médio dos segmentos dos dendritos a densidade dos canais iônicos; o valor médio dos parâmetros elétricos ao longo dos segmentos; e mesmo a própria estrutura axonal. A Figura 7.2 exibe uma célula neural artificial composta por 4 grandes ramos dendríticos, referenciados como acima, abaixo, direito e esquerdo, e seu respectivo 


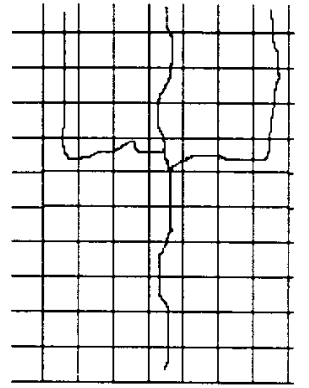

(a)

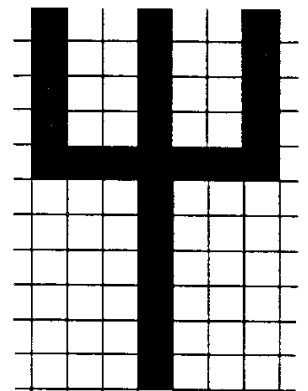

(b)

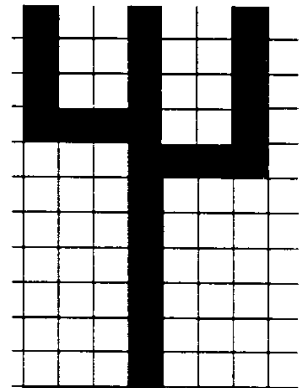

(c)

Figura (7.1): A ocorrência de uma ramificação tripla (b) devido à quantização do neurônio mostrado em (a) pode ser tratada como duas duplas (c).

dendrograma, sendo que o tamanho de cada segmento dendrítico (tamanho de arco entre cada par de bifurcações no grande ramo dendrítico) é proporcional ao tamanho dos segmentos de retas horizontais que são representados no dendrograma.

Além disso, a inclusão dos ângulos entre os segmentos dendríticos permite a generalização do dendrograma para que ele expresse praticamente toda a informação de grande escala contida na estrutura $3 \mathrm{D}$ da maioria das diferentes células neurais. É claro que a representação completa de características microscópicas dos neurônios, tais como a posição exata e o tipo de cada canal, para não mencionar o formato e posição precisa de cada "spine" que caracterizam a maioria das células excitatórias, apresenta-se incompatível com a filosofia por trás dos dendrogramas.

Freqüentemente obtidos a partir de medidas arduamente realizadas por operadores humanos, os dendrogramas têm tendido a apresentar um certo grau de subjetividade, além de o processo de sua geração toma um grande intervalo de tempo, tudo isso devido ao fato de serem sempre obtidos por especialistas humanos. O principal objetivo deste capítulo consiste justamente no desenvolvimento de uma técnica semi-automática que facilita a geração de dendrogramas a partir de imagens de neurônios obtidas por microscopia. Além da estrutura de ramificação dendrítica, os dendrogramas também incorporam o comprimento de cada segmento dendrítico, bem como outras características da forma neural, como será elucidado mais adiante.

Ao contrário do que possa parecer inicialmente, o problema de extração de dendrogramas é freqüentemente complicado por ambigüidades, como será discutido neste capítulo. Além disso, é crítica a identificação dos verdadeiros pontos de ramificação devido à variedade dos ângulos e curvaturas que podem aparecer. Assim, as técnicas de análise multi-escala de curvatura discutidas nesta tese são aproveitadas na determinação dos pontos de ramificação e extremidades ao longo da arborização dendrítica. Porém, apesar da boa precisão obtida pelo método de estimação digital de curvatura introduzido nesta tese, alguns pontos ainda podem não ser detectados, bem como falsos pontos dominantes podem ser tomados inadvertidamente, o que pode implicar na participação interativa de um operador humano para validar a representação obtida automaticamente. Uma interface gráfica razoavelmente versátil foi especialmente desenvolvida para a realização desse processo. Avaliações experimentais realizadas 


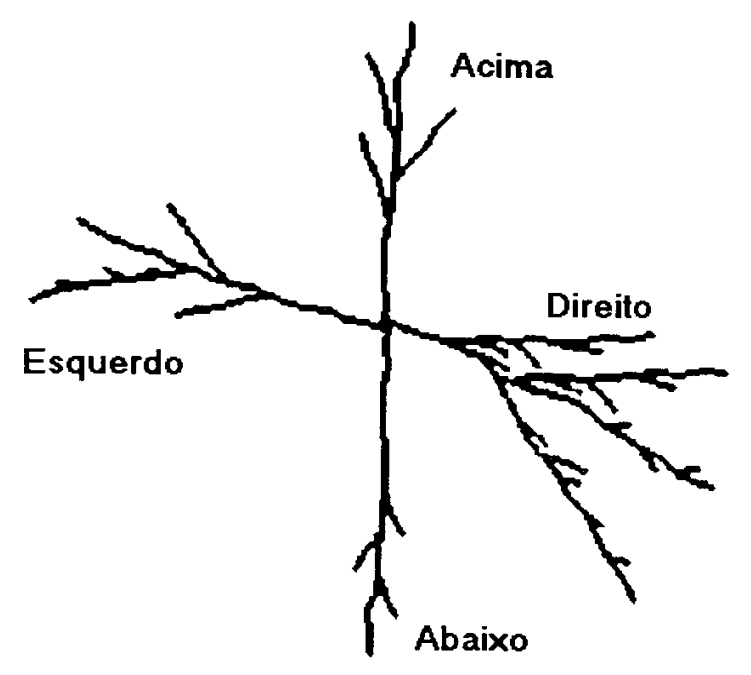

(a)

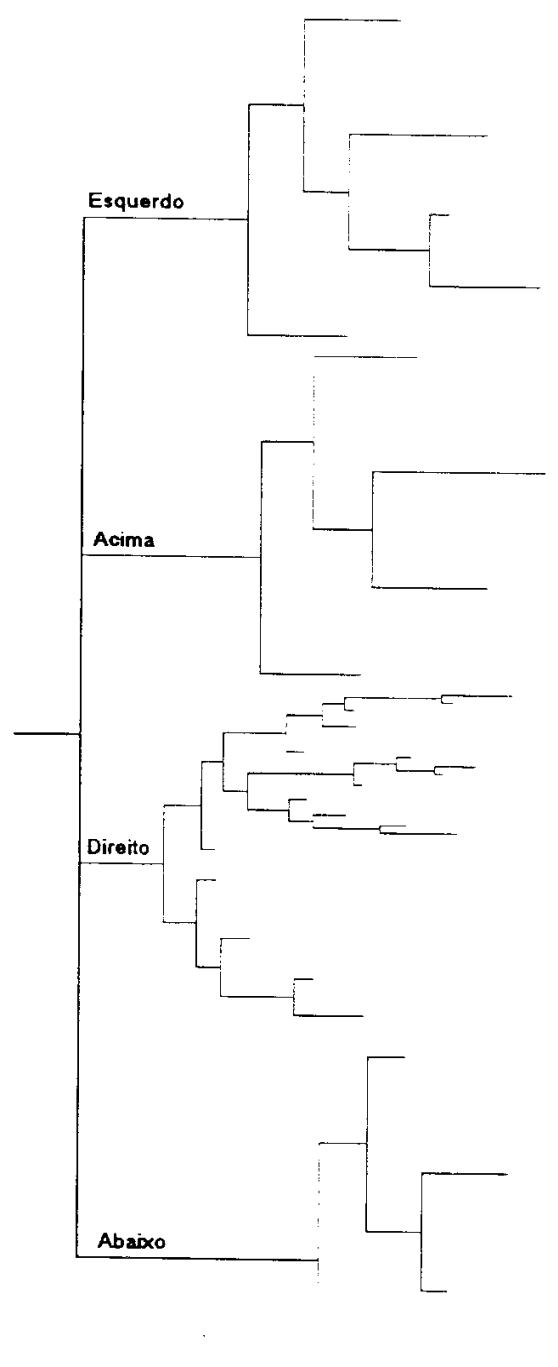

(b)

Figura (7.2): Célula neural artificial e seu respectivo dendrograma.

indicam que a intervenção do operador é requerida para alterar menos de $20 \%$ do total dos pontos dominantes, isto é, extremidades e pontos de ramificação. O problema de ambigüidade foi resolvido em termos de uma abordagem em que os ramos são analisados sintaticamente de acordo com a distância decrescente entre as respectivas extremidades.

Este capitulo começa discutindo os problemas envolvidos na geração do dendrograma e prossegue descrevendo o método de segmentação do contorno em função da curvatura calculada através do curvograma (Capitulo 4), os métodos interativos que fazem uso de interfaces gráficas, o procedimento de análise sintática e a derivação do dendrograma. Uma vez que o dendrograma tenha sido extraído, é possível obter-se, de maneira simples e direta, o esqueleto da respectiva célula, o que também é explicado neste capítulo. Diversos resultados experimentais corroborando a técnica são apresentados. 


\subsection{Convenções de TeRMinologia}

(1) primeiro passo na apresentação do algoritmo de geração semi-automática de dendrogramas é o estabelecimento da terminologia referente às partes das células neurais que devem ser processadas. A Figura 7.3 exibe algumas imagens de um neurônio de retina de galinha que esquematiza os termos usados neste capítulo.

A Figura 7.3(a) apresenta o referido neurônio enfatizando um de seus grandes ramos dendriticos, denominação essa dada à estrutura dendrítica que nasce a partir do

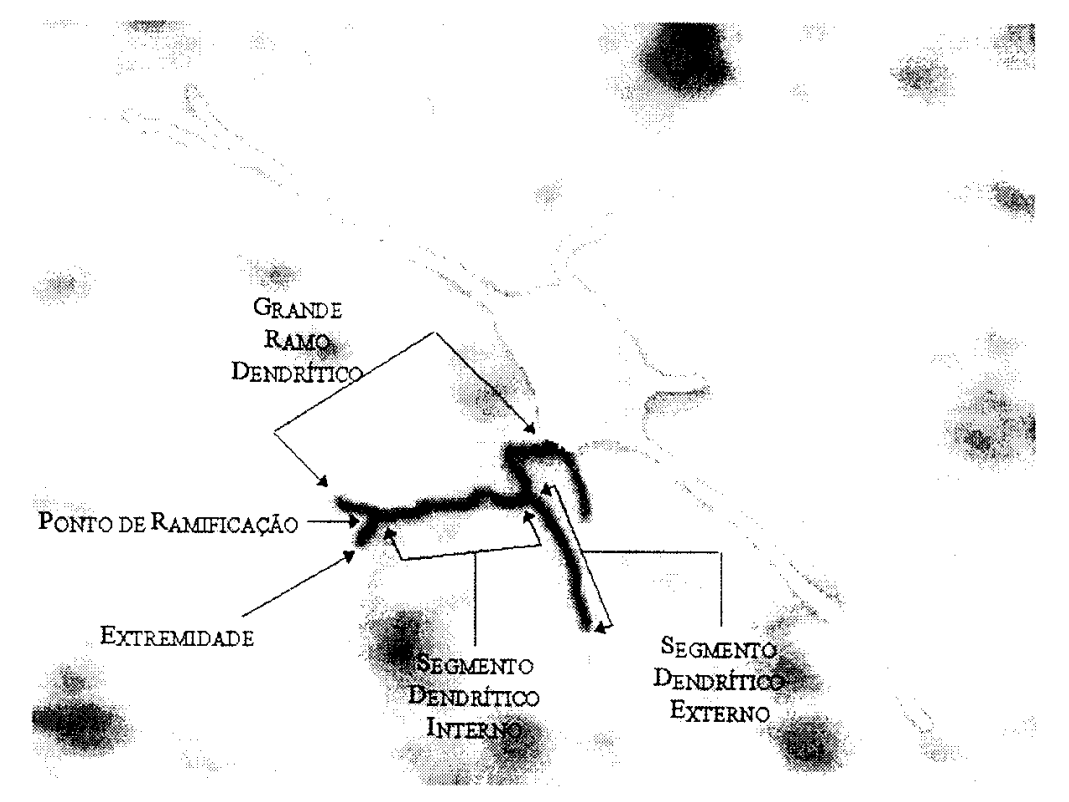

(a)

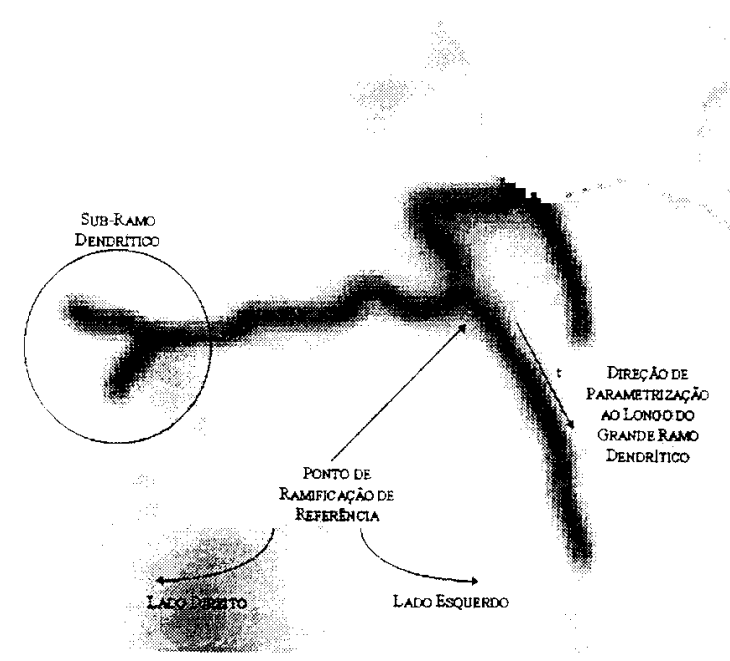

(b)

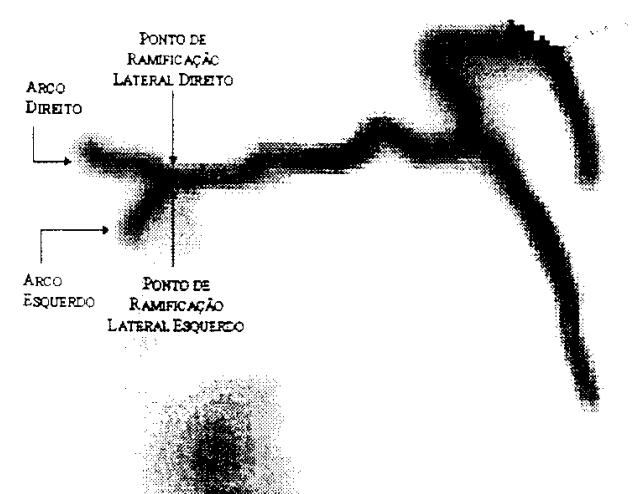

(c)

Figura (7.3): Esquemas ilustrando a terminologia adotada neste capítulo. 


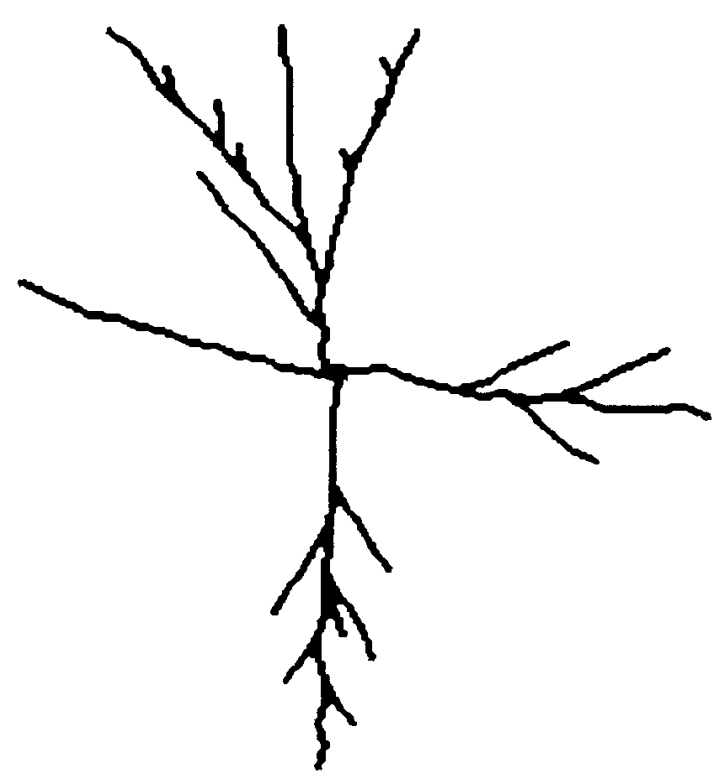

(a)

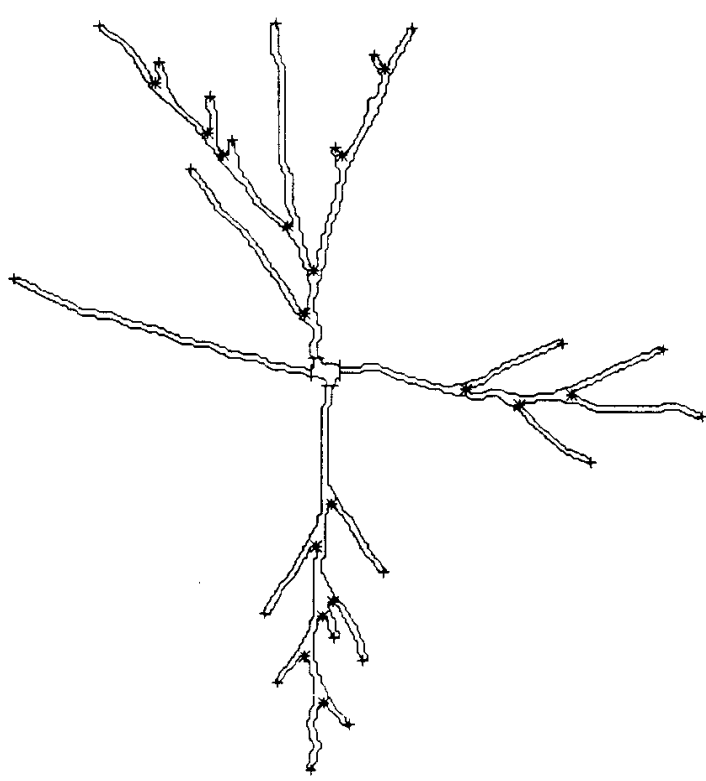

(b)

Figura (7.4): Célula neural artificial e seu respectivo contorno.

soma ou núcleo celular do neurônio. O grande ramo dendrítico é composto por um conjunto de segmentos dendriticos delimitados por pares de pontos de ramificação ou por um ponto de ramificação de um lado e uma extremidade do outro. Os segmentos dendríticos delimitados exclusivamente por pontos de ramificação são chamados de segmentos dendríticos internos, enquanto os limitados por um ponto de ramificação e uma extremidade são denominados segmentos dendríticos externos.

As sub-árvores que compõem o grande ramo dendrítico são denominadas sub-ramo dendritico, como é ilustrado pela Figura 7.3(b). A análise de cada grande ramo dendrítico é feita a partir de seu contorno, que deve começar e terminar junto ao soma do neurônio. Assumir-se-á que esse contorno é percorrido no sentido horário, como está assinalado na Figura 7.3(b). A adoção do sentido que se percorre o contorno do grande ramo dendrítico permite a divisão em lado esquerdo e lado direito do ramo em relação a um ponto de ramificação de referência, o lado esquerdo correspondendo a valores anteriores ao ponto de referência em relação ao parâmetro e o lado direito a valores posteriores.

Uma bifurcação no grande ramo dendrítico é definida por um ponto de ramificação e dois pontos de ramificação laterais associados, conforme esquematizado na Figura 7.3(c). O ponto de ramificação central está ligado a seu ponto de ramificação lateral esquerdo pelo arco esquerdo, o mesmo ocorrendo para o ponto de ramificação lateral direito e o arco direito. Neste capítulo, qualquer segmento de contorno particionado será referido como sendo um arco de maneira geral. 


\subsection{O Problema de Geração do Dendrograma}

(2) método introduzido neste capítulo baseia-se na análise de células neurais por contornos, ou seja, na abordagem adotada em todos os desenvolvimentos desta tese. Com a finalidade de introduzir com maior clareza os algoritmos deste capítulo, um grande ramo dendrítico será usado como modelo ao longo do capítulo.

A Figura 7.4(a) apresenta a forma de uma célula neural artificial , ao passo que a Figura 7.4(b) apresenta seu respectivo contorno. O grande ramo dendrítico à direita, que é destacado na Figura 7.5, será usado como exemplo na introdução e discussão dos algoritmos.

Embora o esqueleto das células possa ser usado na extração das árvores binárias que representam os dendrogramas, tais esqueletos são freqüentemente difíceis de se obter uma vez que o corpo das células é normalmente irregular, largo (principalmente na região do soma) e ruidoso. O principal problema é que os algoritmos de afinamento são em geral complexos e não garantem uma performance ótima. Assim, em vez de se basear em esqueletos, a abordagem introduzida nesta tese considera as arborizações dendríticas diretamente em termos de seu contorno, como mostrado na Figura 7.4(b).

Dois tipos especiais de pontos dominantes são considerados ao longo dos contornos: as extremidades, identificadas pelo prefixo $e$, e os pontos de ramificação, identificados pelo símbolo $b$, os quais são caracterizados por pertencerem a regiões convexas e côncavas do contorno (a concavidade pode ser inferida a partir do sinal da curvatura, como foi discutido no Capítulo 2). Assumindo que tais pontos tenham sido corretamente identificados, é possivel pensar no problema de extração de dendrogramas em termos de uma abordagem gramatical, ou ainda, mais especificamente, através da análise sintática de uma seqüência básica que define átomos estruturais nos dendrogramas, relacionados com a seqüência extremidade/ponto de

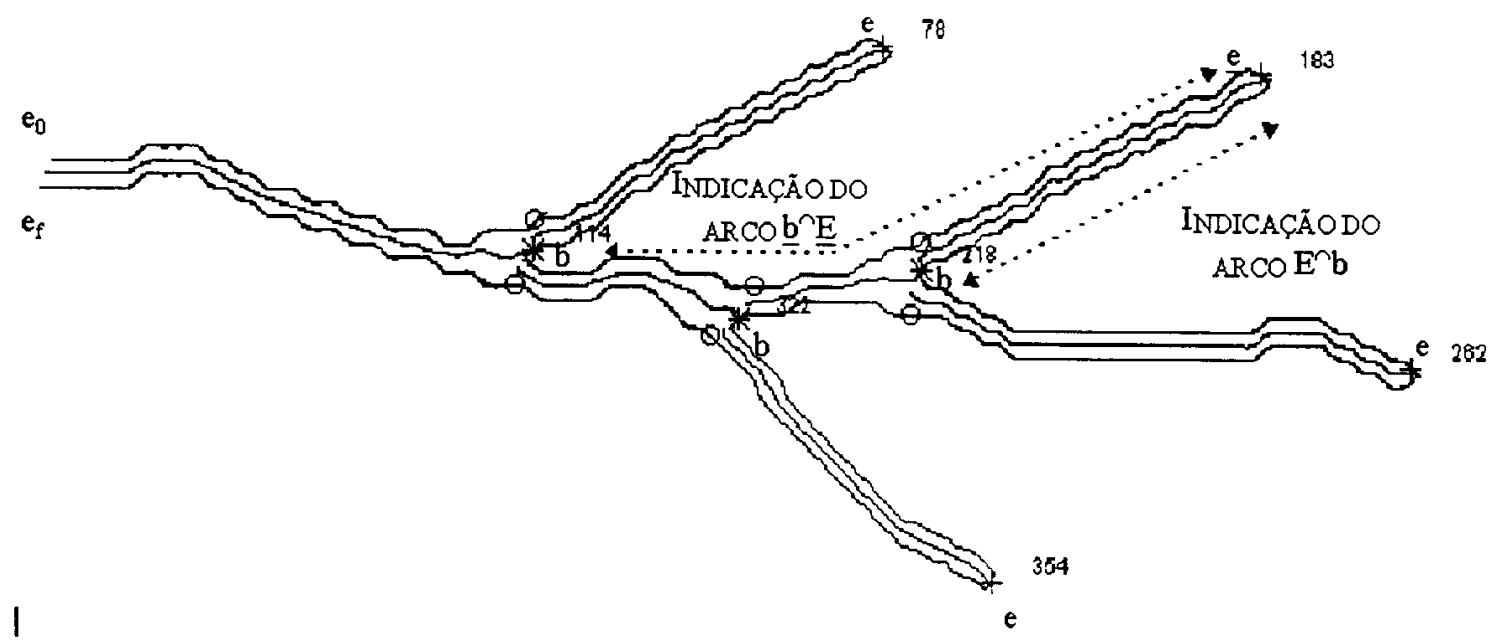

Figura (7.5): Esquema do contorno segmentado de um grande ramo dendrítico. 
ramificação/extremidade. Porém, essa análise sintática não pode ser realizada diretamente devido à existência de ambigüidades na representação gramatical de tais árvores dendríticas. Por exemplo, a mesma sequiência de símbolos que descrevem a árvore dendrítica principal da Figura 7.5, e e ebebebee $e_{f}$, pode possuir diferentes árvores de derivação, como ilustrado na Figura 7.6. A solução para esses problemas é apresentada nas próximas seções.

Deve-se analisar também a etapa de pré-processamento até a extração do contorno da célula neural. Essa etapa começa na captura da imagem digital a partir de uma câmera acoplada a um microscópio e ligada a um computador. Nos experimentos realizados durante o desenvolvimento desta tese, foi digitalizada inicialmente uma série de imagens da mesma célula, obtidas variando-se o foco do microscópio e enfatizando-se diferentes partes da célula em cada uma das imagens. Em seguida, uma imagem é obtida como a média da série inicial de imagens digitais, filtrando-se, assim, parte do ruído da imagem e enfatizando-se as diferentes partes da célula de interesse. Em seguida, a célula é "pintada" de uma cor mais escura interativamente pelo usuário, seguido de uma filtragem passa-baixas para eliminar artefatos devido a essa edição da imagem. Uma segmentação por limiarização seguida de filtragem mediana segmenta a célula neural em questão e elimina o ruído final. A partir dessa imagem segmentada, pode-se extrair o contorno do neurônio e começar o processamento. Depois de um pouco de prática, acredita-se que um operador possa realizar todas essas tarefas de pré-processamento entre 15 e 30 minutos, talvez menos. A geração do dendrograma a partir do contorno pode demorar entre 1 a 20 minutos, dependendo da complexidade da árvore dendrítica. Neurônios contendo muitos intercruzamentos entre seus dendritos podem aumentar bastante a complexidade dessa tarefa e métodos para acelerá-la de maneira semiautomática devereão ser desenvolvidos futuramente.

\subsection{Segmentação do Contorno}

10 métodos utilizados nesta seção baseiam-se na derivação do curvograma, introduzido no Capítulo 4, o qual é dado pela Equação 4.19, isto é:

$$
k(n, a)=\frac{-\operatorname{Im}\left\{\dot{u}(n, a) \ddot{u}^{*}(n, a)\right\}}{|\dot{u}(n, a)|^{3}}
$$

O curvograma $k(n, a)$ descreve a curvatura do contorno $C(n)$ analisado na escala $a$. A segmentação da célula neural é realizada a partir da escolha inicial de uma escala apropriada $a_{0}$, seguida de operações de limiarização, uma para a detecção das extremidades dos neurônios (que são definidos por pontos de mínima curvatura negativa, os quais caracterizam convexidades, assumindo-se que o contorno é atravessado no 


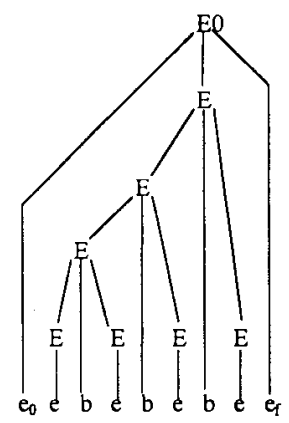

(a)

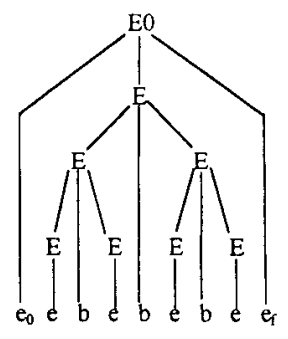

(b)

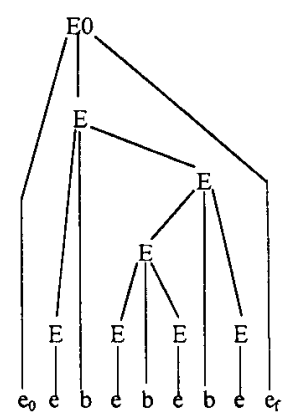

(c)

Figura (7.6): Três diferentes árvores de derivação para a mesma cadeia de caracteres. sentido horário), e outra para a deteç̧ão dos pontos de ramificação (que são definidos por pontos de máxima curvatura positiva, os quais caracterizam concavidades, assumindo-se que o contorno é atravessado no sentido horário). É importante notar que, se o contorno for atravessado no sentido anti-horário, é suficiente a definição das extremidades como pontos de máxima curvatura positiva e pontos de ramificação como pontos de mínima curvatura negativa. Além disso, assume-se que existe uma vizinhança mínima em torno de cada ponto dominante (seja ele uma extremidade ou um ponto de ramificação) dentro do qual só pode existir 1 ponto dominante. Essa suposição implica uma fase de pós-processamento que deve verificar a vizinhança mínima em torno de cada ponto dominante. No caso de existir mais de um de tais pontos, o algoritmo deve escolher apenas um, de modo que a regra da vizinhança mínima seja obedecida. Na implementação realizada, o algoritmo escolhe o ponto mais central dentre os pontos dominantes que estiverem dentro de uma vizinhança mínima comum. $\mathrm{O}$ algoritmo para detecção de pontos dominantes pode ser resumido da seguinte maneira:

\section{Algoritmo 7.1: Detecção de Pontos Dominantes;}

2. Calcule $k\left(n, a_{0}\right)$, definido pela Equação 4.19 , em que $a_{0}$ é uma constante definida $a$ priori;

3. Encontre todos os pontos de ramificação definidos como $B=\left\{u(n) \mid k\left(n, a_{0}\right)>T_{B}\right.$, e $k\left(n, a_{0}\right)$ é um ponto de curvatura máxima positiva local $;$;

4. Encontre todas as extremidades definidas como $E=\left\{u(n) \mid k\left(n, a_{0}\right)<T_{E}, e k\left(n, a_{0}\right) \dot{e}\right.$ um ponto de curvatura mínima negativa local\};

5. Processe $E$ e $B$, de maneira que a vizinhança mínima em torno de cada extremidade (ou ponto de ramificação) contenha apenas 1 extremidade (ou ponto de ramificação), conforme explicado no parágrafo anterior no texto;

6. Fim.

O Algoritmo 7.1 requer a especificação de quatro parâmetros, a saber: a escala de análise $a_{0}$, os limiares $T_{B}$ e $T_{E}$, e o tamanho da vizinhança mínima em torno de cada 
ponto dominante. Em todos os experimentos apresentados, a vizinhança minima para os contornos discretos é de 3 pontos de cada lado do ponto dominante. Os outros 3 parâmetros são ajustados por procedimentos interativos, como é explicado na próxima seção.

\subsection{GUI's e a ABORDAgem SEMI-Automática}

omo toi explicado na Seção 7.4, o algoritmo de segmentação para detecção de pontos dominantes requer a especificação de três parâmetros. Esses parâmetros são ajustados oor três procedimentos semi-automáticos que podem requisitar intervenções do operador. Um quarto procedimento semi-automático é também realizado, o qual pergunta ao operador se existem ajustes finais que devem ser realizados no particionamento do contorno, seja para inclusão ou para exclusão de pontos dominantes detectados pelo Algoritmo 7.1. Os quatro procedimentos utilizam os recursos de interface gráfica com o usuário (GUI's, do inglês "Graphical User Interfaces"), e funcionam da seguinte maneira:

Procedimento 1 (ajuste da escala): Uma janela gráfica apresenta para o usuário o contorno original e sua versão suavizada pela filtragem gaussiana. Três imagens que ilustram esse procedimento podem ser vistas na Figura 7.7. O usuário pode controlar o grau de suavização do contorno através de um controle de barra deslizante que também é apresentado ao operador.. Existe um "trade-off" nesse processo, visto que o contorno filtrado deve ser o mais suave possível, mas sem introduzir distorções grosseiras em comparação com o contorno original. Esse procedimento possui memória no sentido de que o nível inicial de suavização é uma média dos parâmetros das últimas execuções do programa. Verificou-se que essa abordagem é bastante robusta e o operador raramente precisa fazer ajustes trabalhosos. Essa mesma estratégia é adotada pelos próximos procedimentos. A escala de análise $a_{0}$ é ajustada como sendo o desvio padrão do filtro gaussiano correspondente ao contorno suavizado; 


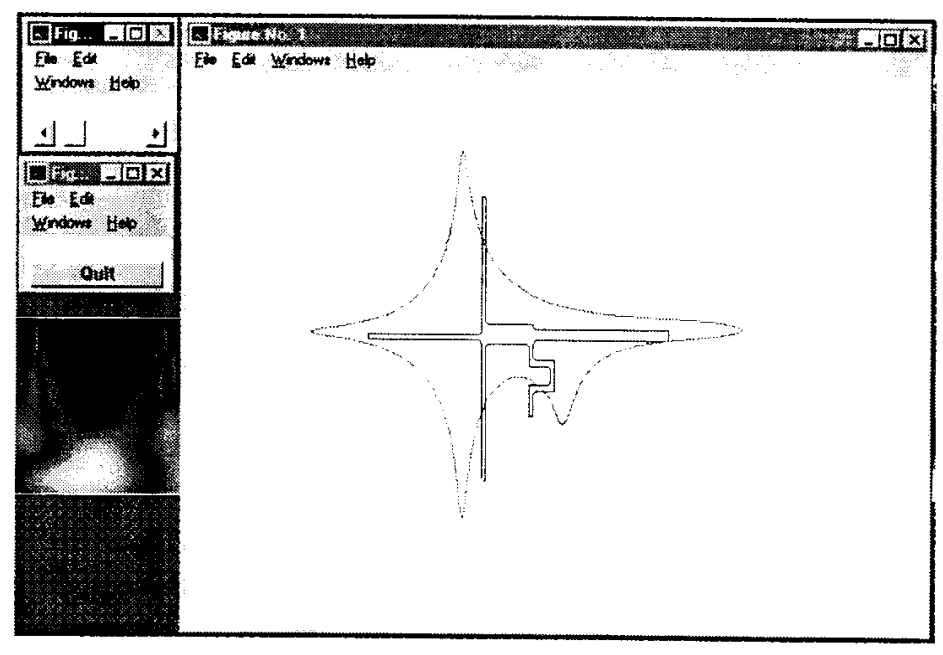

(a)

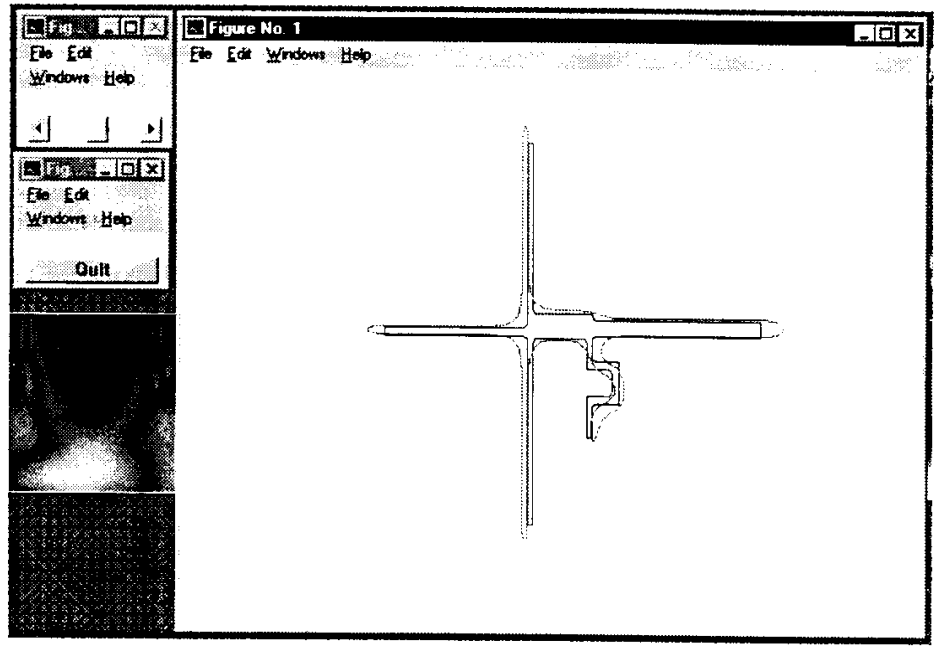

(b)

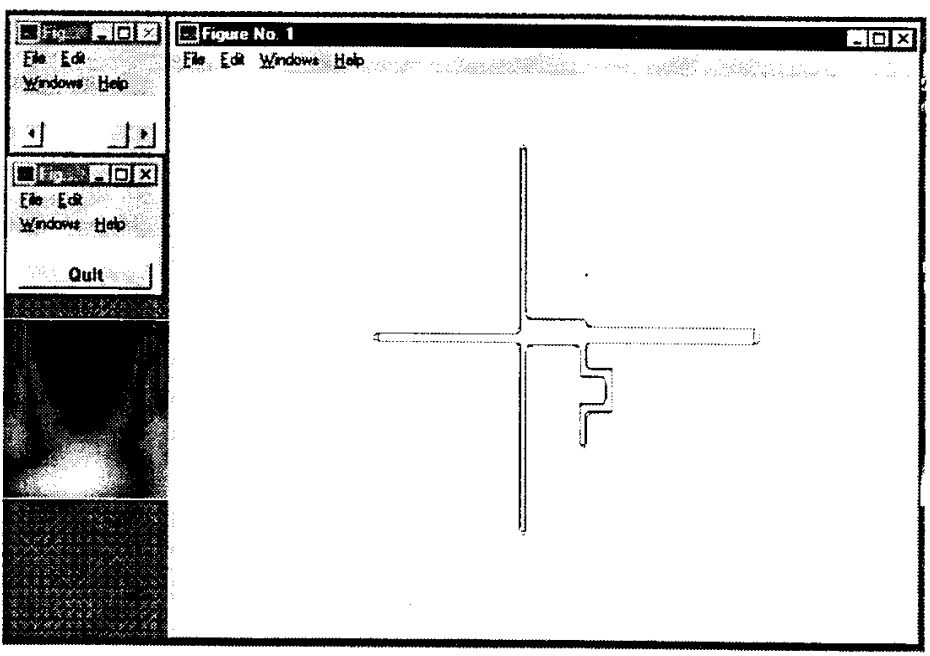

(c)

Figura (7.7): Ilustração do procedimento semi-interativo de ajuste de escala. 


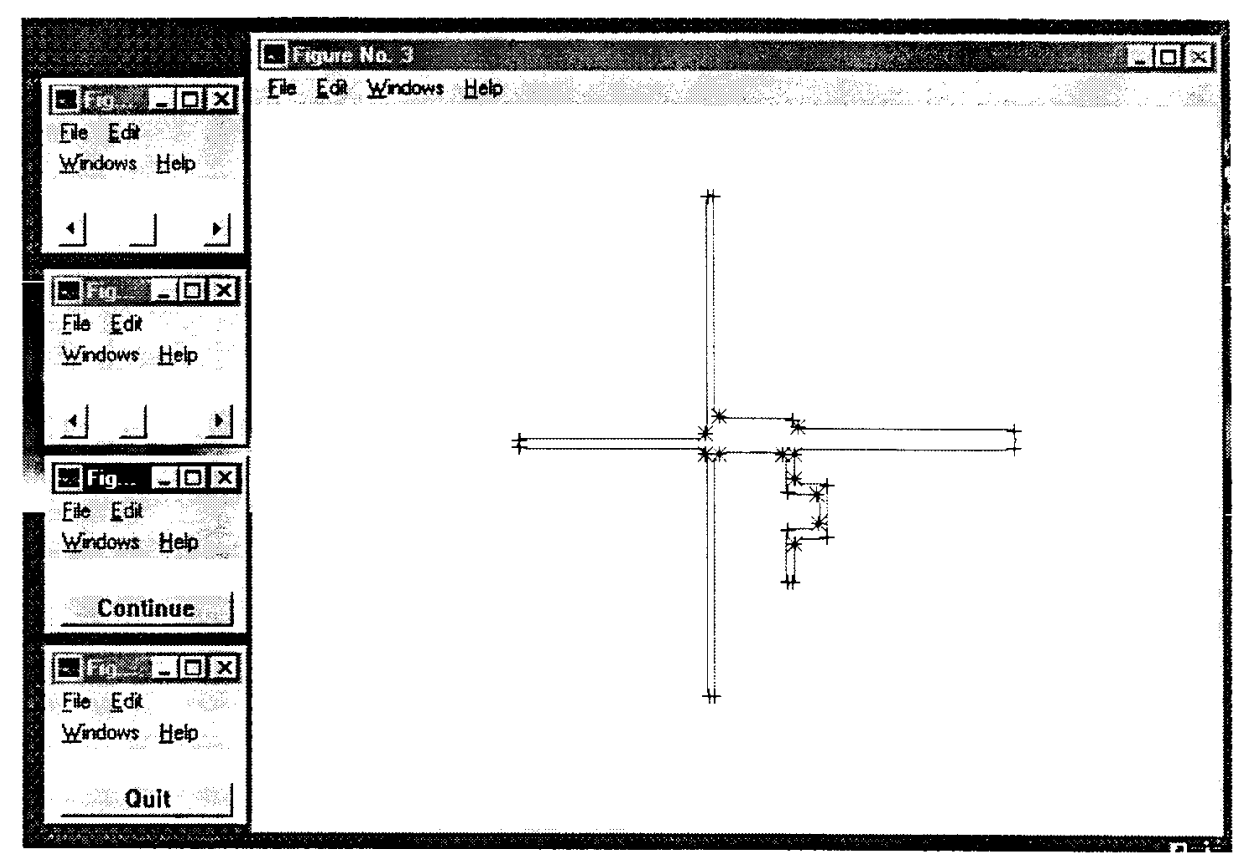

(a)

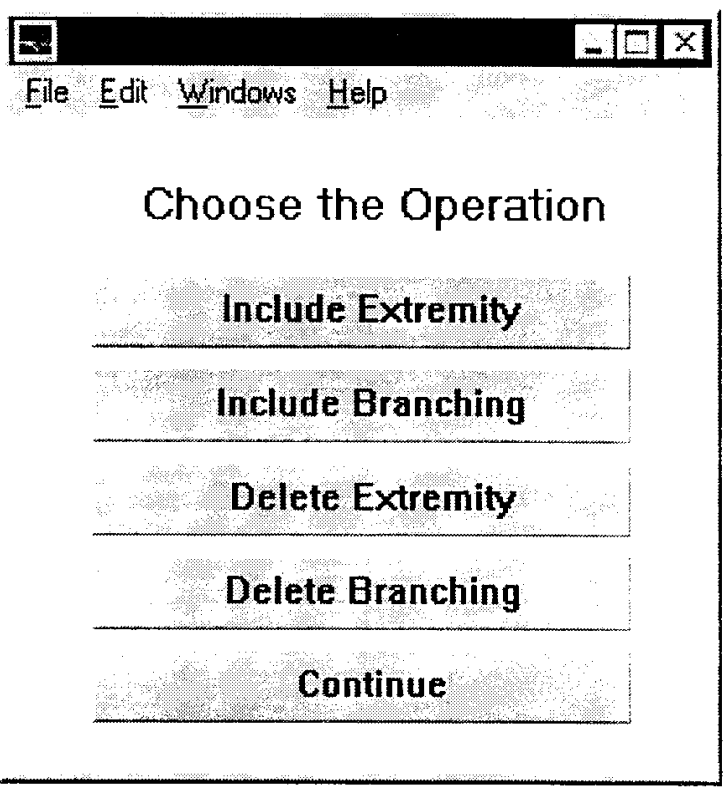

(b)

Figura (7.8): (a) Ajuste dos limiares de segmentação; (b) Ajustes finais de segmentação.

Procedimento 2 (ajuste do limiar para extremidades): Esse procedimento funciona de maneira análoga ao Procedimento 1, ou seja, uma janela gráfica é apresentada ao usuário mostrando o contorno e as extremidades inicialmente encontradas pelo procedimento. A Figura 7.8(a) exibe um exemplo desse procedimento em execução. Novamente o usuário pode controlar o limiar de extremidades através de um controle de barra deslizante. Na medida que o operador altera o valor do limiar de curvatura, extremidades são criadas ou apagadas, processo este que é mostrado "on-line" na janela gráfica. Essas extremidades são encontradas pelo passo 4 do algoritmo 7.1, o 
qual é iniciado com um valor a priori de limiar $T_{E}$. Novamente, esse valor a priori é o mesmo limiar que foi a melhor escolha da última execução do programa, ou seja, o limiar que o programa aprendeu. De maneira similar, os resultados com essa estratégia são bastante robustos e o usuário não precisa interagir intensamente até encontrar um bom limiar;

Procedimento 3 (ajuste do limiar para pontos de ramificação): Esse procedimento funciona de maneira análoga ao procedimento anterior, exceto que o passo 3 do algoritmo 7.1 é aplicado para a identificação dos pontos de ramificação. A Figura 7.8(a) também exibe as janelas de execução desse procedimento;

Procedimento 4 (ajuste final dos pontos dominantes): Apesar de o algoritmo de particionamento de contornos ser freqüentemente robusto, pontos dominantes falsos e ausentes podem ocorrer. $O$ procedimento 4 permite que o operador faça uma checagem no contorno segmentado de maneira que ele possa corrigir possíveis erros do algoritmo automático. Dessa maneira, o contorno segmentado é apresentado ao operador em uma nova janela gráfica, sendo que dois símbolos diferentes são usados para indicar as extremidades e os pontos de ramificação. A seguir, o procedimento apresenta ao usuário um menu em uma janela gráfica (veja a Figura 7.8(b)) que permite a realização de quatro operações, a saber: inclusão de extremidade, exclusão de extremidade, inclusão de ponto de ramificação e exclusão de ponto de ramificação. $O$ usuário executa os ajustes finais escolhendo a operação desejada no menu de controle e indicando o respectivo ponto sobre o contorno segmentado. Finalmente, o procedimento 4 permite que o operador defina cada grande ramo dendrítico, cada um deles começando no soma, devendo marcar os pontos inicial e final do grande ramo. Cada um dos grandes ramos dendríticos é analisado para a geração de um dendrograma respectivo.

É importante notar que o resultado nos casos em que a intervenção do operador for requerida depende de determinados "limiares subjetivos" definidos pela experiência anterior e conhecimento especialista do autor das intervenções. A automação de um determinado trabalho tradicionalmente realizado por profissionais humanos requer que o sistema computacional inclua o conhecimento especialista adquirido por esses profissionais, o que demanda aquisição de conhecimento especialista, o que não é trivial e nem sempre possível de ser realizada. Alternativamente, a abordagem semi-automática resolve esse problema ao incluir a supervisão e possibilidade de interação do sistema computacional com o especialista humano.

Tendo sido definido cada grande ramo dendrítico e realizada corretamente sua segmentação, o programa prossegue analisando cada grande ramo separadamente. Para isso, cada grande ramo é re-parametrizado, com o parâmetro ao longo do grande ramo iniciando no primeiro ponto de ramificação junto ao soma, atravessando todo o grande ramo e terminando junto ao segundo ponto de ramificação no soma da célula. Portanto, no exemplo da Figura 7.5, a nova parametrização começa para $n=1$ no símbolo $e_{0}$, prossegue alcançando $n=78$ na primeira extremidade do grande ramo dendrítico (indicado ao lado do símbolo $e$ na Figura 7.5) e assim por diante. 


\subsection{ANÁlISE SintátICA}

ـ meta da etapa de análise sintática é a obtenção de uma árvore sintática que reflita a estrutura do grande ramo dendrítico. Essa análise começa por rotular os pontos dominantes obtidos na etapa de particionamento do contorno (Seções 7.4 e 7.5), de maneira que os pontos inicial e final da árvore principal sejam rotulados pelos símbolos $e_{0}$ e $e_{f}$, respectivamente; cada extremidade é rotulada pelo símbolo $e$ e cada ponto de ramificação pelo símbolo $b$. Define-se a gramática $G=\left(V_{N}, V_{T}, P, S\right)$, sendo que $\mathrm{V}_{\mathrm{N}}=\{E\}, \mathrm{V}_{\mathrm{T}}=\left\{e_{0}, e_{f}, e, b\right\}, \mathrm{S}=\{E 0\}$ e $\mathrm{P}$ consiste no seguinte conjunto de produções:

$$
\begin{aligned}
& \text { 1. } E O \rightarrow e_{0} E e_{f} \\
& \text { 2. } E \rightarrow E b E \\
& \text { 3. } E \rightarrow e
\end{aligned}
$$

Como ilustração, os símbolos correspondentes foram indicados na árvore principal mostrada na Figura 7.5. Como pode ser visto, a cadeia que representa essa árvore principal é $e_{0} e b e b e b e e_{f}$. O procedimento de análise sintática ascendente ("bottom-up") parece ser, a princípio, bastante simples devido à simplicidade da gramática. A implementação desse procedimento utiliza uma estrutura de dados do tipo árvore ternária (até três filhos por nó) que vai sendo construída ascendentemente na medida que o processo de análise sintática desenvolve-se. Cada nó dessa árvore possui os seguintes campos:

- Parâmetro do Ponto de Ramificação Lateral Esquerdo: No caso em que o nó corrente for um ponto de ramificação, esse campo armazena o valor do parâmetro associado ao respectivo ponto de ramificação lateral esquerdo. Esse parâmetro é calculado e ajustado durante a execução do procedimento de análise sintática;

- Parâmetro do Ponto de Ramificação Lateral Direito: No caso em que o nó corrente for um ponto de ramificação, esse campo armazena o valor do parâmetro associado ao respectivo ponto de ramificação lateral direito. Esse parâmetro é calculado e ajustado durante a execução do procedimento de análise sintática;

- Parâmetro do Ponto Corrente: Se o nó corrente corresponder a um símbolo terminal, o que significa que o ponto associado é um ponto de ramificação, uma extremidade ou um dos dois pontos de ramificação junto ao soma, este campo armazena seu respectivo parâmetro ao longo do contorno do grande ramo dendrítico sob análise. Caso contrário, assume o valor armazenado no mesmo campo do nó filho central do nó corrente;

- Símbolo do Ponto Corrente: Pode assumir um dos símbolos terminais, o símbolo não-terminal ou o símbolo inicial; 
- Ponteiro para o Nó Pai: É atualizado na medida que as produções gramaticais vão sendo substituídas para dar lugar à criação dos nós ascendentes da árvore sintática;

- Ponteiro para o Nó Filho Esquerdo: É atualizado na medida que as produções gramaticais vão sendo substituídas para dar lugar à criação dos nós ascendentes da árvore sintática;

- Ponteiro para o Nó Filho Direito: É atualizado na medida que as produções gramaticais vão sendo substituídas para dar lugar à criação dos nós ascendentes da árvore sintática;

- Ponteiro para o Nó Filho Central: É atualizado na medida que as produções gramaticais vão sendo substituídas para dar lugar à criação dos nós ascendentes da árvore sintática.

É importante notar que, durante a execução da análise sintática ascendente, o algoritmo deve manter uma lista de controle guardando os nós mais acima da árvore , ou seja, os nós que ainda não são filhos de ninguém. Essa lista, chamada cadeia de controle, cumpre um papel central no processo de análise sintática, bem como na determinação dos pontos laterais de ramificação, como será ilustrado.

Uma versão preliminar do algoritmo de análise sintática pode ser criada da seguinte maneira:

\section{Algoritmo 7.2: Análise Sintática (Versão 1);}

2. Troque todas as ocorrências de " $e$ " por " $E$ ", através da aplicação da regra 3;

3. Troque todas as ocorrências de " $E b E$ " por " $E$ ", através da aplicação da regra 2;

4. Troque a ocorrência de " $e_{0} E$ e $e_{f}$ por " $E 0$ ", através da aplicação da regra 1 ; 5.Fim.

Porém, existe um problema importante associado ao passo 3 do algoritmo 7.2, pois diferentes derivações podem ser obtidas a partir da mesma cadeia inicial, o que significa que a ordem de aplicação da regra 2 da gramática definida anteriormente define diferentes

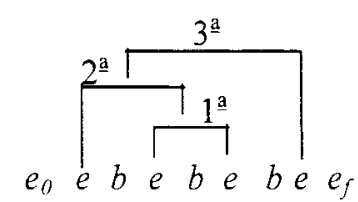

Figura (7.9): Ordem correta das substituições para o grande ramo principal da Figura 7.5. árvores sintáticas (veja a Figura 7.6 para alguns exemplos). Uma heurística foi, portanto, introduzida no passo 3 do algoritmo $7.2 \mathrm{com}$ a finalidade de eliminar esse problema de ambigüidade.

A idéia básica dessa heurística pode ser compreendida imaginando-se que cada aplicação da regra 2 da gramática durante o procedimento de análise sintática é equivalente ao processo físico de "cortar-se" um sub-ramo do grande ramo dendrítico, sub-ramo este 
correspondente ao respectivo $E b E$ que está sendo substituído por $E$. Portanto, a idéia é construir a árvore sintática "cortando-se" primeiramente os sub-ramos menores, os quais são os últimos sub-ramos do grande ramo dendrítico. Nesse sentido, uma simples análise da árvore dendrítica da Figura 7.5 indica que a correta ordem de aplicação da regra 2 para essa árvore é aquela mostrada na Figura 7.9.

Assim, o procedimento de análise sintática percorre a cadeia de controle em busca de sequiências $E b E$, sendo que o algoritmo de análise sintática deve decidir se deve ou não fazer a substituição $E b E \Rightarrow E$ uma vez que uma sub-cadeia $E b E$ tenha sido encontrada. Essa decisão, que se baseia na comparação entre o comprimento de arco dos segmentos do sub-ramo corrente e o dos sub-ramos vizinhos, é tomada da maneira explicada a seguir.

Uma vez que uma sub-cadeia $E b E$ tenha sido encontrada, a qual será denominada a $E b E$ corrente e denotada por $\underline{E b E}$, o algoritmo testa se existe uma outra sub-cadeia $E b E$ à direita de $E b E$, sendo que o segundo " $E$ " da primeira sub-cadeia é o primeiro " $E$ " da segunda sub-cadeia, ou seja, a união dessas duas sub-cadeias forma a sub-cadeia " $\underline{E b E b E}$ ". Nesse caso, o comprimento de arco entre o primeiro " $\underline{b}$ " 11 e o " $E$ " do meio (indicado por "arco $\underline{b}^{\cap} \underline{E}$ " na Figura 7.5) é comparado com o comprimento de arco entre esse " $E$ " do meio e o segundo " $b$ " (indicado por "arco $E$ $b$ " na Figura 7.5). De maneira similar, o algoritmo verifica se existe uma outra sub-cadeia $E b E$ à esquerda de $\underline{E b E}$, sendo que a união dessas duas sub-cadeias forma a cadeia "EbEbE". Nesse caso, o comprimento de arco $b^{\cap} \underline{E}$ é comparado ao comprimento de arco $\underline{E^{n}} \underline{b}$; se (comprimento $\left(\underline{b}^{\cap} \underline{E}\right)<\operatorname{comprimento}\left(\underline{E}^{\cap} b\right)$ ) e $\left(\operatorname{comprimento}\left(\underline{E}^{\cap} \underline{b}\right)<\operatorname{comprimento}\left(b^{\cap} \underline{E}\right)\right.$ ), então a sub-cadeia $\underline{E b E}$ é substituída por $E$. Caso contrário, o algoritmo deixa a subcadeia corrente e tenta substituir a segunda seqüência $E b E$, repetindo os mesmos testes. Essas duas comparações são realizadas assumindo-se a existência de " $E b E b E "$ e " $E b \underline{E b E}$ ". No caso em que um deles (ou ambos) não exista, o respectivo teste é simplesmente ignorado, o que ocorre quando o sub-ramo corrente não possui sub-ramos vizinhos à esquerda ou à direita (ou de ambos os lados). Essa heurística, baseando-se no cruzamento de informação entre as representações simbólica e geométrica, induz o algoritmo a tentar realizar primeiramente as substituições correspondentes aos menores sub-ramos. Portanto, o algoritmo 7.2 deve ser atualizado para a versão 2, a qual será denominada algoritmo 7.3:

\section{Algoritmo 7.3: Análise Sintática (Versão 2)}

2. Troque todas as ocorrências de " $e$ " por " $E$ ", através da aplicação da regra 3 ;

3. Enquanto existirem sub-cadeias " $E b E$ " restantes faça:

4. Se a sub-cadeia “ $\underline{E b E b E}$ ” for encontrada, então:

\footnotetext{
"O ponto de ramificação do contorno correspondente ao símbolo " $b$ " ou a qualquer outro será referenciado por expressões como "o primeiro $b$ ", "o último $e$ " e assim por diante, com o propósito de simplificação de notação durante as explicações.
} 
5. Se (comprimento $\left.\left(\underline{h}^{\bigcap} \underline{E}\right)<\operatorname{comprimento}\left(\underline{E}^{\curvearrowleft} b\right)\right)$ então:

6. Substitution_flag = true;

7. Senão:

8. Substitution_flag = false;

9. Senão:

10. Substitution_flag = true;

11. Se a sub-cadeia " $E b \underline{E b E}$ " for encontrada, então:

12. Se (comprimento $\left.\left(\underline{E}^{\curvearrowleft} \underline{b}\right)<\operatorname{comprimento}\left(b^{\curvearrowleft} \underline{E}\right)\right)$ então:

13. Substitution_flag $=$ true;

14. Senão:

15. Substitution_flag = false;

16. Senão:

17. Substitution_flag = true;

18. Se (Substitution_flag = true) então:

19. Troque " $E b E$ " por " $E$ ", através da aplicação da regra 2;

20. Troque a ocorrência de " $e_{0} E e_{f}$ " por " $E 0$ ", através da aplicação da regra 1; 21.Fim.

Uma característica adicional importante do procedimento de análise sintática é que ele permite a definição de uma segmentação por partes do corpo neural baseada em regiões, ou seja, de cada segmento dendrítico. A Figura 7.10 exibe uma ilustração esquemática dos conceitos envolvidos no processo de segmentação. 


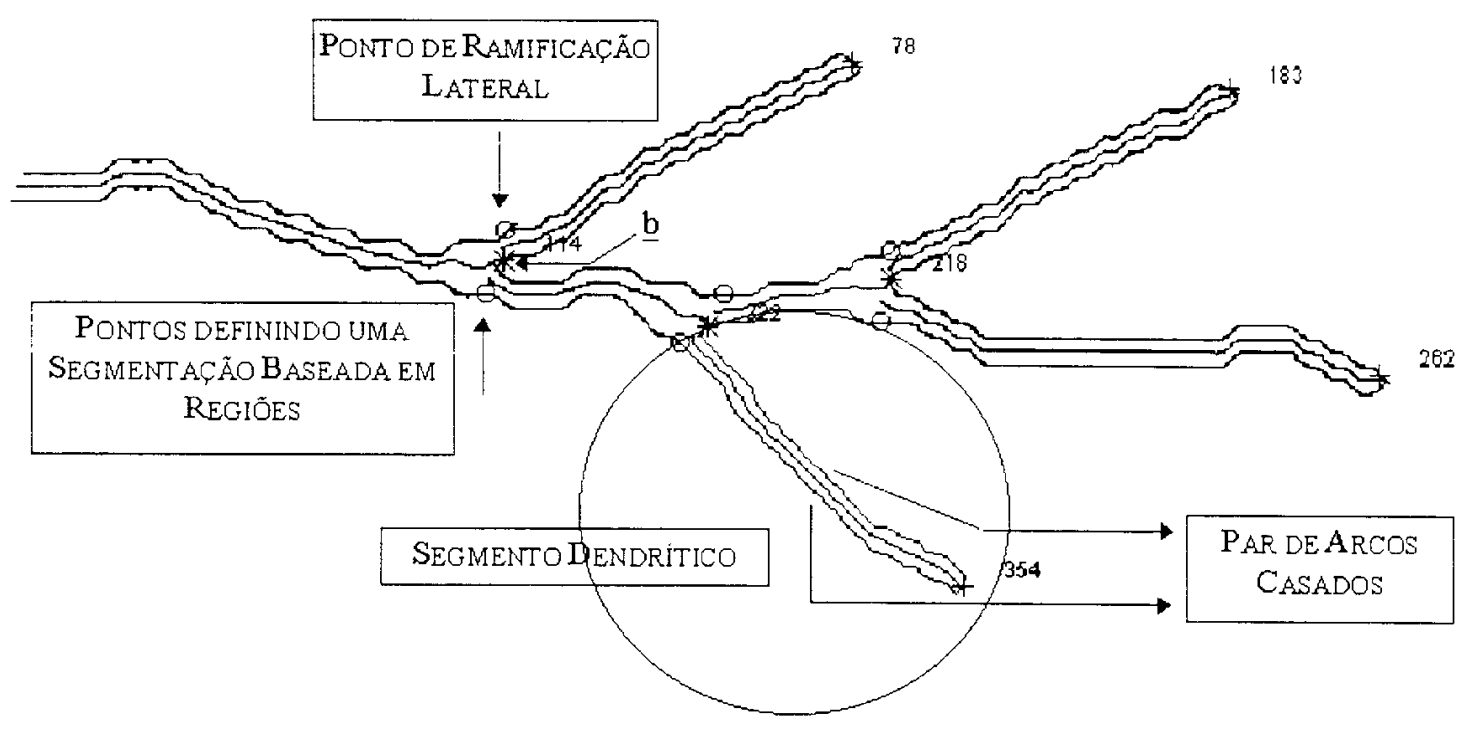

Figura (7.10): Partes de um grande ramo dendrítico.

Note, em primeiro lugar, que cada segmento dendrítico é definido em termos de um par de arcos casados (veja a Figura 7.10). Cada arco desse par, por sua vez, é definido por seu ponto de ramificação e um dos pontos laterais de ramificação associados ao referido ponto de ramificação. Cada ponto de ramificação está associado a dois pontos laterais de ramificação, visto que dois segmentos dendríticos nascem a partir de um ponto de ramificação, sempre existindo uma extremidade ou um sub-ramo dendrítico entre um ponto de ramificação e seu respectivo ponto lateral de ramificação. Por outro lado, pontos laterais de ramificação geralmente não são facilmente localizáveis por algoritmos automáticos, usualmente por não apresentarem nenhuma característica especial do ponto de vista de contornos (como ser um ponto de máxima curvatura, por exemplo). Porém, a cadeia de controle do processo de análise sintática fornece diretamente uma heurística que pode ser aproveitada na localização dos pontos laterais de ramificação. Note que os pontos dominantes encontrados pelo algoritmo de segmentação definem uma partição do contorno em termos de arcos entre cada par " $e b$ " (extremidade-ponto de ramificação) ou " $b e$ " (ponto de ramificação-extremidade) e que a cadeia de controle inicial do grande ramo dendrítico exibido na Figura 7.5 é $e_{0} e b e b e b e e_{f}$. Portanto, o ponto esquerdo de ramificação do primeiro ponto de ramificação (ou seja, $e_{0} e \underline{b} e b e b e e_{f}$ ) é definido pelo ponto mais próximo pertencente ao segmento definido pelos próximos dois símbolos à esquerda de $\underline{b}$, ou seja, entre $e_{0}$ e $e$. O ponto de ramificação $\underline{b}$ e seu ponto esquerdo de ramificação podem ser vistos na Figura 7.10. Todos os pontos laterais de ramificação podem ser localizados durante o processo de análise sintática de maneira similar, procurando-se o ponto mais próximo ao ponto de ramificação corrente no segmento definido pelos próximos dois símbolos à esquerda (ou à direita) da cadeia de controle. 


\subsection{O DENDROGRAMA}

$\boldsymbol{0}$ dendrograma é obtido diretamente da árvore de derivação gerada pelo procedimento de análise sintática, sendo a idéia central do algoritmo fundamentada no fato de que o dendrograma é criado com base nos segmentos dendríticos que compõem cada grande ramo de um neurônio. Além disso, como foi comentado, o procedimento de análise sintática discutido na Seção 7.6 gera uma árvore de derivação do neurônio que respeita a ordem menor-maior ou de crescimento do grande ramo dendrítico. Assim, os pontos de ramificação e as extremidades podem ser recuperados de maneira ordenada a partir da árvore de derivação, tendo-se em vista que cada nó associado ao símbolo " $E$ " é o pai de um nó " $b$ " (um ponto de ramificação) ou de um nó " $e$ ". Portanto, o dendrograma pode ser obtido percorrendo-se a árvore de derivação, começando do nó pai, e calculando-se o tamanho de arco entre o nó corrente e seus filhos, ou seja, o tamanho do segmento dendrítico associado. É igualmente importante observar que cada segmento dendrítico é composto por um par de arcos casados de contorno (veja a Seção 7.6), o que sugere que o tamanho do segmento dendrítico pode ser definido como a média entre o comprimento de arco do par de segmentos casados associado. Em outras palavras, seja $u l(n)$ e $u r(n)$ o par de $\operatorname{arcos}$ casados de contorno, re-parametrizados adequadamente, de um segmento dendrítico qualquer, em que $u l$ e $u r$ designam o segmento de contorno à esquerda e o segmento de contorno à direita, respectivamente. Então, o segmento de reta horizontal do dendrograma correspondente a esse segmento é proporcional à média dos tamanhos de arco de $u l(n)$ e $u r(n)$.

Observe as Figuras 7.11(a) e (b), que exibem, respectivamente, a árvore sintática gerada automaticamente pelo algoritmo discutido na Seção 7.6 e o dendrograma associado, correspondentes ao grande ramo apresentado na Figura 7.5. O primeiro segmento dendrítico é aquele que começa no primeiro e no último pontos do contorno parametrizado e termina nos pontos laterais de ramificação associados ao primeiro ponto de ramificação desse grande ramo $(n=114$, veja a Figura 7.5). O algoritmo então traça uma linha reta cujo tamanho é proporcional ao tamanho desse primeiro segmento dendrítico, como é mostrado na Figura 7.11(b). Dois novos segmentos dendríticos nascem desse primeiro ponto de ramificação e o dendrograma é então bifurcado. $\mathrm{O}$ segmento dendrítico à esquerda na árvore sintática termina em um extremidade $(n=78$, veja a Figura 7.5), definindo um novo par de segmentos casados. $\mathrm{O}$ algoritmo, por sua vez, traça a nova linha horizontal do dendrograma com tamanho proporcional a esse segmento dendrítico e segue recursivamente até que toda a árvore tenha sido percorrida. 


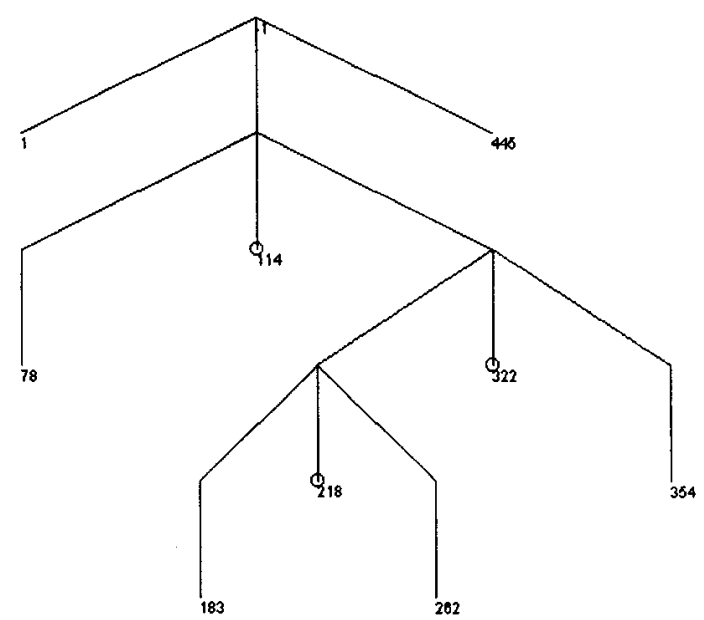

(a)

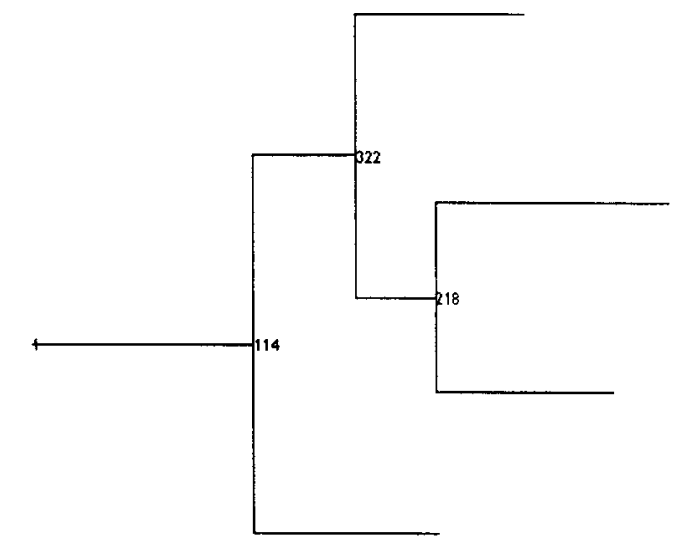

(b)

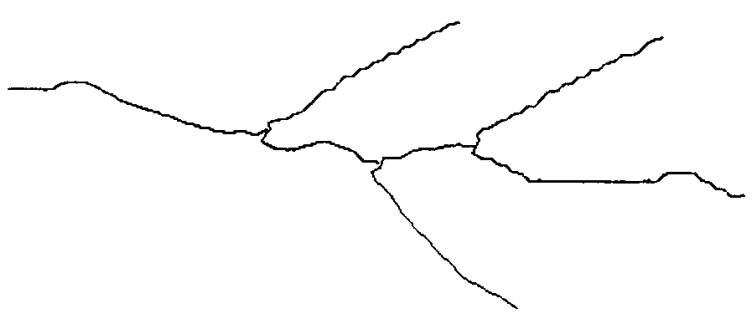

(c)

Figura (7.11): (a) Árvore de derivação sintática; (b) Dendrograma; (c) Esqueleto. Todos obtidos a partir do grande ramo dendrítico da Figura 7.5.

Outras medidas podem ser obtidas sobre cada segmento dendrítico, a partir de cada par $u l(n)$ e $u r(n)$, e similarmente codificadas na representação do dendrograma. Alguns exemplos de medidas complementares incluem:

- Espessura Média de cada Segmento Dendrítico;

- Distância Euclidiana entre os Pontos de Ramificação;

- Energia de Dobramento de cada Segmento Dendrítico; 
No caso da representação de mais de uma característica pelo dendrograma, outros tipos de codificação além do comprimento dos segmentos de reta horizontais devem ser utilizados. A Seção 7.9 apresenta resultados em que três características dos neurônios foram codificadas nos respectivos dendrogramas: comprimento de arco, espessura média e energia de dobramento, codificadas, respectivamente, pelo comprimento, espessura e intensidade de níveis de cinza de cada segmento de reta horizontal do dendrograma. Além disso, a curvatura na região dos pontos dominantes (extremidades, pontos de bifurcação e pontos laterais de bifurcação) foi anulada (3 pontos de cada lado de cada ponto dominante), de modo que a energia de dobramento considera apenas a curvatura da estrutura geral de cada segmento.

\subsection{OBTENDO O ESQUELETO}

^ geração do dendrograma através da abordagem de análise sintática do contorno do neurônio traz ainda uma vantagem adicional em que o esqueleto ${ }^{12}$ [Ballard \& Brown, 1982; Boissonat \& Yvinec, 1995; Chassery \& Montanvert, 1991] da célula neural pode ser obtido diretamente de sua árvore de derivação sintática. Como foi explicado na Seção 7.6, cada segmento dendrítico é composto por um par de arcos casados de contorno. Portanto, o esqueleto de cada segmento dendrítico pode ser estimado como sendo a curva cujos pontos são eqüidistantes a cada arco de contorno que compõe o segmento dendrítico. Em outras palavras, sejam $u l(n)$ e $u r(n)$ o par de $\operatorname{arcos}$ casados de contorno, re-parametrizados adequadamente, de um segmento dendrítico qualquer, em que $u l$ e $u r$ designam o segmento de contomo à esquerda e o segmento de contorno à direita, respectivamente. Então, o esqueleto $\xi(n)$ desse segmento dendrítico é definido por:

$$
\xi(n)=\frac{u_{l}(n)+u_{r}(n)}{2}
$$

O esqueleto do grande ramo da Figura 7.5 é apresentado na Figura 7.11(c).

\subsection{RESULTADOS EXPERIMENTAIS ADICIONAIS}

Figuras 7.2(a) e (b) apresentam resultados experimentais adicionais para uma célula mais complexa que foi aproveitada como exemplo no início deste

\footnotetext{
${ }^{12}$ Não confundir com o esqueleto da transformada em wavelets discutido no Capítulo 5.
} 
capítulo. Como pode ser facilmente inferido a partir da complexidade dessa célula, o problema de geração manual é uma tarefa cansativa e maçante que pode ser largamente agilizada pelo método semi-automático introduzido neste capítulo.

A Figura 7.12 apresenta uma série de resultados de um experimento que ilustra, de maneira didática, a representação de 3 medidas diferentes no dendrograma: o comprimento de cada segmento, sua espessura média e a energia de dobramento, codificadas como explicado na Seção 7.7. A Figura 7.12(a) apresenta o contorno de um grande ramo dendrítico hipotético que possui um ponto de ramificação e 3 segmentos dendríticos, numerados de 1 a 3 conforme indicado. Os segmentos dendríticos possuem as seguintes características:

- Segmento (1): É o mais espesso e de menor complexidade por ser apenas um segmento reto. Além disso, é o segmento mais curto mas de distância euclidiana intermediária entre as extremidades;

- Segmento (2): Possui espessura e complexidade intermediária, sendo o segmento mais comprido e de maior distância euclidiana entre as extremidades;

- Segmento (3): É o mais fino e de maior complexidade, possuindo comprimento intermediário e menor distância euclidiana entre as extremidades.

A Figura 7.12(b) exibe o esqueleto do grande ramo hipotético calculado pelo algoritmo discutido na Seção 7.8, enquanto na Figura 7.12(c) pode-se ver a árvore de derivação sintática do grande ramo em questão. A partir do dendrograma exibido na Figura 7.12(d) pode-se conferir que as características listadas acima foram corretamente medidas pelo algoritmo de cálculo e derivação dos diagramas. Em particular, as quatro características discutidas são mostradas em função do segmento dendrítico na sequiência de gráficos das Figuras 7.12(e)-(h).

Finalmente, com o intuito de apresentar um experimento sobre a geração de um dendrograma para uma célula natural, as Figuras 7.13 e 7.14 exibem os resultados referentes à aplicação do método a um grande ramo dendrítico típico de uma célula ganglionar do tipo $\alpha$ (gato). Como pode ser notado a partir de uma breve análise visual, o dendrograma reflete as características estruturais da forma do grande ramo dendrítico em questão.

É importante sublinhar que, embora a visualização do diagrama consista em uma tarefa importante por si mesma, ela não é a única finalidade da derivação dos dendrogramas. Na verdade, os dendrogramas são estruturas de dados abstratas que descrevem diferentes aspectos das ramificações neurais, podendo ser usadas para cálculos estatísticos, como o do valor médio dos segmentos dendríticos de terceira ordem de uma familia de células, por exemplo, ou em simulações da dinâmica eletroquímica dos neurônios, da maneira como é tradicionalmente adotada. 


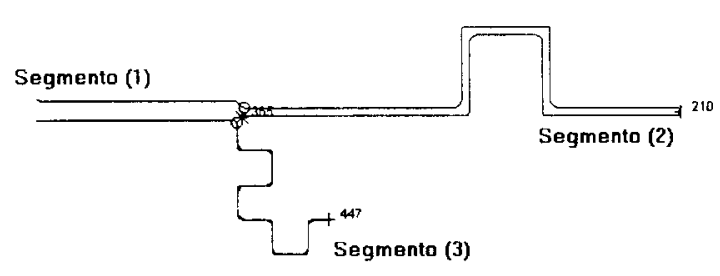

(a)

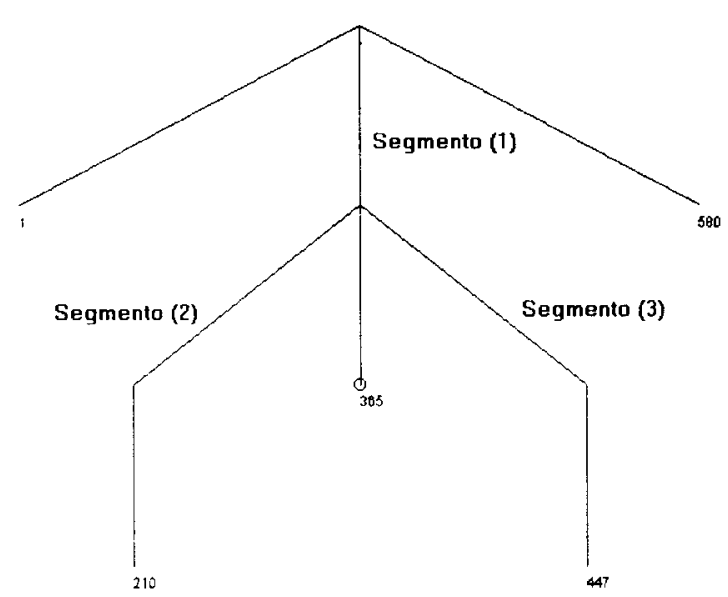

(c)

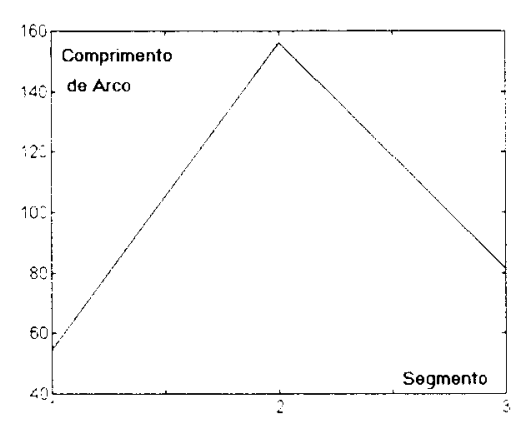

(e)

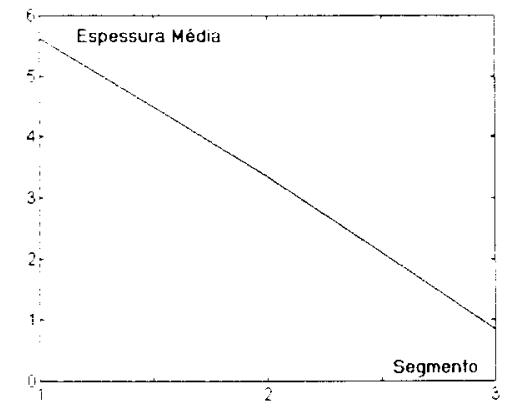

(g)

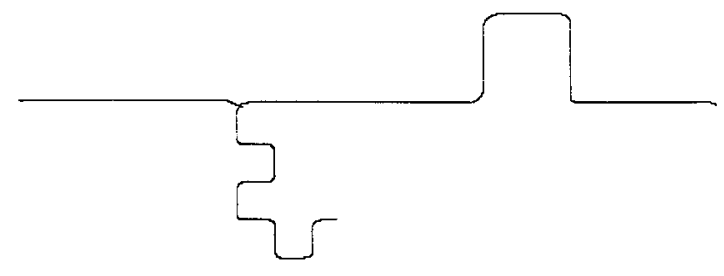

(b)

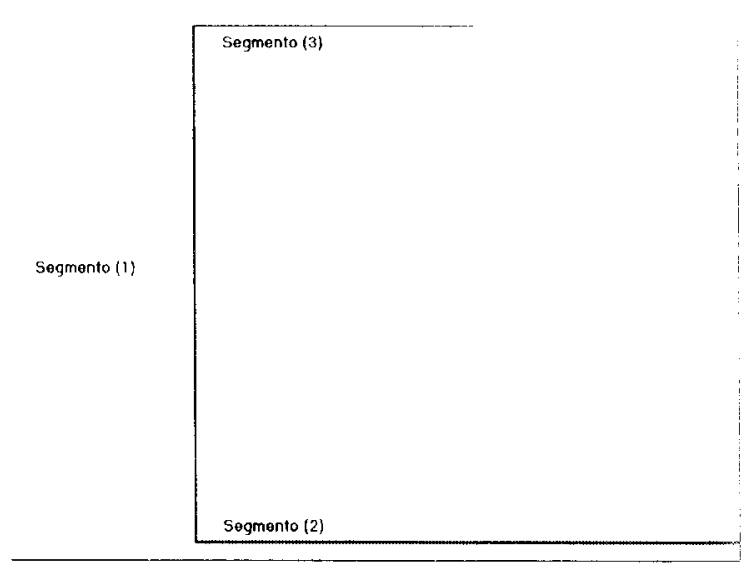

(d)

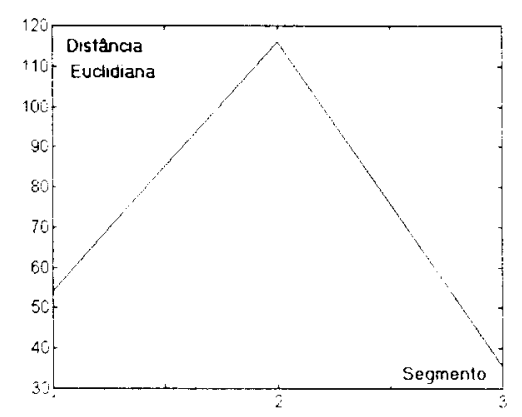

(f)

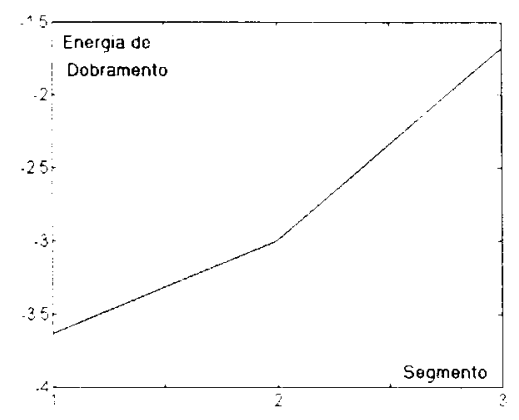

(h)

Figura (7.12): Resultados da utilização de diversas características no dendrograma de um grande ramo dendrítico hipotético. Particularmente, o dendrograma apresentado em (d) codifica o comprimento de cada segmento, sua espessura média e sua energia de dobramento respectivamente pelo comprimento de cada segmento de reta horizontal, sua espessura e seu nível de cinza (maiores valores codificados por níveis mais escuros). 


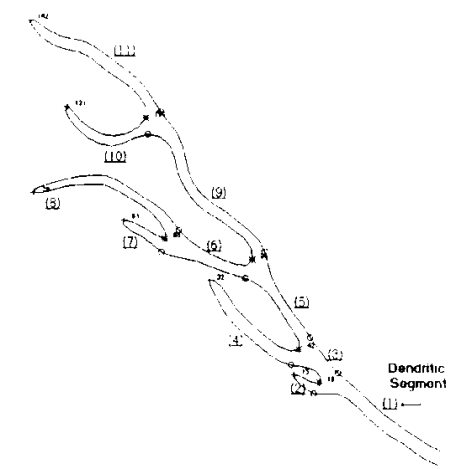

(a)

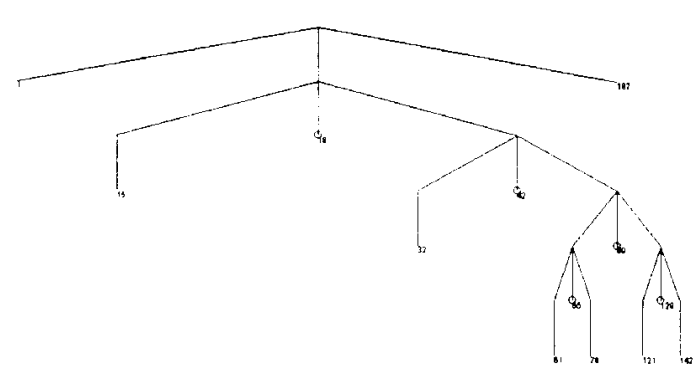

(b)

(c)

Figura (7.13): Geração do dendrograma de um grande ramo dendrítico típico de uma célula ganglionar do tipo $\alpha$ (gato).

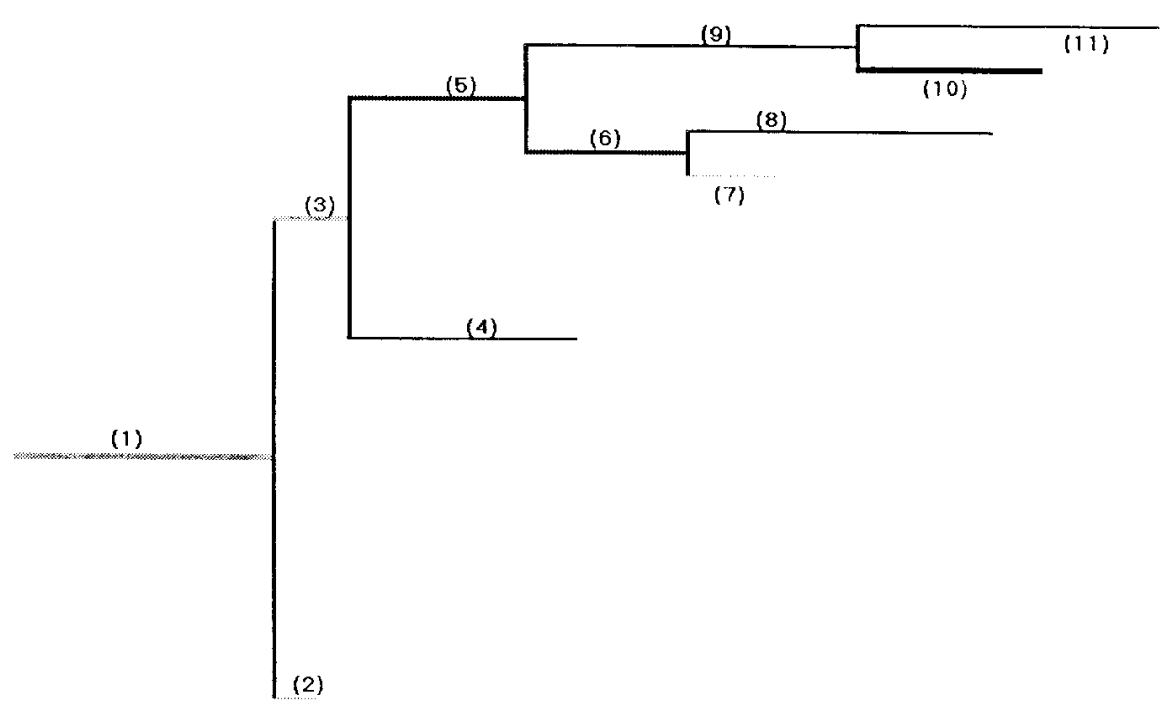

Figura (7.14): Dendrograma do grande ramo apresentado na Figura 7.13(a). 
Capítulo 8 - Conclusão e Comentários Finais

Mas era apenas isso,

era isso, mais nada?

Era só a batida

numa porta fechada?

(...)

Carlos Drummond de Andrade - Viver, 1973 


\section{ConCLUSÃo E COMENTÁRIOS FinAIS}

\subsection{INTRODUÇÃO}

7 ste capítulo tece os comentários conclusivos sobre as contribuições desta tese, incluindo algumas discussões sobre possíveis desenvolvimentos futuros a partir deste trabalho. Assim, o capitulo começa comentando as principais características sobre a análise multi-escala de contornos que foram revistas de maneira introdutória nos Capítulos 1, 2 e 3. Em seguida, cada um dos tópicos ligados às contribuições desta área são abordados, ou seja, a análise multi-escala de curvatura, a análise pelas transformadas tempo-escala e tempo-freqüência, o conceito de energia multi-escala, os dendrogramas e as aplicações em neuromorfometria. São também apontadas algumas possíveis direções para pesquisa futura concernentes a cada um desses tópicos.

De maneira geral, os métodos desenvolvidos nesta tese permitem a caracterização e extração de medidas multi-escala de formas bidimensionais para a aplicação na resolução de diferentes problemas de análise de formas, como reconhecimento automático e caracterização interativa. Em particular, os métodos foram aplicados na análise de formas de células neurais, tanto para classificação como na extração semiautomática de dendrogramas. Futuramente, os métodos deverão ser integrados em ambientes com maiores capacidades computacionais (por exemplo, utilizando o Delphi), e aplicados a problemas como busca de imagens semelhantes em bases de imagens. As próximas seções discutem possíveis desdobramentos do método com maiores detalhes.

\subsection{CONSIDERAÇÕES FINAIS: ANÁLISE MULTI-ESCALA DE FoRMAS}

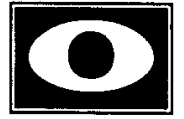

Capítulo 1 desta tese procurou enfatizar uma característica básica da metodologia geral para o tratamento do problema de visão computacional: partindo-se da imagem original, colorida ou em níveis de cinza, deve-se proceder a obtenção de uma série de representações intermediárias da informação pictórica contida na imagem original, procurando-se, simultaneamente, eliminar o volume de dados e a redundância de informação presente na representação anterior e tornar explícitas as características mais importantes dessa mesma informação visual. De fato, os trabalhos de Fred Attneave na década de 50 [Attneave, 1954] já chamavam a atenção para a existência de uma estratégia análoga de análise de informação visual por parte do sistema de visão humana. Em particular, o Capitulo 1 chamou a atenção para a seguinte 
seqüência de representações da informação visual: imagem original $\rightarrow$ contornos $\rightarrow$ características dos contornos (como pontos dominantes e complexidade geral).

Dentro desse contexto, o Capítulo 2 revisou uma série de aspectos relacionados à análise de contornos, o que incluiu a introdução de algumas ferramentas matemáticas comumente adotadas pelas técnicas de caracterização de formas. A importância de uma série de medidas de formas foi ressaltada, tendo-se, em particular, discutido o conceito de escala de análise, que vem a ser um dos pontos que motivaram a adoção do paradigma multi-escala para a análise da informação visual. Esta tese elegeu os métodos de análise multi-escala de sinais como a ferramenta básica para a implementação do paradigma multi-escala para o caso dos contornos, sendo que as idéias básicas dessas ferramentas matemáticas foram revisadas no Capítulo 3.

\subsection{CONSIDERAÇÕES FINAIS: O CURVOGRAMA}

Capítulo 4 introduziu uma nova abordagem para representação e análise multiescala da curvatura de contornos digitais. A técnica relatada baseia-se fortemente em princípios e propriedades de processamento de sinais, fornecendo um meio prático e efetivo de estimação multi-escala de curvatura digital. Deve-se observar que os descritores de Fourier, aproveitados extensamente por essa técnica, formam uma classe de técnicas de representação de formas que vêm sendo usadas há anos; assim, a abordagem proposta nesta tese generaliza, com sucesso, os descritores de Fourier para o tratamento de análise multi-escala de curvatura. A análise muti-escala é obtida multiplicando-se a representação freqüencial do contorno por um conjunto de gaussianas com diferentes desvios padrões, implementando, portanto, filtragem passa-baixas seletiva. É importante lembrar que a filtragem gaussiana possui características intrinsecamente desejáveis para sua adoção em problemas de análise de formas, como a propriedade de não geração de detalhes espúrios na medida que aumenta-se a escala. Foram propostas diferentes soluções para tratar o efeito colateral de contração de contornos acarretado pela filtragem gaussiana. O curvograma foi introduzido a partir dessas técnicas, tendo sido apresentados diversos resultados experimentais, incluindo a avaliação da precisão do método a partir de curvas paramétricas B-splines, corroborando a eficiência do método. De fato, o método apresentou uma precisão na estimação da curvatura superior a de outros métodos relatados na literatura.

\subsubsection{Desenvolvimentos Futuros}

D ada a importância da pesquisa desenvolvida sobre análise de formas baseada em curvatura, diferentes desdobramentos poderão ocorrer a partir das técnicas descritas no Capítulo 4. Dentre esses possíveis desdobramentos, é importante ressaltar a área de análise de formas invariantes por uma transformação afim. Transformações afins aparecem em diferentes contextos de análise de imagens, sendo que métodos para a caracterização de formas que são semelhantes a menos de uma transformação afim entre 
elas vêm recebendo crescente atenção recentemente [Sapiro \& Tannenbaum, 1993]. Assim, poder-se-á trabalhar no desenvolvimento de algoritmos para esse tipo de análise de formas dentro do espírito das transformadas multi-escala descritas no Capítulo 3 deste trabalho. Uma possível aplicação interessante desses métodos é o uso da curvatura, que é uma medida local, na segmentação de objetos parcialmente oclusos.

Uma segunda linha de pesquisa promissora é a do desenvolvimento de métodos que trabalhem diretamente sobre a imagem $2 \mathrm{D}$, descartando a necessidade da extração dos contornos dos objetos. A análise de formas realizada por métodos da abordagem $2 \mathrm{D}$ possui algumas características complementares em relação à abordagem por contornos, incluindo a possibilidade do tratamento e caracterização de texturas, outro importante atributo visual. Assim sendo, algoritmos para extração de características baseados nas transformadas 2D podem ser explorados dado o seu grande potencial de aplicações práticas em sistemas de visão. A definição de medidas de forma confiáveis e o desenvolvimento de algoritmos eficientes para a implementação dos métodos desenvolvidos são tarefas que podem ser incluídas dentro dessa linha de pesquisa. $\mathrm{O}$ trabalho [Costa, 1997b] discute um dos possíveis caminhos para essa pesquisa através dos conceitos de campo escalar e campo vetorial de formas.

\subsection{CONSIDERAÇÕES FINAIS: A REPRESENTAÇÃO-W}

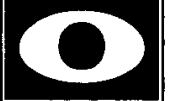

capitulo 5 descreveu uma nova abordagem para análise multi-escala de formas através da transformada contínua em wavelets, abordagem essa que permite 0 tratamento de problemas tradicionais de análise de formas utilizando-se as ferramentas fornecidas pela teoria e propriedades das wavelets. Em particular, foram descritos métodos para particionamento de contornos, detecção de pontos dominantes, definição e análise de escalas naturais e análise fractal de curvas deterministicamente auto-similares. Diversos resultados experimentais corroborando a eficiência das técnicas introduzidas foram apresentados. A teoria das wavelets vem recebendo atenção crescente nos últimos 10 anos, sendo hoje construída a partir de uma base matemática sólida, bem como tendo sido aplicada com sucesso em uma grande diversidade de problemas. Tais características tornam a representação- $W$ uma ferramenta promissora para análise de formas, o que envolverá o desenvolvimento futuro dessa abordagem em diferentes direções, algumas das quais relatadas na próxima sub-seção. É importante notar que parte das ferramentas sobre análise de formas usando wavelets foi desenvolvida durante o estágio de tipo "doutorado sanduíche" realizado pelo autor junto ao grupo do professor Jean-Pierre Antoine no "Institut de Physique Théorique" da "Université Catholique de Louvain" em Louvain-la-Neuve, Bélgica, onde o autor pode aprofundar seus conhecimentos teóricos e práticos sobre análise em wavelets de sinais. 


\subsubsection{Desenvolvimentos Futuros}

10 entre os possíveis desenvolvimentos que as técnicas referentes à

1. Desenvolvimento de outros algoritmos para extração de características e análise de formas a partir da representação- $W$, tais como algoritmos baseados na informação de fase (como se sabe, linhas de fase constante podem ser usadas para a deteç̧ão de singularidades em sinais [Torrésani, 1995]) e na informação cruzada entre módulo e fase, para que se possa aumentar a tolerância do método ao ruído;

2. Extração de diferentes características de formas, como simetria de formas, e introdução de novos conceitos como módulo e freqüência local [Torrésani, 1995];

3. Integração da representação- $W$ com outras abordagens, como "snakes" [Kass et al., 1988] e teoria de regularização. Em relação a esta última, vale lembrar que a aplicação de wavelets em problemas de regularização já foi considerada por Alex Grossmann [Grossmann, 1988], sendo que desenvolvimentos mais recentes começam a ser relatados na literatura [Reginska, 1995];

4. Um estudo mais completo sobre as diferentes wavelets e os problemas que podem ser melhor tratados por cada uma delas;

5. Desenvolvimento da abordagem de análise fractal de curvas a partir da representação$W$, incluindo multifractais e a análise de auto-similaridade e problemas inversos [Arnèodo et al., 1995], isto é, reconhecimento de regras de geração de padrões de formas específicas;

6. Estudo da abordagem baseada em regiões ou abordagem 2D, de maneira similar à discutida na Seção 8.3.1: Os métodos dessa abordagem tratam diretamente a imagem, isto é, tratam com funções $2 \mathrm{D}$ do tipo $I(x, y)$. A principal vantagem que essa abordagem exibe em relação à abordagem anterior é que ela não pressupõe a segmentação e extração do contorno do objeto de interesse, tarefas críticas da etapa de pré-processamento. Como exemplos de técnicas dessa abordagem pode-se citar a morfologia matemática [Pitas \& Venetsanopoulos, 1990; Pitas \& Venetsanopoulos, 1992], decomposição por polígonos e descritores de Fourier 2D [Marshall, 1989]. Particularmente relevantes ao desenvolvimento do trabalho proposto nesta tese são as abordagens multi-escala 2D, tais como as técnicas de espaço-escala e difusão anisotrópica 2D [Lindeberg, 1994], Gabor 2D [Daugman, 1988; Bovik et al., 1990; Dunn et al., 1994; Dunn \& Higgins, 1995], distribuições de Wigner-Ville [Reed \& Wechsler, 1990], outros tipos de "steerable filters" [Watson, 1987; Simoncelli et al., 1992; Freeman \& Adelson, 1991] e wavelets 2D [Murenzi, 1990; Antoine et al., 1993; Antoine, 1994; Antoine et al., 1996; Antoine et al., 1997]. Além disso, essas ferramentas estão sendo cada vez mais pesquisadas para aplicações em análise de textura, conforme esclarecido no próximo item; 
7. A análise de texturas consiste em um outro importante tópico de análise de imagens que também pode ser abordado sob a ótica multi-escala. A caracterização de texturas em imagens é um problema clássico que possui diversas aplicações como segmentação de imagens baseada em regiões de textura homogênea. Métodos de análise de freqüência local são, a princípio, apropriados a essa classe de problemas, visto que a textura é geralmente percebida como uma região em que um determinado padrão (ou uma determinada forma) se repete periodicamente (em termos determinísticos ou estatísticos). Na verdade, a quantidade de artigos recentes sobre esse tipo de aborciagem reflete a crescente importância que essa área tem tido [Daugman, 1988; Lunn et al., 1994; Dunn \& Higgins, 1995; Reed \& Wechsler, 1990; Mallat, 1996].

\subsection{ComentáRIos Finals Sobre as EnERgIAS Multi-ESCALA}

Capítulo 6 apresentou uma técnica para a extração de características de formas através do conceito de energia multi-escala. A energia de dobramento multi-escala normalizada é uma medida global de forma que deve ser usada para caracterização de complexidade de formas a partir de seu contorno, podendo ser calculada a partir do curvograma. Como foi ilustrado por diversos experimentos apresentados nesta tese, a energia de dobramento é bastante robusta a transformações geométricas (translação, rotação, escalonamento e reflexão) e àquelas referentes à aquisição e pré-processamento da imagem.

O efeito de alta curvatura mascarada foi definido e analisado, tendo sido discutidas suas implicações na aplicação da energia de dobramento em análise de formas. Mais especificamente, chamou-se a atenção para uma situação potencial de erro envolvendo o conceito da energia de dobramento como uma medida de discriminação de complexidade de formas. O principal problema é que, embora a energia de dobramento expresse caracteristicas globais do contorno, poucos pontos de altíssima curvatura podem afetar substancialmente a energia de todo o contorno. Foram apresentadas algumas soluções para detecção de tais pontos e para o controle de sua influência na energia total.

Os diversos experimentos de caracterização de células neurais (naturais e artificiais) utilizando a energia de dobramento indicam que essa medida é especialmente bem adaptada para aplicações em neuromorfometria. Os experimentos apresentados indicam que essa medida pode ser usada tanto na análise semi-automática de neurônios quanto em procedimentos de classificação automática de padrões. Além disso, a interpretação física da energia de dobramento sugere que podem ser obtidas informações sobre a energia que deve ser metabolizada para se produzir a arborização dendrítica, de maneira análoga à conjectura sobre formas biológicas genéricas levantada por Bowie em seu trabalho [Bowie \& Young, 1977]. A energia de wavelets foi também introduzida dentro desse contexto, podendo também ser adotada como medida de complexidade de formas. 


\subsubsection{Desenvolvimentos Futuros}

$1 \mathrm{~m}$ dos problemas mais interessantes a serem pesquisados é o do desenvolvimento de métodos automáticos de escolha de características e classificação de padrões. A abordagem multi-escala permite o cálculo de familias de características ou medidas de forma que são definidas em função de um parâmetro de escala, como as energias multi-escala, por exemplo. A correta escolha da(s) escala(s) para a extração de características a serem utilizadas por classificadores de padrões é um problema prático e de grande relevância para o sucesso final do procedimento de reconhecimento de formas, podendo dar continuidade à essa pesquisa.

\subsection{COMENTÁRIOS FINAIS: O DENDROGRAMA}

7 sta tese introduziu uma nova abordagem para análise da forma de células neurais baseada na geração semi-automática de dendrogramas. O esquema proposto, baseado na segmentação do contorno a partir do curvograma seguida pela análise sintática da forma particionada, mostrou-se robusto e com grande potencial para melhorar a tarefa de geração manual de dendrogramas. A abordagem semi-automática adotada através da exploração de interfaces gráficas permite que o operador introduza correções em algumas situações em que os métodos de segmentação falhem.

\subsubsection{Desenvolvimentos Futuros}

1 efinamentos adicionais ao método de geração semi-automática de dendrogramas podem incluir a introdução de mecanismos inteligentes que ajudem nas fases de intervenção do operador, bem como na checagem de cadeias válidas geradas pelo algoritmo de segmentação. A adoção de mecanismos de análise de formas 2D (veja as Seções 8.3.1 e 8.4.1) também pode aumentar a eficiência do método de análise de estruturas neurais.

Além disso, aplicações adicionais como na caracterização de plantas, raizes e árvores também são altamente desejáveis [Cesar \& Costa, 1997b].

\subsection{COMENTÁRIOS FINAIS: NEUROMORFOMETRIA}

7 mbora as técnicas desenvolvidas nesta tese possam ser aplicadas a problemas de análise de formas em visão computacional de maneira geral, experimentos com estruturas neurais formaram um dos focos de atenção do trabalho desenvolvido. Essa outra linha de pesquisa vem sendo desenvolvida pelo Grupo de Visão Cibernética, baseada na caracterização automática de células neurais por meio de procedimentos de visão computacional e processamento de imagens, uma área ainda incipiente e de grande

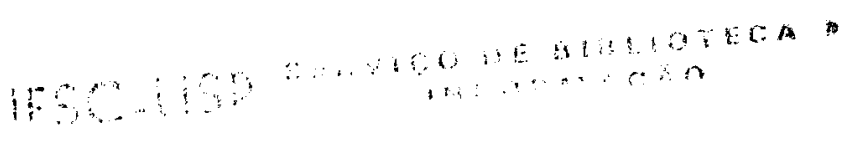


potencial [Costa, 1995; Cesar \& Costa, 1996b, Cesar \& Costa, 1996f; Cesar et al., 1996g; Coelho \& Costa, 1996]. Assim, técnicas clássicas de análise de formas podem ser aplicadas para a extração de medidas como área, perímetro, "convex hull", diagramas de orientação, energia de dobramento e dimensão fractal. Vale notar aqui a relação intrínseca que existe freqüentemente entre várias dessas medidas e métodos multi-escala que foram explorados nesta tese, como no caso da energia de dobramento multi-escala [Cesar \& Costa, 1997a] e da análise fractal de curvas através da representação- $W$. Ainda em relação a esse último tópico, vale lembrar que a teoria das wavelets tem dado um grande impulso à aplicação de análise fractal e multifractal a diferentes problemas em física e biologia como análise de turbulência plenamente desenvolvida ou de seqüenciamento de moléculas de ADN (ver [Arnèodo et al., 1995] e muitas referências ali citadas), apresentando grande potencial para desenvolvimentos subseqüentes. Finalmente, é importante salientar que o desenvolvimento dessa área dentro do Grupo de Visão Cibernética vem tomando grande impulso, o que vem sendo corroborado pela produção de resultados recentemente obtidos [Cesar \& Costa, 1998a; Cesar \& Costa, 1998b; Costa et al., 1998].

\subsubsection{Desenvolvimentos Futuros}

A.

s novas linhas de trabalho indicadas nas seções anteriores poderão ser aplicadas na análise de imagens de neurônios, dando continuidade à pesquisa apresentada nesta tese, por exemplo, a análise de formas neurais a partir do valor da curvatura estimada diretamente sobre a imagem $2 \mathrm{D}$, o que já começou a ser pesquisado no seio do Grupo de Pesquisas em Visão Cibernética [Costa, 1997b]. Adicionalmente, pode-se citar dois importantes problemas a serem pesquisados futuramente: (a) análise estatística de determinadas propriedades morfológicas de grandes bases de imagens de neurônios; e (b) a extração de representações 3D de estruturas neurais a partir de seqüências de imagens microscópicas com diferentes focos, o que envolverá a segmentação das partes focadas em cada imagem e o registro das seções assim obtidas ("optical sectioning").

\subsection{DesenVolvimentos Futuros Adicionals}

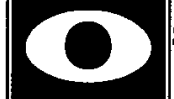

$s$ métodos desenvolvidos poderão ser incorporados em módulos do Cyvis-I, o que permitirá a avaliação dos algoritmos em condições reais. O Cyvis-I é um projeto para um sistema de inspeção visual baseado em diversos conceitos de visão biológica que foi proposto por Luciano da Fontoura Costa e colaboradores, e está sendo desenvolvido no grupo de Visão Cibernética [Costa et al., 1994]. O sistema em desenvolvimento possui aspectos interessantes como a integração de diferentes fontes de informação visual (como textura, cor e análise de formas) e processamento distribuído em uma rede de PC's. Existem diferentes maneiras de se aproveitar os algoritmos introduzidos neste trabalho em um sistema de visão como o Cyvis-I. Em aplicações em que requeiram tarefas de reconhecimento de objetos por parte do Cyvis-I, como, por 
exemplo, busca e reconhecimento de objetos em cenas, poderiam aproveitar vetores de características como os gerados pelas energias multi-escala para guiar preliminarmente $o$ sistema na busca de modelos 3D mais específicos, como aqueles baseados em sólidos ou superfícies, por exemplo. Um outro problema interessante diz respeito a uma classe particular de algoritmos de visão estereo que se baseia no casamento de pontos ou contornos equivalentes no par de imagens estereográficas. Vértices, padrões periódicos e medidas de complexidade de formas poderiam ajudar a guiar tais algoritmos.

\subsection{Aspectos Computacionals}

Seção 4.2.6 já apresentou uma discussão específica sobre o cálculo da representação- $W$ de um contorno. Todos os experimentos desta tese foram implementados como Scripts do Matlab, utilizando largamente as ferramentas matemáticas, de visualização e de interação com o usuário daquele software. Somente o programa de geração interativa de curvas B-Splines utilizado no Capítulo 4. Foi implementado na linguagem $\mathrm{C}$ em um ambiente UNIX e utilizando a biblioteca gráfica XVIEW. Os experimentos do Matlab foram executados em uma estação Digital (ver Seção 4.2.6) e em micros Pentium $150 \mathrm{MHz}$ e $200 \mathrm{MHz}$. O trabalho [Cesar \& Costa, 1995b] discute a implementação em hardware de algumas das técnicas desta tese.

Também como já foi comentado, as transformações multi-escala foram calculadas através de algoritmos baseados em FFT. A obtenção do curvograma é mais cara computacionalmente, visto que envolve o cálculo de $\dot{u}(b, a)$ e $\ddot{u}(b, a)$ (veja a Seção 5.3), e que cada uma dessas funções equivale a uma transformada contínua em wavelets (ou seja, $\dot{u}(b, a)$ equivale a uma representação- $W$ com a primeira derivada da gaussiana como wavelet, enquanto que $\ddot{u}(b, a)$ equivale a uma representação- $W$ com a segunda derivada da gaussiana como wavelet). $O$ cálculo de uma representação- $W$ com 32 escalas

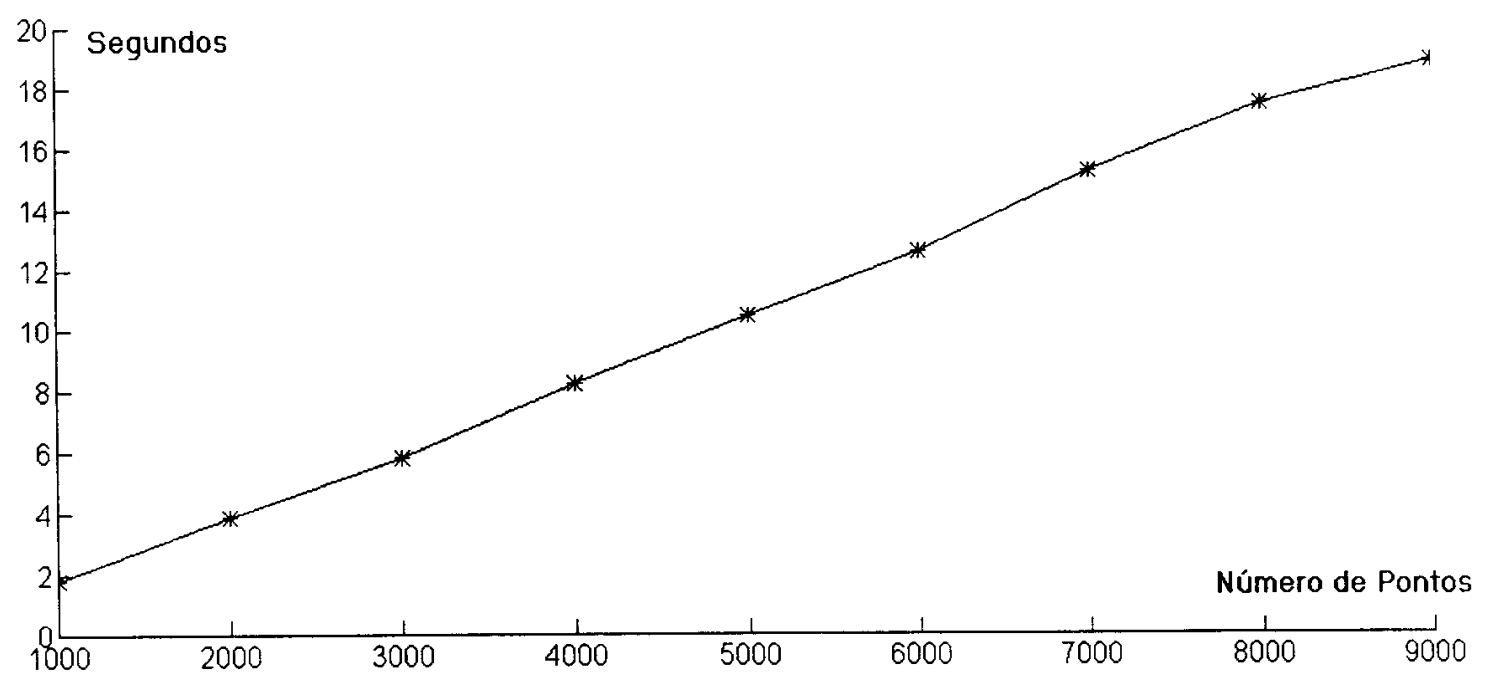

Figura (8.1): Tempo de processamento (segundos) em função do número de pontos do contorno para o cálculo da representação- $W$ com 64 escalas. 
de um contorno de 8192 pontos é da ordem de 15 segundos em um Pentium $150 \mathrm{MHz}$. É importante notar que esse tempo foi medido a partir de um Script do Matlab escrito sem nenhuma preocupação com eficiência e que programas muito mais rápidos e baratos computacionalmente podem ser criados em linguagens de programação como $\mathrm{C}$ ou Delphi. A Figura 8.1 apresenta um gráfico do tempo de processamento para o cálculo da representação- $W$ com 64 escalas em função do número de pontos do contorno. Através do ajuste de uma reta aos dados daquela figura, conclui-se que o tempo de processamento $\mathrm{T}$ em segundos em função do número de pontos $\mathrm{N}$ do contorno é dado por:

$$
\mathrm{T}=0.0022 \mathrm{~N}-0.5167
$$

Essa fórmula é uma boa aproximação para contornos com até 14000 pontos, aproximadamente. Esses dados foram obtidos em um Pentium 200MHz com 64Mbytes de RAM. Foi observado que, acima de 14000 pontos, o Matlab começa a realizar sistematicamente o acesso a disco rígido para utilização de memória virtual, o que faz cair fortemente o desempenho computacional. Implementações mais eficientes em uma linguagem de programação podem evitar tais problemas.

Além disso, o cálculo das energias multi-escala é extremamente simples e barato computacionalmente, sendo desprezivel em relação ao custo computacional do cálculo das representações multi-escala.

Um aspecto importante de implementação concerne o cálculo das convoluções diretamente no domínio do tempo ou no domínio da freqüência. Sabe-se que a convolução de um sinal com uma máscara pequena pode ser implementada de maneira mais eficiente diretamente no domínio do tempo. Isso quer dizer que as transformadas multi-escala para pequenas escalas podem ser calculadas de maneira mais rápida sem a necessidade do cálculo da FFT. Na medida que o tamanho da máscara aumentar, o cálculo da convolução através da FFT torna-se mais eficiente. Assim, esses aspectos devem ser considerados na implementação das técnicas. Por outro lado, a utilização de algoritmos baseados em FFT não requer o truncamento das máscaras, podendo fornecer resultados mais precisos. Além disso, o autor acredita que a transformada de Fourier fornece um esquema bastante genérico e poderoso para o entendimento da grande maioria dos conceitos desenvolvidos nesta tese (bem como em inúmeras áreas de processamento e análise de imagens), e a adoção direta dos algoritmos baseados em FFT, embora possa pagar um preço mais caro computacionalmente em alguns casos, permite uma abordagem direta e unificada para as técnicas apresentadas neste trabalho. 


\section{ReFERÊnCIAS BIBLIOGRÁFICAS}

[Allen \& Rabiner, 1977] J.B. Allen; L.R. Rabiner, A Unified Approach to Short-Time Fourier Analysis and Synthesis, Proceedings of the IEEE, 65(11):1558-1564, November 1977.

[Alves et al., 1996] S.G. Alves, M.L. Martins, P.A. Fernandes; J.E.H. Pittella, Fractal Patterns for Dendrites and Axon Terminals, Physica A, 232:51-60, 1996.

[Anderson, 1995] J.A. Anderson, An Introduction to Neural Networks, The MIT Press, Cambridge, Mass., 1995.

[Antoine et al., 1993] J-P. Antoine, P. Carrette, R. Murenzi; B. Piette, Image Analysis with Two-Dimensional Continuous Wavelet Transform, Signal Processing, 31:241$272,1993$.

[Antoine, 1994] J-P. Antoine, Wavelet Analysis: A New Tool in Signal Processing, Physicalia Magazine, 16:17-42, 1994.

[Antoine et al., 1996] J-P. Antoine; D. Barache; R.M. Cesar Jr.; L. da F. Costa, Multiscale Shape Analysis using the Continuous Wavelet Transform, in P. Delogne (ed.), Proc. IEEE International Conference on Image Processing (ICIP-96), (Lausanne, Switzerland, September 16-19, 1996), Vol. 1, 291-294, IEEE, Piscataway, NJ, 1996.

[Antoine et al., 1997] J-P. Antoine; D. Barache; R.M. Cesar Jr.; L. da F. Costa, Shape Characterization with the Wavelet Transform, Signal Processing, 1997 No prelo/.

[Arnèodo et al., 1995] A. Arnèodo, F. Argoul, E. Bacry, J. Elezgaray; J.-F. Muzy, Ondelettes, Multifractales et Turbulences: de l'ADN aux Croissances Cristallines, Diderot Editeur, Arts et Sciences, Paris, 1995 /Em francês/.

[Asada \& Brady, 1986] H. Asada; M. Brady, The Curvature Primal Sketch, IEEE Transactions on Pattern Analysis and Machine Intelligence, PAMI-8:2-14,1986.

[Attneave, 1954] F. Attneave, Some Informational Aspects of Visual Perception, Psychological Review , 61:183-193, 1954.

[Ballard \& Brown, 1982] D.H. Ballard; C.M. Brown, Computer Vision, Prentice-Hall, Englewood Cliffs, NJ, 1982. 
[Barlow, 1994] H. Barlow, What is the Computational Goal of the Neocortex? In: C. Koch, J.L. Davis (Eds.) Large-scale neuronal theories of the brain, The MIT Press, 1994.

[Baroni \& Barletta, 1992] M. Baroni; G. Barletta, Digital Curvature Estimation for Left Ventricular Shape Analysis, Image and Vision Computing, 10(7):485-494, 1992

[Bastiaans, 1980] M.J. Bastiaans, Gabor's Expansion of a Signal into Gaussian Elementary Signals, Proceedings of the IEEE, 68(4):538-539, April 1980.

[Bengtsson \& Eklund, 1991] A. Bengtsson; J.-O. Eklundh, Shape Representation by Multiscale Contour Approximation, IEEE Transactions on Pattern Analysis and Machine Intelligence, 13(1): 85-93, January 1991.

[Bennett \&. Mac Donald, 1975] J.R. Bennett; J.S. Mac Donald, On the Measurement of Curvature in a Quantized Environment, IEEE Transactions on Computers, C-24(8):803-820, August 1975.

[Boissonat \& Yvinec, 1995] J.-D. Boissonat; M. Yvinec, Géométrie Algorithmique, Ediscience, Paris, 1995 /Em francês/.

[Boomgaard \& Smeulders, 1994] R. van den Boomgaard; A. Smeulders, The Morphological Structure of Images: The Differential Equations of Morphological Scale-Space, IEEE Transactions on Pattern Analysis and Machine Intelligence, 16(11): 1101-1113, November 1994.

[Bovik et al., 1990] A.C. Bovik; M. Clark; W.S. Geisler, Multichannel Texture Analysis using Localized Spatial Features, IEEE Transactions on Pattern Analysis and Machine Inteligence, 12(1):55-73, 1990.

[Bowie \& Young, 1977] J.E. Bowie; I.T. Young, An Analysis Technique for Biological Shape - II, Acta Cytologica, 21(3):455-464, 1977.

[Boycott \& Wässle , 1974] B.B. Boycott; H. Wässle, The Morphological Types of Ganglion Cells of the Domestic Cat's Retina, Journal of Physiology, 240: 297-319, 1974.

[Brigham, 1974] E.O. Brigham, The Fast Fourier Transform, Prentice-Hall, EnglewodCliffs, N.J., 1974.

[Burt \& Adelson, 1983] P.J. Burt; E.H. Adelson, The Laplacian Pyramid as a Compact Image Code, IEEE Transactions on Communications, COM-31(4):532-540, April 1983.

[Calderbank et al., 1997] R. C. Calderbank, Ingrid Daubechies, Wim Sweldens; BoonLock Yeo, Wavelet Transforms that Map Integers to Integers, http://cm.belllabs.com/who/wim/papers/index.html\#integer.

[Campos et al., 1994] A. G. Campos, L. da F. Costa and R. Köberle, Wavelet Boundary Descriptors, Proceedings of the IASTED International Conference on Systems and Control, Lugano, Switzerland, pp. 122, June 1994. 
[Carmona et al., 1996] R. Carmona; W.-L. Hwang; B. Torrésani, Practical TimeFrequency Analysis: Gabor \& Wavelet Transforms with an Implementation in $S$, pré-tiragem de um livro a ser publicado, 1996.

[Caserta et al., 1990] VF. Caserta; H.E. Stanley; W.D. Eldred; G. Daccord; R.E. Haussman; J. Nittmann; Physical Mechanisms Underlying Neurite Outgrowth: A Quantitative Analysis of Neuronal Shape, Physical Review Letters, 64(1):95-98, January 1990.

[Castleman, 1996] K.R. Castleman, Digital Image Processing, Prentice-Hall, Englewood Cliffs, NJ, 1996.

[Cesar, 1989] R.M. Cesar Jr., Algoritmos Numéricos para Aproximação Poligonal de Figuras Planas, Relatório Técnico da Fundação de Amparo à Pesquisa do Estado de São Paulo - FAPESP - processo 89/0610-2- 1989.

[Cesar, 1990] R.M. Cesar Jr., A Abordagem Sintática para o Reconhecimento de Padrões, Relatório Técnico da Fundação de Amparo à Pesquisa do Estado de São Paulo - FAPESP - processo 89/0610-2- 1990.

[Cesar, 1991] R.M. Cesar Jr., Abordagens para Reconstrução Tridimensional de Imagens, Relatório Técnico da Fundação de Amparo à Pesquisa do Estado de São Paulo - FAPESP - processo 89/0610-2- 1991.

[Cesar, 1993] R.M. Cesar Jr Reconstrução Tridimensional por Ajuste de Superficies Paramétricas, dissertação de mestrado, FEE-UNICAMP, Campinas, 1993.

[Cesar \& Costa, 1995a] R.M., Cesar Jr.; L. da F., Costa, The Contour Specialization of Cyvis-I: An Effective Framework for Intermediate Visual Representation, Proc. Simpósio Brasileiro de Computação Gráfica e Processamento de Imagens (SIBGRAPI-95, São Carlos, SP, Out 1995), 205-212, 1995.

[Cesar \& Costa, 1995b] R.M., Cesar Jr.; L. da F., Costa, Piecewise Linear Segmentation of Digital Contours in $\mathrm{O}(\mathrm{N} \cdot \log (\mathrm{N}))$ through a Technique Based on Effective Digital Curvature Estimation, Real-Time Imaging, 1:409-417, 1995.

[Cesar \& Costa, 1996b] R.M., Cesar Jr.; L. da F., Costa, Shape Characterization in Natural Scales by using the Multiscale Bending Energy, Proc. 13th International Conference on Pattern Recognition (Technical University of Vienna, Austria, August 25-30, 1996), Vol. 1 Track A, 735-739, 1996.

[Cesar \& Costa, 1996c] R.M. Cesar Jr.; L. da F. Costa, Shape Characterization by using the Gabor Transform, Proc. 7th IEEE Digital Signal Processing Workshop (Loen, Norway, September 1-4, 1996), 215-218, 1996.

[Cesar \& Costa, 1996e] R.M. Cesar Jr.; L. da F. Costa, Towards Effective Planar Shape Representation with Multiscale Digital Curvature Analysis based on Signal Processing Techniques, Pattern Recognition, 29(9):1559-1569, 1996.

[Cesar \& Costa, 1996f] R.M. Cesar Jr.; L. da F. Costa, Energia de Dobramento MultiEscala: Novas Perspectivas em Neuromorfometria, Proc. Forum Nacional de 
Ciência e Tecnologia em Saúde (III FNCTS, Campos do Jordão, SP, Brazil, Out 1996), 1996.

[Cesar et al., 1996g] R.M. Cesar Junior; R.C. Coelho; L. da F. Costa, Automatic Classification of Retinal Ganglion Cells, Proc. II Workshop on Cybernetic Vision, IFSC - USP, (São Carlos , SP, Brazil, 9-11 December 1996), 1996 /No prelo/.

[Cesar \& Costa, 1997a] R.M. Cesar Jr.; L. da F. Costa, The Application and Assessment of Multiscale Bending Energy for Morphometric Characterization of Neural Cells, Review of Scientific Instruments, 1 68(5): 2177-2186, May 1997.

[Cesar \& Costa, 1997b] R.M. Cesar Jr.; L. da F. Costa, Semi-Automated Dendrogram Generation for Neural Shape Analysis, Proc. Simpósio Brasileiro de Computação Gráfica e Processamento de Imagens (SIBGRAPI-97, Campos do Jordão, SP, Out 1997), 147-154, 1997 (http:/www2.lncc.br/sibgrapi97/anais/ART10/).

[Cesar \& Costa, 1998a] R.M. Cesar Jr.; L. da F. Costa, Neural Cell Classification using Wavelets, Biological Cybernetics, 1997 /Submetido/.

[Cesar \& Costa, 1998b] R.M. Cesar Jr; L. da F. Costa, Dendrogram Generation for Neural Shape Analysis, 1998 /Em preparação/.

[Chassery \& Montanvert, 1991] J.M. Chassery; A. Montanvert, Géométrie Discrète, Hermes, Paris, $1991 /$ Em francês/.

[Chassery \& Waku, 1993] J.M. Chassery; J. Waku, Spécification d'une Ondelette pour l'Analyse Multirésolution d'un Contour Discret, Traitement du Signal et Images, 10(3):231-240, 1993 /Em francês/.

[Chen et al., 1995] C.-H. Chen; J.-S. Lee; Y.-N. Sun, Wavelet Transformation for GrayLevel Corner Detection, Pattern Recognition, 28(6):853-861, 1995.

[Chong et al., 1992] M.M.S. Chong; R.K.L. Gay; H.N. Tan; J. Liu, Automatic Representation of Fingerprints for Data Compression by B-spline Functions, Pattern Recognition, 25(10):1199-1210, 1992.

[Chuang \& Kuo, 1996] C.-H. Chuang; C.-C.J. Kuo, Wavelet Descriptor of Planar Curves: Theory and Applications, IEEE Transactions on Image Processing, 5(1): 56-70, January 1996.

[Coelho \& Costa, 1994] R.C. Coelho; L. da F. Costa, Gramáticas para Síntese de Estruturas Neurais, In Anais do Workshop sobre Visão Cibernética (IFSC-USP, São Carlos, SP, Agosto - 94), 74-79, 1994.

[Coelho \& Costa, 1996] R.C. Coelho; L. da F. Costa, The Box-Counting Fractal Dimensional: Does it Provide an Accurate Subsidy for Experimental Shape Characterization? If So, How to use It?, Proc. Simpósio Brasileiro de Computação Gráfica e Processamento de Imagens (SIBGRAPI-95), (published extraordinarily in Proc. Simpósio Brasileiro de Computação Gráfica e Processamento de Imagens (SIBGRAPI-96, Caxambu, MG, Brazil, Out/Nov, 1996), 183-191, 1995. 
[Cohen, 1989] L. Cohen, Time-Frequency Distributions - A Review, Proceedings of the IEEE, 77(7):941-981, July 1989.

[Cornic, 1997] P. Cornic, Another Look at the Dominant Point Detection of Digital Curves, Pattern Recognition Letters, 18:13-25, 1997.

[Cosgriff, 1960] R.L. Cosgriff, Identification of Shape, Ohio State Univ. Res. Foundation, Columbus, Rep. 820-11, ASTIA AD 254 792, Dec. 1960 (citado em [Zahn \& Roskies, 1972]).

[Costa, 1993] L. da F. Costa, On the Most Advanced Signal Processing System: The Visual Cortex, its Modeling, and Implications for Computer Vision, in Anais Workshop sobre Computação de Alto Desempenho para Processamento de Sinais, 122-141, 1993.

[Costa et al., 1994] L. da F. Costa; V. O. Roda; R. Köberle, A Biologically-Inspired System for Visual Pattern Recognition. Proceedings IEEE International Symposium on Industrial Electronics , 25-30 Santiago, Chile, May 1994 /Artigo convidado/.

[Costa, 1995a] L. da F. Costa, Computer Vision based Morphometric Characterization of Neural Cells, Review of Scientific Instruments, 66(7):3770_-3773, July, 1995.

[Costa, 1995b] L. da F. Costa, Opinions on Wavelet Receptive Field Model, http://vision.arc.nasa.gov/VisionScience/mail/cvnet/1995/0173.html, 1995.

[Costa, 1997] L. da F. Costa, Novas perspectivas em neuromorfometria $e$ neuromodelagem, tese de Livre-Docência - IFSC, Universidade de São Paulo, jan. 1997.

[Costa, 1997b] L. da F. Costa, New Perspectives in Neuromorphometry and Computational Neuroscience, Proc. Simpósio Brasileiro de Computação Gráfica e Processamento de Imagens (SIBGRAPI-97, Campos do Jordão, SP, Out 1997), 1997 (http://www2.lncc.br/sibgrapi97/invited/costa.html).

[Costa et al., 1998] L. da F. Costa; R.M. Cesar Jr.; R. C. Coelho; J. S. Tanaka, Perspective on the Analysis and Synthesis of Morphologically Realistic Neural Networks, In Modeling in the Neurosciences: From Ionic Channels to Neural Networks, Gordon and Breach Science Publishers, 1998 No prelo/ /Artigo especialmente convidado/.

[Daubechies, 1990] I. Daubechies, The Wavelet Transform, Time-Frequency Localization and Signal Analysis, IEEE Transactions on Information Theory, 36(5):961-1005, September 1990.

[Daubechies, 1992] I., Daubechies, Ten Lectures on Wavelets, CBMS-NSF Regional Conference Series in Applied Mathematics, Philadelphia, Pennsylvania, 1992.

[Daubechies, 1996] I. Daubechies, Where do Wavelets Come From? - A Personal Point of View, Proceedings of the IEEE, 84(4):510-513, April 1996. 
[Daugman, 1988] J.G. Daugman, Complete Discrete 2-D Gabor Transforms by Neural Networks for Image Analysis and Compression, IEEE Transactions on Acoustics, Speech, and Signal Processing, 36(7):1169-1179, July 1988.

[Davis, 1977] L.S. Davis, Understanding Shapes: Angles and Sides, IEEE Transactions on Computers, C-26(3):236-242, March, 1977.

[Delprat, 1992] N. Delprat, Extraction of Frequency Modulation Laws in Sound Synthesis, In: Y. Meyer (ed.) Wavelets and Applications (Proc. Int. Conf. Marseille, France, 1989), pp 3-11, Masson/Springer-Verlag, 1992.

[Delprat et al., 1992] N. Delprat; B. Escudié; P. Guillemain; R. K.-Martinet; P. Tchamitchian; B. Torrésani, Asymptotic Wavelet and Gabor Analysis: Extraction of Instantaneous Frequencies, IEEE Transactions on Information Theory, 38(2):644664, March 1992.

[De Valois \& De Valois, 1990] R.L. De Valois; K.K. De Valois, Spatial Vision, Oxford Sciences Publications, 1990.

[Duda \& Hart, 1973] R.O. Duda; P. E. Hart, Pattern Classification and Scene Analysis, John Wiley \& Sons, NY, 1973.

[Duncan et al., 1991] J.S. Duncan, F.A. Lee, A.W.M. Smeulders and B.L. Zaret, A Bending Energy Model for Measurement of Cardiac Shape Deformity, IEEE Transactions on Medical Imaging, 10(3):307-320, September 1991.

[Dunn et al., 1994] D. Dunn; W.E. Higgins; J. Wakeley, Texture Segmentation using 2D Gabor Elementary Functions, IEEE Transactions on Pattern Analysis and Machine Intelligence, 16(2):130-149, February 1994.

[Dunn \& Higgins, 1995] D. Dunn; W.E. Higgins, Optimal Gabor Filters for Texture Segmentation, IEEE Transactions on Image Processing, 4(7):947-964, July 1995.

[DuPain et al., 1986] Y. DuPain; T. Kamae; M. Mendès France, Can One Measure the Temperature of a Curve?, Arch. Rational. Mech. Anal., 94:155-163, 1986.

[Falconer, 1990] K. Falconer, Fractal Geometry: Mathematical Foundations and Applications, John Wiley \& Sons, Chichester, England, 1990.

[Eichmann et al., 1990] G. Eichmann; C. Lu; M. Jankowski; R. Tolimieri, Shape Representation by Gabor Expansion, SPIE Hybrid Image and Signal Processing II, 1297:86-94, 1990.

[Fairney \& Fairney, 1994] D.P. Fairney; P. T. Fairney, On the Accuracy of Point Curvature Estimators in a Discrete Environment, Image and Vision Computing, 12(5):259-265, 1994.

[Feder, 1988] J. Feder, Fractals, Plenum Press, NY, 1988.

[Fischler \& Wolf, 1994] M.A. Fischler; H.C. Wolf, Locating Perceptually Salient Points on Planar Curves, IEEE Transactions on Pattern Analysis and Machine Intelligence, 16(2):113-129, February 1994. 
[Flandrin, 1993] P. Flandrin, Temps-Frequénce, Hermès, 1993 /Em francês/.

[Freeman \& Adelson, 1991] W.T Freeman; E. Adelson, The Design and Use of Steerable Filters, IEEE Transactions on Pattern Analysis and Machine Intelligence, 13(9):891-906, September 1991.

[Fu, 1982] K.S. Fu, Syntactic Pattern Recognition and Applications, Prentice-Hall, Englewood Cliffs, NJ, 1982.

[Fukuda et al., 1984] Y. Fukuda; C.-F. Watanabe; H. Ito, Physiologically Identified Y-, X-, and W- Cells in Cat Retina, Journal of Neurophysiology, 52(6): 999-1013, December 1984.

[Gabor, 1946] D. Gabor, Theory of Communication, Proc. IEE, 93(26):429-457, 1946.

[Garcia \& Fdez-Valdivia, 1994] J.A. Garcia; J. Fdez-Valdivia, Representing Planar Curves by Using a Scale Vector, Pattern Recognition Letters, 15(9):937-942, September, 1994.

[Garcia et al., 1995] J.A. Garcia; J. Fdez-Valdivia; R. Molina, A Method for Invariant Pattern Recognition using the Scale-Vector Representation of Planar Curves, Signal Processing, 43:39-53, 1995.

[García-Silvente et al., 1996] M. García-Silvente; J. Fdez-Valdivia; J.A. García, A Multi-Channel-Based Approach for Extracting Significant Scales on Gray-Level Images, Proc. 13th International Conference on Pattern Recognition (Technical University of Vienna, Austria, August 25-30, 1996), Vol. 2 Track B, 231-235, 1996.

[Gaudart et al., 1993] L. Gaudart; J. Crebassa; J.P. Petrakian, Wavelet Transform in Human Visual Channels, Applied Optics, 32(22):4119-4127, 1993.

[Goshtasby, 1993] A. Goshtasby, Design and recovery of 2-D and 3-D shapes using Rational Gaussian Curves and Surfaces, International Journal of Computer Vision, 10(3):233-256, 1993.

[Granlund, 1972] G.H. Granlund, Fourier Preprocessing for Hand Print Character Recognition, IEEE Transactions on Computers, C-21(2):195-201, February 1972.

[Grossmann \& Morlet, 1984] A. Grossmann; J. Morlet, Decomposition of Hardy Functions into Squared Integrable Wavelets of Constant Shape, SIAM J. Math. Analysis, 15:723-736, 1984.

[Grossmann, 1988] A. Grossmann, Wavelet Transforms and Edge Detection, in S. Albeverio, Ph. Blanchard, M. Hazewinkel and L. Streit (Eds.), Stochastic Processes in Physics and Engineering, Reidel Publishing Company, Dordrecht, 1988.

[Grossmann et al., 1989] A. Grossmann; R. Kronland-Martinet; J. Morlet, Reading and Understanding Continuous Wavelet Transform, In J.-M. Combes, A. Grossmann and P. Tchamitchian (Eds.), Wavelets, Time-Frequency Methods and Phase-Space (Proc. Marseille 1987), Springer-Verlag, Berlin, 1989.

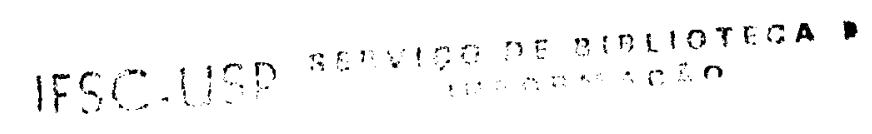


[van der Heijden, 1994] F. van der Heijden, Image Based Measurement Systems, John Wiley \& Sons, NY, 1994.

[Hlwatsch \& Bordreaux-Bartels, 1992] F. Hlwatsch; G.F. Bordreaux-Bartels, Linear and Quadratic Time-Frequency Signal Representations, IEEE Signal Processing Magazine, 21-67, April 1992.

[Hoffman \& Richards, 1988] D.D. Hoffman; W.R. Richards, Representing Smooth Plane Curves for Recognition: Implications for Figure-Ground Reversal, in W. Richards (editor) Natural Computation, The MIT Press, Cambridge Mass., 76-82, 1988.

[Holschneider, 1995] M. Holschneider, Wavelets: An Analysis Tool, Clarendon Press, Oxford, 1995.

[Johnston \& Rosenfeld, 1973] E. Johnston; A. Rosenfeld, Angle Detection on Digital Curves, IEEE Transactions on Computers, C22(7):875-878, 1973.

[Kass et al., 1988] M. Kass; A. Witkin; D. Terzopoulos, Snakes: Active Contour Models, International Journal of Computer Vision, 1:321-331, 1988.

[Kaiser, 1994] G. Kaiser, A Friendly Guide to Wavelets, Birkhauser, Boston, 1994.

[Kashi et al., 1996] R.S. Kashi; P. Bhoi-Kavde; R.S. Nowakowski; T.V. Papathomas, 2D Shape Representation and Averaging using Normalized Wavelet Descriptors, Simulation, 66(3):164-178, March 1996.

[Kimia et al., 1992] B.B. Kimia; A. Tannenbaum; S.W. Zucker, On the Evolution of Curves via a Function of Curvature. I. The Classical Case, Journal of Mathematical Analysis and Applications, 163:438-458, 1992.

[Kimia et al., 1995] B.B., Kimia; A., Tannenbaum; S.W., Zucker, Shapes, Shocks, and Deformations: The Components of Two-Dimensional Shape and the ReactionDiffusion Space, International Journal of Computer Vision, 15:189-224, 1995.

[Kiryati \& Maydan, 1989] N. Kiryati; D. Maydan, Calculating Geometric Properties from Fourier Representation, Pattern Recognition, 22(5):469-475, 1989.

[Kolb et al., 1981] H. Kolb, R. Nelson; A. Mariani, Amacrine Cells, Bipolar Cells and Ganglion Cells of the Cat Retina: A Golgi Study, Vision Research, 21:1081-1114, 1981.

[Koenderink, 1984] J.J. Koenderink, The Structure of Images, Biological Cybernetics, 50:363-370, 1984.

[Lee et al., 1993] J.-S. Lee; Y.-N. Sun; C.-H. Chen; C.-T. Tsai, Wavelet Based Corner Detection, Pattern Recognition, 26(6):853-865, 1993.

[Lee et al., 1995] J.-S. Lee; Y.-N. Sun; C.-H. Chen, Multiscale Corner Detection by Using the Wavelet Transform, IEEE Transactions on Image Processing, 4(1): 100104, January 1995. 
[Leventhal \& Schall, 1983] A.G. Leventhal; J.D. Schall, Structural Basis of Orientation Sensitivity of Cat Retinal Ganglion Cells, The Journal of Comparative Neurology, 220:465-475, 1983.

[Lowe, 1988] D.G. Lowe, Organization of Smooth Image Curves at Multiple Scales, In Proceedings, 2nd ICCV, 558-567, 1988.

[Lindeberg, 1993] T. Lindeberg, Effective Scale: A Natural Unit for Measuring ScaleSpace Lifetime, IEEE Transactions on Pattern Analysis and Machine Intelligence, 15(10):1068-1074, 1993.

[Lindeberg, 1994] T. Lindeberg, Scale-Space Theory in Computer Vision, Kluwer Academic Publishers, Dordrecht, The Netherlands, 1994.

[Lowe, 1989] D.G. Lowe, Organization of Smooth Image Curves at Multiple Scales, International Journal of Computer Vision, 3:119-130, 1989.

[Ma et al., 1986] J. Ma; C.-K. Wu; X.-R. Lu, A Fast Shape Descriptor, Computer Vision, Graphics and Image Processing, 34:282-291, 1986.

[Mahmoud, 1994] S.A. Mahmoud, Arabic Character Recognition using Fourier Descriptors and Character Contour Encoding, Pattern Recognition, 27(6):815-824, 1994.

[Mallat, 1989] S.G. Mallat, A Theory for Multiresolution Signal Decomposition: The Wavelet Representation, IEEE Transactions on Pattern Analysis and Machine Intelligence, 11(7): 674-693, July 1989.

[Mallat \& Hwang, 1992] S. Mallat; W.L. Hwang, Singularity Detection and Processing with Wavelets, IEEE Transactions on Information Theory, 38(2):617-643, March 1992.

[Mallat, 1996] S. Mallat, Wavelets for a Vision, Proceedings of the IEEE, 84(4):604614, April 1996.

[Mandelbrot, 1982] B. Mandelbrot, The Fractal Geometry of Nature, W.H. Freeman and Company, New York, 1982.

[Marcelja, 1980] S. Marcelja, Mathematical Description of the Responses of Simple Cortical Cells, Journal of the Optical Society of America, 70(11):1297-1300, November 1980

[Marr \& Hildreth, 1980] D. Marr; E. Hildreth, Theory of Edge Detection, Proceedings of Royal Society of London B, 207:187-217, 1980.

[Marr, 1982] D. Marr, Vision, W. H. Freeman and Company, 1982.

[Marshall, 1989] S. Marshall, Review of Shape Coding Techniques, Image and Vision Computing, 7(3):281-294, November 1989.

[Medioni \& Yasumoto, 1987] G. Medioni \& Y. Yasumoto, Corner Detection and Curve Representation using Cubic-Splines, Computer Vision, Graphics and Image Processing, 39:267-278, 1987. 
[Meyer, 1992] Y. Meyer, Les Ondelettes, Algorithmes et Applications, Armand Colin, Paris, 1992 /Em francês/.

[Mokhtarian \& Mackworth, 1986] F. Mokhtarian; A. Mackworth, Scale-based Description and Recognition of Planar Curves and Two-Dimensional Shapes, IEEE Transactions on Pattern Analysis and Machine Intelligence., PAMI-8:34-43, 1986.

[Mokhtarian \& Mackworth, 1992] F. Mokhtarian; A. Mackworth, A Theory of Multiscale, Curvature-based Shape Representation for Planar Curves, IEEE Transactions on Pattern Analysis and Machine Intelligence, 14:789-805, 1992.

[Morel \& Solimini, 1995] J.-M. Morel; S. Solimini, Variational Methods in Image Segmentation, Birkhauser, Boston, 1995.

[Mortenson, 1985] M. E. Mortenson, Geometric Modelling, John Wiley \& Sons, 1985.

[Murenzi, 1990] R. Murenzi, Ondelettes Multidimensionelles et Applications à l'analyse d'Images, tese de doutorado, FYMA, UCL, Bélgica, 1990. /Em francês/

[Murray, 1995] J.D. Murray, Use and Abuse of Fractal Theory in Neuroscience, The Journal of Comparative Neurology, 361:369-371, 1995.

[Muzy et al., 1994] J.F. Muzy; E. Bacry; A., Arnèodo, The Multifractal Formalism Revisited with Wavelets, International Journal of Bifurcation and Chaos, 4(2):245302, 1994.

[Nakamura \& Yoshida, 1994] Y. Nakamura; T. Yoshida, Learning Two-Dimensional Shapes using Wavelet Local Extrema, In Proceedings 12th International Conference on Pattern Recognition, Conference C (Jerusalem, Israel, October 9-13, 1994), IEEE Computer Society Press, Los Alamitos, CA, 48-52, 1994.

[Oliensis, 1993] J. Oliensis, Local Reproducible Smoothing without Shrinkage, IEEE Transactions on Pattern Analysis and Machine Intelligence, 15(3):307-312, March 1993.

[Panico \& Sterling, 1995] J. Panico; P. Sterling, Retinal Neurons and Vessels are not Fractal but Space-Filling, The Journal of Comparative Neurology, 361:479-490, 1995.

[Papoulis, 1962] A. Papoulis, The Fourier Integral and its Applications, McGraw-Hill, 1962.

[Pavlidis, 1973] T. Pavlidis, Waveform Segmentation through Functional Approximation, IEEE Transactions on Computers, C22(7):689-697, July, 1973.

[Pavlidis \& Horowitz, 1974] T. Pavlidis; S.L. Horowitz, Segmentation of Plane Curves, IEEE Transactions on Computers, C23(8):860-870, August, 1974.

[Pavlidis, 1977] T. Pavlidis, Structural Pattern Recognition, Springer-Verlag, NY, 1977.

[Pavlidis, 1980] T. Pavlidis, Algorithms for Shape Analysis of Contours and Waveforms, IEEE Transactions on Pattern Analysis and Machine Intelligence, PAMI-2(4):301-312, July 1980. 
[Pavlidis, 1986] T. Pavlidis, Editorial, IEEE Transactions on Pattern Analysis and Machine Intelligence, PAMI-8:1, 1986.

[Pernus et al., 1994] F. Pernus; A Leonardis; S. Kovacic, Two-Dimensional Object Recognition using Multiresolution Non-Information-Preserving Shape Features, Pattern Recognition Letters, 15, 1071-1079 1994

[Persoon \& Fu, 1977] E. Persoon; K.-S. Fu, Shape Discrimination using Fourier Descriptors, IEEE Transactions on Systems, Man and Cybernetics, SMC-7, 170179, 1977.

[Pitas \& Venetsanopoulos, 1990] I. Pitas; A.N. Venetsanopoulos, Morphological Shape Decomposition, IEEE Transactions on Pattern Analysis and Machine Intelligence, 12(1):38-45, January 1990.

[Pitas \& Venetsanopoulos, 1992] I. Pitas; A.N. Venetsanopoulos, Morphological Shape Representation, Pattern Recognition, 25(6):555-565, 1992.

[Poggio et al., 1985] T. Poggio; V. Torre; C. Koch, Computational Vision and Regularization, Nature, 317(26), 1985.

[Poznanski, 1992] R. R. Poznanski, Modelling the Electronic Structure of Starburst Amacrine Cells in the Rabbit Retina: Functional Interpretation of Dendritic Morphology, Bulletin of Mathematical Biology, 54(6):905-928, 1992.

[Ramer, 1972] U. Ramer, An Iterative Procedure for the Polygonal Approximation of Plane Curves, Computer Graphics and Image Processing, 1, 244-256, 1972.

[Ramon y Cajal, 1911] S.R. Ramon y Cajal, Histologie du Système Nerveux de l'Homme et des Vertébrés, Vol. I \& II, Paris: Malione, 1991; Reprinted Madrid, Consejo Superior de Investigaciones Cientificas, 1952 (citado em [Panico \& Sterling, 1995]).

[Rattarangsi \& Chin, 1992] A. Rattarangsi; R.T. Chin, Scale-based Detection of Corners of Planar Curves, IEEE Transactions on Pattern Analysis and Machine Intelligence, 14(4): 430-449, 1992.

[Reed \& Wechsler, 1990] T.R. Reed; H. Wechsler, Segmentation of Textured Images and Gestalt Organization using Spatial/Spatial-Frequency Representations, IEEE Transactions on Pattern Analysis and Machine Intelligence, 12(1):1-12, January 1990.

[Reginska, 1995] T. Reginska, Sideways Heat Equation and Wavelets, Journal of Computational and Applied Mathematics, 63:209-214, 1995.

[Richards et al., 1986] W.R. Richards; B. Dawson; D. Whittington, Encoding Contour Shape by Curvature Extrema, Journal of the Optical Society of America, 3(9):1483-1491, September 1986.

[Rioul \& Vetterli, 1991] O. Rioul; M. Vetterli, Wavelets and Signal Processing, IEEE Signal Processing Magazine, 14-89, 1991. 
[Rioul \& Duhamel, 1992] O. Rioul; P. Duhamel, Fast Algorithms for Discrete and Continuous Wavelet Transforms, IEEE Transactions on Information Theory, 38(2):569-586, 1992.

[Rosin, 1992] P.L. Rosin, Representing Curves at their Natural Scales, Pattern Recognition, 25(11):1315-1325, 1992.

[Rosin \& Venkatesh, 1993] P.L. Rosin; S. Venkatesh, Extracting Natural Scales using Fourier Descriptors, Pattern Recognition, 26(9):1383-1393, 1993.

[Rosin, 1994] P.L. Rosin, Determining Local Natural Scales of Curves, In Proceedings, 12th LAPR International Conference on Pattern Recognition, Conference A (Jerusalem, Israel, October 9-13, 1994), IEEE Computer Society Press, Los Alamitos, CA, 185-189, 1994.

[Saito, 1983] H.-A. Saito, Morphology of Physiologically identified X-, Y-, and WType Retinal Ganglion Cells of the Cat, The Journal of Comparative Neurology, 221:279-288, 1983.

[Salari \& Balaji, 1991] E. Salari; S. Balaji, Recognition of Partially Occluded Objects using B-spline Representation, Pattern Recognition, 24(7):653-660, 1991.

[Sanchiz et al., 1996] J. M. Sanchiz; J. M. Iñesta; F. Pla, A Neural Network-Based Algorithm to Detect Dominant Points from Chain-code of a Contour, Proc. 13th International Conference on Pattern Recognition (Technical University of Vienna, Austria, August 25-30, 1996), Vol. 4 Track D, 325-329, 1996.

[Sapiro \& Tannenbaum, 1993] G. Sapiro; A. Tannenbaum, Affine Invariant Scale-Space, International Journal of Computer Vision, 11(1):25-44, 1993.

[Sapiro et al., 1993] G. Sapiro; R. Kimmel; D. Shaked; B. Kimia; A. Bruckstein, Implementing Continuous-Scale Morphology Via Curve Evolution, Pattern Recognition, 26(9): 1363-1372, 1993.

[Sapiro \& Tannenbaum, 1995] G. Sapiro; A. Tannenbaum, Area and Length Preserving Geometric Invariant Scale-Spaces, IEEE Transactions on Pattern Analysis and Machine Intelligence, 17(1): 67-72, January 1995.

[Schutter \& Bower, 1994] E. De Schutter; J. M. Bower, An Active Membrane Model of the Cerebellar Purkinje Cell I. Simulation of Current Clamps in Slice, Journal of Neurophysiology, 71(1):375-400, January 1994.

[Shen et al., 1994] L. Shen; R.M. Rangayyan; J.E.L. Desautels, Application of Shape Analysis to Mammographic Calcifications, IEEE Transactions on Medical Imaging, 13(2):263-274, 1994.

[Siddiqi \& Kimia, 1995] K. Siddiqi; B.B. Kimia, Parts of Visual Form: Computational Aspects, IEEE Transactions on Pattern Analysis and Machine Intelligence, 17(3):239-251, March 1995. 
[Simoncelli et al., 1992] E.P. Simoncelli; W.T. Freeman; E.H. Adelson; D.J. Heeger, Shiftable Multiscale Transforms, IEEE Transactions on Information Theory, 38(2):587-607, March 1992.

[Smith et al., 1996] T.G. Smith Jr.; G.D. Lange; W.B. Marks, Fractal Methods and Results in Cellular Morphology - Dimensions, Lacunarity and Multifractals, Journal of Neuroscience Methods, 69:123-136, 1996.

[Special Issue, 1992] Special Issue on Wavelet Transforms and Multiresolution Signal Analysis, IEEE Transactions on Information Theory, 38(2), March 1992.

[Special Issue, 1993] Special Issue on Wavelet Transforms and Signal Processing, IEEE Transactions on Signal Processing, 41(12), December 1993.

[Special Issue, 1996] Special Issue on Wavelets, Proceedings of the IEEE, 84(4), April 1996.

[Special Issue, 1998] Special Issue on Wavelets and Filter Banks, IEEE Transactions on Signal Processing, 1998 /A aparecer/.

[Special Issue, 1999] Special Issue on Multiscale Statistical Signal Analysis and Its Applications, IEEE Transactions on Information Theory, March/April 1999 /A aparecer/.

[Stein \& Medioni, 1992] F. Stein, G. Medioni, Structural Indexing Efficient 2D Object Recognition, IEEE Transactions on Pattern Analysis and Machine Intelligence, 14(12), 1198-1204, December, 1992.

[Stoker, 1969] J.J. Stoker Differential Geometry, Wiley-Interscience- John Wiley \& Sons, NY, 1969.

[Tang et al., 1996] Y.Y. Tang; B.F. Li; H. Ma; J. Lu; C.H. Leung; C.Y. Suen, A Novel Approach to Optical Character Recognition Based on Ring-Projection-WaveletFractal Signatures, Proc. 13th International Conference on Pattern Recognition (Technical University of Vienna, Austria, August 25-30, 1996), Vol. 2 Track B, 325-329, 1996.

[Teh \& Chin, 1989] C. The; R.T. Chin, On the Detection of Dominant Points on Digital Curve, IEEE Transactions on Pattern Analysis and Machine Intelligence, 11(8):859-872, 1989.

[Tieng \& Boles, 1995] Q.M. Tieng; W.W. Boles, An Application of Wavelet-Based Affine-Invariant Representation, Pattern Recognition Letters, 16:1287-1296, 1995.

[Tieng \& Boles, 1997a] Q.M. Tieng; W.W. Boles, Wavelet Based Affine Invariant Representation: A Tool for Recognising Planar Objects in 3D Space, IEEE Transactions on Pattern Analysis and Machine Intelligence, 1997 No prelo/.

[Tieng \& Boles, 1997b] Q.M. Tieng; W.W. Boles, Recognition of 2-D Object Contours using the Wavelet Transform Zero-Crossing Representation, IEEE Transactions on Pattern Analysis and Machine Intelligence, 1997 No prelo/. 
[Torrésani, 1992] B. Torrésani, Wavelet Analysis of Asymtoptic Signals: I: Ridge and Skeleton of the Transform, In: Y. Meyer (ed.) Wavelets and Applications (Proc. Int. Conf. Marseille, France, 1989), pp 12-27, Masson/Springer-Verlag, 1992.

[Torrésani, 1995] B. Torrésani, Analyse Continue par Ondelettes, InterEditions et CNRS Editions, Paris, 1995 /Em francês/.

[Tricot, 1993] C. Tricot, Courbes et Dimension Fractale, Springer-Verlag, Paris, 1993 /Em francês/.

[Tsang et al., 1994] W.M. Tsang; P.C. Yuen; F.K. Lam, Detection of Dominant Points on an Object Boundary: a Discontinuity Approach, Image and Vision Computing, 12(9):547-557, November 1994.

[Turner et al., 1995] D.A. Turner; X.-G. Li; G.K. Pyapali; A. Ylinen; G. Buzsaki, Morphometric and Electrical Properties of Reconstructed Hippocampal CA3 Neurons Recorded In Vivo, The Journal of Comparative Neurology, 356:556-580, 1995.

[Velte \& Miller, 1995]T.J. Velte; R.F. Miller, Dendritic Integration in Ganglion Cells of the Mudpuppy Retina, Visual Neuroscience, 12:165-175, 1995.

[Vetterli \& Kovacevic 1995] M. Vetterli; J. Kovacevic, Wavelets and Subband Coding, Prentice Hall, 1995.

[Vliet \& Verbeeck, 1993] L.J. van Vliet; P.W. Verbeeck, Curvature and Bending Energy in Digitized 2D and 3D Images, In K.A. Hogda, B. Braathen and K., Heia (Eds), Proceedings of the 8th Scandinavian Conference on Image Analysis, (Norway), NONIM-Norwegian Soc. Image Process. \& Pattern Recognition, Vol. 2, pp 14031410, 1993.

[Vliet, 1993] L.J. van Vliet, Grey-Scale Measurements in Multi-Dimensional Digitized Images, Technische Universiteit Delft, Delft University Press, 1993.

[Watson, 1987] A.B. Watson, The Cortex Transform: Rapid Computation of Simulated Neural Images, CVGIP: Image Understanding, 39:311-327, 1987.

[Weiss, 1993] I. Weiss, Noise-Resistant Invariants of Curves, IEEE Transactions on Pattern Analysis and Machine Intelligence, 15(9): 943-948, September 1993.

[Weiss, 1994] I. Weiss, High-Order Differentiation Filters That Work, IEEE Transactions on Pattern Analysis and Machine Intelligence, 16(7):734-739, July 1994.

[Widder, 1975] D.V. Widder, The Heat Equation, Academic Press, 1975.

[Witkin, 1983] A.P. Witkin, Scale-Space Filtering, Proc. 8th International Joint Conference on Artificial Intelligence, 1019-1022, 1983.

[Wu \& Levine, 1995] K. Wu; M. D. Levine, 2D Shape Segmentation: a New Approach, Technical Report TR-CIM-95-01, Centre for Intelligent Machines, McGill University, Canada, 1995. 
[Wuescher \& Boyer, 1991] D.M. Wuescher; K.L. Boyer, Robust Contour Decomposition using a Constant Curvature Criterion, IEEE Transactions on Pattern Analysis and Machine Intelligence, 13(1):41-51, January 1991.

[Wunsch \& Laine, 1995] P. Wunsch; A.F. Laine, Wavelet Descriptors for multiresolution Recognition of Handprinted Characters, Pattern Recognition, 28(8): 1237-1249, 1995.

[Young et al., 1974] I.T. Young; J.E. Walker; J.E., Bowie, An Analysis Technique for Biological Shape. I, Information and Control, 25:357-370, 1974.

[Zahn \& Roskies, 1972] C.T. Zahn; R.Z. Roskies, Fourier Descriptors for Plane Closed Curves, IEEE Transactions on Computers, C21, 269-281, 1972.

[Zhu \& Chirlian, 1995] P. Zhu; P. M. Chirlian, On Critical Point Detection of Digital Shapes, IEEE Transactions on Pattern Analysis and Machine Intelligence, 17(8):737-748, August 1995.

[Zucker, 1985] S.W. Zucker, Early Orientation Selection: Tangent Fields and the Dimensionality of their Support, Computer Vision, Graphics and Image Processing, 32:74-103, 1985. 


\section{Apêndice 1}

\section{FFTshift e FFTunshift}

Existe um último ponto para o qual deve-se chamar a atenção em relação à implementação numérica das técnicas de derivação usando FFT (ver Capítulo 4). Tratase do desdobramento e "redobramento" (fftshift e fftunshift) do vetor que armazena a transformada de Fourier de um sinal. Ao contrário do que possa parecer, as duas operações não podem ser realizadas através de duas aplicações sucessivas da função fftshift, a qual normalmente acompanha o Matlab, bem como outros pacotes de software matemático e/ou de processamento de sinais. Para ilustrar isso, tome o seguinte vetor:

$\left[\begin{array}{llll}0 & 1 & 2 & 3\end{array}\right]$

Offtshift do vetor acima é dado por:

$\left[\begin{array}{llll}2 & 3 & 0 & 1\end{array}\right]$

Aplicando-se offtshift novamente, obtém-se:

$\left[\begin{array}{llll}0 & 1 & 2 & 3\end{array}\right]$

Ou seja, obtém-se o vetor original. Por outro lado, tome o seguinte vetor:

$\left[\begin{array}{lllll}0 & 1 & 2 & 3 & 4\end{array}\right]$

Offtshift desse vetor é dado por: 
O problema aparece na aplicação do fftshift novamente, i.e. sobre o vetor acima, o que resulta:

\section{[ $\left.\begin{array}{lllll}1 & 2 & 3 & 4 & 0\end{array}\right]$}

Interpretando-se o vetor acima como sendo a FFT de um sinal, tem-se que o nível DC original "migrou" para o fim do vetor, enquanto que a freqüência 1 virou o DC, o que, obviamente, está errado. Isso deve-se à própria definição do fftshift, que é uma translação circular de floor $(N / 2)$ elementos, e que apresenta problemas todas vez que o número de amostras do sinal for ímpar. A solução para esse problema é a definição da função fftunshift, que leva em consideração o fato do fftshift já ter sido aplicado. A utilização do par fftshift-fftunshift no script acima decorre desses detalhes. 